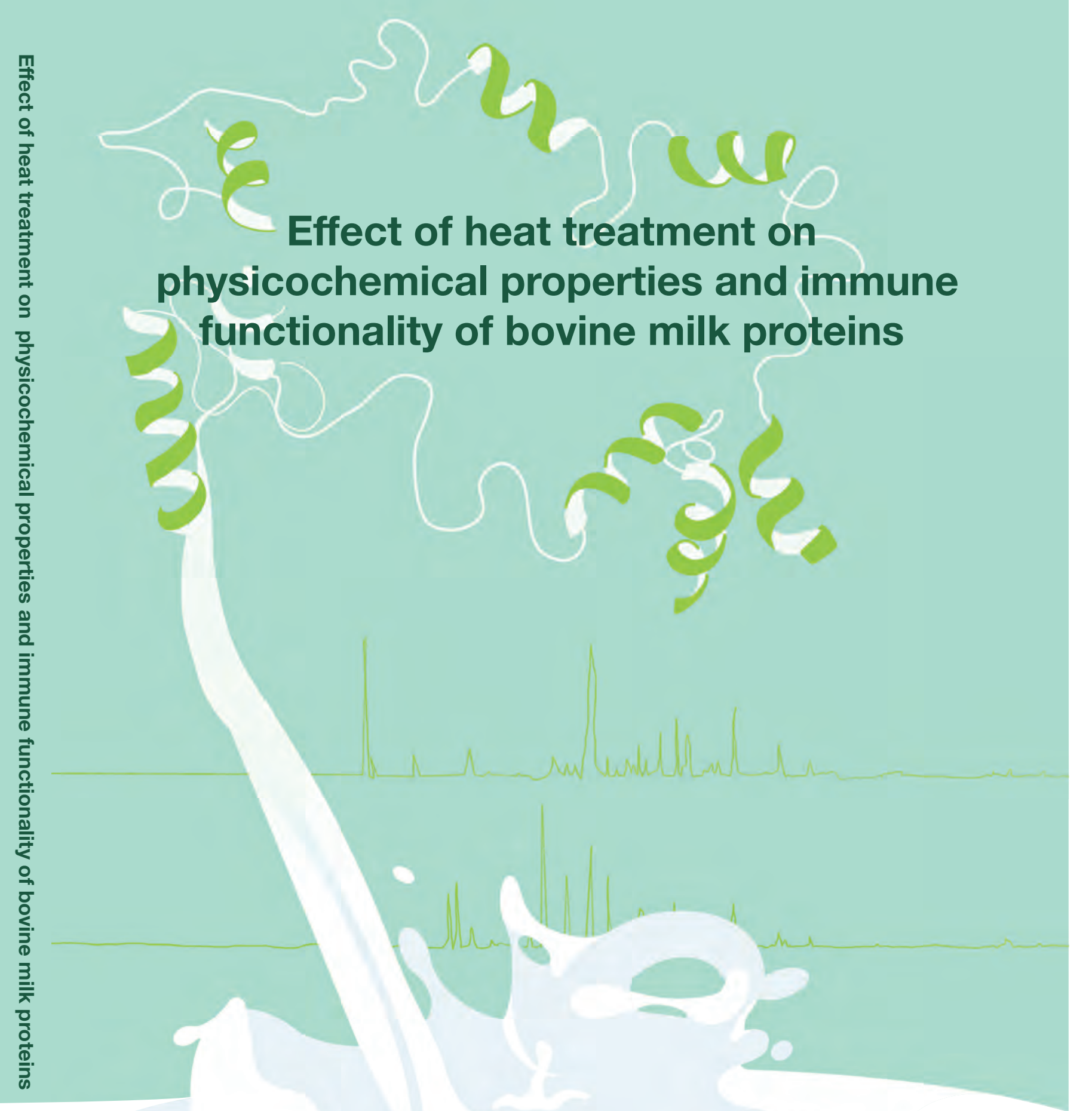




\section{Propositions}

1. $\beta$-lactoglobulin is the most important milk protein influencing the aggregation of lactoferrin. (this thesis)

2. Proteins involved in the allergy-protective effect of raw milk are more heat-labile than the antibacterial proteins.

(this thesis)

3. UHT milk should be advocated because it is more sustainable than pasteurized milk.

4. Giving enough space for failure is the best way to reduce fraud in academia.

5. Wearing safety glasses is not effective for controlling transmission of COVID-19 but obligatory in the lab, whereas wearing facemasks is effective but not obligatory.

6. The easiest way to start a perfect day is to wear a nice dress.

Propositions belonging to the thesis, entitled

Effect of heat treatment on physicochemical properties and immune functionality of bovine milk proteins

Ling Xiong

Wageningen, 15 December, 2020 
Effect of heat treatment on physicochemical properties and immune functionality of bovine milk proteins

Ling Xiong 


\section{Thesis Committee}

\section{Promotor}

Dr K.A. Hettinga

Associate Professor, Food Quality and Design

Wageningen University \& Research

\section{C o-Promotor}

Dr J.J.M. Vervoort

Associate Professor, Laboratory of Biochemistry

Wageningen University \& Research

\section{Other members}

Prof. dr LB Larsen, Aarhus University, Denmark

Dr MW den Besten, Wageningen University \& Research

Dr IB Renes, Nutricia Research, Utrecht

Prof. dr R.J.J. van Neerven, Wageningen University \& Research

This research was conducted under the auspice of the Graduate school VLAG (Advanced studies in Food Technology, Agrobiotechnology, Nutrition and Health Sciences) 


\title{
Effect of heat treatment on physicochemical properties and immune functionality of bovine milk proteins
}

\author{
Ling Xiong
}

\author{
Thesis \\ Submitted in the fulfilment of the requirements for the degree of doctor \\ at Wageningen University \\ by the authority of the Rector Magnificus, \\ Prof. Dr A.P.J. Mol, \\ In the presence of the
}

Thesis Committee appointed by the Academic Board

to be defended in public

on Tuesday $15^{\text {th }}$ December 2020

at 11 a.m. in the Aula 


\section{Ling Xiong}

Effect of heat treatment on physicochemical properties and immune functionality of bovine milk proteins, 174 pages

$\mathrm{PhD}$ thesis Wageningen University, Wageningen, the Netherlands (2020).

With references, with summary in English.

ISBN: 978-94-6395-618-5

DOI: https://doi.org/10.18174/535041 


\section{L ist of contents}

\section{C hapter 1}

General Introduction

\section{C hapter 2}

Aggregation and disulphide bond interchange of lactoferrin with major whey proteins during heat treatment

\section{C hapter 3}

Effect of milk serum proteins on aggregation, bacteri ostatic activity and digestion of lactoferrin after heat treatment

\section{C hapter 4}

Effect of heat treatment on bacteriostatic activity and protein profile of bovine whey proteins

\section{C hapter 5}

Loss of allergy-protective capacity of raw cow's milk after heat treatment coincides with loss of immunologically active whey proteins

\section{C hapter 6}

General Discussion

R eferences

Summary

Acknowledgements

A bout the author

L ist of publications 


\section{CHAPTER 1. \\ General Introduction}




\subsection{Introduction- milk \& heat treatment}

Milk is one of the most important sources of nutrients to the mammalian neonate. Therefore, bovine milk-based products, like infant formula, whey protein isolate and others, are manufactured to meet nutritional requirement for the consumer. Due to its rich nutritional components, a variety of microorganisms can grow and multiply quickly in milk, including pathogens and spoilage organisms (Oliver, Jayarao, \& Almeida, 2005). Public health hazards associated with dairy products have been a safety risk until the application of pasteurization to inactivate those pathogen (Boor, Wiedmann, Murphy, \& Alcaine, 2017). Pasteurization is defined as "A microbiocidal heat treatment aimed at reducing the number of any pathogenic microorganisms in milk and liquid milk products, if present, to a level at which they do not constitute a significant health hazard" (Alimentarius, 2004). Low-temperature, long-time pasteurization (LTLT, $63^{\circ} \mathrm{C} / 30 \mathrm{~min}$ ) and high-temperature, short-time pasteurization (HTST, $72^{\circ} \mathrm{C} / 15 \mathrm{~s}$ ) are generally used in the dairy industry. Not all spoilage organisms are destroyed under such conditions. Therefore, ultra-high temperature processing (UHT, $135-150{ }^{\circ} \mathrm{C}$ for seconds) in combination with aseptic packaging, or in-container sterilization, can be applied to achieve sterilization of milk and milk products, to obtain a long shelf life without the need for cold storage.

Besides nutritional components, milk also contains a broad range of bioactive components that protect the neonate against a hostile environment (Stelwagen, Carpenter, Haigh, Hodgkinson, \& Wheeler, 2009), among which the immune-active proteins play a pivotal role in protecting the gut mucosa against pathogens and contribute to the development of the immunity system of the neonate (Telang, 2018; Ulfman, Leusen, Savelkoul, Warner, \& van Neerven, 2018). This protective effect may be direct, through immune-active proteins in milk, but also through formation of bioactive peptides during digestion of milk proteins (Madureira, Tavares, Gomes, Pintado, \& Malcata, 2010; Szwajkowska, Wolanciuk, Barlowska, Krol, \& Litwinczuk, 2011). However, heat processing may damage the protective activity of bovine milk, as indicated by several recent studies. Raw bovine milk showed a better maturational and protective effect on the immature intestine of preterm piglets than a pasteurized, spray-dried equivalent, whole milk powder or bovine milk protein-based infant formula (Li et al., 2014). Unprocessed cow's milk was reported to show a better protection of infants from common respiratory infections than processed milk (Loss et al., 2015). It has been shown that raw milk exhibited the asthma protective capacity, while heated milk did not show similar effect (Abbring et al., 2017). Such a decrease of biological function of raw milk induced by heat processing is partly ascribed to 
the damage of proteins, especially bioactive whey proteins. Milk proteins consist of caseins and whey proteins. In contrast to caseins, whey proteins are responsible for most of the biological activity found in milk. However, most of whey proteins are heat sensitive (Wijayanti, Bansal, \& Deeth, 2014). Heat induced denaturation, aggregation, hydrolysis, and chemical modification (especially Maillard reaction) can all occur as a result of thermal treatment (Cornacchia, Forquenot de la Fortelle, \& Venema, 2014; Dissanayake, Ramchandran, Piyadasa, \& Vasiljevic, 2013; Gathercole et al., 2017). Proteomic studies on the stability of bovine whey proteins during processing showed that many, especially immune-active, proteins were decreased or absent in their native form in processed milk (Brick et al., 2017; Zhang, Boeren, et al., 2016). Heat processing at $60{ }^{\circ} \mathrm{C}$ for 30,60 or 90 min resulted in denaturation of bioactive proteins in bovine colostrum, such as immunoglobulin G, lactoferrin and lactoperoxidase, all to a different degree (Shimo, Wu, Ding, Xiong, \& Yan, 2015; Tacoma et al., 2017). Although a lot of studies investigated thermal denaturation, aggregation, and chemical modification of whey proteins during industrial heat processing, it is not well understood how those immune-active proteins respond to a more moderate range of heat treatments, and how the resulting changes would affect the biological function of these proteins. Additionally, the mechanisms that underlie the decrease in native immune-active proteins are not well understood. Detailed determination of the changes in immune-active proteins in bovine milk after different heat treatments combined with an evaluation of their biological function may help to understand the loss of function of these proteins, as noted in actual dairy products.

\subsection{Biological activity of whey proteins from bovine milk}

Whey proteins, accounting for approximately $20 \%$ of the total protein amount in bovine milk, consist of $\beta$-lactoglobulin, $\alpha$-lactalbumin, bovine serum albumin, immunoglobulin, lactoferrin, lactoperoxidase and hundreds of low abundant proteins (Hettinga et al., 2011; Wijayanti et al., 2014), which together are involved in multiple biological functions, such as antimicrobial activity (Van Hooijdonk, Kussendrager, \& Steijns, 2000), immunomodulation (Cross \& Gill, 2000), anti-inflammation (Chatterton, Nguyen, Bering, \& Sangild, 2013), enhancement of intestinal maturation (Corrochano et al., 2018), improvement of metabolic disease (Wirunsawanya, Upala, Jaruvongvanich, \& Sanguankeo, 2018). It is therefore extensively used as supplement in food products to improve the health status of its consumers, especially for infants and elderly, who have a compromised immune system. 


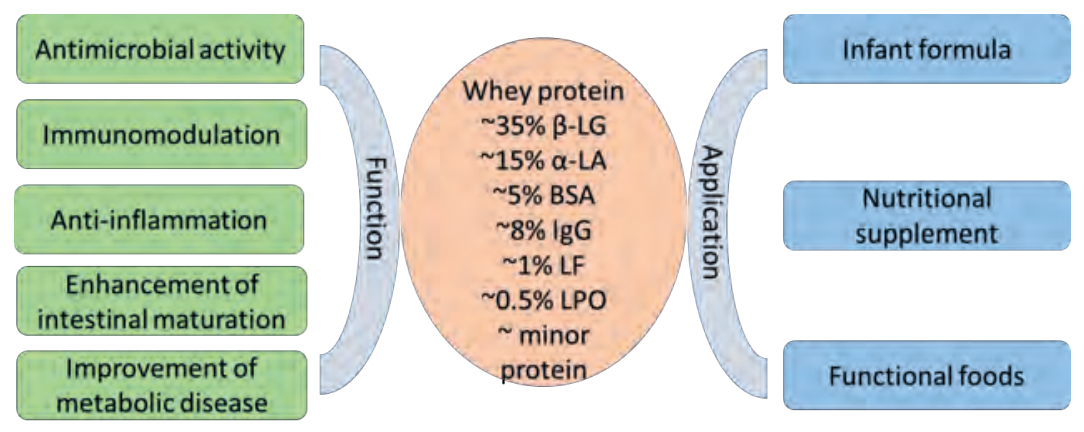

Figure 1-1 Protein composition and biological function of whey protein as well as commercial application.

One specific immune functionality of interest is the potential allergy-protective effect of whey proteins against non-milk allergy, which was explored by several studies in recent years. Exposure to farming in early life protected against development of asthma, hay fever, and atopic sensitisation in children (Riedler et al., 2001), which was associated with the consumption of raw milk (Loss et al., 2011; Perkin \& Strachan, 2006; Waser et al., 2007). Non-pathogenic bacteria, unsaturated fatty acids (Brick et al., 2016), microRNA (Kirchner, Pfaffl, Dumpler, von Mutius, \& Ege, 2016), and immune-active proteins (van Neerven, Knol, Heck, \& Savelkoul, 2012) in raw milk were implied as important factors in this protective function. In a mice model, raw milk prevented house dust mite-induced asthma, while heated milk lost this activity, which indicates the involvement of heat-sensitive components (Abbring et al., 2017), such as the heat labile immune-active proteins. Such a role of immune-active proteins was addressed in several earlier studies. A negative relationship between total and cow's milk-specific IgA levels in colostrum and human milk and subsequent development of cow's milk allergy (CMA) in breastfed infants was observed (Jêvinen, Laine, Jêvenpêê, \& Suomalainen, 2000). IgG immune complexes were reported to be involved in protection from asthma, by inducing antigen-specific FoxP3+ CD25+ regulatory T cells (Mosconi et al., 2010). Lactoferrin was reported to inhibit the IgE-dependent activation of human mast cells that is a key event in allergic reactions $(\mathrm{He}$ et al., 2003). The potential of LF in human allergic inflammatory disorders by suppressing inflammation was also explored (Kruzel, Bacsi, Choudhury, Sur, \& Boldogh, 2006). Although a lot of indirect evidence suggests the potential of immune-active proteins in the protection of allergy, a direct link to specific milk components has not been reported yet. 


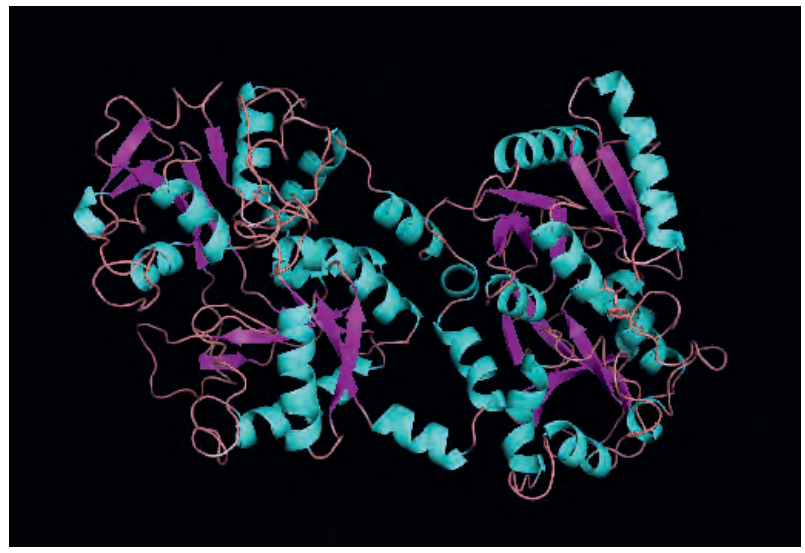

Figure 1-2 C rystal structure of bovine lactoferrin. Blue: $\alpha$-helix, purple: $\beta$-strand, orange: loop.

All these immune-modulatory activities of whey proteins are contributed to the presence of immune-active proteins, such as lactoferrin, lactoperoxidase, immunoglobulins, as well as low abundant bioactive proteins (such as superoxide dismutase, osteopontin, cathelindicins, lactadherin). Lactoferrin is single polypeptide chain glycoprotein with a molecular weight of $80 \mathrm{kDa}$. As one of the most abundant proteins in human milk (1-2 g/l) (Montagne, Cuilliere, Mole, Bene, \& Faure, 2001), lactoferrin plays a critical role in the immune system, due to multiple biological functions, such as delivering iron, and its antibacterial, antifungal and immunomodulatory activity. Bovine lactoferrin, which consist of 689 amino acids, shows a $69 \%$ sequence homology with human lactoferrin and has a similar biological function (Pierce et al., 1991). The unique physicochemical properties of lactoferrin provided by the three dimensional structure contribute to its multiple biological functions. It consists of two symmetric lobes that each can bind a single $\mathrm{Fe}^{3+}$ ion $\left(\mathrm{K} \sim 10^{20} \mathrm{M}\right)$ in a deep cleft together with two $\mathrm{CO}_{2}{ }^{-3}$ ions between two domains (Fig. 1-2) (Baker \& Baker, 2004). This iron-binding capacity is one of the underlying mechanisms against bacterial infection. Lactoferrin possesses a high positive charge ( $\mathrm{pI} \sim 9$ ), and thus can bind to negatively charged component (like LPS) and to immune cells, which is another mechanism by which it can kill bacteria and exert immunomodulatory functions. The immunomodulatory activity of lactoferrin on immune cells, especially antigen presenting cell, was demonstrated in recent years, stressing the role of lactoferrin in maintaining immune homeostasis. It has been shown that recombinant human lactoferrin induced the maturation of human dendritic cells (DCs) derived from monocytes (Spadaro et al., 2008). Bovine lactoferrin skewed monocyte differentiation into DCs with impaired capacity to undergo activation and to promote Th1 responses (Puddu et al., 2011). Dietary bovine 
lactoferrin altered the capacity of mesenteric lymph node and spleen immune cells to respond to stimulation, supporting a role for LF in the initiation of protective immune responses (Comstock, Reznikov, Contractor, \& Donovan, 2014). The biological activity of lactoferrin can be exerted by the intact protein or by the formed bioactive peptides after its digestion (Bruni et al., 2016). Due to its low level in bovine milk (around $0.1 \mathrm{mg} / \mathrm{ml}$ ) compared to human milk (around $2 \mathrm{mg} / \mathrm{ml}$ ) (Donovan, 2016), it was used as a supplement in bovine milk-based infant formula or other liquid functional foods, to provide additional protection for immunecompromised people, although this requires careful processing to prevent its heat-induced inactivation. Processing can modify the structure of lactoferrin, but a direct link between these structural changes and the corresponding changes of its biological function is lacking.

Lactoperoxidase (LPO), containing 612 amino acid residues, is the most predominant enzyme in bovine milk. It can form the LPO-system with $\mathrm{SCN}^{-}$and $\mathrm{H}_{2} \mathrm{O}_{2}$, which can produce an antibacterial component (HOSCN), to inactivate microorganisms. The antibacterial activity of LPO against pathogens and spoilage microorganisms in different food matrices has previously been reported (Björck, 1978; Elliot, McLay, Kennedy, \& Simmonds, 2004; Jooyandeh, Aberoumand, \& Nasehi, 2011). Besides the direct antibacterial activity, an immunomodulatory activity of LPO was also demonstrated. For example, LPO markedly suppressed the $\mathrm{H}_{2} \mathrm{O}_{2}$ induced IL-8 secretion in human intestinal epithelial Caco-2 cells (Matsushita et al., 2008) and inhibited proliferation and interferon- $\gamma$ production of ovine blood lymphocytes in response to mitogenic stimulation (Wong, Seow, Husband, Regester, \& Watson, 1997).

Immunoglobulins are a family of high molecular weight proteins that share common physicochemical characteristics and antigenic determinants (Butler, 1969). Three major classes of immunoglobulins (IgG, IgM and $\operatorname{IgA}$ ) were identified in bovine milk (Korhonen, Marnila, $\&$ Gill, 2007), which are responsible for conferring passive immunity to neonates. The antigen can be recognized by its variable domain, which makes immunoglobulins much more specific than other antimicrobial components (Hurley \& Theil, 2011). Several very early clinical studies showed that enteropathogenic E. coli from the intestine and rotavirus-induced gastroenteritis can be eliminated by milk immunoglobulin concentrate (Brüssow et al., 1987; Mietens et al., 1979). The effect of orally ingested bovine immunoglobulins on gastrointestinal and respiratory tract infections were also reviewed (Ulfman et al., 2018). Polymeric immunoglobulin receptor, a transmembrane glycoprotein, is a key component of the mucosal immune system that bridges innate and adaptive immune defense by mediating the epithelial transcytosis of polymeric IgA (Kaetzel, 2005). 
Table 1-1 Concentration of major whey proteins and several immune-active proteins in bovine mature milk.

\begin{tabular}{lll}
\hline Protein name & Molecular weight $(\mathrm{kDa})$ & Concentration in mature milk $(\mathrm{mg} / \mathrm{ml})$ \\
\hline$\beta$-lactoglobulin & 18 & 3.2 \\
$\alpha$-lactalbumin & 14 & 1.2 \\
Bovine serum albumin & 66 & 0.4 \\
Immunoglobulin G & 150 & 0.61 \\
Immunoglobulin A & 320 & 0.14 \\
Immunoglobulin M & 900 & 0.05 \\
Lactoferrin & 80 & 0.1 \\
Lactoperoxidase & 77.5 & 0.03 \\
Lactadherin & $47 \sim 52$ & 0.03 \\
Osteopontin & 44 & 0.02 \\
Mucin 1 & $120 \sim 225$ & 0.01 \\
Beta-2-microglobulin & 11 & 0.01 \\
Xanthine oxidase & 275 & 0.01 \\
sCD14 & 35.6 & 0.007 \\
Lysozyme & 14.3 & 0.004 \\
Complement factor B & 90 & 0.002
\end{tabular}

Reference : (Rainard, 2002; van Neerven et al., 2012; Wijayanti et al., 2014)

Low abundant immune-active proteins in bovine milk are drawing more attention recently. For example, xanthine oxidase (XO), as a major constituent of the milk fat globule membrane, contributes to the antimicrobial barrier and innate immune system (Martin, Hancock, Salisbury, \& Harrison, 2004). Monocyte differentiation antigen CD14, a 48-kDa polypeptide, may participate in modulating the gut immune response by interacting directly with local $\mathrm{T}$ and $\mathrm{B}$ cells, thereby controlling homeostasis in the neonatal intestine (Labéta et al., 2000). The complement system, consisting of over 20 different proteins, also plays an important role in immune complex clearance, as well as induction and enhancement of antibody responses (Korhonen, Marnila, \& Gill, 2000). Osteopontin (OPN) is a phosphorylated acidic glycoprotein, which showed a wide range of bioactivities, including stimulating brain, intestinal, and immunological development (Jiang \& Lönnerdal, 2016). Lactadherin is a glycoprotein in milk involved in regulation of many biological and physiological processes related to immunity. It was reported to promote intestinal DCs development in vivo and in vitro by inducing $\mathrm{CD}^{3+} \mathrm{CD}^{4+} \mathrm{CD}^{25+} \mathrm{T}$ cell differentiation and enhancing IL-10 production (Zhou et al., 2010). Cathelicidins are a group of structurally diverse antimicrobial peptides, having multiple functions including cell proliferation and migration, immune modulation, wound healing, angiogenesis and regulating the release of cytokines and histamine (Bals \& Wilson, 2003). 
Those bioactive proteins not only work independently, but also in a synergistic way. The combination of LF and the LPO system reduced the mycelial volume of Candida albicans and changed the size and shape of cells more than each agent alone (Nakano et al., 2019). Moreover, it was demonstrated that the LF-OPN complex promotes proliferation and differentiation of intestinal cells significantly more than the individual proteins (Liu, Jiang, \& Lönnerdal, 2019). IgA can enhance the antimicrobial effect of the lactoperoxidase system against Streptococcus mutans (Tenovuo, Moldoveanu, Mestecky, Pruitt, \& Rahemtulla, 1982). XO can act together with LPO as XO-LPO system to generate more potent antimicrobial agents, and physiologically active ROS and RNS that are important mediators in cellular proliferation, differentiation and gene expression (Al-Shehri, Duley, \& Bansal, 2020). From this perspective, whey proteins, as a mixture of many different bioactive proteins, may exert a stronger bioactivity as a whole than its constituent proteins.

\section{$1.3 \mathrm{E}$ ffect of heat treatment on whey protein}

Milk is a complicated system because it contains all kinds of components, such as proteins, lipids, and sugars (Nissen, Bendixen, Ingvartsen, \& Rontvedt, 2013). Heating not only result in unfolding and aggregation of proteins, but also accelerates the Maillard reaction, which can cause numerous chemical modifications of proteins due to its reaction with the milk sugar lactose (Anema, 2008a, 2008b; del Angel \& Dalgleish, 2006; Donato, Guyomarc'h, Amiot, \& Dalgleish, 2007; Miyamoto et al., 2009; Singh, 2004; Ye, Anema, \& Singh, 2008). Unfolding of proteins makes it easier for them to be modified, while chemical modification of proteins may further enhance crosslinking of proteins as well as aggregation among whey proteins or between whey proteins and casein micelles (Donato et al., 2007). Modification, crosslinking and aggregation of proteins may affect its digestion, and thereby cause differences in released bioactive peptides (Deglaire et al., 2016; Leeb, Gotz, Letzel, Cheison, \& Kulozik, 2015; Moscovici et al., 2014). The interaction between those reaction and corresponding consequences are showed in Figure 1-3. 


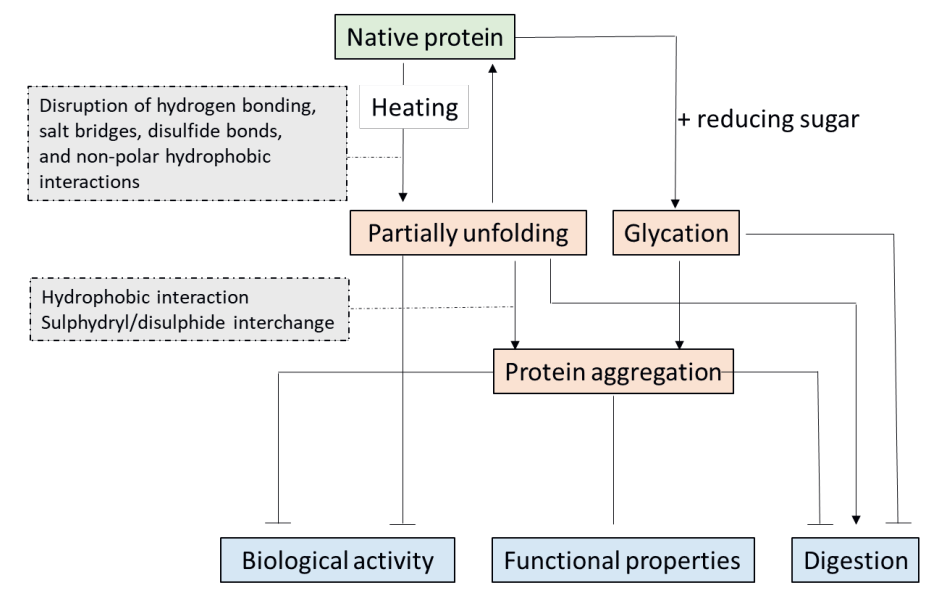

Figure 1-3 The reactions may occur during heating and the consequences on digestion and biological function. A line with arrow: increase; a flat line with a horizontal end: decrease

\subsubsection{Heat induced denaturation of whey protein}

One of the most important heat induced changes of whey proteins is its unfolding and denaturation. Most whey proteins are globular proteins, which easily lose their native tertiary structure upon heating. The denaturation of whey protein can be measured with a variety of techniques, such as HPLC, differential scanning calorimetry, circular dichroism, and Fourier transform infrared spectroscopy (Wagner, Biliaderis, \& Moschakis, 2020). It was reported that $70{ }^{\circ} \mathrm{C}$ is a critical temperature for the denaturation of $\beta$-lactoglobulin at the $\mathrm{pH}$ of milk, 6.7 (De Wit \& Swinkels, 1980). Pure $\alpha$-lactalbumin showed a thermal denaturation temperature with an average of $63.7^{\circ} \mathrm{C}$, at the same pH (McGuffey, Epting, Kelly, \& Foegeding, 2005). Denaturation of lactoperoxidase, measured by loss of activity, showed that only $5.2 \%$ of the enzyme activity was preserved after it was heated at $70{ }^{\circ} \mathrm{C}$ for 5 min (Aprodu, Stănciuc, Dumitraşcu, Râpeanu, \& Stanciu, 2014). The critical temperature for bovine IgG to change secondary structure at neutral $\mathrm{pH}$ is $72{ }^{\circ} \mathrm{C}(\mathrm{Li}$, Bomser, \& Zhang, 2005).

$\mathrm{LF}$, as one of the main immune-active proteins, is of high interest among all whey proteins. The thermal stability of lactoferrin increases with iron saturation, due to the more compact tertiary structure of the protein after binding iron (Andersen, Baker, Morris, Rumball, \& Baker, 1990; Sánchez et al., 1992). The denaturation temperatures of apo-lactoferrin (iron free) and hololactoferrin (iron containing $>90 \%$ ) in aqueous solution are $71 \pm 0.2{ }^{\circ} \mathrm{C}$ and $91 \pm 0.5^{\circ} \mathrm{C}$, respectively (Bokkhim, Bansal, Grøndahl, \& Bhandari, 2013). Heat induced denaturation of lactoferrin in simple model systems was measured with various techniques, which showed that 
its stability was highly dependent on $\mathrm{pH}$, ionic strength. There are conflicting reports about the effect of $\mathrm{pH}$ on the thermal stability of lactoferrin. An early study observed that an acid environment could help lactoferrin resist heat-induced changes at $90{ }^{\circ} \mathrm{C}$ for $5 \mathrm{~min}$ (Abe et al., 1991). However, a recent study demonstrated that the denaturation temperature of bovine lactoferrin and caprine lactoferrin gradually decreased from pH 7.0 to 3.0 (Sreedhara et al., 2010). Ionic strength was reported to negatively affect iron-binding ability of lactoferrin during heat treatment (Kawakami, Tanaka, Tatsumi, \& Dosako, 1992). Similarly, it was shown that the temperature of maximum heat absorption of the three forms of lactoferrin remained consistent within the range of $\mathrm{pH} \mathrm{4-7} \mathrm{at} \mathrm{very} \mathrm{low} \mathrm{ionic} \mathrm{concentration} \mathrm{(Bokkhim} \mathrm{et} \mathrm{al.,} \mathrm{2013).}$

Limited information can found about the denaturation of other immune-active proteins in milk. Pasteurisation $\left(62.5^{\circ} \mathrm{C} / 30 \mathrm{~min}\right)$ significantly reduces the amount of sCD14 in breast milk (Cossey, Jeurissen, Bossuyt, \& Schuermans, 2009). Complement component 3 (C3), osteopontin, glycosylation-dependent cell adhesion molecule 1, lactadherin (MFGE8), polymeric immunoglobulin receptor (PIGR), alpha-1-antiproteinase (SERPINA1), fatty acidbinding protein, heart (FABP3), and xanthine dehydrogenase/oxidase (XDH) decreased 25\%$85 \%$ after pasteurization $\left(65{ }^{\circ} \mathrm{C} / 30 \mathrm{~min}\right)$ and $85 \%-95 \%$ after spray drying (Zhang, Boeren, et al., 2016). XDH, PIGR, C3, MFGE8, Fibronectin, Monocyte differentiation antigen CD 14 showed a decrease of above $10 \%$ in UHT, ESL and boiled milk compared with raw milk and pasteurized milk $\left(72^{\circ} \mathrm{C} / 15 \mathrm{~s}\right)$, measured by label-free proteomics (Brick et al., 2017). A more detailed measurement of the denaturation of these proteins after different heat treatment at relatively low heating temperatures would be useful. Combining the existing denaturation kinetics data of the main whey proteins and low abundant whey proteins, $70{ }^{\circ} \mathrm{C}$ seems to be a critical temperature for heat-induced damage, which is right around the temperature of pasteurisation, making it interesting to see how temperatures around $70{ }^{\circ} \mathrm{C}$ are able to retain proteins.

\subsubsection{Heat induced aggregation between whey proteins}

Protein aggregation, induced by hydrophobic, electrostatic and covalent interaction, affected the functional properties of milk proteins (Brodkorb, Croguennec, Bouhallab, \& Kehoe, 2016; Wijayanti et al., 2014). When skim milk was heated to $90{ }^{\circ} \mathrm{C}$ for up to $10 \mathrm{~min}$, the level of native whey proteins decreased in parallel with an increase in disulphide-linked complexes, including very complex heteropolymers (mainly homopolymers of $\kappa$-casein and $\alpha_{\mathrm{s} 2}$-casein but also some heteropolymeric complexes) as identified by two-dimensional gel-electrophoresis combined with MALDI-TOF (Chevalier, Hirtz, Sommerer, \& Kelly, 2009). Pure $\alpha$-LA rapidly 
aggregated at $95^{\circ} \mathrm{C}, \mathrm{pH} 7.0$, as indicated by development of turbidity (McGuffey et al., 2005), while it aggregates more easily in the presence of $\beta$-LG (de la Fuente, Singh, \& Hemar, 2002). This indicates that thermal behaviour of proteins when heated in a protein matrix differs from that when heated alone, due to the interaction between proteins.

Association of immunoglobulin $\mathrm{G}$ ( $\mathrm{IgG}$ ) with other whey proteins during heating was investigate in a recent study (Bogahawaththa, Chandrapala, \& Vasiljevic, 2017). When IgG was heated with other whey proteins ( $\beta$-LG, $\alpha$-LA and BSA) at $100^{\circ} \mathrm{C}$ for $30 \mathrm{~s}$, thiol-disulphide interchange occurred. BSA did not form covalent complexes with IgG in the absence of $\beta$-LG and $\alpha$-LA when heated at the $100{ }^{\circ} \mathrm{C}$ for $30 \mathrm{~s}$, indicating that BSA is not actively interacting with other proteins.

Compared to denaturation, thermal aggregation of lactoferrin was relatively less investigated. Apo-lactoferrin formed disulphide linked and non-covalently linked aggregates from $60{ }^{\circ} \mathrm{C}$, while holo-lactoferrin formed disulphide linked aggregates above $80{ }^{\circ} \mathrm{C}$ (Brisson, Britten, \& Pouliot, 2007b). Thermal aggregation of lactoferrin with whey proteins was shown to occur in LF-enriched milk (Brisson, Britten, \& Pouliot, 2007a). LF significantly influenced the structural properties of whey protein gels through hydrophobic interactions and disulphide bonds, which were highly dependent on $\mathrm{pH}$ and the structural properties of LF (Li \& Zhao, 2018). However, a detailed investigation about the aggregation between lactoferrin and whey protein and the underlying mechanisms have not yet been performed, which could help to optimize the heat processing of lactoferrin in a complicated matrix, to better retain lactoferrin in its native form.

\subsubsection{Heat induced changes in digestion of whey proteins}

Above mentioned modifications induced by heating can affect many of physicochemical properties of whey proteins, but especially the digestion of protein (van Lieshout, Lambers, Bragt, \& Hettinga, 2019). Protein digestion may be influenced by various physicochemical changes, such as unfolding, chemical modification and aggregation, which are depending on the heating intensity. This probably explains the conflicting results presented about the effect of processing on digestion of milk in scientific literature. For example, raw milk was reported to be digested significantly faster with human proteolytic enzymes than heat-treated milk, probably due to the structural changes in the proteins caused by denaturation and aggregation of the whey proteins during heat treatment (Almaas et al., 2006). However, some studies showed no differences in digestion between raw and processed milk (Wada \& Lonnerdal, 2015). 
Milk heated at higher temperatures showed softer coagulum and higher protein hydrolysis at the end of digestion (Mulet-Cabero, Mackie, Wilde, Fenelon, \& Brodkorb, 2019). Digestion of lactoferrin by trypsin was affected by pasteurisation, as shown by mapping and tracking the pepsin-driven release of peptides from the lactoferrin over the course of the digestion (Moscovici et al., 2014). An in vitro gastric digestion of heat-induced aggregates of $\beta$ lactoglobulin showed that high-molecular-weight non-native aggregates were digested relatively rapidly, whereas some of the non-native dimers showed similar resistance to digestion as native monomers (Peram, Loveday, Ye, \& Singh, 2013). A high protein concentration during heating led to the formation of larger whey protein aggregates, which showed a slower degradation rate (Zhang \& Vardhanabhuti, 2014). Taken together, data shows that the effect of heating on digestion through denaturation and aggregation depends on the specific heat load applied.

Non-enzymatic posttranslational modifications of proteins generally reduce its digestibility. Blockage of the $\varepsilon$-amino groups of Lys residues by Maillard reaction hindered tryptic digestion as well as the action of other digestive enzymes, thereby impairing protein digestibility (Rérat, Calmes, Vaissade, \& Finot, 2002). Lactosylated proteins induced by heating were found to resist hydrolysis by proteases in a model system (Dalsgaard, Nielsen, \& Larsen, 2007). Maillard reaction products of lactoferrin have different enzymatic cleavage patterns and peptide formation compared to native lactoferrin (Moscovici et al., 2014). Although there are negative effects of glycation on digestibility, these reactions hardly occur during mild heat treatment in an aqueous system.

\subsubsection{Heat induced changes in biological activity of whey protein}

The biological activity of whey proteins may be changed upon heating, due to the different changes that can occur to the native proteins, which e.g. have already been tested in bacterial growth experiments, in vitro immune cell models, and animal model studies.

An often studied biological activity associated with whey proteins is its bacteriostatic activity. Heating was generally shown to decrease the bacteriostatic activity of whey proteins. Even heat treatments as mild as holder pasteurization were previously shown to adversely affect the bacteriostatic properties of human milk, which was associated with reduced levels of lysozyme, secretory IgA, lactoferrin, lactoperoxidase and sCD14 (Christen, Lai, Hartmann, Hartmann, \& Geddes, 2013; Van Gysel, Cossey, Fieuws, \& Schuermans, 2012). The antibacterial activity of bovine lactoferrin against food pathogens was decreased after it had been heated at $85{ }^{\circ} \mathrm{C}$ for 
10 min (Conesa et al., 2010). Another study showed that an active LPO system greatly increased the keeping quality of milk pasteurized at $72{ }^{\circ} \mathrm{C} / 15 \mathrm{~s}$ by inhibiting spoilage microflora, but had little effect in milks heated at $80{ }^{\circ} \mathrm{C} / 15 \mathrm{~s}$ due to the inactivation of LPO at $80{ }^{\circ} \mathrm{C}$ (Marks, Grandison, \& Lewis, 2001). The capacity of bovine whey to inhibit rotavirus infection in MA104 cells was not affected by treatment at $75{ }^{\circ} \mathrm{C}$ for $20 \mathrm{~s}$, but decreased after heating at $85{ }^{\circ} \mathrm{C}$ for $10 \mathrm{~min}$ (Parrón et al., 2016).

Compromised intestinal barrier function plays a major role in the pathogenesis of NEC (Halpern \& Denning, 2015) and food allergy (Sicherer \& Sampson, 2010). Premature infants have impaired epithelial barrier function compared to term infants, which may be improved by supplementation of native whey proteins in a piglet model (De Vos et al., 2014). Heating decreased the intestinal integrity enhancing activity of whey protein. It was reported that industrial processing (pasteurization, filtration, spray-drying) of whey protein concentrate (WPC) affected intestinal structure, function, and integrity when included in formulas fed to preterm piglets ( $\mathrm{Li}$ et al., 2013). Low-heat-treated WPC, especially when derived from acid whey, enhanced proliferation and cytokine response of intestinal epithelial cells, due to higher levels of bioactive proteins, such as lactoferrin and transforming growth factor- $\beta 2$ (Nguyen, Sangild, Li, Bering, \& Chatterton, 2016). A formula based on mildly pasteurized $\left(73{ }^{\circ} \mathrm{C} / 30 \mathrm{~s}\right)$ WPC limited gut inflammation and stimulated gut maturation in preterm and near-term piglets, compared to extensively heated $\left(73{ }^{\circ} \mathrm{C} / 30 \mathrm{~s}+80^{\circ} \mathrm{C} / 6 \mathrm{~min}\right)$ WPC (Navis et al., 2020).

Another earlier discussed function of milk proteins is related to the allergy protection of raw milk as has been shown in several epidemiological and animal studies (Loss et al., 2011; Sozańska, Pearce, Dudek, \& Cullinan, 2013), which was speculated to be partly associated with the presence of immune-active proteins, possibly due to their anti-inflammatory and immunomodulatory activity. Heat induced loss of allergy protection of raw milk may have been due to denaturation of those immune-active proteins (Abbring et al., 2017), because most of the immune-active proteins in milk are heat-labile (Brick et al., 2017; Zhang, Boeren, et al., 2016). Although there is ample indirect evidence for this effect, the direct evidence for elucidating the contribution of individual whey proteins in the allergy protective activity still needs to be provided, where especially which whey protein is involved in the protection remains to be addressed. Besides, how the raw milk can be mildly processed to preserve the allergy protective capacity while at the same time ensuring microbiological safety is great of importance. Generally, heat-induced changes to physicochemical properties and biological function of immune-active protein still needs to be studied in more detail. 


\subsection{Proteomic analysis on heat-induced changes of milk protein}

Identification and characterization of low abundant milk proteins was a challenge until the application of proteomics techniques, varying from identification of the basic composition of milk proteins to their post-translational modifications, which increased the range of proteins we can detect. Combination of centrifugation and filter-aided separation preparation was shown to yield higher rates of protein identification. This method was used to compare the proteome between human milk and bovine milk (Hettinga et al., 2011). After that, identification and quantification of milk fat globule membrane proteome was done ( $\mathrm{Lu}$ et al., 2011). The measurement of the dynamic changes of the proteome of both human milk and bovine milk were followed (Zhang et al., 2015a; Zhang et al., 2015b; Zhang, de Waard, et al., 2016).

The effect of processing on the whey protein proteome were also characterized by a combination of acid precipitation to remove denatured/aggregated proteins, combined with identification and quantification of proteins by LC-MS/MS. The damage of industrial processing (freezing, spray drying and pasteurization) on immune-active milk serum proteins in different species was analysed by proteomics (Zhang, Boeren, et al., 2016). Another study showed that a heat treatment of $80{ }^{\circ} \mathrm{C}$ for 60 min significantly affected bovine whey proteins, as measured by LC-MS/MS following electrophoresis (Felfoul, Jardin, Gaucheron, Attia, \& Ayadi, 2017). Brick et al. (Brick et al., 2017) found that 23 proteins were reduced by heating after comparing the native milk serum proteome between raw cow's milk and various industrially applied processing methods, i.e., homogenization, fat separation, pasteurization, ultra-heat treatment (UHT), treatment for extended shelf-life (ESL) and conventional boiling. Heating colostrum at $60{ }^{\circ} \mathrm{C}$ for 0 (untreated control), 30, 60, or 90 min showed that up to 62 proteins differed in abundance in heat-treated samples compared with the unheated control, which included immune active proteins, like lactadherin, chitinase-3-like protein 1, and complement component C9 (Tacoma et al., 2017).

Chemical modifications due to heating of proteins can also be analysed by LC-MS/MS. For example, lactosylation of milk proteins in different milk products was identified and quantified (Le, Deeth, Bhandari, Alewood, \& Holland, 2012, 2013; Milkovska-Stamenova \& Hoffmann, 2016; Rauh et al., 2015). Disulphide bond identification and rearrangement between milk proteins induced by heating or other harsh treatments was mapped by proteomics (Creamer et al., 2004; Lowe et al., 2004; Rombouts et al., 2015). 
Although there is an increasing application of proteomics for quantification of milk proteins, most studies focused on the identification and comparison of proteome from different species. Although several studies compared the effect of industrial processing on whey protein proteome detailed information about how different mild heat treatments, i.e. within the pasteurization range, affects the immune-active proteins, is still to be discovered. The results of such research can help to optimize the preservation of immune-active proteins, through mild heat treatment.

\subsection{Aim and outline of this thesis}

The above mentioned heat induced changes of whey protein were often investigated for different proteins separately, and mainly focused on the abundant whey proteins, neglecting the contribution of low-abundant immune-active proteins. A systematic and comprehensive investigation of heat-induced changes in those low-abundant proteins and their corresponding biological functions is lacking. The aim of the project is thus to study the effect of heat processing, within the pasteurization temperature range, on immune-active proteins in milk from the perspective of protein denaturation and aggregation, and connecting these modifications to digestibility and biological function.

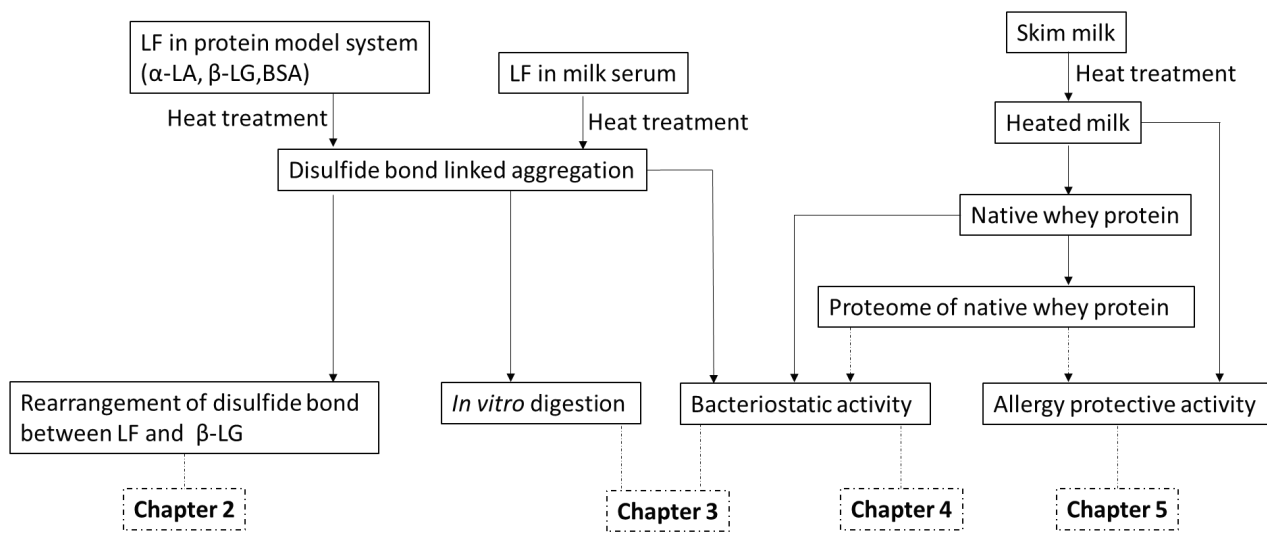

Figure 1-4 Outline of the experimental design of the different chapters of this thesis.

The general experimental design is shown in Figure 1-4. To get more insights in the interaction of lactoferrin with each of major whey proteins, the aggregation and disulphide bond rearrangement of lactoferrin with $\beta$-lactoglobulin, $\alpha$-lactalbumin, and bovine serum albumin were studied in C hapter 2. After the role of disulphide bond interchange between the abundant whey proteins was determined, the next step was to study the interaction between lactoferrin 
and whey proteins as a whole. In addition, the effect on the digestibility and bacteriostatic activity ensuing from these changes was investigated in Chapter 3, to obtain more detailed insights into heat-induced changes of lactoferrin in a milk serum matrix. In addition to lactoferrin, there are more bacteriostatic proteins present in whey. To establish a direct relationship between denaturation of immune-active proteins globally and bacteriostatic activity, the changes of these proteins and bacteriostatic activity of milk after heating was investigated in Chapter 4. Besides bacteriostatic activity, whey proteins are linked to many more biological functions, of which the allergy protective effect is a highly relevant one. To determine the mechanistic relation between heat damage to whey proteins and allergy development, and gain more insight in the actual whey protein(s) involved in the allergyprotective effects of raw cow's milk, the change of immune-active proteins and allergy protective activity of milk after different heating intensities was investigated $\mathbf{C h a p t e r} \mathbf{5}$. Finally, the results of this thesis were discussed from a holistic perspective in Chapter $\mathbf{6}$. This research has contributed to new knowledge on the effect of mild heat treatments on immune-active proteins in general and lactoferrin in particular. Such knowledge is beneficial for the production of milk products that have improved immunological functionality, like infant formula. Based on this thesis, an improved heat treatment for preservation of bacteriostatic activity and allergy protective activity of immune-active proteins may be developed. 

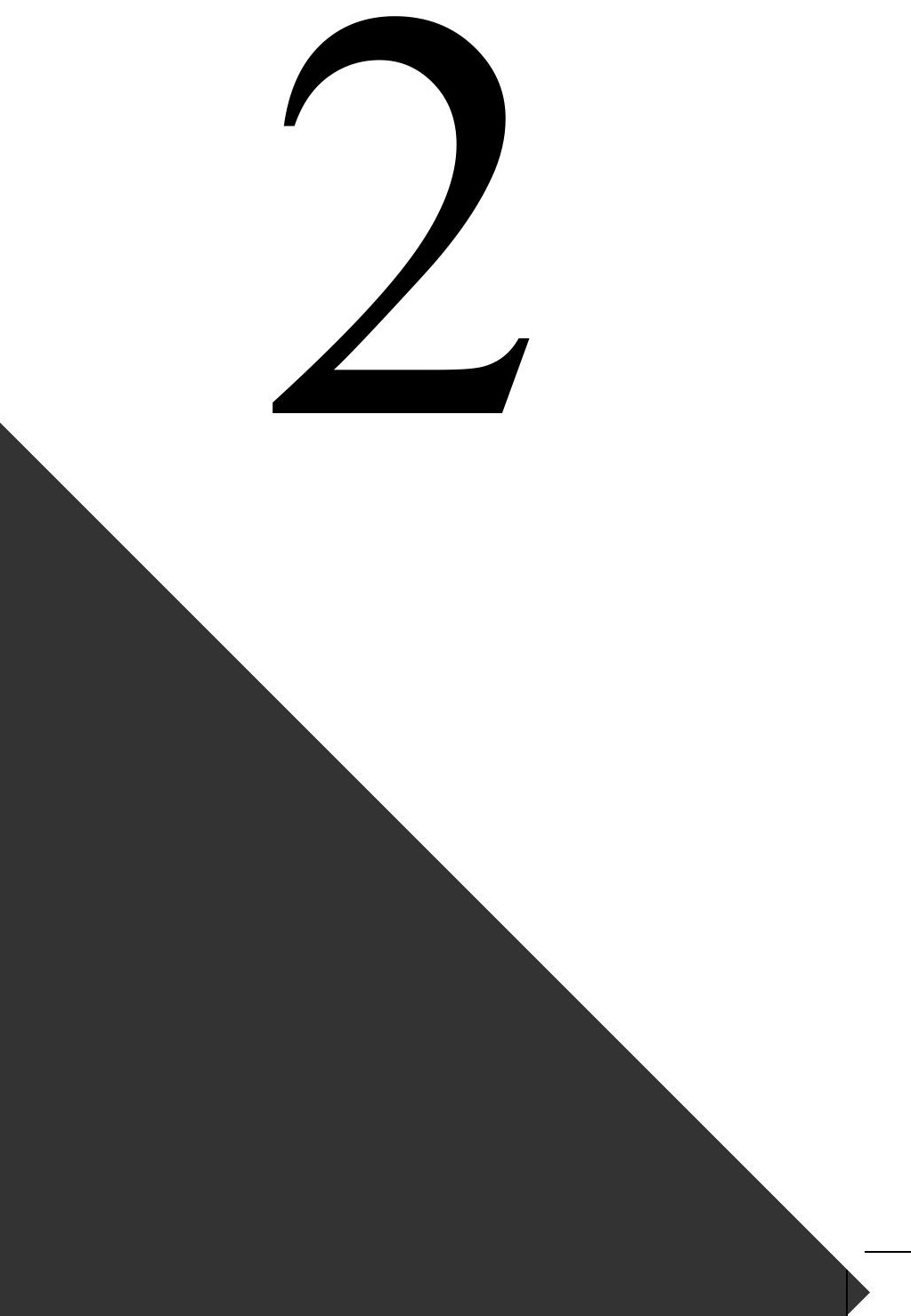


\section{CHAPTER 2.}

Aggregation and disulphide bond interchange of lactoferrin with major whey proteins during heat treatment

This chapter is based on:

Xiong, L., Liu, J., Boeren, S., Vervoort, J., \& Hettinga, K. (2020). Aggregation and disulphide bond interchange of lactoferrin with major whey proteins during heat treatment. In preparation 


\section{Abstract}

Lactoferrin is an important immune-active protein in milk. Upon heating of milk, e.g. during pasteurization, the physicochemical characteristics of lactoferrin are modified, leading to, amongst others, aggregation. Lactoferrin can aggregate with whey proteins during heat treatment, but the exact mechanisms underlying this aggregation are not clear. The present study aims to determine the thermal behaviour of lactoferrin in the presence of $\beta$-lactoglobulin ( $\beta$-LG), $\alpha$-lactalbumin ( $\alpha-\mathrm{LA})$, and bovine serum albumin (BSA), which are the three most abundant whey proteins in bovine milk. SDS-PAGE and LC-MS/MS were applied to characterize the thermal aggregation characteristics of lactoferrin. Upon heating of lactoferrin in the absence or presence of $\beta-\mathrm{LG}, \alpha$-LA or BSA, changes in the physicochemical characteristics of LF aggregation were observed. Lactoferrin, in the absence of these proteins showed disulphide linked aggregation at elevated temperatures $\left(65{ }^{\circ} \mathrm{C}\right.$ or above). This aggregation was not significantly affected by the presence of $\alpha$-LA or BSA, but was accelerated by the presence of $\beta$-LG. This aggregation was shown to be related to intra- and intermolecular disulphide bond formation of LF and $\beta$-LG. The free cysteine group of $\beta$-LG was proposed to be the catalyst for reduction and rearrangements of the disulphide bonds. Cys36, Cys45, Cys115, Cys198, Cys405, Cys457, Cys515, Cys573 and Cys647 residues formed 36 different disulphide bonds in 47 different crosslinked peptides between lactoferrin molecules (inter- and intramolecular disulphide bonds). Among these cysteines, except for Cys647, the same cysteines from lactoferrin formed 9 different disulphide bonds with Cys60 and Cys 160 from $\beta$ LG in 21 heterologous crosslinked peptides (intermolecular disulphide bonds).

Keywords: Lactoferrin, whey protein, thermal aggregation, disulphide bond rearrangement, cysteine 


\subsection{Introduction}

Lactoferrin is an important protein in milk, which is involved in protection of neonates from infectious processes (Telang, 2018). As a consequence, lactoferrin is extensively used as an ingredient in infant foods as well as other functional foods. Heat treatments (e.g. pasteurization, sterilisation) are generally applied in dairy processing to guarantee microbial safety and to extend shelf life. However, such heat treatments can also induce changes to proteins, thereby influencing their biological activity. Disruption of disulphide bonds, followed by formation of non-native intra- and intermolecular disulphide bonds is one of the possible heat-induced changes, which could contribute to the formation of protein aggregates. Disulphide bond rearrangements can affect the biological function of a protein by the resulting irreversible protein denaturation, which can also lead to changes in functional properties, including emulsifying, foaming, and gelling properties (Havea, Carr, \& Creamer, 2004; Mounsey \& O’Kennedy, 2007; Nguyen, Wong, Fanny, Havea, \& Anema, 2012; Visschers \& de Jongh, 2005). Lactoferrin (LF, approximately $0.1 \mathrm{~g} / \mathrm{L}$ in bovine milk) contains 17 disulphide bonds which play an important role in stabilizing its structure (Pierce et al., 1991). Lactoferrin does not have a free cysteine group. Disulphide linked aggregation of lactoferrin with itself and with other milk proteins was observed in earlier studies upon heating, like during pasteurization (Brisson et al., 2007a, 2007b). Next to LF, other abundant whey proteins are $\beta$-lactoglobulin ( $\beta$-LG, approximately $3.2 \mathrm{~g} / \mathrm{L}$ ), $\alpha$-lactalbumin ( $\alpha$-LA; approximately $1.2 \mathrm{~g} / \mathrm{L}$ ) and bovine serum albumin (BSA; approximately $0.4 \mathrm{~g} / \mathrm{L}$ ) (Raikos, 2010). Of these, $\beta$-LG has 2 disulphide bonds and one free sulfhydryl group (Creamer et al., 2004), $\alpha$-LA contains 4 disulphide bonds and no free sulfhydryl group (Ewbank \& Creighton, 1993), and BSA contains 17 disulphide bonds and one free sulfhydryl group (Rombouts et al., 2015). Heat induced aggregation of $\beta$-LG, $\alpha$-LA , BSA, and other whey proteins involves sulfhydryl (-SH)/disulphide ( $\mathrm{S}-\mathrm{S})$ interchange reactions (Wijayanti et al., 2014). Generally, thermal aggregation of these proteins is enhanced when these proteins are heated together, as compared to them being heated alone. BSA and $\beta$ LG could enhance the heat-induced incorporating of $\alpha$-LA into both disulphide-bonded and hydrophobically associated aggregates (Havea, Singh, \& Creamer, 2000; Schokker, Singh, \& Creamer, 2000). In a whey protein concentrate heated at $75^{\circ} \mathrm{C}$, BSA formed disulphide-bonded strands faster than $\beta$-LG thereby catalysing the aggregation of $\alpha$-LA (Havea, Singh, \& Creamer, 2001). When heating $\beta$-LG and BSA in different ratios, at a protein concentration of $10 \%$, the gelling behaviour of the mixture was dependent on the predominant protein in the mixture (Gezimati, Singh, \& Creamer, 1995). Therefore, these proteins may also affect aggregation of 
lactoferrin when they are heated in a mixture, which has hardly been studied yet. LF was reported to enhance the denaturation of $\beta$-LG when heated at $67.5-80{ }^{\circ} \mathrm{C}$, indicating that an interaction occurred between LF and $\beta$-LG (Halabi et al., 2020). We found that $\beta$-LG accelerated heat-induced disulphide linked aggregation of LF in a previous study (C hapter 3). However, the exact mechanisms of this heat-induced aggregation were not reported yet. Also, the role of $\alpha$-LA and BSA in the thermal aggregation of lactoferrin with whey proteins is not clear.

To characterize disulphide bond rearrangements in proteins, mass spectrometry-based techniques have been applied in recent years (Lakbub, Shipman, \& Desaire, 2018; Rombouts et al., 2015). For example, when $\beta$-LG was heated without other proteins present, the Cys $160-$ Cys66 disulphide bond was broken with concurrent reduction of the Cys160 side chain in heated $\beta$-LG aggregates (Creamer et al., 2004; Zhan, Liu, Xie, Xiong, \& Nie, 2018). When a mixture of $\beta$-LG and $\kappa$-casein was heated, Cys 160 from $\beta$-LG was covalently linked to Cys 88 from $\kappa-$ casein, indicating that Cys 160 tended to participate in intermolecular disulphide bond formation. Cys 160 is in a disulphide bond with Cys66 in the native $\beta$-LG molecule. This disulphide bond was proposed to be reduced (as also found for $\beta$-LG heated alone), after which Cys 160 could crosslink with Cys 88 from $\kappa$-casein. This reduction of the disulphide bond of Cys160-Cys66 was probably due to intramolecular thiol-disulphide exchange reactions of $\beta$-LG preceding the reaction of Cys 160 with Cys 88 of $\kappa$-casein (Lowe et al., 2004). A recent study by us showed that lactoferrin accelerated aggregation of $\beta$-LG compared to when it was heated alone, which was associated with sulfhydryl/disulphide interchange (Chapter 3). Therefore, the rearrangement of disulphide bonds between lactoferrin and $\beta$-LG may be different from when lactoferrin is heated alone. The identification of disulphide bonds interchange among proteins is useful for better characterizing the heat-induced changes in protein structure, thereby enabling better insights into the effect of heat treatment on functionality of these proteins. In the current study, we demonstrate the heat-induced aggregation of lactoferrin with $\beta$-LG, $\alpha$-LA, and BSA, and address the rearrangement of intra- and intermolecular disulphide bonds in the aggregates of LF and $\beta-L G$ in isolation, and in a mixture of LF and $\beta-L G$.

\subsection{M aterial and methods}

\subsubsection{Material}

Bovine lactoferrin were provided by FrieslandCampina Ingredients (Vivinal Lactoferrin; estimated purity, $95 \%$; iron saturation: $9 \%$; ash: $0.5 \%$; Veghel, the Netherlands). $\beta$-LG (L3908), 
$\alpha$-LA (L5385) and BSA (05470) were purchased from Sigma-Aldrich (Sigma-Aldrich, St. Louis, Missouri, US).

\subsubsection{Sample preparation and heat treatment}

Milk ultrafiltrate was used to simulate the aqueous environment of milk, which was prepared according to the following method. Raw milk was centrifuged at $1500 \mathrm{~g}$ for 20 minutes at $4{ }^{\circ} \mathrm{C}$ to remove the fat, followed by ultracentrifugation at $100,000 \mathrm{~g}$ for $90 \mathrm{~min}$ at $30^{\circ} \mathrm{C}$ to precipitate casein, thereby obtaining milk serum. Milk serum was filtered through a $0.2 \mu \mathrm{m}$ filter, and was then ultra-filtered by a $3 \mathrm{kDa}$ tube to get the permeate, which was the milk ultrafiltrate. The milk ultrafiltrate was loaded on an SDS-PAGE gel to check for the absence of the whey proteins

The concentration of lactoferrin used was $1 \mathrm{mg} / \mathrm{ml}$ according to the maximum level allowed by the Novel Food and GRAS regulations in the EU (https://eurlex.europa.eu/eli/dec impl/2012/727/). These three whey proteins, $\beta$-LG, $\alpha$-LA and BSA, were dissolved in milk ultrafiltrate at $3.2 \mathrm{mg} / \mathrm{ml}, 1.2 \mathrm{mg} / \mathrm{ml}$, and $0.4 \mathrm{mg} / \mathrm{ml}$, respectively, corresponding to their concentrations in bovine milk (Raikos, 2010). Finally, 8 different samples, all including LF, were prepared: LF alone, two proteins model system (3 groups: $\mathrm{LF}+\alpha-\mathrm{LA}, \mathrm{LF}+\beta-\mathrm{LG}, \mathrm{LF}+\mathrm{BSA})$, three or four proteins model system (4 groups: $\mathrm{LF}+\alpha-\mathrm{LA}+\beta-$ $\mathrm{LG}, \mathrm{LF}+\alpha-\mathrm{LA}+\mathrm{BSA}, \mathrm{LF}+\beta-\mathrm{LG}+\mathrm{BSA}, \mathrm{LF}+\alpha-\mathrm{LA}+\beta-\mathrm{LG}+\mathrm{BSA})$. In the meantime, 7 control model systems without LF were prepared, single protein model system (3 groups: $\alpha$-LA, $\beta$-LG, BSA), and two or three proteins model system (4 groups: $\alpha$-LA+ $\beta-L G, \alpha-L A+B S A, \beta-L G+B S A$, $\alpha$-LA+ $\beta$-LG+BSA). Aliquots $(1.0 \mathrm{~mL})$ of sample solutions were transferred into $15 \mathrm{~mL}$ plastic centrifuge tubes which were covered with caps and heated in shaking water baths for $30 \mathrm{~min}$ at $55,60,65,70,75,80,85,90^{\circ} \mathrm{C}$ (for single or two proteins model systems), or 65,75 and $85^{\circ} \mathrm{C}$ (for three or four proteins model systems). After heating, the samples were rapidly cooled to room temperature in ice water for further analysis.

\subsubsection{SDS-PAGE}

The protocol of SDS-PAGE in both reducing and non-reducing condition was according to our previous publication (Xiong, Li, Boeren, Vervoort, \& Hettinga, 2020a).

\subsubsection{Free thiol group by DTNB}

The measurement of free sulfhydryl was based on the DTNB method with some modifications (Riddles, Blakeley, \& Zerner, 1979). First, 4 mg of Ellman's Reagent (Thermo Fisher Scientific, Massachusetts, United States) was dissolved in $1 \mathrm{~mL}$ of reaction buffer $(0.1 \mathrm{M}$ sodium phosphate, $\mathrm{pH} 8.0$, containing $1 \mathrm{mM}$ EDTA). Then, $250 \mu \mathrm{L}$ sample was added into the tube 
containing $50 \mu \mathrm{L}$ of Ellman's Reagent solution and $2.5 \mathrm{~mL}$ of the reaction buffer. As a blank, $250 \mu \mathrm{L}$ of reaction buffer was added to a separate test tube. All the samples were mixed and incubated at room temperature for 15 minutes, after which the absorbance of each sample was measured at $412 \mathrm{~nm}$ with a spectrophotometer (Agilent Technologies, California, US). The concentrations of sulfhydryl in the samples were calculated according to the formula $C=\frac{A}{b E}$, where $\mathrm{C}=$ concentration in moles/liter $(=\mathrm{M}), \mathrm{A}=$ absorbance, $\mathrm{b}=$ path length in centimeters, $\mathrm{E}=$ molar extinction coefficient of TNB $\left(14,150 \mathrm{M}^{-1} \mathrm{~cm}^{-1}\right)$.

\subsubsection{LC-MS/MS}

$\beta$-LG, $\mathrm{LF}$ and $\mathrm{LF}+\beta-\mathrm{LG}$ samples heated at $85^{\circ} \mathrm{C}$ were used to determine which cysteines of $\mathrm{LF}$ and $\beta$-LG participated in the formation of non-native disulphide bonds. For this, non-reducing SDS-PAGE (prepared as described before), in-gel digestion, and LC-MS/MS were combined. To collect all the disulphide-linked aggregates involving lactoferrin, lanes above (including) the monomeric lactoferrin band $(80 \mathrm{kDa})$ were cut out and sliced into small pieces of about 1 $\mathrm{mm}^{2}$ with a clean scalpel and then transferred into $2 \mathrm{~mL}$ centrifuge tubes. To the sliced gel pieces, $50 \mu \mathrm{L}$ freshly prepared trypsin in bicinchoninic acid (ABC) solution $(5 \mathrm{ng} / \mu \mathrm{L}$ in $\mathrm{ABC})$ was added, after which sufficient $\mathrm{ABC}$ was added to cover all the gel pieces, then incubated at $45^{\circ} \mathrm{C}$ for 2 hours. The peptide fraction was cleaned up with a $\mathrm{C} 18 \mu$ Column according to a previous study (Dingess et al., 2017).

The LC-MS/MS parameters are described as followed. One microliter of the peptide samples were loaded directly onto a $0.10 * 250 \mathrm{~mm}$ ReproSil-Pur 120 C18-AQ $1.9 \mu \mathrm{m}$ beads analytical column (prepared in-house) at a constant pressure of 800 bar with $1 \mathrm{ml} / \mathrm{L} \mathrm{HCOOH}$ in water and eluted at a flow of $0.5 \mu \mathrm{L} / \mathrm{min}$ with a 50 min linear gradient from $9 \%$ to $34 \%$ acetonitrile in water with $1 \mathrm{ml} / \mathrm{L}$ formic acid with a Thermo EASY nanoLC1000. An electrospray potential of $3.5 \mathrm{kV}$ was applied directly to the eluent via a stainless steel needle fitted into the waste line of the micro cross that was connected between the pump and the analytical column. Full scan positive mode FTMS spectra were measured between m/z 380 and 1400 on a Q-Exactive HF$\mathrm{X}$ (Thermo electron, San Jose, CA, USA) in the Orbitrap at high resolution (60000). MS and MSMS AGC targets were set to $3 \times 10^{6}, 50000$ respectively or maximum ion injection times of $50 \mathrm{~ms}$ (MS) and $25 \mathrm{~ms}$ (MSMS) were used. HCD fragmented (Isolation width $1.2 \mathrm{~m} / \mathrm{z}, 24 \%$ normalized collision energy) MSMS scans of the 20 most abundant 2-5+ charged peaks in the MS scan were recorded in data dependent mode (threshold $1.2 \times 10^{5}, 15 \mathrm{~s}$ exclusion duration for the selected $\mathrm{m} / \mathrm{z}+/-10 \mathrm{ppm})$. LC-MS runs with all MSMS spectra obtained were analysed with 
MaxQuant 1.6.3.4 (Cox \& Mann, 2008) using the "specific" digestion mode and further default settings for the Andromeda search engine (first search $20 \mathrm{ppm}$ peptide tolerance, main search $4.5 \mathrm{ppm}$ tolerance, MSMS fragment match tolerance of $20 \mathrm{ppm}$ ). Variable modifications were set for protein $\mathrm{N}$-terminal acetylation and $\mathrm{M}$ oxidation, which were completed by non-default settings for de-amidation of $\mathrm{N}$ and $\mathrm{Q}$, and the maximum number of modifications per peptide was 5 (Cox et al., 2011). nLC-MS/MS system quality was checked with PTXQC (Bielow, Mastrobuoni, \& Kempa, 2016) using the MaxQuant result files.

For the crosslinked peptides, the theoretic monoisotopic molecular weight can be calculated by equation 1. For crosslinked peptides with two disulphide bonds, equation 2 was employed. For self-loop-linked peptides, equation 3 was employed.

M_cp=M_1+M_2 $-(2 \times 1.0078) \quad$ Equation 1

M_cp=M_1+ M_2 - (4×1.0078) Equation 2

M_cp=M_r $-(2 \times 1.0078) \quad$ Equation 3

M_cp : monoisotopic molecular weight of crosslinked peptide

M_r : monoisotopic molecular weight of self-loop peptide

M_1 : monoisotopic molecular weight of peptide 1

M_2 : monoisotopic molecular weight of peptide 2

Thermo Xcalibur and MaxQuant were used to analyse the MS/MS raw data, while pLink 2, which can be downloaded at http://pfind.ict.ac.cn/software/pLink/index.html, was used to search for potential disulphide crosslinked peptides (Chen et al., 2019). The difference of monoisotopic molecular weight of potential crosslinked peptides and theoretical monoisotopic molecular weight should be within $10 \mathrm{ppm}$. MS/MS spectra of all potential crosslinked peptides were manually checked.

\subsubsection{Data analysis}

All experiments were performed at least in duplicate. Multiple comparisons of means was performed with SPSS statistics 25. ANOVA with Tukey's HSD for post-hoc testing was used 
to identify which treatments were significantly different, based on $p<0.05$. Data were presented as mean \pm standard deviation of replicates.

\subsection{Results \& Discussion}

\subsubsection{Disulphide linked aggregation of lactoferrin with $\alpha-L A, \beta-L G$ or BSA}
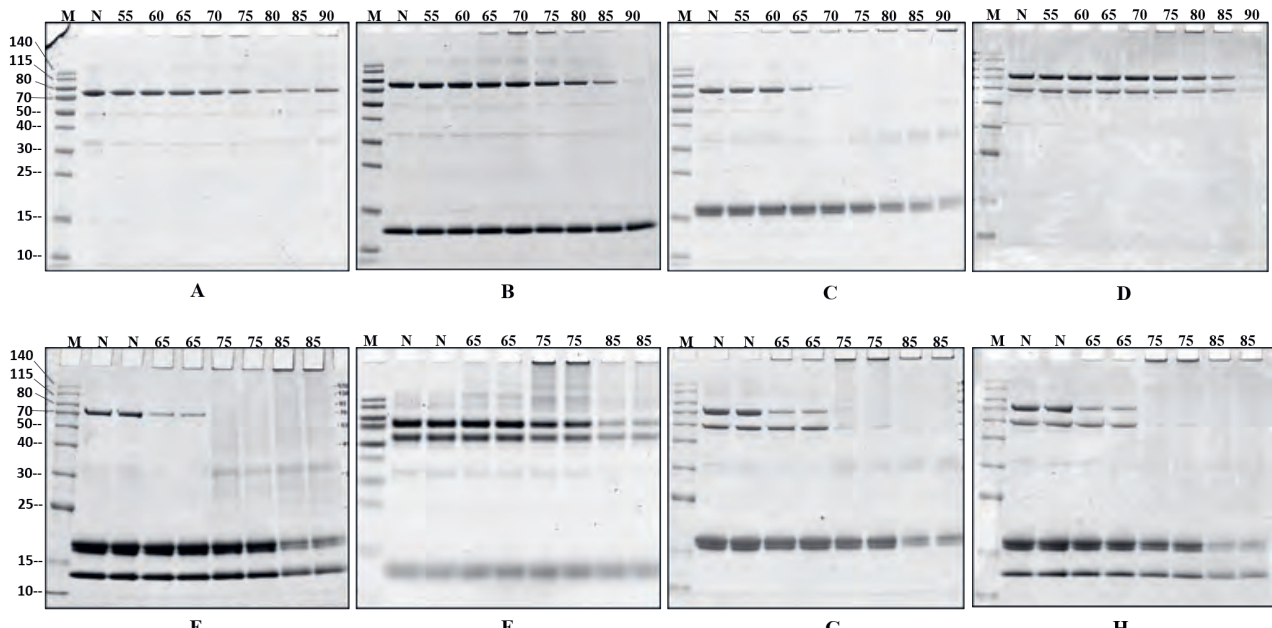

Figure 2-1 Non-reducing SDS-PAGE of lactoferrin heating with $\alpha-L A, \beta-L G$ or BSA .

Note: LF (A) , LF + $\alpha-L A(B), L F+\beta-L G(C), L F+B S A(D), L F+\alpha-L A+\beta-L G(E), L F+\alpha-L A+B S A(F), L F+\beta-L G+B S A$ (G), LF+ $\alpha-L A+\beta-L G+B S A(H)$. Red rectangles represented bands of large aggregates. Arabic numbers represented heating temperatures $\left({ }^{\circ} \mathrm{C}\right)$. C apital letter $\mathrm{M}$ represented per-stained marker and capital letter; $\mathrm{N}$ represented unheated protein sample.

\subsubsection{Lactoferrin heated without $\alpha$-LA, $\beta$-LG or BSA.}

When LF was heated alone, an apparent decrease of the intensity of the LF band was observed when the heating temperature was above $65^{\circ} \mathrm{C}(\mathbf{F i g} . \mathbf{2 - 1 A})$. In addition, large aggregates were observed at elevated temperatures. Both the decrease of the LF band intensity upon heating and the concomitant observation of large aggregates was not found in the reducing gel of LF (Supplementary Fig.2-1), indicating that the aggregates were linked by disulphide bonds. Some monomeric lactoferrin remained at elevated temperatures $\left(90^{\circ} \mathrm{C}\right)$. The iron saturation of the lactoferrin used in our study was about $9 \%$, indicating that the protein was a mixture of apolactoferrin, mono-ferric lactoferrin and holo-lactoferrin. The denaturation temperature of apolactoferrin and holo-lactoferrin were previously found to be around $61{ }^{\circ} \mathrm{C}$ and $91{ }^{\circ} \mathrm{C}$, respectively (Bokkhim et al., 2013). Unfolding of the LF molecule is the initial step for covalent and noncovalent aggregation (Wang, Nema, \& Teagarden, 2010). Holo-lactoferrin may still be in its 
native form after heating at $90{ }^{\circ} \mathrm{C}$ for $30 \mathrm{~min}$, which can explain the occurrence of aggregates (from apo- and mono-ferric lactoferrin) from $65{ }^{\circ} \mathrm{C}$ onwards, while this process is still not occurring at $90{ }^{\circ} \mathrm{C}$ for holo-lactoferrin.

\subsubsection{Lactoferrin heated in the presence of $\alpha$-LA}

When lactoferrin was heated with $\alpha$-LA (Fig. 2-1B), the monomeric LF showed an apparent decrease in intensity as temperature increased from $60{ }^{\circ} \mathrm{C}$ to $85^{\circ} \mathrm{C}$, which appears to be similar to the sample where LF was heated alone. It was previously reported that no self-aggregation of $\alpha$-LA occurred, even after being heated at $90{ }^{\circ} \mathrm{C}$ for $24 \mathrm{~min}$ in milk ultrafiltrate, based on size exclusion chromatography (Calvo, Leaver, \& Banks, 1993). A study on heat-induced structural changes of $\alpha$-LA demonstrated that reshuffling of disulphide bonds occurred above $90{ }^{\circ} \mathrm{C}$, resulting in the irreversible denaturation of $\alpha$-LA (McGuffey et al., 2005). This explains why no differences in intensity of monomeric $\alpha$-LA were observed when it was heated below $90{ }^{\circ} \mathrm{C}$. In conclusion, owing to the lack of free sulfhydryl groups and its high heat stability, $\alpha$ LA can hardly influence the heat-induced aggregation of $\mathrm{LF}$ in the temperature range $55-85^{\circ} \mathrm{C}$.

\subsubsection{Lactoferrin heated in the presence of $\beta-\mathrm{LG}$}

When LF was heated with $\beta$-LG (Fig. 2-1C), an obvious decrease of monomeric LF occurred after heating at $65^{\circ} \mathrm{C}$, and LF completely disappeared when temperatures were $\geq 70{ }^{\circ} \mathrm{C}$, whereas the band of monomeric $\beta$-LG decreased from $80{ }^{\circ} \mathrm{C}$ onwards, suggesting that aggregation between $\mathrm{LF}$ and $\beta$-LG mainly occurred at $65-70{ }^{\circ} \mathrm{C}$, whereas the self-aggregation of $\beta$-LG started from $80^{\circ} \mathrm{C}$. Accordingly, large aggregates in the sample were observed. Oldfield's twostage mechanism describing heat-induced aggregation of $\beta$-LG could explain the formation of large aggregates when heating LF $+\beta$-LG samples at $60^{\circ} \mathrm{C}$ (Oldfield, Singh, Taylor, \& Pearce, 1998). In the first stage, owing to the exposure of the free sulfhydryl group on the surface of $\beta$ LG, intra- and intermolecular disulphide bonds formation can be initiated, which increases with elevated temperatures due to the increased entropy. Therefore, $\beta$-LG facilitated the heatinduced disulphide linked aggregation of LF due to the presence of the free thiol group within the $\beta$-LG molecule.

\subsubsection{Lactoferrin heated in the presence of BSA}

When LF was heated with BSA (Fig. 2-1D), as the temperature increased, LF monomers diminished in intensity, while large aggregates appeared. However, the aggregation of LF was 
similar to when it was heated alone. Aggregation of BSA in the presence of LF was also similar to when it was heated alone (Supplementary Figure 2-1). These results indicate that LF and BSA do not affect the each other's response to heating.

\subsubsection{Lactoferrin heated in the presence of $\alpha$-LA, $\beta$-LG and BSA}

When lactoferrin was heated with a combination of two proteins among $\alpha-\mathrm{LA}, \beta-\mathrm{LG}$ and BSA, or with all these three proteins together (Fig. 2-1E-H), the role of $\alpha$-LA, $\beta$-LG and BSA in the combined model systems could be evaluated. The results of these model systems showed that $\alpha$-LA was not the driving force for the disulphide linked aggregation, by comparing the results from $L F+\beta-L G$ (Fig. 2-1C) with $L F+\alpha-L A+\beta-L G$ (Fig. 2-1E), and LF+BSA (Fig. 2-1D) with $\mathrm{LF}+\alpha-\mathrm{LA}+\mathrm{BSA}$ (Fig. 2-1F). A similar result was found for BSA, by comparing $\mathrm{LF}+\alpha-\mathrm{LA}$ (Fig. 2-1B) with $L F+\alpha-L A+B S A$ (Fig. 2-1F), and $L F+\beta-L G$ (Fig. 2-1C) with $L F+\beta-L G+B S A$ (Fig. 2-1G), indicating that BSA was also not a driving factor for the disulphide linked aggregation, even though it has a free sulfhydryl group. Obvious differences, on the other hand, were observed when $\beta-L G$ was present. Comparing $L F+\alpha-L A$ (Fig. 2-1B) with $L F+\alpha-L A+\beta-L G$ (Fig. 2-1E), it can be observed that monomeric LF dramatically decreased at $65{ }^{\circ} \mathrm{C}$ in the presence of $\beta-\mathrm{LG}$, similar to $\mathrm{LF}+\beta-\mathrm{LG}$ (Fig. 2-1C). Additionally, a decrease of monomeric $\alpha$-LA was shown in the presence of $\beta-L G$, which was different from $L F+\alpha-L A$ (Fig. 2-1B), indicating that $\beta$-LG also induced the aggregation of $\alpha$-LA. Comparing LF+BSA (Fig. 2-1D) with LF+ $\beta$ LG+BSA (Fig. 2-1G), a similar decrease of monomeric LF was observed in the presence of $\beta$ $\mathrm{LG}$ as was found for $\mathrm{LF}+\beta-\mathrm{LG}$ (Fig. 2-1C). The response of $\mathrm{LF}, \alpha-\mathrm{LA}$, and BSA to heating in our model system with all four proteins, $\mathrm{LF}+\alpha-\mathrm{LA}+\beta-\mathrm{LG}+\mathrm{BSA}(\mathbf{F} \mathbf{i g} . \mathbf{2 - 1 H})$, was similar to all two and three protein model systems that included $\beta$-LG. Comparing all models systems, it is evident that the presence of $\beta$-LG had the largest influence on the heat-induced aggregation of LF. Although it was previously shown that BSA, due to its free sulfhydryl group, can induce the aggregation of $\alpha$-LA (Calvo et al., 1993), a similar effect for LF was not seen in our experiments, possibly due to the low BSA protein concentration in our model systems. In particular, the concentration of $\beta$-LG $(3.2 \mathrm{mg} / \mathrm{mL})$ was much higher than that of BSA $(0.4$ $\mathrm{mg} / \mathrm{mL}$ ), which, combined with the lower molecular weight of $\beta$-LG compared to BSA, led to a free sulfhydryl group concentration of $\beta$-LG containing model systems being almost 28 times higher. This may therefore partly explain why no significant decrease of monomeric $\alpha$-LA was seen for LF $+\alpha-\mathrm{LA}+\mathrm{BSA}$ (Fig. 2-1F) and $\alpha$-LA+BSA (Supplementary Fig. 2-1). In summary, 
$\beta$-LG not only facilitated aggregation of LF, but also enhanced the involvement of $\alpha$-LA and BSA in the aggregates formed at higher temperatures.

\subsubsection{Concentrations of free thiol groups in the samples}

Table 2-1 Sulfhydryl group content of samples

\begin{tabular}{|c|c|c|c|c|}
\hline \multicolumn{5}{|c|}{ Sulfhydryl group content /(umol/g) } \\
\hline Sample & Native & $65^{\circ} \mathrm{C}$ & $75^{\circ} \mathrm{C}$ & $85^{\circ} \mathrm{C}$ \\
\hline LF & ND & $0.81 \pm 0.35^{\mathrm{a}}$ & ND & $0.93 \pm 1.86^{\mathrm{a}}$ \\
\hline $\mathrm{LF}+\alpha-\mathrm{LA}$ & ND & $1.65 \pm 2.71^{\mathrm{a}}$ & ND & $1.02 \pm 1.21^{\mathrm{a}}$ \\
\hline $\mathrm{LF}+\beta-\mathrm{LG}$ & $21.69 \pm 2.09^{\mathrm{ab}}$ & $24.07 \pm 0.41^{\mathrm{c}}$ & $22.52 \pm 0.91^{\mathrm{bc}}$ & $19.94 \pm 1.96^{\mathrm{a}}$ \\
\hline $\mathrm{LF}+\mathrm{BSA}$ & ND & ND & $0.38 \pm 0.75$ & ND \\
\hline $\mathrm{LF}+\alpha-\mathrm{LA}+\beta-\mathrm{LG}$ & $15.72 \pm 0.17^{\mathrm{a}}$ & $19.43 \pm 0.4^{\mathrm{c}}$ & $16.85 \pm 0.87^{\mathrm{b}}$ & $16.61 \pm 0.25^{\mathrm{b}}$ \\
\hline $\mathrm{LF}+\alpha-\mathrm{LA}+\mathrm{BSA}$ & ND & $0.37 \pm 0.44^{\mathrm{a}}$ & $0.2 \pm 0.4^{\mathrm{a}}$ & ND \\
\hline $\mathrm{LF}+\beta-\mathrm{LG}+\mathrm{BSA}$ & $18.79 \pm 0.7^{\mathrm{b}}$ & $23.75 \pm 0.92^{\mathrm{d}}$ & $22.06 \pm 0.9^{c}$ & $16.01 \pm 0.37^{\mathrm{a}}$ \\
\hline$L F+\alpha-L A+\beta-L G+B S A$ & $13.67 \pm 0.05^{\mathrm{a}}$ & $18.85 \pm 1.19^{\mathrm{c}}$ & $15.1 \pm 0.3^{\mathrm{b}}$ & $12.94 \pm 1.39^{\mathrm{a}}$ \\
\hline
\end{tabular}

Note: Different lowercase letters indicate significant differences at different heating temperatures in the same sample $(p<0.05)$. ND: content too low to be detected.

Free sulfhydryl group concentrations may vary among the heating temperatures. $\beta$-LGcontaining samples had more free sulfhydryl groups than the other samples (Table 2-1). The fact that no free sulfhydryl groups were detected in the BSA-containing samples was possibly due to the sensitivity of the Ellman method, as well as the low concentration of BSA. However, the 4 samples containing $\beta$-LG revealed a trend of increasing free sulfhydryl group concentrations between the unheated and $65{ }^{\circ} \mathrm{C}$ heated samples, slightly decreasing when heated from $65^{\circ} \mathrm{C}$ to $85^{\circ} \mathrm{C}$. This observation can probably be explained by the unfolding of $\beta$ LG at $65^{\circ} \mathrm{C}$, while at higher temperatures sulfhydryl groups are more easily oxidised and as a consequence crosslinked. This is in agreement with two processes that would influence the amount of sulfhydryl groups (Iametti, Cairoli, De Gregori, \& Bonomi, 1995). First, the free sulfhydryl groups hidden inside the folded protein get exposed when the protein is unfolded, and second, oxidation transforms the free sulfhydryl groups into disulphide bonds. When $\beta$-LG was heated alone, the maximum extent of thiol group exposure was reached after heating at 
$80^{\circ} \mathrm{C}$ for $45 \mathrm{~min}$ (Sava, Van der Plancken, Claeys, \& Hendrickx, 2005). The maximum content of thiol groups in the present study occurred after heating at $65{ }^{\circ} \mathrm{C}$ for $30 \mathrm{~min}$, suggesting that interaction of lactoferrin with $\beta$-LG changed the content of free thiol group. In summary, an increasing concentration of sulfhydryl groups indicates that protein unfolding is the dominant reaction at lower heating temperatures, while the decreasing concentration of sulfhydryl group at higher temperature indicates that aggregation and sulfhydryl-disulphide reactions are more important at these higher temperatures.

\subsubsection{Rearrangement of disulphide bonds between lactoferrin and $\beta$-LG}

2.3.3.1 Amino acid sequence of lactoferrin

\begin{tabular}{|c|c|c|c|c|}
\hline 10 & 20 & 30 & 40 & 50 \\
\hline APRKNVRWC & ISQPEWFKCR & RWQWRMKKLG & APSITCVRRA & FALECIRAIA \\
\hline 60 & 70 & 80 & 90 & 100 \\
\hline EKKADAVTLD & GGMVFEAGRD & PYKLRPVAAE & IGTKESPQTY & HYYAVAVVKK \\
\hline 110 & 120 & 130 & 140 & 150 \\
\hline GSNFQLDQLQ & GRKSCHTGLG & RSAGWIIPMG & ILRPYLSWTE & SLEPLQGAVA \\
\hline 160 & 170 & 180 & 190 & 200 \\
\hline KFFSAS VP & IDRQAYPNL & QL KGEGENQ & A SSREPYF & GYSGAFKCLQ \\
\hline 210 & 220 & 230 & 240 & 250 \\
\hline DGAGDVAFVK & ETTVFENLPE & KADRDQYELL & CLNNSRAPVD & AFKECHLAQV \\
\hline 260 & 270 & 280 & 290 & 300 \\
\hline PSHAVVARSV & DGKEDLIWKL & LSKAQEKFGK & NKSRSFQLFG & SPPGQRDLLF \\
\hline 310 & 320 & 330 & 340 & 350 \\
\hline KDSALGFLRI & PSKVDSALYL & GSRYLTTLKN & LRETAEEVKA & RYTRVVWCAV \\
\hline 360 & 370 & 380 & 390 & 400 \\
\hline GPEEQKKCQQ & WSQQSGQNVT & CATASTTDDC & IVLVLKGEAD & ALNLDGGYIY \\
\hline 410 & 420 & 430 & 440 & 450 \\
\hline TAGKCGLVPV & LAENRKSSKH & SSLDCVLRPT & EYLAVAVVK & KANEGLTWNS \\
\hline 460 & 470 & 480 & 490 & 500 \\
\hline LKDKKS HTA & VDRTAGWNIP & MGLIVNQTGS & CAFDEFFSQS & CAPGADPKSR \\
\hline 510 & 520 & 530 & 540 & 550 \\
\hline L AL $A G D D Q$ & GLDKCVPNSK & EKYYGYTGAF & RCLAEDVGDV & AFVKNDTVWE \\
\hline 560 & 570 & 580 & 590 & 600 \\
\hline NTNGESTADW & AKNLNREDFR & LL LDGTRKP & VTEAQS HLA & VAPNHAVVSR \\
\hline 610 & 620 & 630 & 640 & 650 \\
\hline SDRAAHVKQV & LLHQQALFGK & NGKN PDKF & LFKSETKNLL & FNDNTECLAK \\
\hline 660 & 670 & 680 & 689 & \\
\hline LGGRPTYEEY & LGTEYVTAIA & NLKK STSPL & LEA AFLTR & \\
\hline
\end{tabular}

Figure 2-2 Identified peptides of bovine lactoferrin from L F and L F+ $\beta-L G$ samples. Arabic numbers are the position of amino acid residue; sequences found were highlighted in yellow; within found sequences, self-loop-linked sequences were highlighted in green; shaded sequences were not found. C rossed linked peptides and disulphide bonds were not shown in this figure. Cysteine residuals were marked in red.

The profile of identified peptides from lactoferrin is shown in Fig. 2-2. For mature native bovine lactoferrin, there were 17 disulphide bonds and no free sulfhydryl group, so all cysteine residues 
were in the oxidized state (Moore, Anderson, Groom, Haridas, \& Baker, 1997). Protein unfolding requires loss of secondary and tertiary structure, in which also disulphide bonds may be broken. In that case, a broken disulphide bond may result in the formation of free sulfhydryl groups. Multiple peptides with reduced cysteines from lactoferrin were identified, revealing that some disulphide bonds were broken during heating or sample preparation.

For the sequences that were not found in this experiment (shaded in Figure 2-2), three possible reasons can explain their absence. (1) After tryptic digestion some sequences were too short to be detected. For instance, after tryptic digestion, $\operatorname{LF}(1-8)$ would be cleaved into two short sequences due to the lysine in it. These two sequences would be too short for MS/MS identification. (2) Lactoferrin is a glycoprotein, and asparagine residues with a glycans attached would influence the detection of peptides. In bovine lactoferrin, Asn233, Ans281, Asn368, Asn476 and Asn545 are known to be glycosylated (Spik et al., 1994; Wei, Nishimura, \& Yoshida, 2000; Yoshida, Wei, Shinmura, \& Fukunaga, 2000). This glycosylation would inhibit the detection of these Asn containing peptides. (3) The largest expected sequence LF(357-386) has 30 amino acid residues. Trypsin can only cleave peptide chains at the carboxyl side of the lysine and arginine, leading to such a long sequence, that may also be difficult to detect.

\subsubsection{Identification of homologous crosslinked peptides of lactoferrin}

Identified homologous crosslinked peptides of bovine LF are shown in T able 2-2 and T able 2-

3. In $\mathrm{LF}$ and $\mathrm{LF}+\beta-\mathrm{LG}$ samples heated at $85^{\circ} \mathrm{C}$, a total of 47 different homologous crosslinked peptides, including 36 different disulphide bonds were identified. In addition, 14 different selfloop-linked peptides in LF, including 7 different disulphide bonds, of which four are non-native, were identified. Although some sequences were only present in LF samples and some only in LF $+\beta-L G$ samples, crosslinked peptides found in both samples shared a similar retention times, $\mathrm{m} / \mathrm{z}$-values, and MS/MS fragmentation patterns. It is evident that extensive heat-induced rearrangement of disulphide bonds occurred. For instance, one peptide can have two cysteine residues, resulting in self-loop-linked peptides. Among these peptides, Cys573-Cys587 and Cys625-Cys630 were in line with the disulphide bonds known to be present in native LF, whereas the other five were related to non-native disulphide bonds. Among the crosslinked peptides, Cys457-Cys532, Cys573-Cys587 and Cys115-Cys198 probably were native disulphide bonds, whereas all others were non-native disulphide bonds. Noticeably, some of these peptides were linked by two disulphide bonds, for example, peptides [LF(152-163)-( $\left.{ }_{S S}^{S S}\right)$ - 
$\mathrm{LF}(152-163)], \quad\left[\mathrm{LF}(152-163)-\left(\begin{array}{c}S S \\ s S\end{array}\right)-\mathrm{LF}(175-186)\right], \quad\left[\mathrm{LF}(175-186)-\left(\begin{array}{c}S S \\ s S\end{array}\right)-\mathrm{LF}(175-186)\right]$, and $\left[\mathrm{LF}(164-174)-\left(\begin{array}{c}S S \\ s S\end{array}\right)-\operatorname{LF}(175-186)\right]$.

T able 2-2 Self-loop-linked peptides of bovine lactoferrin identified by peptide mapping

\begin{tabular}{|c|c|c|c|c|c|c|c|c|c|c|}
\hline \multicolumn{4}{|c|}{ Observed in LF } & \multicolumn{4}{|c|}{ Observed in LF+Blg } & \multicolumn{3}{|c|}{ Matched Peptides } \\
\hline $\mathrm{t}_{\mathrm{R}} /(\min )$ & $\mathrm{m} / \mathrm{z}^{\mathrm{a}}$ & charge $^{b}$ & $\operatorname{mass}^{\mathrm{a}}$ & $\mathrm{t}_{\mathrm{R}} /(\min )$ & $\mathrm{m} / \mathrm{z}^{\mathrm{a}}$ & charge $^{b}$ & $\operatorname{mass}^{\mathrm{a}}$ & $\operatorname{mass}^{\mathrm{a}}$ & peptides & S-S position ${ }^{\mathrm{c}}$ \\
\hline 19.46 & 671.831 & 2 & 1341.647 & 19.46 & 671.801 & 2 & 1341.586 & 1341.585 & LF(152-163) & Cys157-Cys160 \\
\hline 18.13 & 639.804 & 2 & 1277.592 & 18.21 & 639.804 & 2 & 1277.592 & 1277.590 & LF(164-174) & Cys170-Cys 173 \\
\hline 8.71 & 619.731 & 2 & 1237.446 & 8.91 & 619.729 & 2 & 1237.443 & 1237.445 & LF(175-186) & Cys181-Cys183 \\
\hline 17.29 & 829.01 & 3 & 2484.008 & 17.30 & 829.011 & 3 & 2484.011 & 2484.011 & LF(175-197) & Cys181-Cys183 \\
\hline 21.31 & 579.961 & 3 & 1736.859 & 21.30 & 579.962 & 3 & 1736.862 & 1736.859 & LF(674-689) & Cys675-Cys684 \\
\hline 17.34 & 710.317 & 2 & 1418.619 & 17.38 & 710.316 & 2 & 1418.616 & 1418.617 & $\mathrm{LF}(501-514)$ & Cys502-Cys505 \\
\hline 17.34 & 473.881 & 3 & 1418.619 & & & & & & & \\
\hline 15.65 & 796.669 & 4 & 3182.646 & 15.64 & 796.669 & 4 & 3182.643 & 3182.644 & $\mathrm{LF}(571-600)$ & Cys573-Cys587 \\
\hline 15.59 & 637.538 & 5 & 3182.651 & 15.61 & 637.536 & 5 & 3182.642 & & & \\
\hline 15.70 & 531.45 & 6 & 3182.651 & 15.69 & 531.449 & 6 & 3182.649 & & & \\
\hline 16.20 & 756.361 & 2 & 1510.707 & 16.24 & 504.577 & 3 & 1510.706 & 1510.706 & LF(621-633) & Cys625-Cys630 \\
\hline 16.18 & 504.577 & 3 & 1510.707 & & & & & & & \\
\hline 14.55 & 652.983 & 3 & 1955.926 & 14.59 & 652.983 & 3 & 1955.927 & 1955.923 & LF(621-637) & Cys625-Cys630 d \\
\hline 14.51 & 489.989 & 4 & 1955.924 & 14.76 & 489.989 & 4 & 1955.923 & & & \\
\hline 14.46 & 392.193 & 5 & 1955.924 & 14.60 & 392.192 & 5 & 1955.923 & & & \\
\hline 18.08 & 606.781 & 2 & 1211.546 & 17.95 & 606.782 & 2 & 1211.548 & 1211.547 & $\mathrm{LF}(624-633)$ & Cys625-Cys630 \\
\hline \multirow[t]{3}{*}{18.06} & 404.856 & 3 & 1211.545 & 17.93 & 404.857 & 3 & 1211.547 & & & \\
\hline & & & & 16.08 & 829.388 & 2 & 1656.760 & 1656.764 & $\mathrm{LF}(624-637)$ & Cys625-Cys630 \\
\hline & & & & 16.17 & 553.260 & 3 & 1656.757 & & & \\
\hline 16.26 & 415.199 & 4 & 3217.541 & 16.25 & 415.199 & 4 & 1656.765 & & & \\
\hline 23.31 & 805.393 & 2 & 1608.771 & 23.67 & 805.386 & 2 & 1608.757 & 1608.764 & LF(675-689) & Cys675-Cys684 \\
\hline 16.70 & 831.886 & 2 & 1661.756 & 16.70 & 556.5926 & 3 & 1666.754 & 1661.750 & LF(499-514) & Cys502-Cys505 \\
\hline 16.69 & 554.926 & 3 & 1661.753 & & & & & & & \\
\hline \multirow[t]{2}{*}{16.56} & 833.351 & 3 & 2497.028 & 16.98 & 833.352 & 3 & 2497.032 & 833.352 & LF(164-186) & Cys170-Cys 173 \\
\hline & & & & & & & & & & Cys181-Cys183 \\
\hline
\end{tabular}

Note: a: monoisotopic masses; b: positively charged; c: disulfide amino acid residual sequence position in lactoferrin; d: same disulfide bonds with native lactoferrin. And original proteins and amino acid sequence numbers are indicated (signal peptide included).

Table 2-3 H omologous crosslinked peptides of bovine lactoferrin identified by peptide mapping

\begin{tabular}{|c|c|c|c|c|c|c|c|c|c|c|}
\hline \multicolumn{4}{|c|}{ Observed in LF } & \multicolumn{4}{|c|}{ Observed in $\mathrm{LF}+\mathrm{Blg}$} & \multicolumn{3}{|c|}{ Matched Peptides } \\
\hline $\begin{array}{c}\mathrm{t}_{\mathrm{R}} /( \\
\mathrm{min})\end{array}$ & $\mathrm{m} / \mathrm{z}^{\mathrm{a}}$ & $\begin{array}{c}\text { char } \\
\mathrm{ge}^{\mathrm{b}}\end{array}$ & $\operatorname{mass}^{\mathrm{a}}$ & $\mathrm{t}_{\mathrm{R}} /(\min )$ & $\mathrm{m} / \mathrm{z}^{\mathrm{a}}$ & $\begin{array}{c}\text { cha } \\
\text { rge }\end{array}$ & $\operatorname{mass}^{\mathrm{a}}$ & $\operatorname{mass}^{\mathrm{a}}$ & Peptide Sequence & S-S position ${ }^{\mathrm{c}}$ \\
\hline 14.4 & 452.721 & 4 & 1806.852 & 14.4 & 452.720 & 4 & 1806.850 & 1806.851 & LF(40-47)-(SS)-LF(456-463) & Cys45-Cys457 \\
\hline \multirow[t]{3}{*}{14.4} & 438.246 & 4 & 1748.954 & & & & & 1748.845 & LF(40-47)-(SS)-LF(114-121) & Cys 45 -Cys 115 \\
\hline & & & & 18.8 & 453.240 & 4 & 1808.928 & 1808.928 & LF(40-47)-(SS)-LF(571-578) & Cys45-Cys 573 \\
\hline & & & & 18.8 & 603.985 & 3 & 1808.932 & & & \\
\hline 19.3 & 523.278 & 4 & 2089.083 & 19.3 & 523.278 & 4 & 2089.082 & 2089.081 & LF(405-415)-(SS)-LF(40-47) & Cys405-Cys45 \\
\hline 19.3 & 697.370 & 3 & 2089.086 & & & & & & & \\
\hline \multirow[t]{2}{*}{19.0} & 515.275 & 4 & 2057.067 & 19.0 & 515.276 & 4 & 2057.073 & 2057.076 & LF(405-415)-(SS)-LF(571- 578) & Cys405-Cys 573 \\
\hline & & & & 19.0 & 686.701 & 3 & 2057.079 & & & \\
\hline \multirow[t]{2}{*}{14.4} & 514.758 & 4 & 2055.000 & 14.5 & 514.759 & 4 & 2055.004 & 2054.999 & LF(405-415)-(SS)-LF(456-463) & Cys405-Cys457 \\
\hline & & & & 12.7 & 437.626 & 5 & 2183.090 & 2183.094 & LF(405-416)-(SS)-LF(456-463) & Cys $405-$-Cys 457 \\
\hline 15.9 & 670.662 & 3 & 2008.962 & 15.9 & 670.662 & 3 & 2008.961 & 2008.960 & $\mathrm{LF}(532-544)-(\mathrm{SS})-\mathrm{LF}(515-520)$ & Cys532-Cys 515 \\
\hline 14.6 & 476.635 & 5 & 2378.137 & & & & & 2378.136 & LF(532-544)-(SS)-LF(455-463) & Cys532-Cys 457 \\
\hline 19.1 & 564.038 & 4 & 2252.121 & 19.2 & 564.038 & 4 & 2252.119 & 2252.118 & LF(532-544)-(SS)-LF(571-578) & Cys532-Cys573 \\
\hline 15.5 & 563.518 & 4 & 2250.042 & 15.5 & 563.519 & 4 & 2250.045 & 2250.041 & LF(532-544)-(SS)-LF(456-463) & Cys532-Cys 457 \\
\hline 15.5 & 751.022 & 3 & 2250.042 & & & & & & & \\
\hline
\end{tabular}


Aggregation and disulphide bond interchange of lactoferrin with whey proteins

\begin{tabular}{|c|c|c|c|c|c|c|c|c|c|c|}
\hline \multicolumn{4}{|c|}{ Observed in LF } & \multicolumn{4}{|c|}{ Observed in $\mathrm{LF}+\mathrm{Blg}$} & \multicolumn{3}{|c|}{ Matched Peptides } \\
\hline $\begin{array}{c}t_{R} /( \\
\min )\end{array}$ & $\mathrm{m} / \mathrm{z}^{\mathrm{a}}$ & $\begin{array}{c}\text { char } \\
\text { ge }^{b}\end{array}$ & mass $^{\mathrm{a}}$ & $t_{R} /(\min )$ & $\mathrm{m} / \mathrm{z}^{\mathrm{a}}$ & $\begin{array}{l}\text { cha } \\
\text { rge }\end{array}$ & $\operatorname{mass}^{\mathrm{a}}$ & $\operatorname{mass}^{\mathrm{a}}$ & Peptide Sequence & S-S position ${ }^{c}$ \\
\hline 18.3 & 561.281 & 4 & 2241.094 & 18.3 & 561.283 & 4 & 2241.100 & 2241.092 & LF(198-210)-(SS)-LF(40-47) & Cys198-Cys45 \\
\hline 18.3 & 830.757 & 3 & 2489.249 & 18.3 & 830.756 & 3 & 2489.245 & 2489.241 & LF(198-210)-(SS)-LF(405-415) & Cys198-Cys405 \\
\hline 18.3 & 623.319 & 4 & 2489.243 & 18.3 & 623.320 & 4 & 2489.247 & & & \\
\hline 17.4 & 881.427 & 3 & 2641.256 & $\begin{array}{l}17.5 \\
18.3\end{array}$ & $\begin{array}{c}881.424 \\
66132\end{array}$ & $\begin{array}{l}3 \\
4\end{array}$ & $\begin{array}{l}2641.247 \\
2641.249\end{array}$ & 2641.252 & LF(198-210)-(SS)-LF(198-210) & Cys198-Cys198 \\
\hline 14.0 & 656.318 & 3 & 1965.931 & 10.5 & 001.32 & 4 & 2041.249 & 1965.929 & LF(198-210)-(SS)-LF(515-520) & Cys198-Cys515 \\
\hline 13.4 & 760.041 & 3 & 2277.101 & & & & & 2277.099 & LF(198-210)-(SS)-LF(113-121) & Cys198-Cys $115^{\mathrm{e}}$ \\
\hline 13.5 & 570.283 & 4 & 2277.102 & & & & & & & \\
\hline 13.4 & 456.428 & 5 & 2277.100 & & & & & & & \\
\hline 16.9 & 584.800 & 4 & 2335.169 & 16.9 & 584.801 & 4 & 2335.174 & 2335.166 & LF(198-210)-(SS)-LF(29-38) & Cys198-Cys36 \\
\hline 16.9 & 779.397 & 3 & 2335.168 & & & & & & & \\
\hline 17.7 & 553.280 & 4 & 2209.087 & $\begin{array}{l}17.7 \\
17.7\end{array}$ & $\begin{array}{l}553.280 \\
737.373\end{array}$ & $\begin{array}{l}4 \\
3\end{array}$ & $\begin{array}{l}2209.088 \\
2209.094\end{array}$ & 2209.087 & LF(198-210)-(SS)-LF(571-578) & Cys198-Cys573 \\
\hline 13.7 & 552.761 & 4 & 2207.013 & & & & & 2207.010 & LF(198-210)-(SS)-LF(456-463) & Cys198-Cys 457 \\
\hline 14.3 & 538.260 & 4 & 2149.008 & 14.5 & 538.257 & 4 & 2148.998 & 2149.005 & LF(198-210)-(SS)-LF(114-121) & Cys198-Cys115 \\
\hline 14.4 & 641.139 & 5 & 3200.658 & & & & & 3200.655 & LF(579-600)-(SS)-LF(571-578) & Cys587-Cys 573 \\
\hline 13.8 & 470.243 & 4 & 1876.940 & & & & & 1876.940 & LF(113-121)-(SS)-LF(40-47) & Cys115-Cys45 \\
\hline 12.8 & 462.240 & 4 & 1844.930 & & & & & 1844.935 & LF(113-121)-(SS)-LF(571-578) & Cys $115-$-Cys 573 \\
\hline 17.7 & 646.012 & 3 & 1935.013 & 17.7 & 646.011 & 3 & 1935.009 & 1935.007 & LF(29-38)-(SS)-LF(40-47) & Cys36-Cys 45 \\
\hline 17.7 & 484.760 & 4 & 1935.009 & 17.7 & 484.760 & 4 & 1935.009 & & & \\
\hline & & & & 15.8 & 555.808 & 4 & 2219.202 & 2219.203 & LF(28-38)-(SS)-LF(39-47) & Cys36-Cys45 \\
\hline 12.4 & 476.238 & 4 & 1900.921 & & & & & 1900.925 & LF(29-38)-(SS)-LF(456-463) & Cys36-Cys 457 \\
\hline 12.4 & 381.192 & 5 & 1900.923 & & & & & & & \\
\hline 13.2 & 461.738 & 4 & 1842.922 & 13.3 & 716.738 & 4 & 2862.919 & 1842.919 & LF(29-38)-(SS)-LF(114-121) & Cys36-Cys115 \\
\hline 16.6 & 523.785 & 4 & 2091.111 & & & & & 2091.108 & LF(29-39)-(SS)-LF(40-47) & Cys36-Cys45 \\
\hline 18.7 & 593.315 & 3 & 1776.923 & 18.7 & 445.238 & 4 & 1776.922 & 1776.923 & LF(571-578)-(SS)-LF(571-578) & Cys $573-$ Cys 573 \\
\hline 12.9 & 444.719 & 4 & 1774.845 & 13.0 & 444.719 & 4 & 1774.844 & 1774.845 & LF(571-578)-(SS)-LF(456-463) & Cys573-Cys457 \\
\hline 12.9 & 592.623 & 3 & 1774.845 & 13.1 & 592.623 & 3 & 1774.846 & & & \\
\hline 14.2 & 430.218 & 4 & 1716.841 & & & & & 1716.840 & LF(571-578)-(SS)-LF(114-121) & Cys573-Cys115 \\
\hline 19.9 & 666.340 & 4 & 2661.330 & 19.8 & 666.34 & 4 & 2661.328 & 2661.325 & LF(638-650)-(SS)-LF(405-415) & Cys647-Cys 405 \\
\hline 19.9 & 888.120 & 3 & 2661.335 & 19.9 & 888.12 & 3 & 2661.336 & & & \\
\hline 20.2 & 715.100 & 4 & 2856.369 & & & & & 2856.367 & LF(638-650)-(SS)-LF(532-544) & Cys647-Cys532 \\
\hline 18.7 & 704.342 & 4 & 2813.338 & 18.8 & 704.346 & 4 & 2813.354 & 2813.336 & LF(638-650)-(SS)-LF(198-210) & Cys647-Cys198 \\
\hline 18.7 & 938.787 & 3 & 2813.338 & 18.8 & 938.789 & 3 & 2813.345 & & & \\
\hline 14.2 & 627.807 & 4 & 2507.199 & & & & & 2507.190 & LF(638-650)-(SS)-LF(455-463) & Cys647-Cys457 \\
\hline 14.8 & 613.303 & 4 & 2449.180 & & & & & 2449.184 & LF(638-650)-(SS)-LF(113-121) & Cys647-Cys 115 \\
\hline 19.2 & 596.301 & 4 & 2381.171 & 19.2 & 596.301 & 4 & 2381.174 & 2381.172 & LF(638-650)-(SS)-LF(571-578) & Cys647-Cys573 \\
\hline 19.2 & 794.734 & 3 & 2381.178 & 19.2 & 794.734 & 3 & 2381.178 & & & \\
\hline 15.4 & 794.040 & 3 & 2379.098 & 15.4 & 794.041 & 3 & 2379.100 & 2379.095 & LF(638-650)-(SS)-LF(456-463) & Cys647-Cys457 \\
\hline 15.4 & 595.784 & 4 & 2379.105 & 15.4 & 595.783 & 4 & 2379.102 & & & \\
\hline \multirow[t]{8}{*}{15.4} & 476.827 & 5 & 2379.096 & 15.4 & 476.829 & 5 & 2379.104 & & & \\
\hline & & & & 19.2 & 613.301 & 4 & 2349.173 & 2449.184 & LF(638-650)-(SS)-LF(113-121) & Cys647-Cys115 \\
\hline & & & & 19.7 & 604.300 & 4 & 2413.170 & 2413.177 & LF(638-650)-(SS)-LF(40-47) & Cys647-Cys45 \\
\hline & & & & 19.5 & 996.147 & 3 & 2985.419 & 2985.421 & LF(638-650)-(SS)-LF(638-650) & Cys647-Cys647 \\
\hline & & & & 19.5 & 747.369 & 4 & 2985.445 & & & \\
\hline & & & & 18.5 & 628.825 & 4 & 2511.269 & 2511.261 & LF(345-356)-(SS)-LF(405-415) & Cys348-Cys405 \\
\hline & & & & 19.3 & 671.801 & 4 & 2683.172 & 2683.169 & $\mathrm{LF}(152-163)-(\mathrm{SS})-\mathrm{LF}(152-163)^{\mathrm{d}}$ & $\begin{array}{l}\text { Cys } 157 / \text { Cys } 160- \\
\text { Cys157/Cys160 }\end{array}$ \\
\hline & & & & 15.6 & 645.765 & 4 & 2579.030 & 2579.030 & LF(152-163)-(SS)-LF(175-186) & $\begin{array}{l}\text { Cys } 157 / \text { Cys } 160- \\
\text { Cys } 181 / \text { Cys } 183\end{array}$ \\
\hline 13.4 & 572.591 & 3 & 1714.750 & & & & & 1714.763 & LF(456-463)-(SS)-LF(114-121) & Cys457-Cys 115 \\
\hline 8.8 & 415.196 & 4 & 1656.754 & & & & & 1656.757 & LF(114-121)-(SS)-LF(114-121) & Cys115-Cys 115 \\
\hline 9.0 & 619.731 & 4 & 2474.893 & & & & & 2474.890 & $\mathrm{LF}(175-186)-(\mathrm{SS})-\mathrm{LF}(175-186)^{\mathrm{d}}$ & $\begin{array}{l}\text { Cys181/Cys183- } \\
\text { Cys181/Cys183 }\end{array}$ \\
\hline 15.2 & 839.354 & 3 & 2515.040 & 15.3 & 839.354 & 3 & 2515.037 & 2515.035 & LF(164-174)-(SS)-LF(175-186) ${ }^{\mathrm{d}}$ & Cys170/Cys173- \\
\hline 15.2 & 629.767 & 4 & 2515.039 & 15.3 & 629.767 & 4 & 2515.037 & & (t) & Cys181/Cys 183 \\
\hline
\end{tabular}


2.3.3.3 Identification of heterologous crosslinked peptides between $\beta$-LG and lactoferrin Identified heterologous crosslinked peptides between LF and $\beta-\mathrm{LG}$ are shown in Table 2-4. In total, 21 heterologous crosslinked peptides were identified in the LF+ $\beta$-LG sample. Only the participation of Cys66 and Cys160 from $\beta-L G$ into newly formed disulphide bonds was observed, while other cysteines were not shown to participate, indicating the predominant roles of Cys66 and Cys160 in intermolecular disulphide bond interchange. Similarly, only Cys66 and Cys160 were identified for the intermolecular disulphide interchange among $\beta$-LG (Supplementary table 2-1), which is in line with previous studies. For example, it was reported that one-third of the Cys160 residues could be available to interchange with other protein (Creamer et al., 2004). In addition, Cys160-Cys160 was found as intermolecular disulphide bond (Surroca, Haverkamp, \& Heck, 2002), whereas only Cys160 and Cys66 participated in disulphide interchange with $\kappa$-casein in heated milk (Lowe et al., 2004). This can be explained by the fact that the Cys66-Cys160 disulphide bond is located in one of the external loops of $\beta$ LG, making it more available for rearrangement reactions (Papiz et al., 1986).

Table 2-4 H eterologous crosslinked peptides between bovine $\beta$-L G and lactoferrin identified by peptide mapping

\begin{tabular}{|c|c|c|c|c|c|c|}
\hline Observed & $\mathrm{LF}+\beta-\mathrm{LG}$ & & 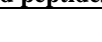 & Matcl & tides & 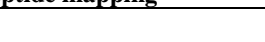 \\
\hline $\mathrm{t}_{\mathrm{R}} /(\min )$ & $\mathrm{m} / \mathrm{z}^{\mathrm{a}}$ & charge $^{b}$ & $\operatorname{mass}^{\mathrm{a}}$ & $\operatorname{mass}^{\mathrm{a}}$ & Peptide Sequence & S-S position ${ }^{\mathrm{c}}$ \\
\hline 9.1 & 416.388 & 5 & 2076.899 & 2076.911 & $\beta-L G(61-69)-(S S)-L F(113-121)$ & $\beta$-LG(Cys66)-LF(Cys115) \\
\hline 9.7 & 488.212 & 4 & 1948.816 & 1948.816 & $\beta-\mathrm{LG}(61-69)-(\mathrm{SS})-\mathrm{LF}(114-121)$ & $\beta-\mathrm{LG}(\mathrm{Cys} 66)-\mathrm{LF}(\mathrm{Cys} 115)$ \\
\hline 9.2 & 502.712 & 4 & 2006.819 & 2006.821 & $\beta-\mathrm{LG}(61-69)-(\mathrm{SS})-\mathrm{LF}(456-463)$ & $\beta$-LG(Cys66)-LF(Cys457) \\
\hline 9.2 & 669.946 & 3 & 2006.816 & 2006.821 & & \\
\hline 15.4 & 670.642 & 3 & 2008.901 & 2008.898 & $\beta-\mathrm{LG}(61-69)-(\mathrm{SS})-\mathrm{LF}(571-578)$ & $\beta$-LG(Cys66)-LF(Cys573) \\
\hline 8.8 & 552.259 & 4 & 2205.003 & 2205.006 & $\beta-\mathrm{LG}(61-70)-(\mathrm{SS})-\mathrm{LF}(113-121)$ & $\beta-\mathrm{LG}($ Cys66)-LF(Cys457) \\
\hline 8.84 & 534.736 & 4 & 2134.911 & 2134.916 & $\beta-\mathrm{LG}(61-70)-(\mathrm{SS})-\mathrm{LF}(456-463)$ & $\beta$-LG(Cys66)-LF(Cys457) \\
\hline 8.84 & 427.99 & 5 & 2134.910 & 2134.916 & & \\
\hline 8.79 & 474.465 & 4 & 1893.831 & 1893.835 & $\beta-\mathrm{LG}(61-70)-(\mathrm{SS})-\mathrm{LF}(515-520)$ & $\beta-\mathrm{LG}($ Cys66)-LF(Cys515) \\
\hline 8.97 & 404.788 & 5 & 2018.900 & 2018.905 & $\beta-\mathrm{LG}(61-69)-(\mathrm{SS})-\mathrm{LF}(113-121)$ & $\beta-L G(C y s 66)-L F(C y s 115)$ \\
\hline 9.02 & 488.211 & 4 & 1948.812 & 1948.816 & $\beta-\mathrm{LG}(61-69)-(\mathrm{SS})-\mathrm{LF}(456-463)$ & $\beta$-LG(Cys66)-LF(Cys457) \\
\hline 15.12 & 488.731 & 4 & 1950.894 & 1950.893 & $\beta-\mathrm{LG}(61-69)-(\mathrm{SS})-\mathrm{LF}(571-578)$ & $\beta-\mathrm{LG}($ Cys66)-LF(Cys573) \\
\hline 8.90 & 505.733 & 4 & 2018.903 & 2018.905 & $\beta-\mathrm{LG}(61-70)-(\mathrm{SS})-\mathrm{LF}(114-121)$ & $\beta-L G(C y s 66)-L F(C y s 115)$ \\
\hline 15.90 & 523.657 & 5 & 2613.244 & 2613.243 & $\beta-L G(149-162)-(S S)-L F(113-121)$ & $\beta-\mathrm{LG}(\mathrm{Cys} 160)-\mathrm{LF}(\mathrm{Cys} 115)$ \\
\hline
\end{tabular}




\begin{tabular}{|c|c|c|c|c|c|c|}
\hline \multicolumn{4}{|c|}{ Observed in $L F+\beta-L G$} & \multicolumn{2}{|c|}{ Matched Peptides } & \multirow[b]{2}{*}{ S-S position ${ }^{\mathrm{c}}$} \\
\hline $\mathrm{t}_{\mathrm{R}} /(\min )$ & $\mathrm{m} / \mathrm{z}^{\mathrm{a}}$ & charge $^{b}$ & $\operatorname{mass}^{a}$ & mass $^{\mathrm{a}}$ & Peptide Sequence & \\
\hline 16.87 & 498.038 & 5 & 2485.151 & 2485.148 & $\bar{\beta}$-LG(149-162)-(SS)-LF(114-121) & $\beta$-LG(Cys160)-LF(Cys115) \\
\hline 19.27 & 745.356 & 4 & 2977.391 & 2977.395 & $\beta-\mathrm{LG}(149-162)-(\mathrm{SS})-\mathrm{LF}(198-210)$ & $\beta-\mathrm{LG}(\mathrm{Cys} 160)-\mathrm{LF}(\mathrm{Cys} 198)$ \\
\hline 20.49 & 645.316 & 4 & 2577.232 & 2577.236 & $\beta-\mathrm{LG}(149-162)-(\mathrm{SS})-\mathrm{LF}(40-47)$ & $\beta-\mathrm{LG}($ Cys160)-LF(Cys45) \\
\hline 19.27 & 591.705 & 5 & 2953.488 & 2953.479 & $\beta$-LG(149-162)-(SS)-LF(405-416) & $\beta-\mathrm{LG}(\mathrm{Cys} 160)-\mathrm{LF}(\mathrm{Cys} 405)$ \\
\hline 16.36 & 509.639 & 5 & 2543.156 & 2543.153 & $\beta$-LG(149-162)-(SS)-LF(456-463) & $\beta-\mathrm{LG}(\mathrm{Cys} 160)-\mathrm{LF}(\mathrm{Cys} 457)$ \\
\hline 16.40 & 636.796 & 4 & 2543.152 & 2543.153 & & \\
\hline 16.95 & 768.365 & 3 & 2302.072 & 2302.072 & $\beta-\mathrm{LG}(149-162)-(\mathrm{SS})-\mathrm{LF}(515-520)$ & $\beta-\mathrm{LG}(\mathrm{Cys} 160)-\mathrm{LF}(\mathrm{Cys} 515)$ \\
\hline 16.95 & 576.527 & 4 & 2302.077 & 2302.072 & & \\
\hline 20.28 & 637.316 & 4 & 2545.234 & 2545.231 & $\beta-\mathrm{LG}(149-162)-(\mathrm{SS})-\mathrm{LF}(571-578)$ & $\beta-\mathrm{LG}(\mathrm{Cys} 160)-\mathrm{LF}(\mathrm{Cys} 573)$ \\
\hline 15.66 & 611.274 & 4 & 2441.063 & 2441.063 & $\beta$-LG(61-69)-(SS)-LF(198-210) & $\beta-L G(C y s 66)-L F(C y s 198)$ \\
\hline 14.68 & 534.753 & 4 & 2134.979 & 2134.978 & $\beta-L G(61-69)-(S S)-L F(29-38)$ & $\beta-L G(C y s 66)-L F(C y s 36)$ \\
\hline
\end{tabular}

Note: a: monoisotopic masses; b: positively charged; c: disulphide amino acid residual sequence position in lactoferrin. And original proteins and amino acid sequence numbers were indicated (signal peptide included).

The overview of disulphide interchange of lactoferrin alone, as well as between lactoferrin and $\beta$-LG, is displayed in Figure 2-3. In terms of cysteines originating from lactoferrin, 8 different cysteine residues were observed to participate in heterologous crosslinked peptide formation with $\beta$-LG, Cys36, Cys45, Cys115, Cys198, Cys405, Cys457, Cys515 and Cys573, which exactly matched with the cysteines that had a high frequency of occurrence in homologous crosslinked peptides. Only Cys647 of lactoferrin, which participated in 8 different homologous disulphide bonds, was not observed to participate in heterologous intermolecular crosslinked peptides. From the conformational structure of lactoferrin, four of these cysteines are known to be present on the surface of native lactoferrin, of which three, Cys405, Cys517 and Cys573, are located in the $\mathrm{C}$-lobe, while the others are located in the $\mathrm{N}$ lobe. Although it was reported that the C-lobe of lactoferrin was more compact than the N-lobe (Anderson et al., 1987), no difference in reactivity between cysteines present in the two different lobes was found. This was probably due to the fact that the intense heat treatment unfolded both lobes simultaneously. 


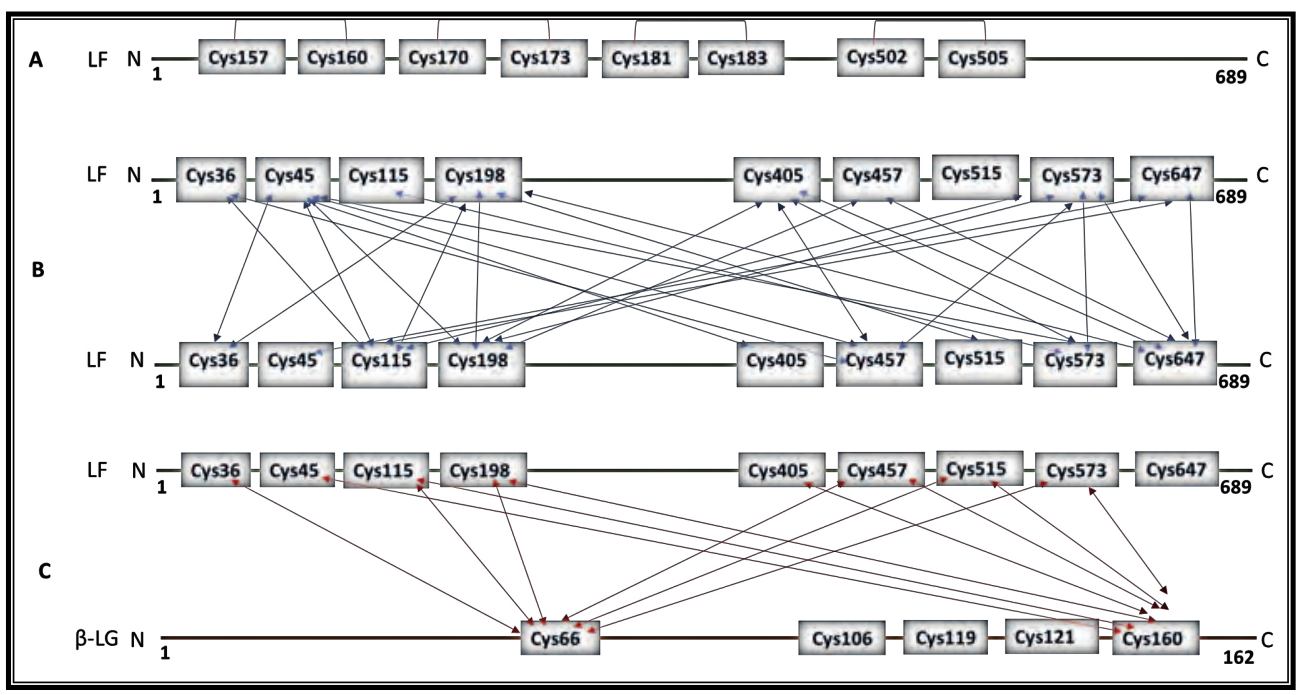

Figure 2-3 Overview of disulphide interchange within lactoferrin (A), between lactoferrin molecules (B), and between lactoferrin and $\beta-L G(C)$.

\subsection{Conclusion}

$\alpha$-LA and BSA by itself do not increase the heat-induced aggregation of LF, even if heated at $90{ }^{\circ} \mathrm{C}$ for $30 \mathrm{~min}$. $\beta$-LG not only increased the aggregation of lactoferrin during heating, but was also able to involve $\alpha$-LA and BSA into heat-induced aggregation of lactoferrin. As the heating temperature increased, the content of free sulfhydryl groups first increased and then decreased, indicating that sulfhydryl groups and disulphide bond interchange play an increasingly important role in aggregation as temperature increased. Several crosslinked peptides of lactoferrin were detected, proving that intra- and intermolecular disulphide bond rearrangements occurred during heat treatment. Cys36, Cys45, Cys115, Cys198, Cys405, Cys457, Cys515, Cys573 and Cys647 were the most reactive cysteines in lactoferrin for homologous disulphide bond interchange. Except for Cys647, the same cysteines were also were the most reactive cysteines in lactoferrin for heterologous disulphide interchange with $\beta$ LG.

\section{Acknowledgements}

This research was funded by the Sino Dutch Dairy Development Centre (http://www.sdddc.org), and Sino-Dutch Doctoral Program on Sustainable Dairy from China Scholarship Council. The authors have no conflict of interest to declare. 


\section{Supplementary M aterial}

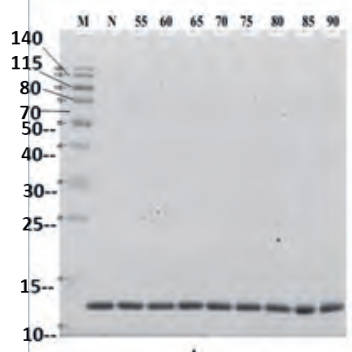

A

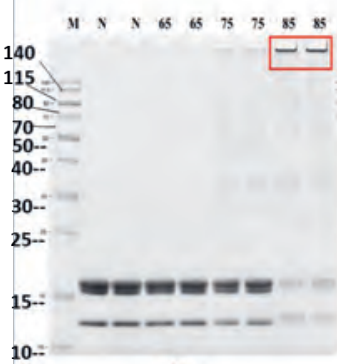

D

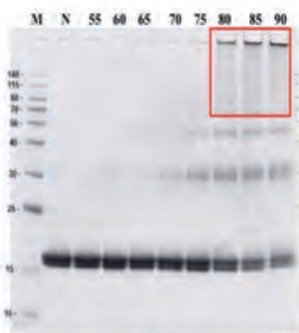

B

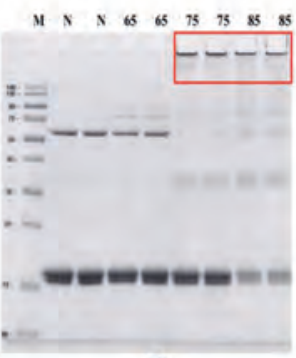

$\mathbf{E}$

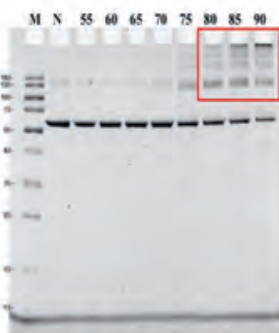

C

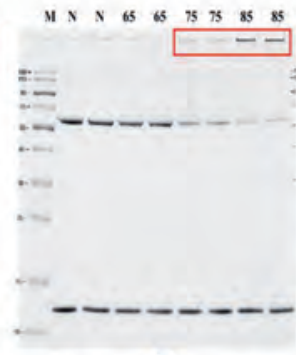

$\mathbf{F}$

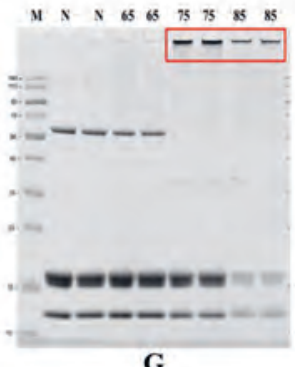

G

Supplementary figure 2-1 Non-reducing SDS-PA GE of control samples Note: $\alpha$-LA (A), $\beta$-L G (B), BSA (C), $\alpha$-LA+ $\beta$ L G (D), $\beta$-LG+BSA (E), $\alpha$-LA+BSA (F), $\alpha-L A+\beta-L$ G +BSA (G). Red rectangles represented bands of large aggregates. A rabic numbers represented heating temperatures $\left({ }^{\circ} \mathrm{C}\right)$. C apital letter $\mathrm{M}$ represented per-stained marker and capital letter $\mathbf{N}$ represented native protein sample.

Supplementary table 2-1 Homologous crosslinked peptides of $\beta$-L G identified by peptide mapping

\begin{tabular}{|c|c|c|c|c|c|c|c|}
\hline \multicolumn{3}{|c|}{ Observed in B-LG } & \multicolumn{3}{|c|}{ Observed in LF+B-LG } & \multicolumn{2}{|c|}{ Matched Peptides } \\
\hline $\mathrm{m} / \mathrm{z}^{\mathrm{a}}$ & charge ${ }^{b}$ & $\operatorname{mass}^{\mathrm{a}}$ & $\mathrm{m} / \mathrm{z}^{\mathrm{a}}$ & charge $^{\mathrm{b}}$ & mass $^{\mathrm{a}}$ & $\operatorname{mass}^{\mathrm{a}}$ & peptides \\
\hline \multirow[t]{3}{*}{829.394} & 4 & 3313.543 & 829.394 & 4 & 3313.543 & 3313.538 & $\beta$-LG (149-160)-(SS)- $\beta$-LG (149-162) \\
\hline & & & 680.804 & 4 & 2719.183 & 2719.201 & $\beta-L G(61-69)-(S S)-\beta-L G(149-162)$ \\
\hline & & & 570.465 & 5 & 2847.287 & 2847.296 & $\beta$-LG (61-70)-(SS)- $\beta$-LG (149-162) \\
\hline
\end{tabular}

a: Monoisotopic masses, b: positively charged; original proteins and amino acid sequence numbers were indicated (signal peptide sequence number included. 

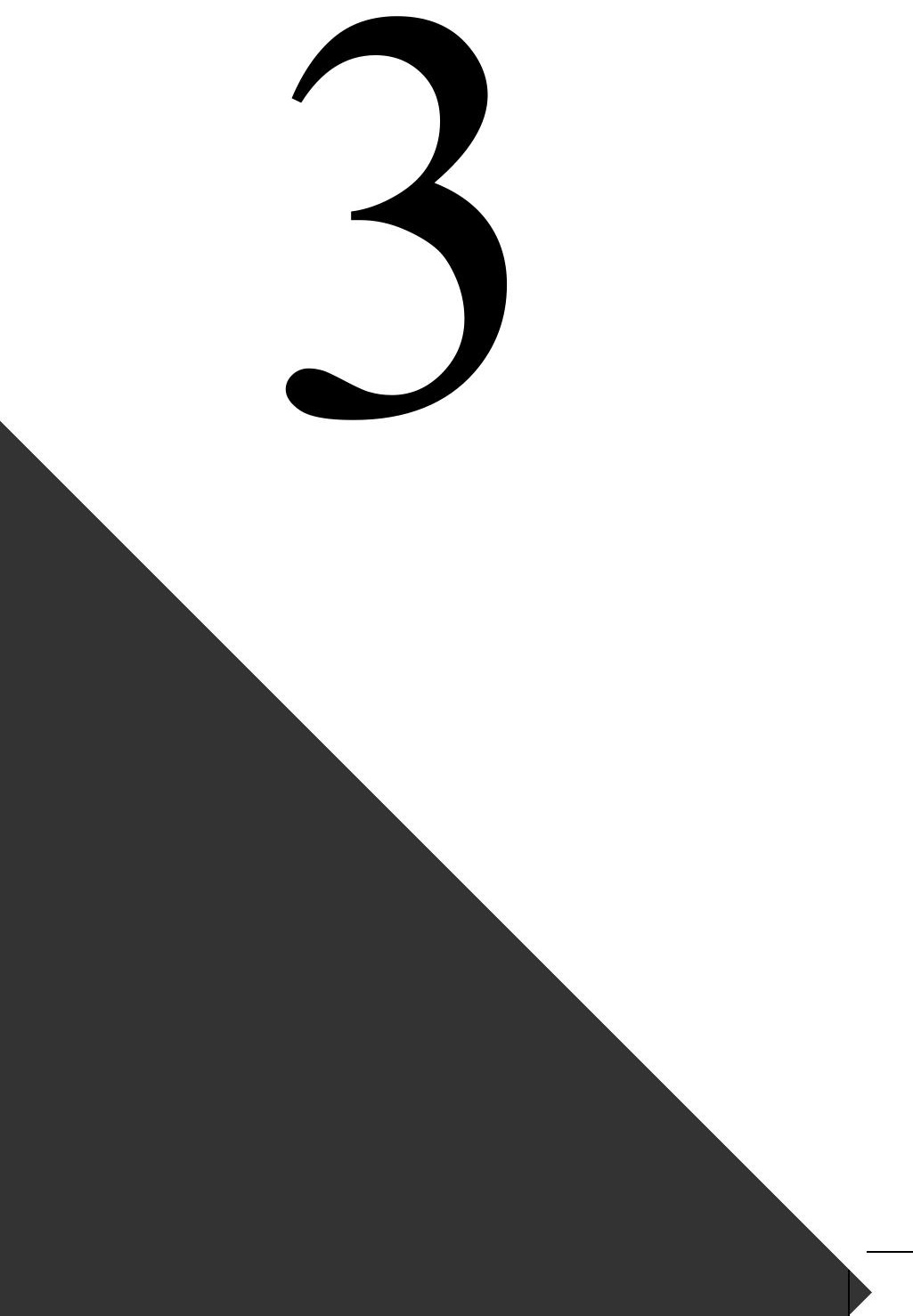


\section{CHAPTER 3.}

E ect of milk serum proteins on aggregation, bacteriostatic activity and digestion of lactoferrin after heat treatment

This chapter has been published as:

Xiong, L., Boeren, S., Vervoort, J., \& Hettinga, K. (2020). E ect of milk serum proteins on aggregation, bacteriostatic activity and digestion of lactoferrin after heat treatment. Food Chemistry, 337, 127973. 


\section{A bstract}

To establish the effect of the presence of milk serum proteins on heat-induced changes to lactoferrin, lactoferrin alone, and lactoferrin mixed with either milk serum or $\beta$-lactoglobulin was heated at $65^{\circ} \mathrm{C}, 70^{\circ} \mathrm{C}$ and $75^{\circ} \mathrm{C}$ for $30 \mathrm{~min}$. After heating, the effect of milk serum proteins on aggregation of lactoferrin was characterized, after which the effect of such aggregation on digestion and bacteriostatic capacity of lactoferrin were determined. The presence of milk serum proteins accelerated the aggregation of lactoferrin during heating through thiol/disulphide interchange. Lactoferrin also formed disulphide-linked aggregates when it was heated with $\beta$-lactoglobulin. Protein aggregates formed at $75{ }^{\circ} \mathrm{C}$ were much more resistant to infant digestion, causing decreased peptide release from lactoferrin. Heating lactoferrin and milk serum proteins together accelerated the loss of bacteriostatic activity upon heating. In conclusion, heat-induced aggregation of lactoferrin with milk serum proteins affected both its digestion and its bacteriostatic activity.

Keywords: Lactoferrin, milk serum proteins, thermal aggregation, bacteriostatic activity, in vitro digestion 


\subsection{Introduction}

Lactoferrin is a multifunctional iron-binding glycoprotein with bacteriostatic and immunomodulatory activities, which protects neonates against infection. Therefore, it is added to infant formula and other functional food products. Heat treatment is extensively applied for the processing of such products to inactivate foodborne pathogen and food spoilage bacteria, which may induce denaturation and aggregation of lactoferrin, leading to a decrease or loss of its bacteriostatic activity. Lactoferrin is a heat labile protein, of which the denaturation and aggregation are affected by multiple factors, including iron saturation (Bokkhim et al., 2013), pH (Abe et al., 1991; Sreedhara et al., 2010), ionic strength of the solution (Bokkhim et al., 2013; Kawakami et al., 1992) or the presence of polysaccharides (Li, Lan, \& Zhao, 2019; Xu, Zhao, Guo, \& Du, 2019). The protein composition could modify the denaturation kinetics of whey protein. In a recent study, $\beta$-lactoglobulin $(\beta-L G)$ enhanced the denaturation of $\alpha$ lactalbumin ( $\alpha$-LA), without any effect on denaturation of lactoferrin (Halabi et al., 2020), a result similar to an earlier study (Sánchez et al., 1992).

Most of the research discussed above is on the denaturation of lactoferrin. However, in complex systems (biological mixtures) not only denaturation is important but perhaps even more aggregation of proteins concomitant with denaturation. Heat-induced aggregation as occurs on milk processing may have important implications for the properties of lactoferrin-containing milk products. Bovine lactoferrin contains 17 intramolecular disulphide bonds (Moore et al., 1997), which could influence its interaction with other proteins through disulphide interchange. Studies showed that lactoferrin formed large insoluble aggregates through non-covalent interactions and intermolecular thiol/disulphide interchange after being heated at $60{ }^{\circ} \mathrm{C}-70{ }^{\circ} \mathrm{C}$ for $5 \mathrm{~min}$ in the absence of other proteins (Brisson et al., 2007b). However, the effects will probably be different when lactoferrin is heated in a complex milk-like system that includes multiple milk proteins. These milk proteins are not only present in milk products, but also are extensively utilized as ingredient in food products. Most of them are thermo-labile, tending to interact with each other and other proteins after heat treatment. For example, interactions and association of $\beta-\mathrm{LG}, \alpha_{\mathrm{s} 2}$-casein, and $\kappa$-casein $(\kappa-\mathrm{CN})$ via disulphide interchange in heated milk was previously reported (Chevalier \& Kelly, 2010). Aggregation among $\beta$-LG, $\alpha$-LA, and bovine serum albumin (BSA), and the consequences of this aggregation, were extensively explored in the past years (Havea et al., 2001; Krämer, Torreggiani, \& Davies, 2017; Oldfield, Singh, \& Taylor, 2005; Peram et al., 2013). Due to its high concentration in milk, and the presence of free thiol group within its structure, $\beta$-LG is more reactive than other whey proteins 
in disulphide interchange and often is recognized as the initiating protein in the thermal aggregation of whey protein (Wagner et al., 2020; Wijayanti et al., 2014). It was reported that $\alpha$-LA aggregated slowly when heated alone, while it was readily involved in disulphide-bonded and hydrophobically associated aggregates when heated with $\beta-L G$, indicating that aggregation of these two proteins is governed by $\beta$-LG (Schokker et al., 2000). In addition, interaction between $\beta$-LG and $\kappa-\mathrm{CN}$ was recognized as the main force involved in the formation of the casein-whey protein complexes (Cho, Singh, \& Creamer, 2003; Corredig \& Dalgleish, 1999). However, little is known about interaction of lactoferrin specifically with other milk proteins.

Although a few studies reported the formation of lactoferrin/whey protein complexes after heat treatment (Brisson et al., 2007a; Li \& Zhao, 2018), detailed information is lacking about the aggregation of lactoferrin and whey proteins, including the microstructure of the resulting protein aggregates, the mechanisms of aggregate formation, and the involvement of $\beta$-LG. More in particular, the effect of such aggregation on in vitro digestion and bacteriostatic activity of lactoferrin has not been investigated. Therefore, the aim of this study was to explore the aggregation of lactoferrin with milk serum proteins after different heating intensities, and its effect on in vitro digestion and bacteriostatic activity.

\subsection{Material and methods}

\subsubsection{Material}

Bovine lactoferrin was obtained from FrieslandCampina Ingredients (Vivinal Lactoferrin; estimated purity: 95\%; iron saturation: 9\%; ash: 0.5\%; Veghel, the Netherlands) and was used without further purification. Bovine raw tank milk was obtained from the Wageningen University farm (Wageningen, Netherlands) from clinically healthy cows. Raw milk was centrifuged at $1500 \times \mathrm{g}$ for $20 \mathrm{~min}$ at $4{ }^{\circ} \mathrm{C}$ (with rotor 16.250 , Avanti Centrifuge J-26 XP, Beckman Coulter, USA) to remove the fat. Skim milk was ultracentrifuged at $100,000 \times \mathrm{g}$ for $90 \mathrm{~min}$ at $30^{\circ} \mathrm{C}$ (with rotor $70 \mathrm{Ti}$, Beckman L-60, Beckman Coulter, USA), to precipitate casein micelles. The supernatant was milk serum, containing whey proteins and non-micellar caseins, named "milk serum proteins (MS)" further on. For the preparation of milk ultrafiltrate, milk serum was filtered through a $0.2 \mu \mathrm{m}$ membrane (Minisart ${ }^{\circledR}$ syringe filters, Sartorius AG, Göttingen, Germany), and was then ultrafiltered with a $10 \mathrm{kDa}$ filter tube (Amicon ${ }^{\circledR}$ Ultra Centrifugal Filters, Sigma-Aldrich, St. Louis, Missouri, United States). The milk ultrafiltrate was loaded onto an SDS-PAGE gel to check for the absence of the main milk proteins. The 
ultrafiltrate was collected and used to dissolve the lactoferrin and $\beta$-LG to simulate the milk environment.

\subsubsection{Sample preparation and heat treatment}

To study the interaction of lactoferrin with $\beta-\mathrm{LG}, 1 \mathrm{mg} / \mathrm{ml}$ lactoferrin was mixed with $3 \mathrm{mg} / \mathrm{ml}$ $\beta$-LG in milk ultrafiltrate ( $\mathrm{pH}$ 6.6). For the interaction of lactoferrin with whey proteins, 1 $\mathrm{mg} / \mathrm{ml}$ lactoferrin was added into milk serum, named "LFMS" further on. Lactoferrin at 1 $\mathrm{mg} / \mathrm{ml}$ was heated, freeze-dried and mixed with heated milk serum before analysis as a control, named "LF+MS" further on. The concentration of lactoferrin was set at $1 \mathrm{mg} / \mathrm{ml}$ according to the maximum use levels of bovine LF in infant formula, as defined by Novel Food and GRAS regulations in the EU https://eur-lex.europa.eu/eli/dec impl/2012/727/ (European Commission, 2012). All samples were prepared in duplicate and were heated in $15 \mathrm{~mL}$ plastic tubes by immersion in a temperature-controlled water bath at $65^{\circ} \mathrm{C}, 70^{\circ} \mathrm{C}, 75^{\circ} \mathrm{C}$, respectively, for 30 min. The corresponding samples were named as "LFMS-65", "LFMS-70", "LFMS-75", "LF+MS-65", "LF+MS-70", and "LF+MS-75". After heat treatment, all samples were cooled with ice water and stored at $4{ }^{\circ} \mathrm{C}$ for further analysis.

\subsubsection{Measurement of turbidity and particle size}

The turbidity of protein samples was measured according to the absorbance at $600 \mathrm{~nm}$ with a Cary 60 UV-Vis Spectrophotometer (Agilent Technologies, California, US). The particle size distribution was determined using a Zeta-sizer Nano ZS (Malvern Instruments Ltd., Malvern, UK). All the measurements were performed in triplicate at $25^{\circ} \mathrm{C}$. The refractive index was set to 1.38 for all samples according to the refractive index used for a whey protein concentrate solution in a previous study (Westerik, Scholten, \& Corredig, 2015).

\subsubsection{SDS-PAGE}

Milk serum and lactoferrin samples were loaded onto an SDS-PAGE and proteins were visualized using Coomassie Brilliant Blue R-250 (1610436, Biorad, California, USA) to determine the presence of the most abundant milk proteins in the samples. The reducing SDSPAGE was carried out as described previously (Xiong et al., 2020a). For the non-reducing SDSPAGE, all samples were prepared without dithiothreitol, and running buffer was prepared without antioxidant. The rest of the procedure was performed as described for the reducing SDS-PAGE. After destaining, the gels were scanned using ChemiDoc XRS+ Imaging System with Image Lab Software (Bio-Rad, California, USA). 


\subsubsection{Bacteriostatic assay}

Enterobacter doacae subsp. cloacae (ATCC ${ }^{8} 13047^{\mathrm{TM}}$, American Type Culture Collection, Manassas, USA) and Staphylococcus epi dermidis (ATCC $® 14990^{\mathrm{TM}}$, American Type Culture Collection, Manassas, USA) were selected, to have one Gram-negative and one Gram-positive species that are known to occur in milk and clinically relevant. The two stains were activated in nutrient broth (CM0001, Thermo Fisher Scientific, Massachusetts, USA) from frozen stock for 16-24 hours at their optimum growth temperature (Enterobacter cloacae $30{ }^{\circ} \mathrm{C}$; Staphylococcus epidermidis, $37^{\circ} \mathrm{C}$ ). Reactivated bacterial strains were centrifuged for $5 \mathrm{~min}$ at 4,000 × g (with Rotor FA-45-30-11, Microcentrifuge 5430R, Eppendorf, Hamburg, Germany), after which the bacterial pellets were dissolved in PFZ (peptone physiological salt solution; Tritium Microbiology, The Netherlands). After the optical density (OD) had been measured with a spectrophotometer (Cary 50 UV-Visible Spectrophotometer, Agilent Technologies, USA) to estimate bacterial numbers, dilutions of bacteria were made with PFZ for inoculation. All milk serum samples were micro-filtrated by RC membrane (Ø $0.2 \mu \mathrm{m}$ with $26 \mathrm{~mm}$ syringe filters; Phenomenex, Torrance, Canada) to eliminate bacteria in the starting material $(<10$ $\mathrm{CFU} / \mathrm{ml})$. Bacterial solutions in PFZ $(0.1 \mathrm{ml})$ were inoculated into $0.9 \mathrm{ml}$ milk serum samples, to reach a final bacterial concentration of around $3 \times 10^{3} \mathrm{CFU} / \mathrm{ml}$. After incubation at their optimum growth temperatures for 2 hours, $0.1 \mathrm{ml}$ of the sample was taken for plating on tryptone soya agar (CM0131, Thermo Fisher Scientific, Massachusetts, USA) and then incubated at $30{ }^{\circ} \mathrm{C}$ for 24 hours for Enterobacter cloacae, or on mannitol salt agar (CM0085B, Thermo Fisher Scientific, Massachusetts, USA) and then incubated at $37{ }^{\circ} \mathrm{C}$ for 48 hours for Staphylococcus epidermidis. Only the plates with between 20 and 300 colonies were used for determining bacterial levels $(\mathrm{CFU} / \mathrm{ml})$. Multiplication rate per hour $=\frac{N t}{N 0} / t, \mathrm{~N}_{0}=$ number of bacteria immediately after inoculation, $\mathrm{N}_{\mathrm{t}}=$ number of bacteria after 2 hours or 4 hours of incubation, $\mathrm{t}=$ incubation time ( 2 hours or 4 hours).

\subsubsection{In vitro digestion}

After heat treatment, the sample was digested with a simulated in vitro infant digestion model according to Menard et al. (Ménard et al., 2018), with some modifications. Lactoferrin samples were mixed with gastric simulated fluid including $268 \mathrm{U} / \mathrm{ml}$ pepsin (P6887, Sigma, St. Louis, Missouri, USA), with a ratio (v/v) of 63 to 37 (sample to simulated gastric fluid), the $\mathrm{pH}$ of the mixture was adjusted to 5.3 , and the samples were incubated at $37{ }^{\circ} \mathrm{C}$ for $1 \mathrm{~h}$. After $1 \mathrm{~h}$ gastric digestion, the $\mathrm{pH}$ was adjusted to 6.6 to stop the pepsin activity. For gastrointestinal digestion, gastric digested samples were mixed with simulated intestinal fluid including $16 \mathrm{U} / \mathrm{ml}$ trypsin 
(P7550, 4×USP, Sigma, St. Louis, Missouri, USA), with a ratio (v/v) of 39 to 61 (samples to total simulated fluid). $\mathrm{pH}$ of the mixture was adjusted to 6.6 and was incubated at $37^{\circ} \mathrm{C}$ for $1 \mathrm{~h}$. After $1 \mathrm{~h}, 50 \mu \mathrm{l}$ of Pefabloc $(0.1 \mathrm{M})$ per $\mathrm{ml}$ of intestinal digesta was added to the mixture to stop the intestinal digestion. The digested samples were collected at $0,15,30$ and $60 \mathrm{~min}$ in the gastric phase and at the end of the intestinal phase. All samples were frozen at $-20^{\circ} \mathrm{C}$ for further analysis.

\subsubsection{Liquid chromatography with tandem mass spectrometry}

\subsubsection{Proteomics}

To determine the composition of aggregates, the bands of aggregates in the SDS-PAGE gel were cut into small pieces of $<1 \mathrm{~mm}^{2}$ with a sharp clean scalpel. The gel pieces were transferred into a clean $0.5 \mathrm{ml}$ low binding micro centrifuge tube and were reduced by $20 \mathrm{mM}$ dithiothreitol, followed by alkylation with $20 \mathrm{mM}$ acrylamide. After that, the gel pieces were thoroughly washed with water and digested with $50 \mu 1(5 \mathrm{ng} / \mu \mathrm{l})$ cold freshly prepared trypsin solution at $45{ }^{\circ} \mathrm{C}$ for 2 hours. The peptide fraction was cleaned up with a $\mathrm{C} 18 \mu$ Column according to a previous study (Dingess et al., 2017).

The LC-MS/MS parameters are described as followed. One microliter of the peptide samples were loaded directly onto a $0.10 * 250 \mathrm{~mm}$ ReproSil-Pur $120 \mathrm{C} 18$-AQ $1.9 \mu \mathrm{m}$ beads analytical column (prepared in-house) at a constant pressure of 800 bar with $1 \mathrm{ml} / \mathrm{L} \mathrm{HCOOH}$ in water and eluted at a flow of $0.5 \mu \mathrm{l} / \mathrm{min}$ with a 50 min linear gradient from $9 \%$ to $34 \%$ acetonitrile in water with $1 \mathrm{ml} / \mathrm{L}$ formic acid with a Thermo EASY nanoLC1000. An electrospray potential of $3.5 \mathrm{kV}$ was applied directly to the eluent via a stainless steel needle fitted into the waste line of the micro cross that was connected between the pump and the analytical column. Full scan positive mode FTMS spectra were measured between m/z 380 and 1400 on a Q-Exactive HFX (Thermo electron, San Jose, CA, USA) in the Orbitrap at high resolution (60000). MS and MSMS AGC targets were set to $3 \times 10^{6}, 5 \times 10^{4}$ respectively or maximum ion injection times of $50 \mathrm{~ms}$ (MS) and $25 \mathrm{~ms}$ (MSMS) were used. HCD fragmented (Isolation width $1.2 \mathrm{~m} / \mathrm{z}, 24 \%$ normalized collision energy) MSMS scans of the 20 most abundant 2-5+ charged peaks in the MS scan were recorded in data dependent mode (Threshold $1.2 \times 10^{5}, 15 \mathrm{~s}$ exclusion duration for the selected $\mathrm{m} / \mathrm{z}+/-10 \mathrm{ppm})$. LCMS runs with all MSMS spectra obtained were analysed with MaxQuant 1.6.3.4 (Cox \& Mann, 2008) using the "specific" digestion mode and further default settings for the Andromeda search engine (First search $20 \mathrm{ppm}$ peptide tolerance, main search $4.5 \mathrm{ppm}$ tolerance, MSMS fragment match tolerance of $20 \mathrm{ppm}$. Variable modifications 
were set for Protein N-terminal Acetylation and $\mathrm{M}$ oxidation which were completed by nondefault settings for de-amidation of $\mathrm{N}$ and $\mathrm{Q}$ the maximum number of modifications per peptide was 5 (Cox et al., 2011). The UP000009136 bovine database containing 23965 protein sequences (Boggs et al., 2016) was used together with a contaminants database that contains sequences of common contaminants like Trypsins (P00760, bovine and P00761, porcine) and human keratins (Keratin K22E (P35908), Keratin K1C9 (P35527), Keratin K2C1 (P04264) and Keratin K1CI (P35527)). The "label-free quantification" as well as the "match between runs" options were enabled. De-amidated peptides were allowed to be used for protein quantification and all other quantification settings were kept default. nLC-MSMS system quality was checked with PTXQC (Bielow et al., 2016) using the MaxQuant result files.

\subsubsection{Peptidomics}

To determine the peptides profile from lactoferrin, the isolation and purification of peptides from digested mixture were carried out based on previously described methods (Dingess et al., 2017). The LC-MS/MS parameters was the same as mentioned above except that the digestion mode was set as "Unspecific" and that instead of the complete bovine database a partial bovine database was used with all proteins observed in bovine milk serum as founded by Boggs et al. (Boggs et al., 2016).

\subsubsection{Data analysis}

Analysis of proteomics data was performed as described previously (Xiong et al., 2020a). Data analysis was performed using R 3.6.1. The package "ggplot2" was used for graphical representation of the data. Multiple comparisons of means was performed with SPSS statistics 25. ANOVA and Tukey's HSD for post-hoc testing, were used to identify which treatments were significantly different, where $p<0.05$ was considered to indicate significant differences among groups. Data were presented as mean \pm standard deviation of duplicates. 


\subsection{Results}

3.3.1 Changes of turbidity and particle size in differently heated lactoferrin samples
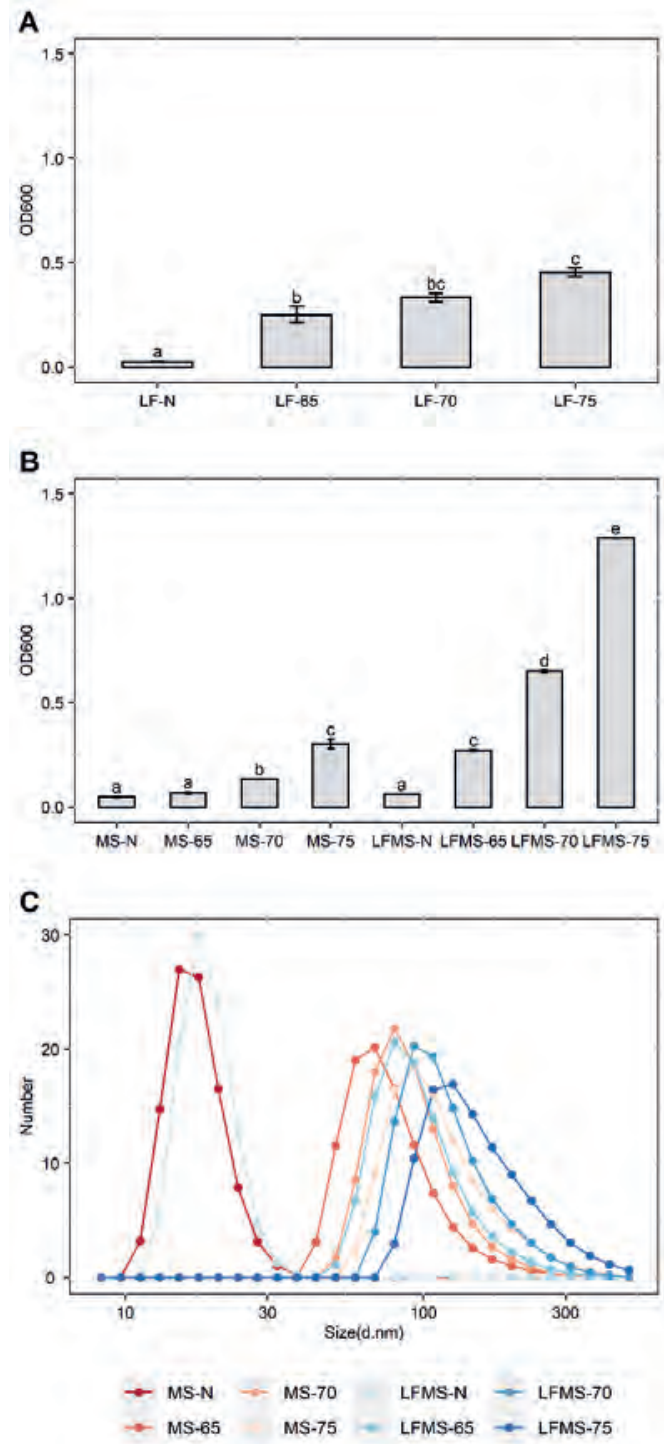

Figure 3-1 The effect of heating of lactoferrin in the absence and presence of milk serum proteins on its aggregation. Change of turbidity of lactoferrin (A) and milk serum sample (B), and number based particle size distribution of different samples (C) after heating. LF, lactoferrin; MS, milk serum; LFMS, milk serum with addition of $1 \mathrm{mg} / \mathrm{ml}$ lactoferrin. N, sample without heat treatment; 65/70/75 refer to samples being heated at $65 / 70 / 75{ }^{\circ} \mathrm{C}$ for $30 \mathrm{~min}$, respectively. Statistical significance for (A) and (B) was analyzed using ANOVA and Tukey's HSD test. Means were compared and marked as "a, b, c, d, e" from small to large. Means followed by the same letter were not significantly different $(p>0.05)$. Different letters indicate statistically significant difference among different heat treatments $(p<$ 0.05). 
The turbidity of differently heated samples was measured according to their absorbance at 600 nm (Fig. 3-1). When lactoferrin was heated alone, the turbidity of the solution increased after being heated at $65^{\circ} \mathrm{C}$ for $30 \mathrm{~min}$, followed by a further increase after being heated at $70{ }^{\circ} \mathrm{C}$ or $75{ }^{\circ} \mathrm{C}$ for $30 \mathrm{~min}$ (Fig. 3-1A, p <0.05). For all MS samples, the turbidity of the samples increased slowly from the unheated to the $75^{\circ} \mathrm{C}$ heated samples. A statistically significant difference in turbidity was observed between the $65^{\circ} \mathrm{C}$ and $70{ }^{\circ} \mathrm{C}$ heated samples (Fig. 3-1B, $\mathrm{p}<0.05)$. A further increase of turbidity in the $75^{\circ} \mathrm{C}$ heated samples was observed, probably due to an increased number of small aggregates or formation of larger aggregates (Fig. 3-1B). Compared to MS samples, turbidity of LFMS samples showed a larger increase from unheated to $75^{\circ} \mathrm{C}$. Statistically significant increases in turbidity were found among all samples (Fig. 31B, $\mathrm{p}<0.05$ ), with a rapid increase of turbidity from $65^{\circ} \mathrm{C}$ to $75^{\circ} \mathrm{C}$. The changes in the size distribution of all samples showed a similar trend to the changes of turbidity (Fig. 3-1C). The size of particles in unheated MS and LFMS samples are in the range of 9-37 nm, with a dominant particle size of 15-17 nm (Fig. 3-1C). After heating, the size distribution became broader, with the size of the dominant particles becoming above $50 \mathrm{~nm}$ in all heated samples. For heated MS samples, the peak gradually changed from $68 \mathrm{~nm}$ to $92 \mathrm{~nm}$ with increasing temperatures, whereas for heated LFMS samples, the peak gradually changed from $79 \mathrm{~nm}$ to $125 \mathrm{~nm}$.

\subsubsection{Aggregation of lactoferrin with milk serum proteins after heat treatment}

Disulphide-linked aggregates can be identified through differences between reducing (Fig. 32C\& 2D) and non-reducing SDS-PAGE (Fig. 3-2A\& 2B). The rate of decrease of the monomeric lactoferrin band was rapid when heated in the presence of whey protein, compared with it being heated alone. Comparing reducing (Fig. 3-2C) and non-reducing gels (Fig. 3-2A), lactoferrin heated alone started to form disulphide-linked aggregates from $65^{\circ} \mathrm{C}$. The intensity and number of bands representing aggregates increased from $65{ }^{\circ} \mathrm{C}$ to $75{ }^{\circ} \mathrm{C}$ (Fig. 3-2A). Lactoferrin formed different aggregates when heated in the presence of milk serum proteins, of which the size and protein composition changed with the heating temperatures (Fig. 3-2B), when compared with the reducing gel (Fig. 3-2D). When the LFMS sample was heated at $65^{\circ} \mathrm{C}$, the intensity of the band of monomeric lactoferrin decreased, while new bands appeared between lactoferrin $(80 \mathrm{kDa})$ and immunoglobulin $(150 \mathrm{kDa})$ that were not visible in the similarly heated MS samples (Fig. 3-2B). When the LFMS sample was heated at $70{ }^{\circ} \mathrm{C}$, monomeric lactoferrin and the aggregates between $80 \mathrm{kDa}$ and $150 \mathrm{kDa}$ decreased, while larger aggregate were formed, as shown in Fig. 3-2B. Monomeric lactoferrin almost disappeared after 
heating at $75{ }^{\circ} \mathrm{C}$, accompanied by a sharp decrease of monomeric BSA and immunoglobulin, suggesting that these proteins were also involved in the formation of large aggregates (Fig. 32B ). Bands of monomeric $\beta$-LG and $\alpha$-LA were also decreasing in $70{ }^{\circ} \mathrm{C}$ and $75^{\circ} \mathrm{C}$ heated milk serum to which lactoferrin was added, although this decrease was not as obvious as for BSA and immunoglobulin.
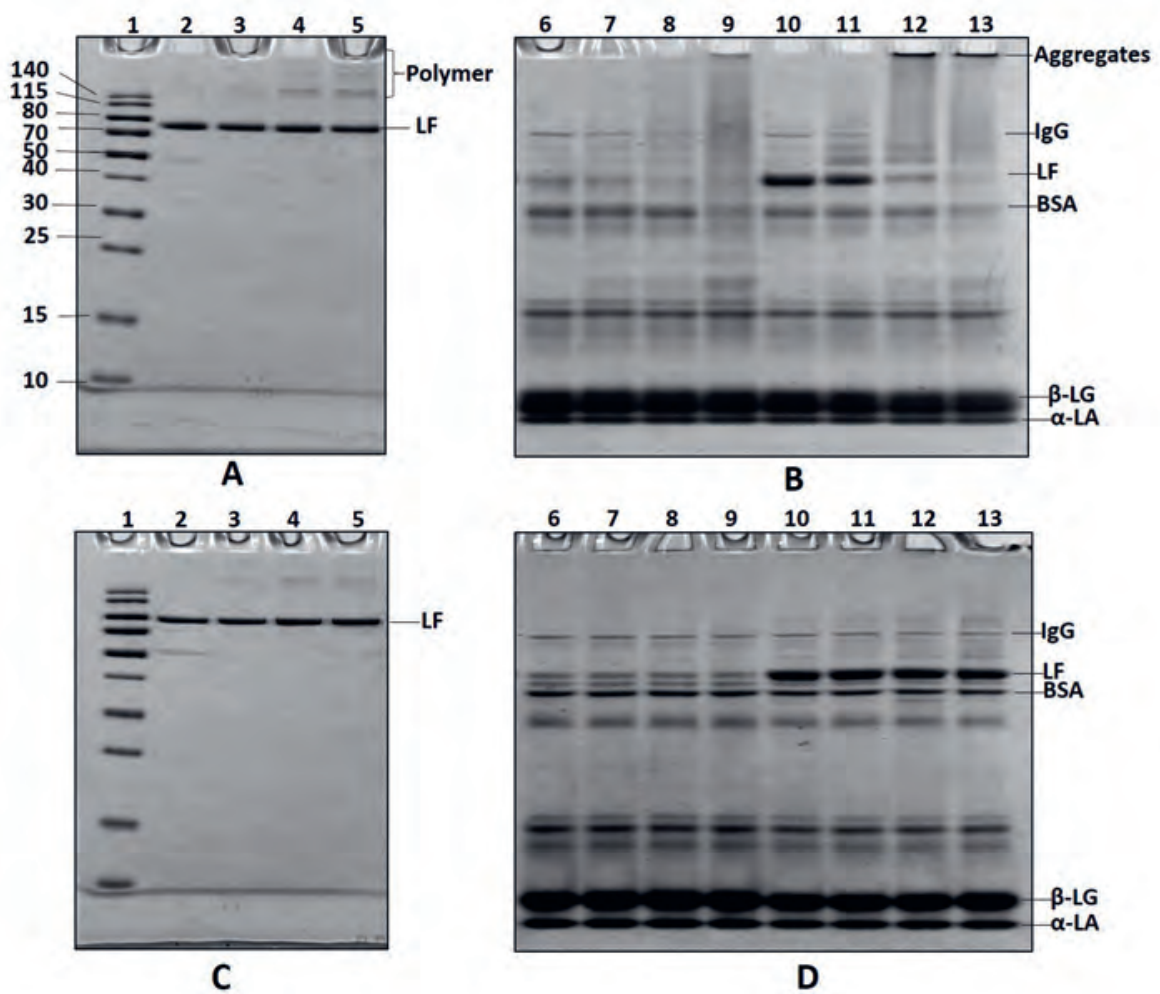

Figure 3-2 The effect of heating of lactoferrin in the absence and presence of milk serum proteins on its disulphide linked aggregation. Non-reducing SDS-PA GE gel of differently heated lactoferrin (A) and milk serum samples (B), and reducing SDS-PAGE gel of differently heated lactoferrin (C) and milk serum samples (D), with the main proteins indicated. $L$ ane 1, protein marker; $L$ ane 2 , unheated lactoferrin; $L$ ane $3,4,5$, lactoferrin being heated at $65 / 70 / 75{ }^{\circ} \mathrm{C}$ for $30 \mathrm{~min}$, respectively. $L$ ane 6, milk serum without heat treatment; $L$ ane $7,8,9$, milk serum being heated at $65 / 70 / 75{ }^{\circ} \mathrm{C}$ for $30 \mathrm{~min}$, respectively. $L$ ane 10, milk serum with addition of $1 \mathrm{mg} / \mathrm{ml}$ lactoferrin without heat treatment; $L$ ane 11, 12, 13 , milk serum with addition of $1 \mathrm{mg} / \mathrm{ml}$ lactoferrin being heated at $65 / 70 / 75^{\circ} \mathrm{C}$ for $30 \mathrm{~min}$, respectively. A bbreviations: IgG, immunoglobulin G; LF, lactoferrin; BSA, bovine serum albumin; $\beta$-LG, $\beta$-lactoglobulin; $\alpha$-LA, $\alpha$-lactalbumin.

From the SDS-PAGE gel, the decrease of the monomeric lactoferrin and the decrease of the main whey proteins like BSA can be observed. It is assumed that aggregates were formed during heat treatment. Therefore, LC-MS/MS based proteomics was used to identify the protein composition of the aggregates. In total, 36 proteins were quantified, for which the detailed 
information was shown in Supplementary table 3-1. A clustering heatmap of these proteins was made to find differences in the protein profile between the differently heated samples. In MS samples, the protein profile of aggregates in $75{ }^{\circ} \mathrm{C}$ heated samples was different from unheated samples and lower temperature heated samples (Fig. 3-3A). In LFMS samples, $70{ }^{\circ} \mathrm{C}$ and $75{ }^{\circ} \mathrm{C}$ heated samples showed a similar protein profile of the aggregates, differing from unheated samples and $65^{\circ} \mathrm{C}$ heated samples (Fig. 3-3B). Comparing MS and LFMS samples, it could be observed that the presence of lactoferrin appeared to accelerate the aggregation of milk serum proteins. This thus indicates that thiol/disulphide interchanges occurred between lactoferrin and other milk serum proteins.
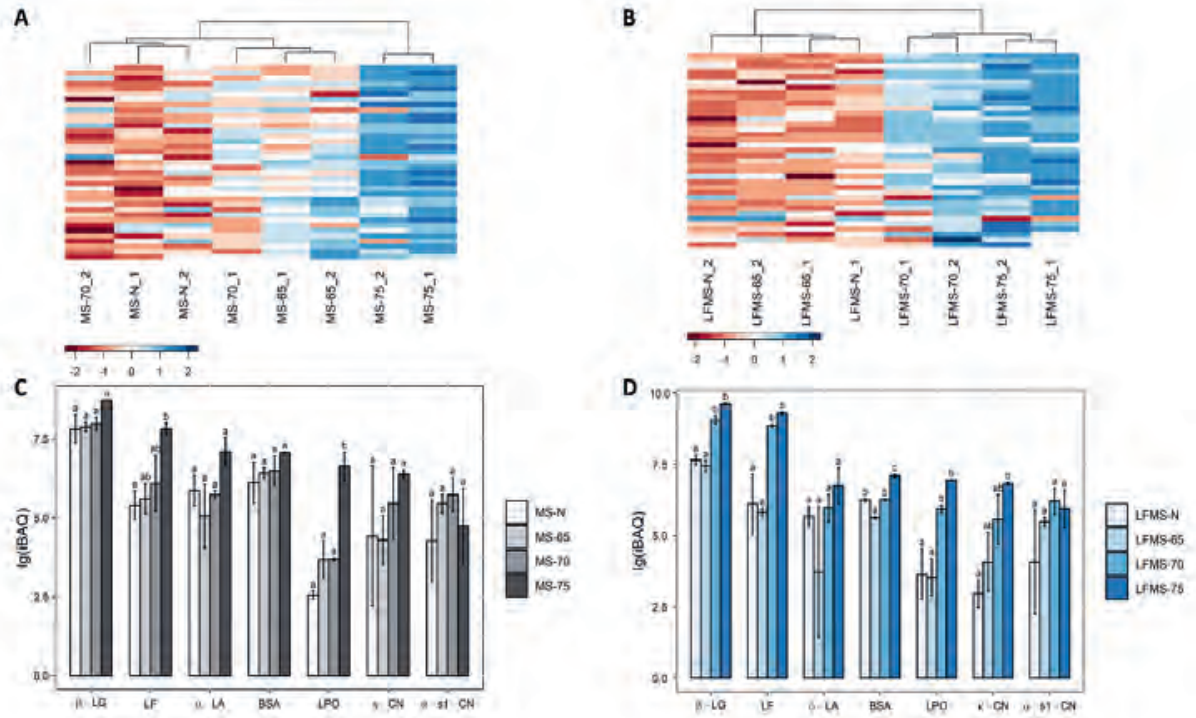

Figure 3-3 The effect of lactoferrin on protein composition of disulphide linked aggregates in the presence of milk serum proteins after heat treatment. Heatmap of protein aggregates in M S samples (A) and LFM S samples (B), and changes of individual milk protein in aggregates from M S samples (C) and L F M S samples (D). The number indicates the heating temperature, while the number after the underscore indicates the replicate. M S, milk serum; L F M S, milk serum with addition of $1 \mathrm{mg} / \mathrm{ml}$ lactoferrin; $\mathrm{N}$, sample without heat treatment; $65 / 70 / 75$ refer to samples being heated at $65 / 70 / 75{ }^{\circ} \mathrm{C}$ for $30 \mathrm{~min}$, respectively. The number behind underscore indicates the heating temperature, while the number after the underscore indicates the duplicate Abbreviations: $\beta$-LG, $\beta$-lactoglobulin; LF, lactoferrin; $\alpha$-LA, $\alpha$-lactalbumin; BSA, bovine serum albumin; LPO, lactoperoxidase; $\kappa-C N$, kappa casein; $\alpha-s 1-C N$, alpha-sl casein. Statistical significance for (C) and (D) was analyzed using ANOV A and Tukey's HSD test. Means were compared and marked as " $a$, b" from small to large. M eans followed by the same letter were not significantly different $(p>0.05)$. Different letters indicate statistically significant difference among different heat treatments $(p<0.05)$.

To get more insights about how lactoferrin quantitatively affected the main milk proteins, the levels of the main milk proteins in the aggregates were shown in Fig. 3-3C and Fig. 3-3D. In the MS samples, $\beta$-LG, $\alpha$-LA, BSA, $\kappa-\mathrm{CN}$, and $\alpha_{s 1}$-casein $\left(\alpha_{\mathrm{s} 1}-\mathrm{CN}\right)$ were present at similar 
levels in the aggregates of all differently heated samples. Lactoferrin and lactoperoxidase (LPO), on the other hand, significantly increased in the $75^{\circ} \mathrm{C}$ heated samples (F ig. 3-3C ). After adding lactoferrin into the milk serum, obvious changes were observed for these proteins, except for $\alpha$-LA and $\alpha_{\mathrm{s} 1}-\mathrm{CN}$. The levels of $\beta$-LG, LF and LPO in the aggregates increased after heating at $70{ }^{\circ} \mathrm{C}$, whereas the level of BSA increased in $75{ }^{\circ} \mathrm{C}$ heated LFMS samples. $\mathrm{\kappa}-\mathrm{CN}$ showed a gradually increase in the aggregates in the $65{ }^{\circ} \mathrm{C}$ and $70{ }^{\circ} \mathrm{C}$ heated samples, which further increased in $75^{\circ} \mathrm{C}$ heated samples (Fig. 3-3D). The changes of those proteins among samples indicate that aggregation of $\beta-\mathrm{LG}, \mathrm{BSA}, \mathrm{LPO}$, and $\kappa-\mathrm{CN}$ were all affected by the presence of lactoferrin.

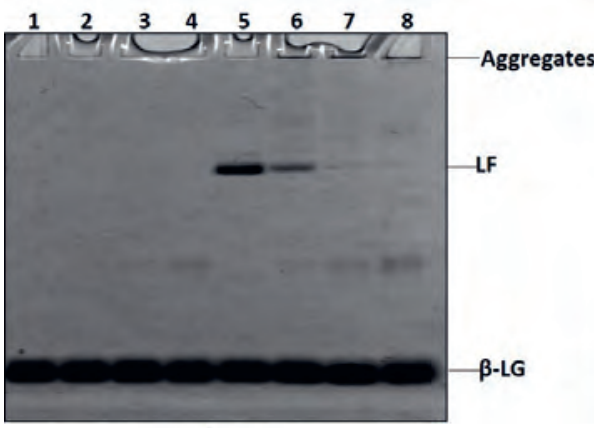

A

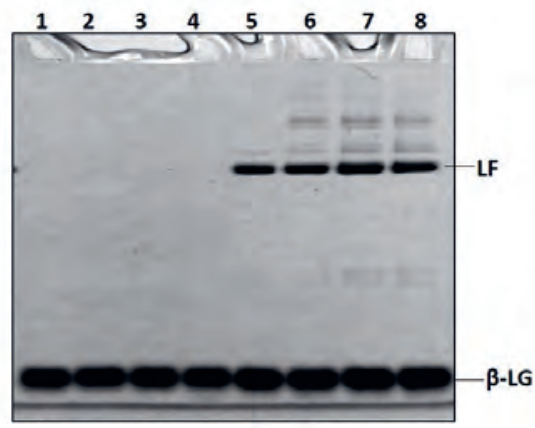

B

Figure 3-4 The effect of heating of lactoferrin in the absence and presence of $\beta$-lactoglobulin on its disulphide linked aggregation. Non-reducing (A) and reducing (B) SDS-PAGE gel of different heated mixture of lactoferrin and $\beta$ lactoglobulin. Lane 1, $\beta$-LG without heat treatment; Lane 2, 3, 4, $\beta$-L G being heated at $65 / 70 / 75{ }^{\circ} \mathrm{C}$ for 30 min, respectively. Lane 5, mixture of lactoferrin and $\beta-L G$ without heat treatment; $L$ ane $6,7,8$, mixture of lactoferrin and $\beta$-LG being heated at $65 / 70 / 75{ }^{\circ} \mathrm{C}$ for $30 \mathrm{~min}$. Abbreviations: LF, lactoferrin; $\beta$-LG, $\beta$-lactoglobulin.

$\beta$-LG is the predominant whey protein in milk and is highly reactive due to the free thiol group buried inside its folded structure (Hoffmann \& van Mil, 1997). Proteomics data also showed that the amount of $\beta$-LG in proteins aggregates increased after adding lactoferrin. Therefore, a more simple lactoferrin/ $\beta$-LG model system was used to investigate the role of $\beta$-LG in the aggregation of lactoferrin. When heating lactoferrin with purified $\beta-\mathrm{LG}$, monomeric lactoferrin showed a sharp decrease from $65{ }^{\circ} \mathrm{C}$, almost disappearing from $70{ }^{\circ} \mathrm{C}$ onwards. Correspondingly, larger aggregates were observed from $65^{\circ} \mathrm{C}$, which further increased after heating at $70{ }^{\circ} \mathrm{C}$ and $75{ }^{\circ} \mathrm{C}$ (Fig. 3-4). After adding a reducing agent, larger aggregates disappeared, but still some small aggregates, corresponding to the bands between $80 \mathrm{kDa}$ and $150 \mathrm{kDa}$ in the LFMS samples (Fig. 3-2B), remained visible. This is probably due to difficulties in achieving full reduction of disulphide bonds for all protein aggregates. A decrease in the 
level of monomeric $\beta$-LG was not clearly visible on the SDS-PAGE gel after heating with lactoferrin, which may have been caused by overloading of the sample (Fig. 3-4A). After decreasing the concentration of $\beta-\mathrm{LG}$ to $1 \mathrm{mg} / \mathrm{ml}$, a decrease of monomeric $\beta$-LG was observed from $65{ }^{\circ} \mathrm{C}$ when it was heated with lactoferrin (Supplementary fig. 3-1). When $\beta$-LG was heated alone, no larger aggregates were observed until $75^{\circ} \mathrm{C}$. Taken together, this data confirmed that $\beta-\mathrm{LG}$ and lactoferrin influenced each other's response to the heat treatment.

\subsubsection{Bacteriostatic activity of differently heated lactoferrin and milk serum samples}
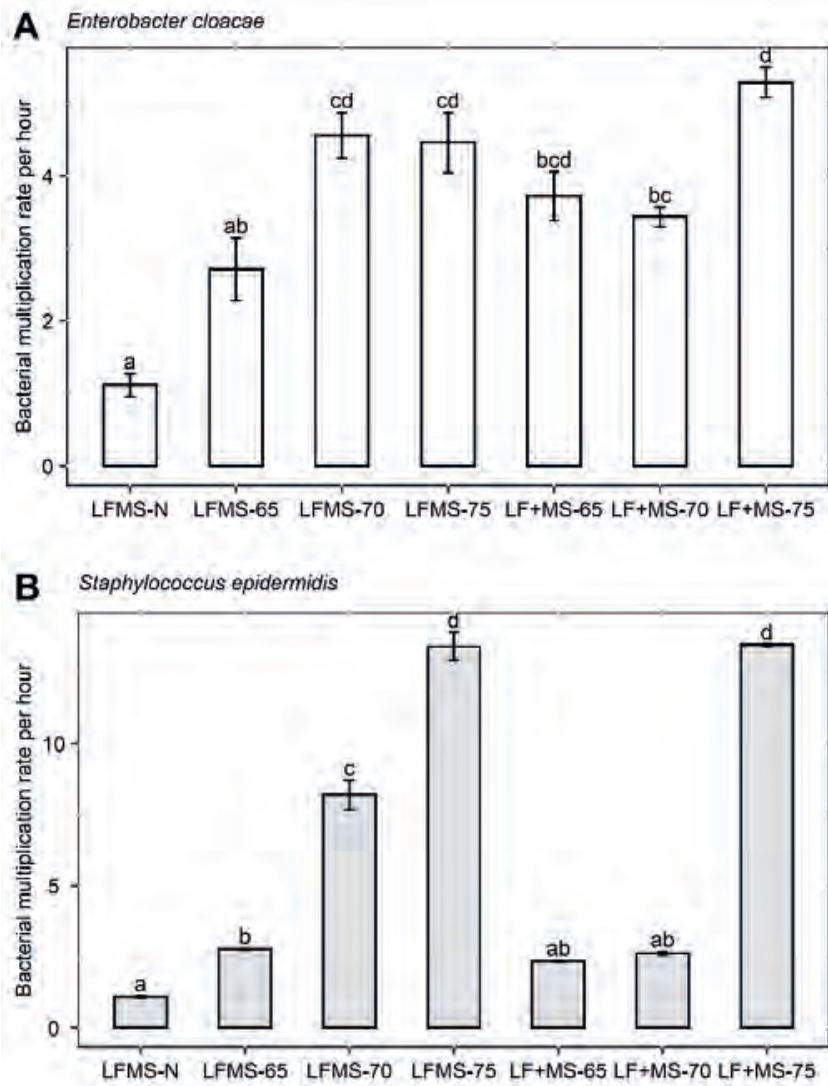

Figure 3-5 The effect of heating of lactoferrin and milk serum proteins on bacteriostatic activity. M ultiplication rates of Enterobacter doacae(A) and Staphylococausepidermidis(B) in differently heated lactoferrin and milk serum samples. LFMS, milk serum with addition of $1 \mathrm{mg} / \mathrm{ml}$ lactoferrin; LF +MS, lactoferrin and milk serum samples were heated at same temperature separately, and then mixed before the bacteriostatic activity assay. 65/70/75 refer to samples being heated at $65 / 70 / 75{ }^{\circ} \mathrm{C}$ for $30 \mathrm{~min}$, respectively. Statistical significance was analyzed using ANOVA and Tukey's HSD test. M eans were compared and marked as "a, b, c, d" from small to large. M eans followed by the same letter were not significantly different $(p>0.05)$. Different letters indicate statistically significant difference among different heat treatments $(p<0.05)$. 
Both lactoferrin and milk serum have been shown to have bacteriostatic activity (Wang, Timilsena, Blanch, \& Adhikari, 2019; Xiong et al., 2020a). Inhibition on bacterial growth may change after different heat treatments, due to the denaturation and/or aggregation of antibacterial proteins (Xiong et al., 2020a). Bacteriostatic activity of LFMS samples and LF+MS samples was tested to investigate the effect of aggregation of lactoferrin with milk serum proteins on the bacteriostatic capacity. Unheated LFMS showed the highest inhibition capacity among all samples. For heated LFMS samples, a rapid decrease of bacteriostatic activity against Enterobacter doacae occurred from LFMS-65 to LFMS-70 (Fig. 3-5A). Bacteriostatic capacity already started to decrease in the LFMS-65 samples (Fig. 3-5A), although not statistically significant, whereas its capacity decreased significantly in the LFMS70 and LFMS-75 samples. LF+MS samples showed a different trend compared to LFMS samples (Fig. 3-5A). Compared to unheated LFMS, LF+MS-65 and LF+MS-70 showed a similar, but reduced, bacteriostatic activity, while LF+MS-75 showed the lowest activity. The largest change of bacteriostatic activity against Enterobacter doacae occurred between LF+MS-70 and LF+MS-75 (Fig. 3-5A, p <0.05). A similar pattern was observed for the activity against Staphylococcus epidermidis, where the bacteriostatic activity was similar in LFMS, LFMS-65, LF+MS-65 and LF+MS-70 samples (F ig. 3-5B). However, it significantly decreased in LFMS-70 samples compared with LFMS-65 ( $\mathrm{p}<0.05)$. The bacteriostatic activity further decreased in LFMS-75 samples, as well as the LF+MS-75 samples. In general, the largest reduction of bacteriostatic activity occurred between $70{ }^{\circ} \mathrm{C}$ and $75{ }^{\circ} \mathrm{C}$, when lactoferrin and milk serum were heated separately, while the largest reduction of bacteriostatic activity occurred from $70{ }^{\circ} \mathrm{C}$ onwards when they were heated together. Although the bacteriostatic activity of all samples decreased to the same level after being heated at $75^{\circ} \mathrm{C}$, the decrease was accelerated by heating lactoferrin and milk serum proteins together during $65{ }^{\circ} \mathrm{C}-75^{\circ} \mathrm{C}$. 
3.3.4 Protein degradation and peptide release of heated lactoferrin after in vitro infant digestion

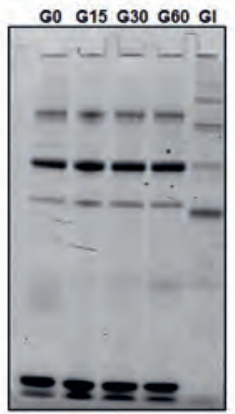

A

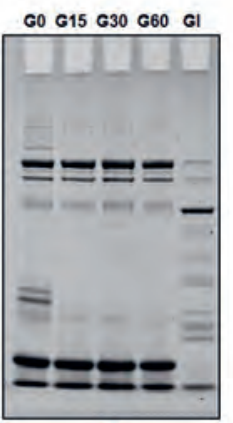

E

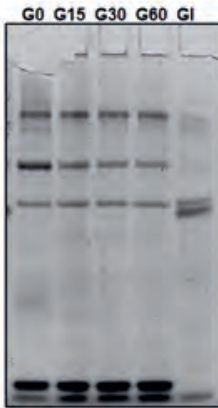

B

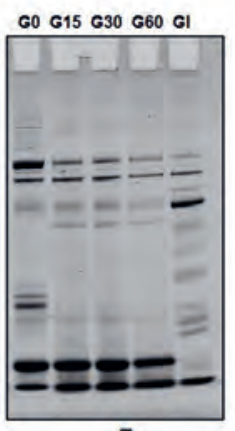

$\mathbf{F}$

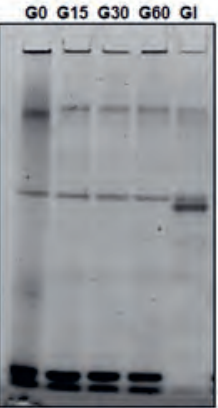

C

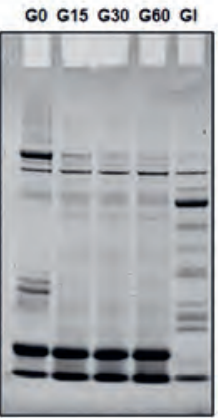

G

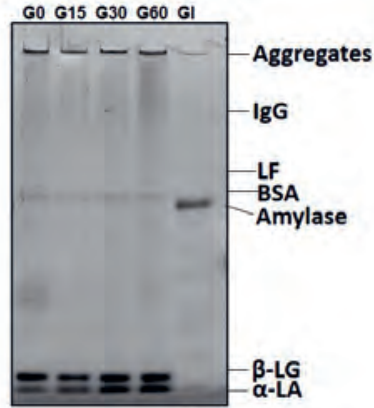

D

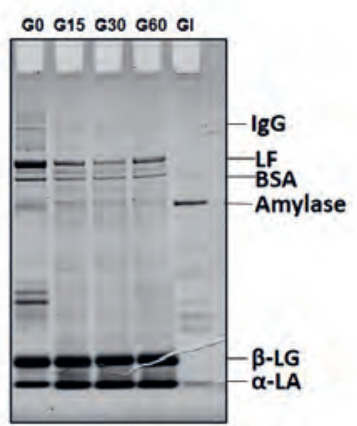

H

Figure 3-6 The effect of heating of lactoferrin in the absence and presence of milk serum proteins on its degradation after infant gastric digestion. A, B, C and D refer to LF M S sample without heat treatment, being heated at $65 / 70 / 75^{\circ} \mathrm{C}$ for $30 \mathrm{~min}$ under non-reducing conditions, respectively. E, F, G, H refer to L FM S sample without heat treatment, being heated at $65 / 70 / 75{ }^{\circ} \mathrm{C}$ for $30 \mathrm{~min}$ under reducing condition, respectively. G 0/G 15/G 30/G 60 are digested samples collected after 0/15/30/60 min of gastric digestion, respectively; GI means samples collected after complete gastrointestinal digestion. A bbreviations: IgG , immunoglobulin G; LF, lactoferrin; BSA, bovine serum albumin; $\beta$-L G, $\beta$-lactoglobulin; $\alpha$-LA, $\alpha$-lactalbumin.

Different heat treatments resulted in differences in the degradation pattern of lactoferrin upon in vitro digestion. The protein degradation of LFMS samples was displayed in Fig.3-6. The identification of these bands according to protein marker was shown in Supplementary Fig 32. For the unheated LFMS sample (Fig. 3-6A), no significant degradation of lactoferrin was observed in the gastric phase, which differed from the intestinal digestion, after which complete disappearance of monomeric lactoferrin was observed. For LFMS heated at $65{ }^{\circ} \mathrm{C}$ (Fig. 3-6B), monomeric lactoferrin decreased after 15 min gastric digestion, and then remained similar in the later gastric digestion. The bands $>150 \mathrm{kDa}$ became lighter during gastric digestion and almost disappeared after intestinal digestion, possibly due to partial digestion of the aggregates. For LFMS heated at $70{ }^{\circ} \mathrm{C}$ (F ig. 3-6C), more aggregates $>150 \mathrm{kDa}$ were present in the sample, 
which decreased after gastric digestion for $60 \mathrm{~min}$, although some aggregates remained. All aggregates almost completely disappeared after intestinal digestion. For the LFMS heated at $75^{\circ} \mathrm{C}$ (Fig. 3-6D), a decrease of aggregates after gastric digestion was not found, but the aggregates disappeared completely after intestinal digestion.

The non-reducing gel showed the changes of the aggregates during digestion. Because multiple proteins were involved in the aggregates, it was hard to see the change of individual proteins, like lactoferrin. Therefore, the reducing gel was used as well to achieve more detailed insights. Combining the reducing and non-reducing gel, the effect of aggregation on individual proteins can be better observed. For the unheated LFMS in the reducing gel (Fig. 3-6E), the result was the same as for the non-reducing gel, because of the absence of disulphide related aggregation. For the LFMS heated at $65{ }^{\circ} \mathrm{C}$ (Fig. 3-6F), partial digestion of lactoferrin was found, which is similar to the results of the non-reducing gel. For the LFMS heated at $70{ }^{\circ} \mathrm{C}$ (Fig. 3-6G), no monomeric lactoferrin was observed in the non-reducing gel due to aggregation, while some monomeric lactoferrin appeared in the reducing gel, even after gastric digestion for $60 \mathrm{~min}$, indicating that lactoferrin in these aggregates wasn't digested completely. Similar result occurred in LFMS heated at $75{ }^{\circ} \mathrm{C}$ (Fig. 3-6H). When the digestion of the differently heated LFMS samples was compared, lactoferrin was shown to be digested better in $65^{\circ} \mathrm{C}$ and $70{ }^{\circ} \mathrm{C}$ heated samples than in unheated samples. Remarkably, lactoferrin appeared to be slightly less digested in the $75^{\circ} \mathrm{C}$ heated sample than the $70{ }^{\circ} \mathrm{C}$ heated sample.

Differential release of peptides from lactoferrin due to differences in its degradation may occur. Our data showed a similar cleavage pattern for all samples (Supplementary Fig. 3-3), although the intensity profile of peptides originating from lactoferrin showed differences (Supplementary Fig. 3-4). Corresponding to the least degradation of intact lactoferrin, the unheated LFMS sample released the lowest levels of peptides from lactoferrin after digestion. From Supplementary Fig. 3-4, peptide profiles of LF+MS sample was different from that of LFMS sample, with a lower signal in all LF+MS samples. No significant trend was observed in differently heated LF+MS samples. When it comes to LFMS, peptides profile showed an obvious difference between differently heated samples, with LFMS being heated at $70{ }^{\circ} \mathrm{C}$ showing the highest peptide signals, followed by the samples heated at $65{ }^{\circ} \mathrm{C}$. The samples heated at $75^{\circ} \mathrm{C}$ showed the lowest peptide signals (Supplementary Fig. 3-4). 


\subsection{Discussion}

\subsubsection{Whey proteins accelerate disulphide linked aggregation involving lactoferrin}

In the present study, a combination of turbidity and particle size determination, SDS-PAGE, and proteomics was used to investigate the thermal aggregation of lactoferrin with milk serum proteins and its consequences. When lactoferrin was heated alone, an increase in turbidity was observed at $65^{\circ} \mathrm{C}$ (Fig. 3-1A), indicating that insoluble aggregates started to form from $65{ }^{\circ} \mathrm{C}$. The turbidity further increased in the $70^{\circ} \mathrm{C}$ and $75^{\circ} \mathrm{C}$ heated samples (Fig. 3-1A), which may have been due to the formation of either larger or more aggregates in those samples. Disulphidelinked aggregates of lactoferrin were observed in the $70{ }^{\circ} \mathrm{C}$ and $75{ }^{\circ} \mathrm{C}$ heated samples (Fig. 32A). From this data, it can be concluded that non-covalent interactions are underlying the protein aggregation in the $65{ }^{\circ} \mathrm{C}$ heated samples. Intermolecular disulphide interchange reactions occur upon heating, leading to aggregation of proteins as also suggested in a previous study (Brisson et al., 2007b). This formation of aggregates indicates that lactoferrin has undergone significant structural changes.

The results also showed that the presence of lactoferrin altered the thermal aggregation of milk serum proteins (Fig. 3-3 \& Supplementary table 3-1). For the MS samples, the sharp increase of turbidity from $70^{\circ} \mathrm{C}$ onward indicated the formation of aggregates (Fig. 3-1B). With a further increase in temperature, the aggregates increased in size, as indicated by the increase of turbidity and particle size (Fig. 3-1C). When MS and LFMS samples heated at the same temperature were compared, the turbidity and the average size of all heated LFMS samples was higher than that of the respective MS samples (Fig. 3-1B \& 1C). Therefore, the differences between these samples seem to result from the interaction between lactoferrin and whey proteins during heating. Combining data on the changes in particle size distribution and turbidity shows that this is induced by the formation of larger aggregates rather than an increase of the number of small aggregates. The aggregates with different size, as formed at various heating temperatures, may behave differently during the digestion.

The aggregation of lactoferrin was faster when heated in the presence of milk serum proteins (Fig. 3-2B), due to intermolecular thiol/disulphide interchange reactions, as shown by the disappearance of the aggregates under reducing conditions (Fig. 3-2D). The proteomics data

(Fig. 3-3C \& 3D) highlighted the involvement of several high abundant whey proteins in the aggregation during heating. Lactoferrin contains 17 intramolecular disulphide bonds without a free thiol group (Pierce et al., 1991). The presence of proteins containing free thiol groups, such 
as $\beta-\mathrm{LG}$ or BSA, facilitates aggregation via intermolecular thiol/disulphide interchanges. This was also demonstrated by previous studies, which showed no rapid self-aggregation of $\alpha$-LA upon heating, whereas the concomitant presence of $\beta-\mathrm{LG}$ or BSA was shown to considerably enhance the heat-induced aggregation of $\alpha$-LA (Dalgleish, Senaratne, \& Francois, 1997; Havea et al., 2001; Schokker et al., 2000). The presence of $\beta$-LG and/or BSA may thus increase the tendency of other proteins, like lactoferrin, to aggregate upon heating.

Our data confirms the direct thiol/disulphide interchange between lactoferrin and $\beta$-LG (Fig. 34), in accordance with another study that also reported the aggregation of lactoferrin with $\beta$-LG in lactoferrin-enriched milk (Brisson et al., 2007a). Our data indicate that upon heating, lactoferrin will have exposed S-S bridges that can be reduced by for instance free SH-groups of $\beta-\mathrm{LG}$ or BSA. This was further confirmed by the bands between $80 \mathrm{kDa}-150 \mathrm{kDa}$ on the SDS-PAGE gel (Fig. 3-2B) that were not visible in the similarly heated MS samples, indicating the formation of aggregates consisting of lactoferrin and other milk proteins in the LFMS samples. Interestingly, the above-mentioned bands in the LFMS samples were similar in appearance to those on the SDS-PAGE gel of lactoferrin with $\beta$-LG (Fig. 3-4B). When $\beta$-LG was heated alone, no change of turbidity (Supplementary Fig. 3-5) and no formation of disulphide linked aggregates was observed (Fig. 3-4), indicating that it is stable in the temperature range of $65{ }^{\circ} \mathrm{C}-75^{\circ} \mathrm{C}$. Our data also showed that lactoferrin affected the response of $\beta$-LG to the heat treatment, which confirms the recent study (Halabi et al., 2020) that reported a more extensive loss of native $\beta-L G$ in the presence of lactoferrin upon heating. Due to the heat sensitivity of lactoferrin, its disulphide bridges may have been more exposed when $\beta$-LG started unfolding to expose its free thiol group in the temperature range of $65{ }^{\circ} \mathrm{C}-75^{\circ} \mathrm{C}$. The free thiol group from $\beta$-LG may subsequently have undergone disulphide interchange reactions with the exposed S-S bridges of lactoferrin, which explains the enhanced aggregation of $\beta$-LG in the presence of lactoferrin. When heated in milk serum, lactoferrin probably mainly interact with $\beta$-LG, making $\beta$-LG more available for other proteins to aggregate at lower temperature, resulting in the change of protein aggregate composition (Fig. 3-3B). In summary, the data shows that acceleration of the aggregation of lactoferrin in the presence of milk serum proteins can be partly ascribed to $\beta$-LG. Whether aggregation of lactoferrin with other milk serum proteins is mainly mediated by $\beta-\mathrm{LG}$, or that other proteins like BSA also play a role, is not clear. Further studies should be done to confirm the contribution of individual whey proteins to the thiol/disulphide induced aggregation of lactoferrin. 


\subsubsection{Aggregation caused loss of bacteriostatic activity of lactoferrin and whey protein}

The bacteriostatic activity of whey proteins is highly dependent on their native structure and is negatively affected by denaturation and aggregation (Xiong et al., 2020a). The observed changes in bacteriostatic activity after different heat processing were generally consistent with the changes due to aggregation in these samples. When lactoferrin and whey proteins were heated separately, a rapid decrease of bacteriostatic activity was observed after heating at $75{ }^{\circ} \mathrm{C}$ (Fig. 3-5), which corresponds to the extensive aggregation of lactoferrin and milk serum proteins when heated separately (Fig. 3-2A \& 2B). Similar changes of the bacteriostatic capacity of milk serum after heat treatment were reported in our previous study (Xiong et al., 2020a). When lactoferrin in milk serum was heated at $70{ }^{\circ} \mathrm{C}$ and above, a rapid decrease of bacteriostatic activity was observed (Fig. 3-5), which coincides with the observed aggregation of LFMS samples (Fig. 3-2B). The bacteriostatic mechanisms of lactoferrin have been ascribed to its ability in iron scavenging and LPS binding (Wang et al., 2019). After heating at $85{ }^{\circ} \mathrm{C}$ for $20 \mathrm{~min}$, the ability to bind iron of soluble lactoferrin remained at $50 \%$, while aggregates of lactoferrin lost their ability to bind iron (Mata, Sánchez, Headon, \& Calvo, 1998). It was reported that aggregated lactoferrin had lost its bacteriostatic activity against E. coli O157:H7 and S. enteritidis (Conesa et al., 2010). These studies together with our data thus suggest that aggregation diminishes the bacteriostatic activity of lactoferrin. Aggregation between lactoferrin and milk serum proteins may change the iron binding domain of lactoferrin during heat treatment, thus causing a more extensive loss of its bacteriostatic activity.

\subsubsection{Aggregation decreased peptic degradation of lactoferrin and release of peptides}

In the present study, most of the lactoferrin was degraded after the complete gastrointestinal digestion in all samples, without much differences between different heat treatments (Fig. 3-6). Nevertheless, large differences in first phase of gastric digestion of lactoferrin were observed, indicating that unfolding and aggregation of lactoferrin affected gastric digestion more than intestinal digestion. Native lactoferrin was hardly digested after the infant gastric digestion (Fig. 3-6A \& E), which is consistent with an early study, showing that native lactoferrin is not extensively digested by infant's gastric secretions (Spik, Brunet, Mazurier - Dehaine, Fontaine, \& Montreuil, 1982). Even for in vivo and in vitro adult studies, it was shown that still some lactoferrin molecules remained intact after gastric digestion (Bokkhim, Bansal, Grøndahl, \& Bhandari, 2016). Heating induced structural changes of lactoferrin to a different extent, depending on the intensity of the heat treatment, which may affect the digestion pattern of lactoferrin. Grosvenor et al. (Grosvenor, Haigh, \& Dyer, 2014) reported that pasteurization 
$\left(72{ }^{\circ} \mathrm{C} / 15 \mathrm{~s}\right)$ altered the kinetics of release of specific peptides during gastric digestion of lactoferrin. On the other hand, Wang et al. reported that no difference in the degradation of lactoferrin was observed between samples heated at $70{ }^{\circ} \mathrm{C}$ for $10 \mathrm{~min}$ and its unheated counterparts based on an in vitro adult digestion model (Wang, Timilsena, Blanch, \& Adhikari, 2017). We observed a more extensive decrease of the intact lactoferrin band on SDS-PAGE and a higher peptide intensity in all heated samples compared to their unheated counterparts (Fig. 3-6 \& Supplementary Fig. 3-4), indicating that conformational changes induced by heat treatment enhanced the susceptibility of lactoferrin to gastric hydrolysis.

When lactoferrin was heated in the presence of milk serum proteins, the digestion pattern showed a difference among the three differently heated samples (Fig. 3-6). This difference was probably associated with the extent of aggregation. The lowest retention of intact lactoferrin after gastric digestion in the LFMS-70 samples in the reducing gel suggests that most of the lactoferrin that was present in these aggregates was hydrolysed by pepsin. The increased retention of intact lactoferrin and the lowest level of peptides in the LFMS-75 samples indicates that at this heat load lactoferrin present in larger aggregates can't be digested as well as the samples treated at lower temperature. It was previously demonstrated that heat-induced increases in protein digestibility due to unfolding of protein may be overwhelmed by formation of proteolytic-resistant aggregates (Yasuaki Wada \& Loennerdal, 2014), and physicochemical properties of protein aggregates significantly affected their digestion behaviour, with a higher degradation rate for smaller aggregates (Zhang \& Vardhanabhuti, 2014). Combining the data from our study and existing studies, it can be concluded that aggregation not only affected the overall digestibility of milk serum proteins but also played a critical role in the kinetics of digestion of specific proteins, in this case lactoferrin. The rate of digestion of lactoferrin is thus a balance of an increased digestion rate due to unfolding and a decreased digestion rate due to aggregation.

In summary, the data show how heating of lactoferrin in a milk matrix may change its digestion kinetics and cause a loss of its activity. It thereby corroborates that heating lactoferrin and other protein ingredients in food products separately may decrease the disulphide linked aggregation of lactoferrin with other proteins, which may ultimately help to retain its bioactivity. This can be of important relevance for producers of lactoferrin-containing functional foods. 


\subsection{Conclusion}

Milk serum proteins accelerated the aggregation of lactoferrin via thiol/disulphide interchange reactions during heat treatment, which was partly mediated by $\beta$-LG. Interaction of lactoferrin with milk serum proteins accelerated the loss of its bacteriostatic activity. Moderate heat treatment could enhance hydrolysis of lactoferrin during gastric digestion. However, extensive aggregation of lactoferrin with milk serum proteins into large aggregates counteracted the improved digestion induced by unfolding, and subsequently changes the peptide profile after in vitro infant gastric digestion.

\section{Acknowledgements}

This research was funded by the Sino Dutch Dairy Development Centre (http://www.sdddc.org), and Sino-Dutch Doctoral Program on Sustainable Dairy from China Scholarship Council. The authors have no conflict of interest to declare. 


\section{Supplementary M aterials}

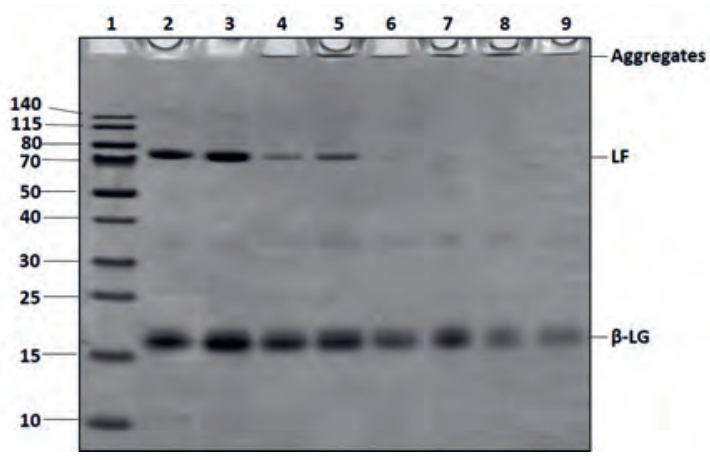

Supplementary figure 3-1 The effect of heating of lactoferrin in the absence and presence of $\beta$-lactoglobulin on its disulphide linked aggregation. $L$ ane 1, protein marker; Lane 2, 3, mixture of lactoferrin and $\beta$-lactoglobulin without heat treatment; Lane 4, 5 mixture of lactoferrin and $\beta$-lactoglobulin being heated at $65^{\circ} \mathrm{C}$ for $30 \mathrm{~min}$; L ane 6,7 , mixture of lactoferrin and $\beta$-lactoglobulin being heated at $75^{\circ} \mathrm{C}$ for $30 \mathrm{~min}$;. Lane 8,9 , mixture of lactoferrin and $\beta$-lactoglobulin being heated at $85^{\circ} \mathrm{C}$ for $30 \mathrm{~min}$; Abbreviations: LF, lactoferrin; $\beta$-LG, $\beta$-lactoglobulin.
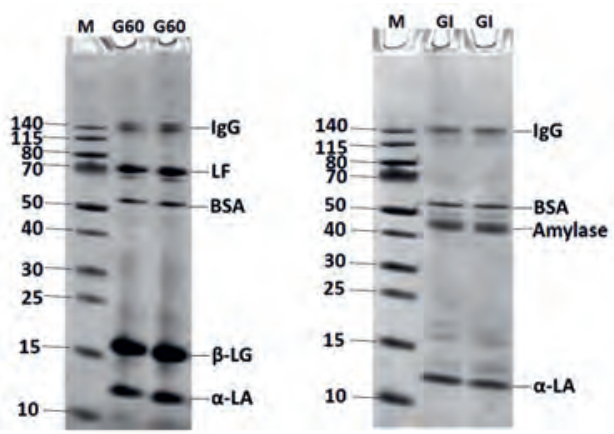

Supplementary figure 3-2 In vitro digestion of unheated LFMS samples after gastric digestion and gastrointestinal digestion. M , protein marker; $G 60$ means digested samples collected after 60 min of gastric digestion; $G$ I means samples collected after complete gastrointestinal digestion. Abbreviations: IgG, immunoglobulin G; LF, lactoferrin; BSA, bovine serum albumin; $\beta$-LG, $\beta$-lactoglobulin; $\alpha$-LA, $\alpha$-lactalbumin. 


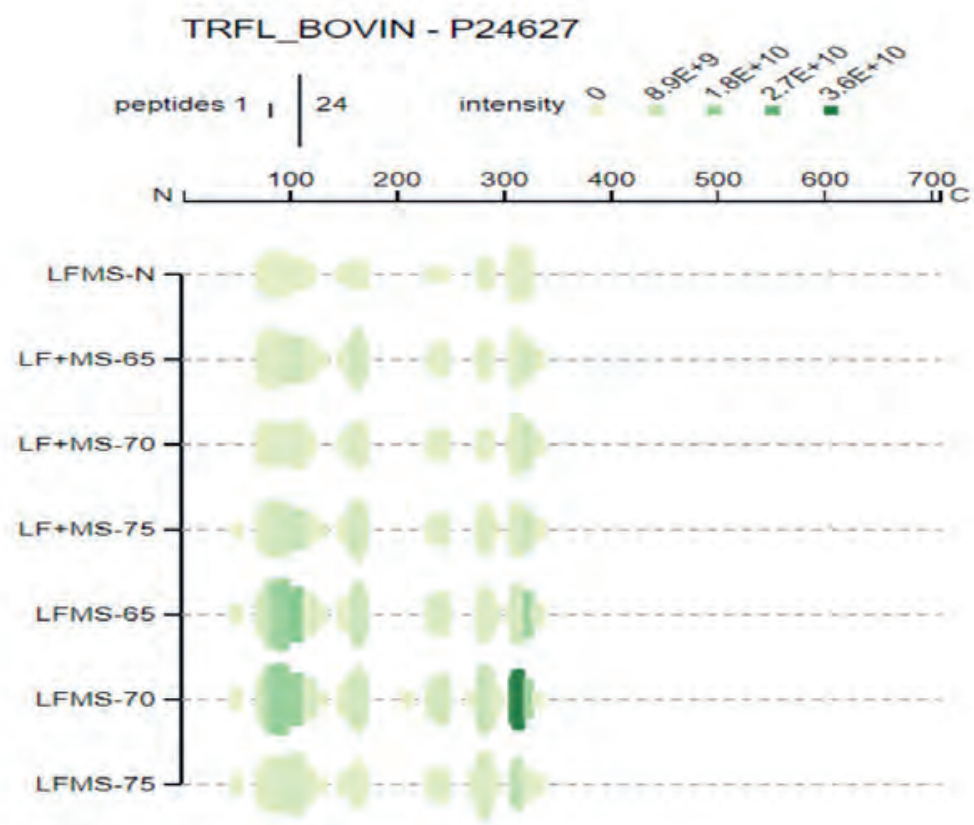

Supplementary figure 3-3 Cleavage pattern of lactoferrin in the absence and presence of milk serum protein on after infant gastric digestion. L FMS, milk serum with addition of $1 \mathrm{mg} / \mathrm{ml}$ lactoferrin; $L F+M S$, lactoferrin and milk serum samples were heated at same temperature separately, and then mixed before digestion. $\mathrm{N}$, sample without heat treatment; $65 / 70 / 75$ refer to samples being heated at $65 / 70 / 75{ }^{\circ} \mathrm{C}$ for $30 \mathrm{~min}$, respectively. 


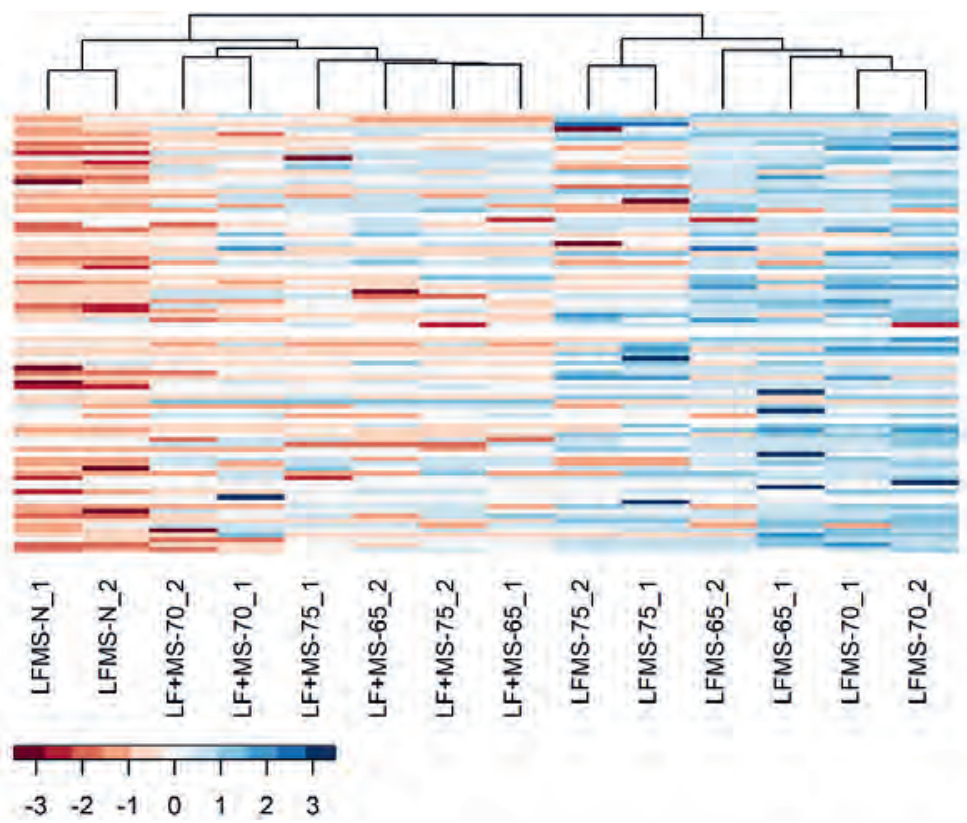

Supplementary figure 3-4 Peptide profiles from lactoferrin in differently heated milk serum samples after infant digestion. LFMS, milk serum with addition of $1 \mathrm{mg} / \mathrm{ml}$ lactoferrin; LF +M S, lactoferrin and milk serum samples were heated at same temperature separately, and then mixed before digestion. $N$, sample without heat treatment; 65/70/75 refer to samples being heated at $65 / 70 / 75^{\circ} \mathrm{C}$ for $30 \mathrm{~min}$, respectively.

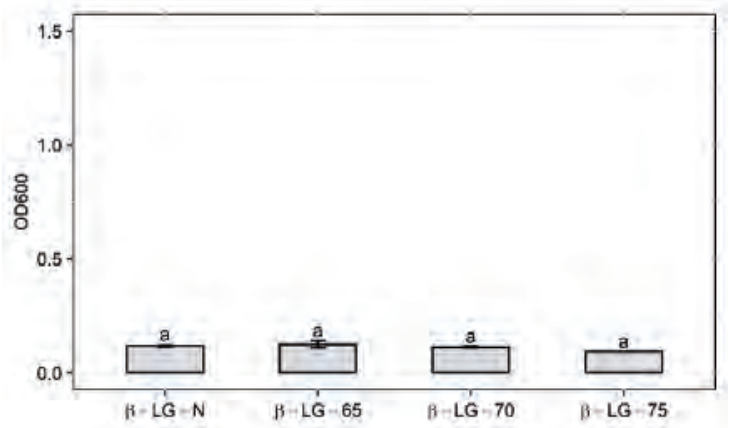

Supplementary figure 3-5 Change of turbidity of $\beta$-lactoglobulin after heating. $N$, sample without heat treatment; $65 / 70 / 75$ refer to samples being heated at $65 / 70 / 75{ }^{\circ} \mathrm{C}$ for $30 \mathrm{~min}$, respectively. Abbreviations: $\beta$-LG, $\beta$-lactoglobulin. Statistical significance was analyzed using A NOVA. M eans followed by the same letter were not significantly different $(p>0.05)$. Different letters indicate statistically significant difference among different heat treatments $(p<0.05)$ based on Tukey's HSD test. 
Supplementary table 3-1 The level of proteins in aggregates after different heat treatment.

\begin{tabular}{|c|c|c|c|c|c|c|c|c|}
\hline Log10(iBAQ) & MS-N & MS-65 & MS-70 & MS-75 & LFMS-N & LFMS-65 & LFMS-70 & LFMS-75 \\
\hline Lactoferrin & $5.40 \pm 0.45$ & $5.60 \pm 0.48$ & $6.09 \pm 0.90$ & $7.81 \pm 0.18$ & $6.11 \pm 1.05$ & $5.81 \pm 0.14$ & $8.85 \pm 0.04$ & $9.28 \pm 0.05$ \\
\hline Beta-lactoglobulin & $7.81 \pm 0.44$ & $7.87 \pm 0.15$ & $7.97 \pm 0.20$ & $8.73 \pm 0.01$ & $7.65 \pm 0.18$ & $7.43 \pm 0.19$ & $9.05 \pm 0.14$ & $9.61 \pm 0.03$ \\
\hline Alpha-lactalbumin & $5.86 \pm 0.64$ & $5.05 \pm 0.16$ & $5.74 \pm 0.47$ & $7.10 \pm 0.01$ & $5.67 \pm 0.06$ & $3.72 \pm 0.03$ & $5.96 \pm 0.02$ & $6.74 \pm 0.05$ \\
\hline Bovine serum albumin & $6.11 \pm 0.02$ & $6.42 \pm 0.11$ & $6.49 \pm 1.39$ & $7.06 \pm 0.20$ & $6.24 \pm 0.41$ & $5.62 \pm 0.22$ & $6.25 \pm 0.07$ & $7.10 \pm 0.13$ \\
\hline Lactoperoxidase & $2.55 \pm 0.47$ & $3.68 \pm 0.03$ & $3.69 \pm 1.17$ & $6.62 \pm 0.29$ & $3.64 \pm 0.15$ & $3.53 \pm 0.63$ & $5.93 \pm 0.16$ & $6.94 \pm 0.03$ \\
\hline Kappa-casein & $4.41 \pm 0.48$ & $4.29 \pm 1.01$ & $5.45 \pm 0.11$ & $6.39 \pm 0.42$ & $2.95 \pm 0.35$ & $4.06 \pm 2.31$ & $5.56 \pm 0.48$ & $6.82 \pm 0.63$ \\
\hline Alpha-S1-casein & $4.26 \pm 0.35$ & $5.45 \pm 0.26$ & $5.73 \pm 1.59$ & $4.74 \pm 0.20$ & $4.07 \pm 0.09$ & $5.48 \pm 0.39$ & $6.20 \pm 0.10$ & $5.93 \pm 0.14$ \\
\hline $\begin{array}{l}\text { Xanthine } \\
\text { dehydrogenase/oxidase }\end{array}$ & $4.77 \pm 0.35$ & $6.50 \pm 0.28$ & $5.72 \pm 0.12$ & $7.48 \pm 0.02$ & $4.16 \pm 0.60$ & $5.64 \pm 0.45$ & $7.19 \pm 0.10$ & $7.67 \pm 0.07$ \\
\hline $\begin{array}{l}\text { Polymeric } \\
\text { immunoglobulin } \\
\text { receptor }\end{array}$ & $3.90 \pm 0.76$ & $4.66 \pm 0.89$ & $4.69 \pm 0.18$ & $7.19 \pm 0.88$ & $3.69 \pm 0.47$ & $3.94 \pm 0.60$ & $7.01 \pm 0.06$ & $7.53 \pm 0.39$ \\
\hline $\begin{array}{l}\text { Butyrophilin subfamily } \\
1 \text { member }\end{array}$ & $6.52 \pm 0.13$ & $6.81 \pm 0.58$ & $4.89 \pm 0.04$ & $6.80 \pm 0.45$ & $6.02 \pm 0.88$ & $5.78 \pm 0.65$ & $6.40 \pm 0.14$ & $6.60 \pm 0.02$ \\
\hline $\begin{array}{l}\text { Ig-like domain- } \\
\text { containing protein }\end{array}$ & $2.99 \pm 0.23$ & $3.94 \pm 0.41$ & $3.60 \pm 0.39$ & $6.56 \pm 0.31$ & $3.29 \pm 0.63$ & $3.31 \pm 0.18$ & $5.75 \pm 1.12$ & $6.89 \pm 0.75$ \\
\hline $\begin{array}{ll}\text { Fibroblast } & \text { growth } \\
\text { factor-binding } & \text { protein } \\
1 & \end{array}$ & $4.48 \pm 2.21$ & $4.44 \pm 0.77$ & $5.02 \pm 1.13$ & $4.66 \pm 0.13$ & $4.64 \pm 0.49$ & $3.81 \pm 1.03$ & $5.97 \pm 0.87$ & $7.42 \pm 0.04$ \\
\hline $\begin{array}{l}\text { Uncharacterized } \\
\text { protein }\end{array}$ & $2.74 \pm 1.34$ & $3.93 \pm 0.02$ & $3.52 \pm 1.81$ & $5.83 \pm 0.23$ & $3.37 \pm 0.76$ & $3.31 \pm 0.19$ & $4.34 \pm 0.16$ & $5.21 \pm 0.30$ \\
\hline $\begin{array}{l}\text { Sodium-dependent } \\
\text { phosphate transport } \\
\text { protein 2B }\end{array}$ & $3.63 \pm 0.24$ & $6.01 \pm 0.53$ & $4.73 \pm 1.83$ & $6.67 \pm 0.27$ & $3.35 \pm 0.04$ & $5.43 \pm 0.36$ & $6.02 \pm 0.08$ & $6.22 \pm 0.13$ \\
\hline Lactadherin & $3.99 \pm 0.10$ & $4.49 \pm 0.18$ & $4.01 \pm 2.17$ & $6.43 \pm 0.35$ & $2.30 \pm 0.23$ & $3.25 \pm 1.18$ & $6.15 \pm 0.30$ & $6.83 \pm 0.43$ \\
\hline $\begin{array}{l}\text { Ig-like domain- } \\
\text { containing protein }\end{array}$ & $3.53 \pm 0.31$ & $4.36 \pm 0.75$ & $4.37 \pm 0.37$ & $6.43 \pm 0.24$ & $3.56 \pm 0.27$ & $3.93 \pm 0.13$ & $6.07 \pm 0.12$ & $6.20 \pm 0.09$ \\
\hline Complement $\mathrm{C} 3$ & $3.38 \pm 0.22$ & $4.24 \pm 0.83$ & $4.03 \pm 1.03$ & $5.87 \pm 0.20$ & $3.32 \pm 0.54$ & $2.87 \pm 0.02$ & $5.70 \pm 0.09$ & $6.46 \pm 1.21$ \\
\hline Serotransferrin & $2.42 \pm 1.30$ & $4.07 \pm 0.29$ & $3.96 \pm 0.54$ & $6.38 \pm 1.20$ & $3.31 \pm 1.81$ & $3.80 \pm 0.16$ & $6.34 \pm 0.47$ & $5.99 \pm 0.65$ \\
\hline $\begin{array}{l}\text { ATP-binding cassette } \\
\text { sub-family G member } \\
2\end{array}$ & $5.13 \pm 0.26$ & $6.03 \pm 0.27$ & $4.73 \pm 1.41$ & $6.49 \pm 0.02$ & $5.32 \pm 0.30$ & $5.14 \pm 0.18$ & $5.84 \pm 0.49$ & $6.06 \pm 0.18$ \\
\hline Platelet glycoprotein 4 & $4.59 \pm 0.49$ & $5.51 \pm 0.20$ & $3.35 \pm 0.21$ & $6.38 \pm 0.17$ & $2.93 \pm 0.78$ & $3.65 \pm 1.58$ & $4.38 \pm 0.96$ & $5.79 \pm 0.15$ \\
\hline $\begin{array}{l}\text { Uncharacterized } \\
\text { protein }\end{array}$ & $3.81 \pm 1.35$ & $3.86 \pm 0.43$ & $3.30 \pm 0.73$ & $6.13 \pm 0.18$ & $3.38 \pm 0.72$ & $3.70 \pm 0.57$ & $5.25 \pm 0.29$ & $6.41 \pm 0.43$ \\
\hline $\begin{array}{l}\text { Beta-1,4- } \\
\text { galactosyltransferase } 1\end{array}$ & $2.63 \pm 0.31$ & $4.25 \pm 0.84$ & $4.39 \pm 1.08$ & $5.93 \pm 0.09$ & $3.36 \pm 0.01$ & $3.02 \pm 0.30$ & $4.59 \pm 1.62$ & $6.65 \pm 0.10$ \\
\hline $\begin{array}{l}\text { Uncharacterized } \\
\text { protein }\end{array}$ & $3.26 \pm 0.18$ & $3.86 \pm 0.04$ & $3.41 \pm 0.44$ & $4.61 \pm 0.25$ & $3.49 \pm 1.29$ & $3.18 \pm 0.15$ & $4.93 \pm 0.57$ & $6.01 \pm 0.21$ \\
\hline $\begin{array}{l}\text { Fatty acid-binding } \\
\text { protein }\end{array}$ & $3.98 \pm 1.75$ & $5.33 \pm 0.66$ & $5.16 \pm 0.34$ & $6.08 \pm 0.08$ & $4.07 \pm 0.99$ & $3.46 \pm 1.59$ & $4.97 \pm 0.13$ & $5.03 \pm 0.78$ \\
\hline Complement factor B & $3.08 \pm 1.07$ & $4.00 \pm 0.10$ & $3.62 \pm 0.70$ & $5.39 \pm 0.20$ & $3.49 \pm 0.82$ & $3.27 \pm 0.03$ & $4.57 \pm 0.81$ & $5.13 \pm 1.12$ \\
\hline Actin, cytoplasmic 2 & $3.97 \pm 0.23$ & $5.89 \pm 0.49$ & $3.90 \pm 0.18$ & $5.51 \pm 0.48$ & $3.08 \pm 0.10$ & $3.31 \pm 0.15$ & $5.16 \pm 0.57$ & $5.32 \pm 0.53$ \\
\hline Lipocalin 2 & $2.64 \pm 0.10$ & $4.00 \pm 0.28$ & $3.36 \pm 0.15$ & $3.95 \pm 0.27$ & $3.31 \pm 0.99$ & $2.91 \pm 0.35$ & $4.36 \pm 1.13$ & $6.45 \pm 0.08$ \\
\hline Junction plakoglobin & $5.49 \pm 0.43$ & $5.56 \pm 0.20$ & $4.83 \pm 0.04$ & $5.73 \pm 0.41$ & $4.93 \pm 0.42$ & $4.66 \pm 0.55$ & $4.68 \pm 1.50$ & $4.86 \pm 0.73$ \\
\hline Sulfhydryl oxidase & $2.58 \pm 0.11$ & $4.04 \pm 0.19$ & $3.59 \pm 0.37$ & $4.20 \pm 0.31$ & $3.13 \pm 0.08$ & $2.83 \pm 0.33$ & $5.70 \pm 0.08$ & $5.56 \pm 0.67$ \\
\hline
\end{tabular}


E ect of milk serum proteins on aggregation of lactoferrin during heat treatment

\begin{tabular}{|c|c|c|c|c|c|c|c|c|}
\hline Protein name & MS-N & MS-65 & MS-70 & MS-75 & LFMS-N & LFMS-65 & LFMS-70 & LFMS-75 \\
\hline $\begin{array}{l}\text { Fibrinogen gamma-B } \\
\text { chain }\end{array}$ & $3.18 \pm 0.06$ & $4.10 \pm 0.01$ & $3.23 \pm 0.12$ & $5.25 \pm 0.29$ & $2.95 \pm 1.00$ & $2.65 \pm 0.43$ & $4.68 \pm 0.54$ & $5.44 \pm 0.60$ \\
\hline Perilipin-2 & $5.41 \pm 0.42$ & $4.80 \pm 0.71$ & $3.82 \pm 0.43$ & $5.52 \pm 0.16$ & $3.30 \pm 0.54$ & $4.68 \pm 0.37$ & $4.17 \pm 1.15$ & $4.96 \pm 0.56$ \\
\hline $\begin{array}{l}\text { Uncharacterized } \\
\text { protein }\end{array}$ & $5.16 \pm 0.13$ & $5.42 \pm 0.04$ & $3.99 \pm 0.67$ & $5.41 \pm 0.44$ & $5.02 \pm 0.24$ & $4.62 \pm 0.64$ & $4.46 \pm 0.19$ & $3.60 \pm 0.31$ \\
\hline Fibronectin & $2.93 \pm 0.61$ & $3.88 \pm 0.12$ & $3.09 \pm 0.16$ & $4.49 \pm 0.08$ & $3.51 \pm 0.10$ & $2.80 \pm 0.27$ & $3.90 \pm 0.05$ & $4.62 \pm 0.30$ \\
\hline Fatty acid synthase & $4.95 \pm 0.48$ & $4.95 \pm 0.27$ & $3.76 \pm 0.73$ & $4.61 \pm 1.02$ & $3.86 \pm 0.01$ & $4.07 \pm 0.05$ & $3.98 \pm 0.51$ & $4.88 \pm 0.07$ \\
\hline Complement C7 & $3.15 \pm 0.19$ & $4.10 \pm 0.40$ & $3.49 \pm 0.14$ & $4.82 \pm 0.08$ & $3.64 \pm 0.22$ & $2.72 \pm 0.30$ & $4.66 \pm 0.23$ & $4.50 \pm 0.72$ \\
\hline Desmoplakin & $4.07 \pm 0.09$ & $4.92 \pm 0.36$ & $3.42 \pm 0.02$ & $4.86 \pm 0.32$ & $3.87 \pm 0.17$ & $4.03 \pm 0.48$ & $4.26 \pm 1.31$ & $4.17 \pm 0.08$ \\
\hline
\end{tabular}

Result was expressed as M ean \pm SD calculated logarithm of iBAQ value. MS, milk serum; LFMS, milk serum with addition of $1 \mathrm{mg} / \mathrm{ml}$ lactoferrin. $\mathrm{N}$, sample without heat treatment; $65 / 70 / 75$ refer to samples being heated at $65 / 70 / 75{ }^{\circ} \mathrm{C}$ for $30 \mathrm{~min}$, respectively. 

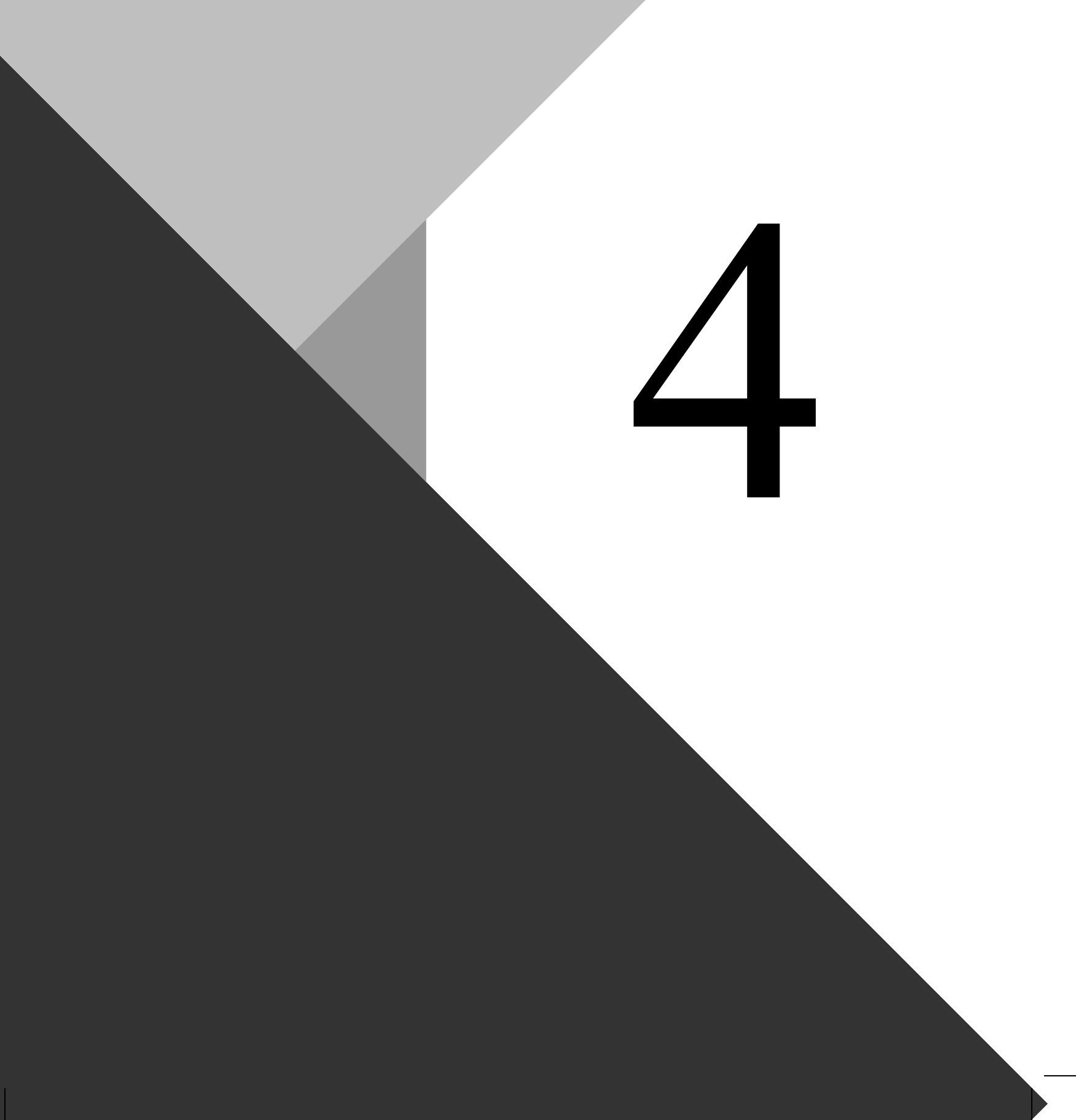


\section{CHAPTER 4.}

E ect of heat treatment on bacteriostatic activity and protein pr le of bovine whey proteins

This chapter has been published as:

Xiong, L., Li, C., Boeren, S., Vervoort, J., \& Hettinga, K. (2020). E ect of heat treatment on bacteriostatic activity and protein pr le of bovine whey proteins. Food Research International, 127, 108688. 


\section{Abstract}

Bovine milk shows bacteriostatic activity mainly due to the presence of antibacterial proteins, like lactoferrin, lactoperoxidase and immunoglobulins. Heat treatment is applied to kill bacteria and thereby extend shelf life of dairy products. Such heat treatment may, however, impair the activity of native antibacterial proteins in milk. The aim of this study was to investigate bacteriostatic capacity and retention of antibacterial proteins in unheated and heated bovine milk. Skim milk samples were heated at $65^{\circ} \mathrm{C}, 70{ }^{\circ} \mathrm{C}, 75^{\circ} \mathrm{C}, 80^{\circ} \mathrm{C}$ and $85^{\circ} \mathrm{C}$, for 30 minutes. Whey was isolated from the heat-treated skim milk and the bacteriostatic capacity of this whey was tested against Streptococcus thermophilus, Escherichia coli, Lactococcus lactis and Pseudomonas fluorescens. The proteomic profile of native whey was determined using LCMS/MS-based proteomics. Results showed that the bacteriostatic activity of whey negatively correlated with intensity of heat treatment, which was also reflected in the reduced level of native antibacterial proteins. There is a significant difference between milk samples treated for 30 minutes at $<75{ }^{\circ} \mathrm{C}$ and milk samples treated at $\geq 75{ }^{\circ} \mathrm{C}$ in both bacteriostatic capacity and native antibacterial proteins. Growth rates of Streptococcus thermophilus, Lactococcus lactis and Pseudomonas fluorescens were negatively correlated with retention of lactoferrin and lactoperoxidase. In conclusion, our study shows that the bacteriostatic capacity of whey decreases with increasing heating intensity, which is strongly correlated with the denaturation of antibacterial proteins. Bacteriostatic activity can be a biomarker for loss of function of antibacterial proteins, and can thereby be used as an indicator for the extent of heat processing of dairy products including antibacterial proteins in a mild heat treatment.

Keywords: Proteomics, milk, antibacterial, thermal treatment, pasteurization, milk enzymes. 


\subsection{Introduction}

Bovine milk exerts bacteriostatic ability due to the presence of various antibacterial proteins and peptides, such as lactoperoxidase, immunoglobulin and lactoferrin. Heat treatment is applied to milk and dairy products to ensure their microbiological safety and shelf life. Thermal processes can, however, impact functional properties of milk proteins, e.g. their ability to exert an bacteriostatic capacity. It was reported that consumption of raw cow's milk reduced the risk of common respiratory infections (Loss et al., 2015), while processed human milk and bovine milk (e.g. pasteurization, boiling, ultra-high temperature processing) had significantly increased risks for these diseases for new born (Dritsakou, Liosis, Valsami, Polychronopoulos, \& Skouroliakou, 2016; Loss et al., 2015; Montjaux-Regis et al., 2011), which may be due to the presence of immune-active proteins in raw milk that have been destroyed upon heat treatment. Bacteriostatic capacity of human milk against Escherichia coli was decreased after hightemperature treatment (Silvestre, Ruiz, Martinez-Costa, Plaza, \& Lopez, 2008). Studies on the stability of whey proteins during heat processing showed that many, especially immune-active, proteins were decreased or absent in processed milk (Brick et al., 2017; Zhang, Boeren, et al., 2016). Although milk contains many immune-active proteins, lactoferrin, lactoperoxidase and immunoglobulin are the main ones in bovine milk (Madureira, Pereira, Gomes, Pintado, \& Malcata, 2007). In addition, low abundant immune-active proteins including monocyte differentiation antigen CD14 and complement components could contribute to beneficial immune effects of milk. All these immune-active proteins are strongly affected by heat processing (Brick et al., 2017).

Lactoferrin (LF) is an iron-binding glycoprotein present in the milk and other secretory fluids of many mammalian species. Bovine lactoferrin consists of 689 amino acids and is present at around 20-200 mg/L in cow's milk (Steijns \& van Hooijdonk, 2000). It was reported to exert a broad range of biological activity including being antibacterial, antivirus, immunomodulatory. Lactoferrin is therefore added into infant formula to improve health of new-born (King et al., 2007). The antimicrobial activity of lactoferrin is mainly contributed to its iron-sequestering and lipopolysaccharide-binding properties (Farnaud \& Evans, 2003). Studied showed that heat treatment could reduce iron-binding capacity of lactoferrin (Mata et al., 1998). Therefore, a decrease of the antibacterial activity of lactoferrin may be caused by reduction of its ironbinding capacity. A study showed that holder pasteurization $\left(63{ }^{\circ} \mathrm{C} / 30 \mathrm{~min}\right)$ of skim milk reduced the native lactoferrin content by about $40 \%$. It was also reported that pasteurisation at a different temperature/time combination $\left(72{ }^{\circ} \mathrm{C} / 15 \mathrm{~s}\right)$ led to a similar $40 \%$ - $50 \%$ denaturation, 
though it showed similar bacteriostatic properties as unheated lactoferrin. Ultra-hightemperature treated lactoferrin, on the other hand, was completely denatured and lost its inhibitory capacity on Escherichia coli (Paulsson, Svensson, Kishore, \& Naidu, 1993).

Lactoperoxidase (LPO) is one of the most prominent enzymes in bovine milk containing 612 amino acids, which exerts its function as LPO system with hydrogen peroxidase and the pseudohalogen thiocyanate. Lactoperoxidase catalyses the peroxidation of thiocyanate and some halides to produce components that inhibit the growth of a variety of bacteria (Bjorck, Rosen, Marshall, \& Reiter, 1975; Kussendrager \& van Hooijdonk, 2000; Reiter, Marshall, Bjorck, \& Rosen, 1976), which may contribute to the prevention of enteric infections in neonates (Reiter, Marshall, \& Philips, 1980; Still, Delahaut, Coppe, Kaeckenbeeck, \& Perraudin, 1990). Activity of lactoperoxidase decreased when it was heated at $62{ }^{\circ} \mathrm{C} / 20 \mathrm{~min}$ or $72{ }^{\circ} \mathrm{C} / 6$ min (Claeys, Van Loey, \& Hendrickx, 2002) and showed a complete inactivation at $78{ }^{\circ} \mathrm{C} / 15 \mathrm{~s}$ in bovine milk (Dumitrascu, Stanciuc, Stanciu, \& Rapeanu, 2012). LPO was completely inactivated in milk samples subject to heat treatment at $\geq 80{ }^{\circ} \mathrm{C}$ for $10 \mathrm{~min}$, which is used as an indicator of heat treatment of milk around $80{ }^{\circ} \mathrm{C}$ (Sharma \& Rajput, 2014).

Immunoglobulins (Ig) are secreted by mammals to control infections, and consequently can also be part of passively transferred immunity to neonates. Three classes of immunoglobulins have been identified in bovine milk, IgA, IgM and IgG. Previous studies found that oral administration of bovine colostrum could provide passive immune protection for humans through its immunoglobulins (He, 2001; Hurley \& Theil, 2011). It was reported that holder pasteurisation $\left(63{ }^{\circ} \mathrm{C} / 30 \mathrm{~min}\right)$ denatured $33 \%$ of $\operatorname{IgM}$, but had no effect on the other two major immunoglobulins (Mainer, L. Sanchez, Ena, \& Calvo, 1997). However, heat-sterilization denatured all immunoglobulins (Kummer et al., 2008). In vitro antibacterial activity of immunoglobulin is controversial. It was reported that isolated bovine IgG from a single cow did not reveal any inhibitory activity on Escherichia coli, but it can enhance specifically the bacteriostatic activity of lactoferrin against the strain pathogenic to calves, NCTC 10444 (Spik, Cheron, Montreuil, \& Dolby, 1978; Stephens, Dolby, Montreuil, \& Spik, 1980).

The effect of heat processing on the bovine milk proteome was reported in several studies in recent years, helped by the development of high-throughput methods, equipment, and software approaches (Greenwood \& Honan, 2019). In these studies, industrial heating processes or single heat treatments were applied to observe differences in the protein profile, as induced by heat treatment (Brick et al., 2017; Felfoul et al., 2017; Tacoma et al., 2017; Zhang, Boeren, et al., 
2016). However, these studies did not look at the effect of small variations in temperature on the protein profile. Also, denaturation of proteins was generally studied without directly linking this to the protein's biological function. A biomarker for protein function is the bacteriostatic capacity, which should be based on a wide range of bacteria that can grow in milk and are known to be sensitive to antibacterial proteins. A detailed study about how heat treatment affects both protein denaturation and the bacteriostatic capacity of bovine milk in a temperature range under $100{ }^{\circ} \mathrm{C}$ would thus be useful, because previous studies showed that in this temperature range part of the antibacterial proteins may survive the heat treatment. Therefore, the aim of this study was to investigate the effect of such heat treatments on denaturation of a wide range of immune-active milk protein, and the bacteriostatic capacity of milk, to provide evidence for the relation between the denaturation and bioactivity of these milk proteins.

\subsection{M aterial and methods}

The experimental approach of this study is depicted in Fig. 4-1.

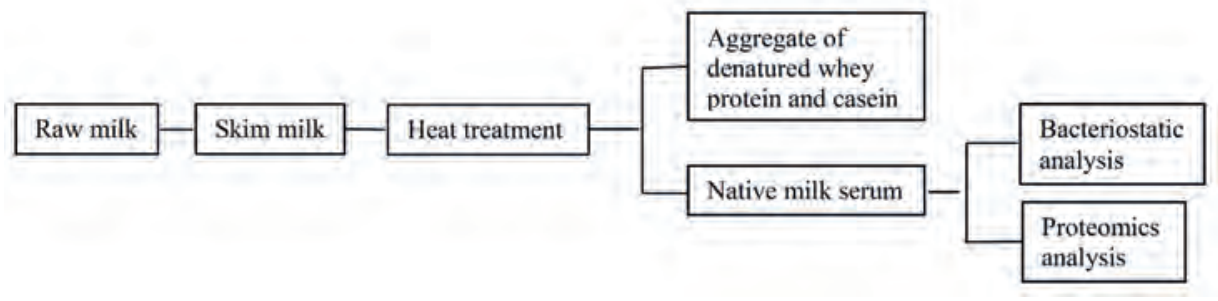

Figure 4-1 The flow chart of the general procedures of the research.

\subsubsection{Material}

Bovine raw tank milk was obtained from Wageningen University farm (Wageningen, Netherlands) from clinically healthy cows.

\subsubsection{Methods}

\subsubsection{Heat treatment}

Raw milk was centrifuged at $1500 \times \mathrm{g}$ for 20 minutes at $4{ }^{\circ} \mathrm{C}$ (with rotor 16.250 , Avanti Centrifuge J-26 XP, Beckman Coulter, USA) to remove the fat. After centrifugation, skimmed milk samples were heated. For this, $50 \mathrm{ml}$ raw milk samples were poured into centrifuge tubes and heated for $30 \mathrm{~min}$ in a water bath at $65^{\circ} \mathrm{C}, 70{ }^{\circ} \mathrm{C}, 75^{\circ} \mathrm{C}, 80{ }^{\circ} \mathrm{C}$ and $85{ }^{\circ} \mathrm{C}$ in triplicate. After heat treatment, samples were immediately cooled to room temperature for further analysis. 


\subsubsection{Whey preparation}

After heat treatment, the milk samples were immediately cooled to room temperature. Casein and denatured proteins was removed according to a previous paper (Law \& Leaver, 2000), all skimmed milk samples were acidified by drop-wise addition of $1 \mathrm{M} \mathrm{HCl}$ under stirring, until a $\mathrm{pH}$ of 4.6 was reached. The samples were then kept at $4{ }^{\circ} \mathrm{C}$ for $30 \mathrm{~min}$ to equilibrate. The acidified skim milk was ultracentrifuged at $100,000 \times \mathrm{g}$ for $90 \mathrm{~min}$ at $30^{\circ} \mathrm{C}$ (with rotor $70 \mathrm{Ti}$, Beckman L-60, Beckman Coulter, USA). After ultracentrifugation, samples were separated into three phases. The top layer was milk fat, the middle layer was whey with the native milk proteins, and the bottom layer (pellet) was micellar casein with the denatured whey proteins.

\subsubsection{SDS-polyacrylamide gel electrophoresis}

The Protein content of the whey was determined by Milkoscan (FT120, FOSS, Hillerød, Denmark), as previous paper (Somers, Guinee, \& Kelly, 2002). Whey was diluted 5-fold with distilled water. Two microliter of each protein sample was heated at $70^{\circ} \mathrm{C}$ for 10 minutes with $5 \mu \mathrm{L} 4 \mathrm{X}$ concentrated LDS sample buffer (NP0007, Thermo Fisher Scientific, Massachusetts, USA), $2 \mu \mathrm{L}$ 10X concentrated Sample reducing agent (NP0009, Thermo Fisher Scientific, Massachusetts, USA) and $13 \mu \mathrm{L}$ of water. Ten microliter of each protein sample was loaded onto a 10\% Bis-Tris gel (NP0301BOX, Thermo Fisher Scientific, Massachusetts, USA). A prestained protein ladder (26616, Thermo Fisher Scientific, Massachusetts, USA), ranging from $10 \mathrm{kDa}$ to $180 \mathrm{kDa}$, was used to monitor the progress of SDS-polyacrylamide gel electrophoresis. The gel was run in MES buffer (NP0002, Thermo Fisher Scientific, Massachusetts, USA) at $120 \mathrm{~V}$ for approximately 120 minutes at room temperature (XCell SureLock Mini-Cell, Thermo Fisher Scientific, Massachusetts, USA). The gel was stained with Coomassie Brilliant Blue R-250 (1610436, Biorad, California, USA) for one hour and then destained for four hours with washing buffer $(10 \%(\mathrm{v} / \mathrm{v})$ ethanol and $7.5 \%(\mathrm{v} / \mathrm{v})$ acetic acid) while mildly shaking at room temperature.

\subsubsection{Proteomics analysis}

The FASP (Filter Aided Sample Preparation) method was carried out according to previous articles (Hettinga et al., 2011; Lu et al., 2011; Wiśniewski, Zougman, Nagaraj, \& Mann, 2009). Whey samples $(20 \mu \mathrm{L})$ were diluted in SDT-lysis buffer $(100 \mathrm{mM}$ Tris/ $\mathrm{HCl} \mathrm{pH} 8.0+4 \%$ SDS $+0.1 \mathrm{M}$ dithiothreitol) to reach a protein content of approximately $1 \mu \mathrm{g} / \mu \mathrm{L}$. Samples were then incubated for $10 \mathrm{~min}$ at $95^{\circ} \mathrm{C}$. They were centrifuged at $13524 \times \mathrm{g}$ for $10 \mathrm{~min}$ after being cooled 
E ect of heat treatment on bacteriostatic activity and protein pr le of bovine whey proteins

down to room temperature (Eppendorf 5424, Eppendorf, Hamburg, Germany). Then, $20 \mu \mathrm{L}$ of sample in SDT was directly added to the middle of $180 \mu \mathrm{L} 0.05 \mathrm{M}$ IAA (Iodoacetamide)/UT (100 mM Tris/ $\mathrm{HCl} \mathrm{pH} 8.0+8 \mathrm{M}$ urea) in a low binding Eppendorf tube and incubated for 10 min while mildly shaking at room temperature. The sample $(100 \mu \mathrm{L})$ was transferred to a Pall 3K omega filter (10-20 kDa cutoff, OD003C34; Pall, Washington, NY, USA) and centrifuged at $13524 \times \mathrm{g}$ for $30 \mathrm{~min}$. Another three centrifugations at $13524 \times \mathrm{g}$ for $30 \mathrm{~min}$ were carried out after adding three times $100 \mu \mathrm{L} \mathrm{UT}$, respectively. After that, $110 \mu \mathrm{L} 0.05 \mathrm{M} \mathrm{ABC}(0.05 \mathrm{M}$ $\mathrm{NH}_{4} \mathrm{HCO}_{3}$ in water) was added to the filter unit and centrifuged at $13524 \times \mathrm{g}$ for $30 \mathrm{~min}$. The filter was transferred to a new low-binding Eppendorf tube. Then, $100 \mu \mathrm{L} \mathrm{ABC}$ containing 0.5 $\mu \mathrm{g}$ trypsin was added to the filter. After incubation for 2 hours at $45^{\circ} \mathrm{C}$, the tube with filter was centrifuged at $13524 \times \mathrm{g}$ for $30 \mathrm{~min}$. Finally, the filter was removed and $6 \mu \mathrm{L} 10 \%$ trifluoroacetic acid (TFA) was added to adjust the $\mathrm{pH}$ of the sample to around 2 . These samples were ready for LC-MS/MS.

The LC-MS/MS parameters are the same as described previously (Zhang et al., 2015a, 2015b). First, $18 \mu \mathrm{L}$ of the trypsin-digested whey protein fractions was injected on a $0.10 * 30 \mathrm{~mm}$ Magic C18AQ 200A $5 \mu$ m beads (Michrom Bioresources Inc., USA) pre-concentration column (prepared in house) at a maximum pressure of 800 bar. Peptides were eluted from the preconcentration column onto a $0.10 * 200 \mathrm{~mm}$ ReproSil-Pur 120 C18-AQ $1.9 \mu \mathrm{m}$ beads analytical column with an acetonitrile gradient at a flow of $0.5 \mu \mathrm{L} / \mathrm{min}$, using gradient elution from $8 \%$ to $33 \%$ acetonitrile in water with $0.5 \mathrm{v} / \mathrm{v} \%$ acetic acid in $50 \mathrm{~min}$. The column was washed using an increase in the percentage acetonitrile to $80 \%$ (with $20 \%$ water and $0.5 \mathrm{v} / \mathrm{v} \%$ acetic acid in the acetonitrile and water) in $3 \mathrm{~min}$. Between the pre-concentration and analytical column, an electrospray potential of $3.5 \mathrm{kV}$ was applied directly to the eluent a stainless steel needle fitted into the waste line of the micro cross. Full scan positive mode FTMS spectra were measured between m/z 380 and 1400 on an LTQ-Orbitrap XL (Thermo Electron, San Jose, CA, USA). CID-fragmented MSMS scans of the four most abundant doubly- and triply-charged peaks in the FTMS scan were recorded in data-dependent mode in the linear trap (MSMS threshold $=5.000$ ).

\subsubsection{Bacteriostatic properties analysis}

Streptococcus thermophilus (C106 strain, CSK Food Enrichment culture collection, Ede, Netherlands), Escherichia coli K12 (DSM 498, DSMZ, Braunschweig, Germany), Lactococcus lactis ssp. lactis (DSM 20481, DSMZ, Braunschweig, Germany), and Pseudomonas 
fluorescens (DSM 50900, DSMZ, Braunschweig, Germany) were activated in nutrient broth from frozen stock for $24-48$ hours at their optimum temperature (Streptococcus thermophilus, $45^{\circ} \mathrm{C}$; Escherichia coli, $37^{\circ} \mathrm{C}$; Lactococcus lactis ssp. lactis, $30^{\circ} \mathrm{C}$; Pseudomonas fluorescens, $30{ }^{\circ} \mathrm{C}$ ). The suspensions of these four strains were stored at $4{ }^{\circ} \mathrm{C}$ and reactivated before inoculation. Reactivated bacterial strains were centrifuged for $5 \mathrm{~min}$ at 12,000 $\times \mathrm{g}$ (with Rotor FA-45-30-11, Microcentrifuge 5430R, Eppendorf, Hamburg, Germany) after which the bacterial pellets were dissolved in PFZ (peptone physiological salt solution; Tritium Microbiology, The Netherlands). After the optical density (OD) had been measured with a spectrophotometer (Cary 50 UV-Visible Spectrophotometer, Agilent Technologies, USA), dilutions of bacteria were made with PFZ for inoculation.

All whey samples were micro-filtrated by $\mathrm{RC}$ membrane $(\varnothing 0.45 \mu \mathrm{m}$ with $26 \mathrm{~mm}$ syringe filters; Phenex) to eliminate bacteria in the starting material $(<10 \mathrm{CFU} / \mathrm{ml})$, and transferred into glass culture tubes. Bacteria were inoculated into the prepared whey samples at final bacterial concentration around $10^{2}$ to $10^{3} \mathrm{CFU} / \mathrm{ml}$, after which they were incubated at their optimum temperatures for 2 hours based on our preliminary study (Data not shown). One milliliter of the samples was taken out for plating on specific agar and then incubated overnight.

Only the plates with between 20 and 300 colonies were counted. If only one dilution had proper counts (between 20 and 300 colonies), $\mathrm{N}=\mathrm{n} * \mathrm{~d}$; If two dilutions for the same sample had proper counts, the calculation of the $\mathrm{CFU} / \mathrm{ml}$ was according to the following equation: $N=\frac{\sum C}{\left[\left(1 \times n_{1}\right)+\left(0.1 \times n_{2}\right) \times(d)\right.}$, where $\mathrm{N}=$ number of colonies per $\mathrm{ml}$ of product, $\Sigma \mathrm{C}=$ sum of all colonies on all plates counted, $\mathrm{n}_{1}=$ number of plates in lower dilution counted, $\mathrm{n}_{2}=$ number of plates in next higher dilution counted, $\mathrm{d}=$ dilution from which the first counts were obtained. This calculation was based on Bacteriological Analytical Manual (BAM) from the U.S. Food and Drug Administration (https://www.fda.gov/food/laboratory-methods-food/bam-aerobicplate-count\#conventional, accessed August 20, 2019)(Maturin \& Peeler, 2001)

\subsubsection{Assay of enzyme activity}

The LPO activity was measured by following the $\mathrm{H}_{2} \mathrm{O}_{2}$-dependent oxidation of pyrogallol at $420 \mathrm{~nm}$ (Chance \& Maehly, 1955). Briefly, $0.32 \mathrm{~mL}$ potassium phosphate buffer $(0.1 \mathrm{M}, \mathrm{pH}$ 6.0), $0.32 \mathrm{~mL} 5 \%$ pyrogallol and $0.16 \mathrm{ml} 0.5 \%$ hydrogen peroxide solution were mixed in a cuvette. The reaction was initiated by the addition of $0.1 \mathrm{ml}$ milk sample. Blank measurements were carried out with pyrogallol and milk sample only. The increase in absorbance at $420 \mathrm{~nm}$ 
E ect of heat treatment on bacteriostatic activity and protein $\mathrm{pr}$ le of bovine whey proteins

$(\Delta \mathrm{A} 420 \mathrm{~nm})$ for approximately 5 minutes was recorded. The $\Delta \mathrm{A} 420 \mathrm{~nm} / 20$ seconds was obtained using the maximum linear rate for both the test and blank. One unit will form 1.0 milligram of purpurogallin from pyrogallol in 20 seconds at $\mathrm{pH} 6.0$ at $20{ }^{\circ} \mathrm{C}$. All tests were performed in triplicate.

\subsubsection{Data analysis}

For proteomics, each run with all MSMS spectra obtained was analyzed with Maxquant 1.6.0.1 with the Andromeda search engine (Cox \& Mann, 2008). Carbamidomethylation of cysteines was set as a fixed modification. The digestion of enzyme was set as trypsin. Oxidation of methionine, $\mathrm{N}$-terminal acetylation and de-amidation of asparagine or glutamine were set as variable modifications for both identification and quantification. The bovine (taxonomy ID: 9913) reference database for peptide and protein searches was downloaded as fasta file from Uniprot with reverse sequences generated by Maxquant. All fasta files were downloaded from http://www.uniprot.org/ (accessed Dec 2013). A set of 31 protein sequences of common contaminants was used as well, which included Trypsin (P00760, bovine), Trypsin (P00761, porcine), Keratin K22E (P35908, human), Keratin K1C9 (P35527, human), Keratin K2C1 (P04264, human), and Keratin K1C1 (P35527, human). A maximum of two missed cleavages were allowed, and a mass deviation of $0.5 \mathrm{Da}$ for fragment MS/MS peaks and $20 \mathrm{ppm}$ and 4.5 ppm for the peptide MS peaks during the first and main search, respectively. The false discovery rate (FDR) was set to $1 \%$ on both peptide and protein level. The length of peptides was set to at least seven amino acids. Finally, proteins were identified based on minimally 2 distinct peptides of which at least one unique and at least one unmodified. The intensity based absolute quantification (iBAQ) algorithm calculates the sum of all peptide intensities divided by the number of theoretically observable tryptic peptides, which has been reported to have a good correlation with known absolute protein concentrations over at least four orders of magnitude (Schwanhäusser et al., 2011). The iBAQ values can thus be used as an indication for the absolute amount of proteins in the samples and was therefore used to show the quantitative effect of heating on the milk proteins.

Data analysis was performed using R 3.4.0. Packages "plyr" and "ggplot2" were used for multiple comparisons of means, and graphical representation of the data, respectively. $p<0.05$ was considered to indicate significant differences among groups. ANOVA, and Tukey's HSD for post-hoc testing, were used to identify which treatments were significantly different. 
Correlation analysis was performed by calculating Pearson correlations. Data were presented as mean \pm standard deviation of three independent experiments.

\subsection{Results and discussion}

\subsubsection{Bacterial growth rate in differentially heated whey}

Bacteriostatic capacity of whey isolated from heat treated milk was determined with four different bacteria. We observed that the growth rate of bacteria in whey increased with the heating intensity (Fig. 4-2). Unheated whey had the lowest growth rate, while whey heated at $85^{\circ} \mathrm{C}$ showed the highest growth rate. For heat treated samples, whey heated at $65^{\circ} \mathrm{C}$ and $70{ }^{\circ} \mathrm{C}$ showed a lower growth rate for Streptococcus thermophilus, Lactococcus lactis, and Pseudomonas fluorescens than milk samples heated at $\geq 75{ }^{\circ} \mathrm{C}(p<0.05)$ (Fig. 4-2). No significant change was observed in growth rate of Escherichia coli among differently heat treated whey samples, although all were higher than unheated whey samples (Fig. 4-2). In general, bacteriostatic capacity of whey decreased after heat treatment, and decreased in the order: unheated whey $>$ whey heated at $65{ }^{\circ} \mathrm{C}$ and $70{ }^{\circ} \mathrm{C}>$ whey heated at $75{ }^{\circ} \mathrm{C}, 80{ }^{\circ} \mathrm{C}$, and $85^{\circ} \mathrm{C}$.

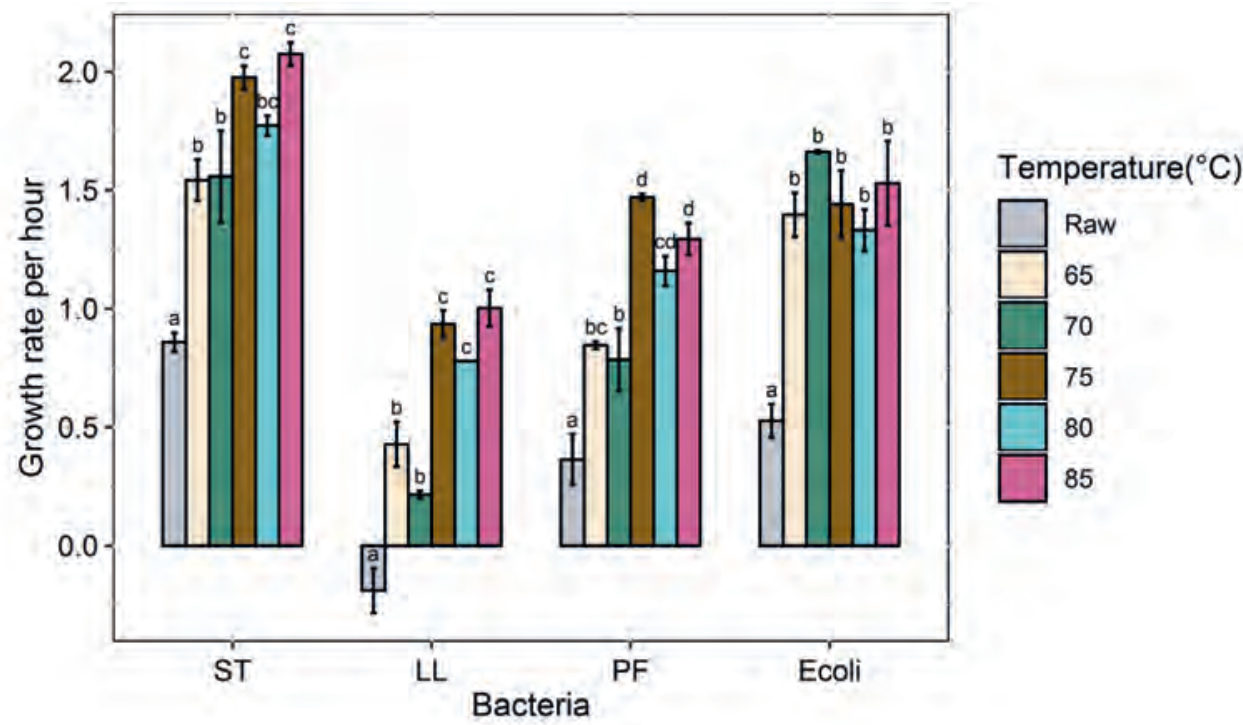

Figure 4-2 G rowth rate per hour of Streptococaus themophilus (ST ), Lactococaus lactis (L L ), Pseudomonas fluorescens (PF) and Escherichia coli (E coli) in milk serum after different heat treatment. Values are expressed as means \pm SD. Statistical significance was analyzed using ANOVA. M eans followed by the same letter are not significantly different $(p>0.05)$. Different letters indicate statistically significant difference among different heat treatments $(p<0.05)$ based on Tukey's HSD test. Raw, 65-85 reflect the data from raw skim milk or skim milk heated at the temperatures mentioned for 30min. 
E ect of heat treatment on bacteriostatic activity and protein $\mathrm{pr}$ le of bovine whey proteins

Milk contains a variety of antimicrobial components, especially proteins, that are sensitive to heat treatment, and that may thus be related to this decreased bacteriostatic capacity. The unheated sample was considered as the reference, with the highest bacteriostatic capacity, as no protein denaturation had occurred. As a result, bacteria are expected to have the lowest growth rate in the unheated sample. In contrast, higher bacterial growth rates are expected to appear at more intensively heat treated samples, as was found for most bacteria (Fig. 4-2). However, a difference was found among the different bacterial species. Our study showed that unheated whey showed the decreased growth rate of Lactococcus lactis, Streptococcus thermophilus and Pseudomonas fluorescens compared with heat treated milk samples. This indicates that the antimicrobial milk proteins are bacteriostatic to both gram-positive and gram-negative bacteria. As with the other three bacteria, we found that unheated whey has the lowest growth rate of Escherichia coli compared with heat treated milk samples. However, no differences were observed among differently heat treated whey samples with regards to the growth rate of Escherichia coli. This may be contributed to resistance of Escherichia coli to antimicrobial components in milk, such as lactoferrin. For example, Escherichia coli 0126 was observed to be more resistant to the bactericidal action of human lactoferrin than Vibrio cholerae and Streptococcus mutans, due to its synthesis of enterochelin (Arnold \& Cole, 1977). Different response to lactoferrin in strains of Escherichia coli was reported by Tomita's and Branen's studies, which observed different inhibitory concentration of lactoferrin hydrolysate on Escherichia coli O111 and Escherichia coli O157:H7 (Branen \& Davidson, 2000; Tomita et al., 1991). Another explanation may be specific low abundant heat sensitive components to which different bacteria may be sensitive.

\subsubsection{Serum protein content in differently heated whey}

After heat treatment, denatured whey protein precipitated with casein during acidification and these were subsequently removed with ultracentrifugation. The whey samples thus only contained the native whey proteins. Total protein concentration in these native whey samples are shown in Fig. 4-3. This figure shows that the total native whey protein content gradually decreased with increasing heating intensity, as expected. 


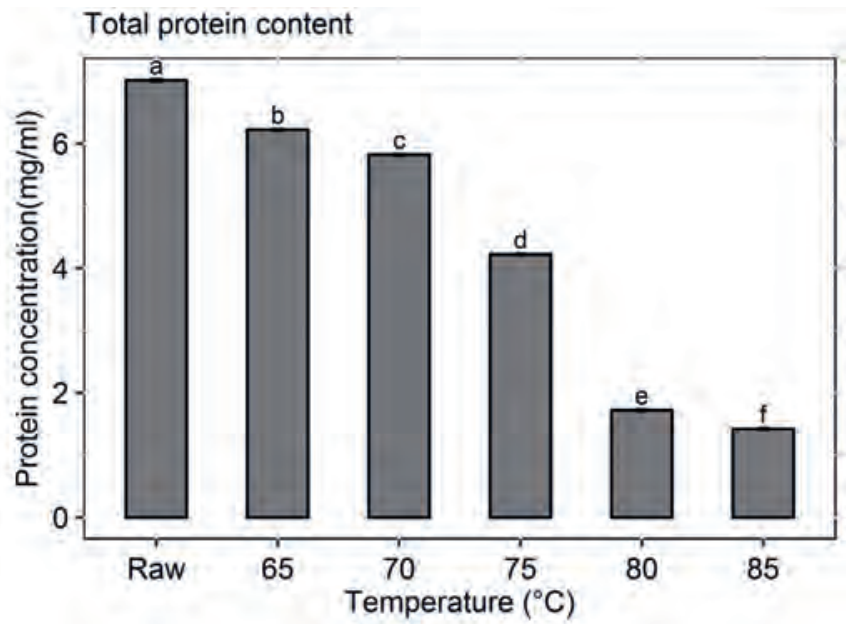

Figure 4-3 T otal protein concentration $(\mathrm{mg} / \mathrm{ml})$ in native milk serum after different heat treatments using MilkoScan. Values are expressed as means \pm SD. Statistical significance was analyzed using ANOVA. M eans followed by the same letter are not significantly different $(p>0.05$ ). Different letters indicate statistically significant difference among different heat treatments ( $p<0.05$ ) based on T ukey's HSD test. R aw, 65-85 reflect the data from raw skim milk or skim milk heated at the temperatures mentioned for $30 \mathrm{~min}$.

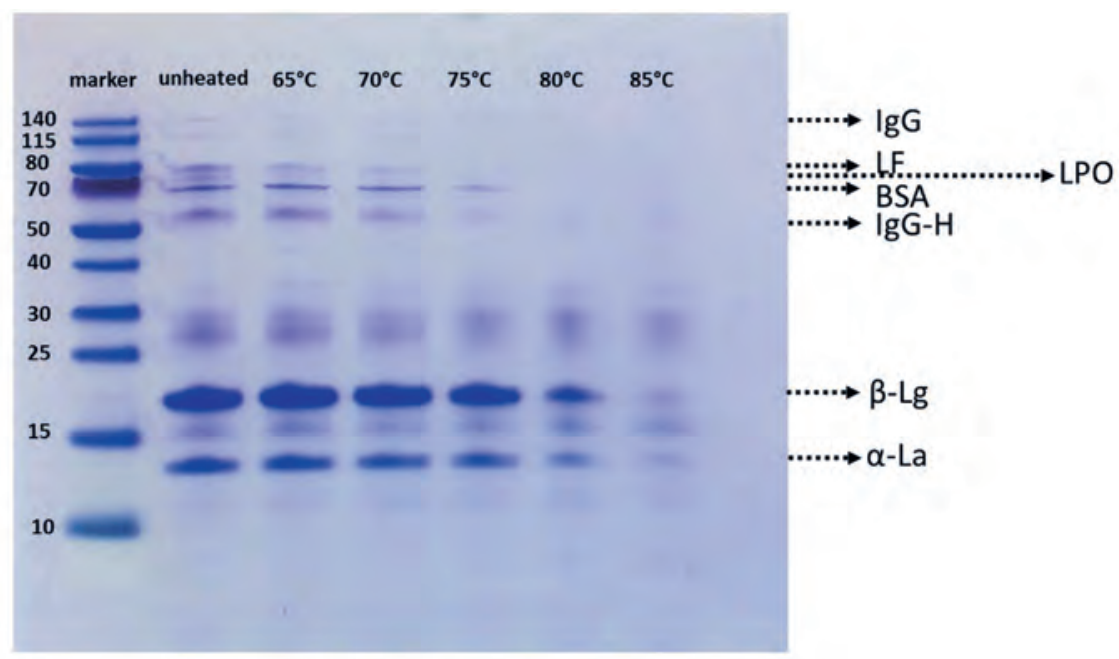

Figure 4-4 SDS-PAGE gel of different heat treated milk serum samples, with the main proteins that can be identified on the gel indicated. Raw, 65-85 reflect the data from raw skim milk or skim milk heated at the temperatures mentioned for 30min. A bbreviations: IgG , immunoglobulin G; LF, lactoferrin; L PO, lactoper oxidase; BSA, bovine serum albumin; IgG-H, immunoglobulin G heavy chain; $\beta$-Lg, $\beta$-lactoglobulin; $\alpha$-La, $\alpha$-lactalbumin.

To confirm which proteins were denatured after heat treatment, we performed an SDS-PAGE analysis to visualize the changes in the whey protein profile (Fig. 4-4). All sample for SDSPAGE were prepared in the same way to guarantee the protein changes only caused by heat 
treatment. Both abundance and variety of native whey proteins decreased with increasing heating intensities. The data of total protein content and SDS-PAGE (Figs. 4-3 \& 4-4) show that the decrease of total protein content is associated with denaturation of several individual whey proteins after heating at different intensities. Protein content of whey heated at $65^{\circ} \mathrm{C} / 30$ min already showed a significantly decreased total native protein content compared with unheated whey $(p<0.05)$. This decrease may be caused by the denaturation of lactoferrin and disappearance of lactoperoxidase, as visible on the SDS-PAGE (Fig. 4-4). Whey treated at $70{ }^{\circ} \mathrm{C} / 30$ min showed a further decrease in total protein content, which could be explained by a further decrease of lactoferrin. Total protein content of whey heated at $75{ }^{\circ} \mathrm{C} / 30 \mathrm{~min}$ showed an even bigger decrease due to disappearance of lactoferrin and immunoglobulin, in addition to a decrease of bovine serum albumin, $\alpha$-lactalbumin and $\beta$-lactoglobulin. Whey heated at $80{ }^{\circ} \mathrm{C} /$ $30 \mathrm{~min}$ and $85{ }^{\circ} \mathrm{C} / 30 \mathrm{~min}$ showed the disappearance of the earlier mentioned low abundant proteins combined with a significant decrease of $\alpha$-lactalbumin and $\beta$-lactoglobulin, the two major whey proteins present in bovine milk, which also explains the large drop in total native protein content between $75{ }^{\circ} \mathrm{C}$ and $80{ }^{\circ} \mathrm{C}$ (Fig. 4-3). The result was consistent with the proteomic result for $\beta$-lactoglobulin, $\alpha$-lactalbumin and bovine serum albumin (Supplementary Fig. 4-1). Another study also showed that significant physicochemical and structural changes of milks proteins occurred after bovine milk was heated at $80{ }^{\circ} \mathrm{C}$ for $60 \mathrm{~min}$, mainly characterized by the disappearance of native $\alpha$-lactalbumin and $\beta$-lactoglobulin (Felfoul et al., 2017). From the SDS-PAGE gel, the temperature at which denaturation of proteins started was: lactoperoxidase $<$ lactoferrin $<$ immunoglobulin $<$ bovine serum albumin $<\alpha$ lactalbumin, $\beta$-lactoglobulin. The change of these major proteins after different thermal treatments is generally in accordance with a previous study, which indicated that the sensitivity to heat denaturation decreases in the order: Ig $>$ BSA, $\beta-\mathrm{LG}>\alpha$ - LA (Larson \& Rolleri, 1955). 
4.3.3 Protein profile, antibacterial proteins content, and lactoperoxidase activity in differentially heated whey
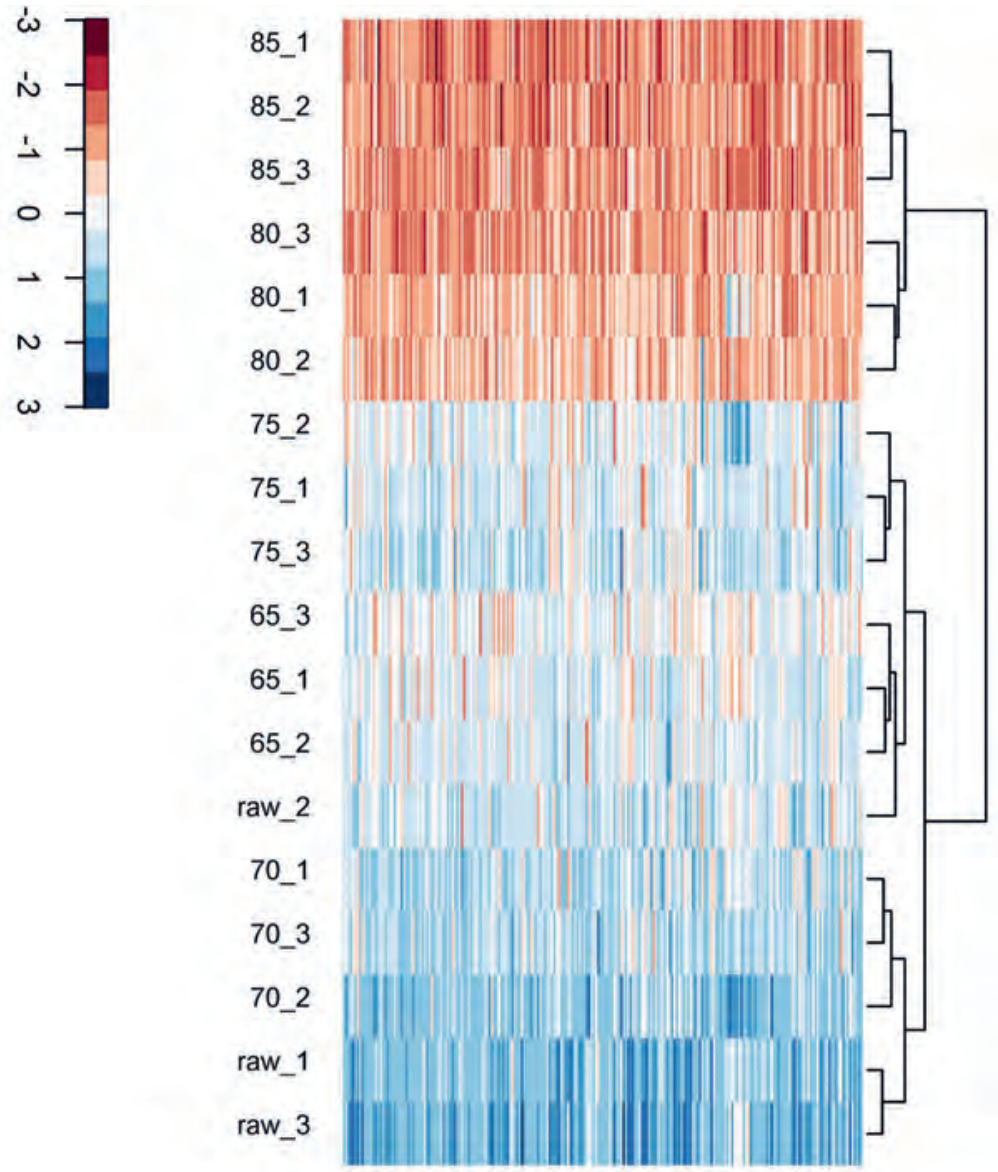

Figure 4-5 Protein profile of differentially heated milk serum samples. R ows reflect individual samples. The number indicates the heating temperature, while the number after the underscore indicates the replicate. Individual proteins are given in columns. $Z$ score normalized heat map of the iBAQ values. Hierarchical clustering was performed using complete agglomeration method and a Euclidean distance metric. The color scale means the iBAQ value standard deviations from the mean, with red for low values and blue for the high values. Raw, 65-85 reflect the data from raw skim milk or skim milk heated at the temperatures mentioned for $30 \mathrm{~min}$.

Proteomic analysis of the native whey proteins after different heat treatments allowed detection of many proteins, including the main antibacterial proteins discussed in section 4.3.2. A total of 246 proteins could be identified and quantified in the sample. In the whey preparation, denatured proteins were removed together with casein by acid precipitation, so only the native protein remained in the whey for detection by LC-MS/MS. The protein level detected thus reflects the level of native protein in the heated milk samples. The number of identified proteins 
after the different heat treatments decreased from 228 proteins at $65^{\circ} \mathrm{C}$ to 86 proteins at $85^{\circ} \mathrm{C}$. To visualize the protein profile of these samples, a clustered heat map based on iBAQ value of proteins was prepared that showed the overall protein profile in all samples (Fig. 4-5). These samples with similar protein pattern would be classified into one cluster and the distance between samples indicates the difference in protein pattern. It was found that milk samples heated at $80{ }^{\circ} \mathrm{C}$ formed a cluster with samples heated at $85{ }^{\circ} \mathrm{C}$, indicating a similar protein profile in those samples. This cluster was different from the cluster that consisted of the samples heated at $75{ }^{\circ} \mathrm{C}$ and lower temperatures, suggesting a clear distinction between samples heated at $\leq 75{ }^{\circ} \mathrm{C}$ and $>75{ }^{\circ} \mathrm{C}$. Noticeably, in the cluster of $\leqslant 75{ }^{\circ} \mathrm{C}$ heated samples, $75^{\circ} \mathrm{C}$ heated samples are nearer to the $80{ }^{\circ} \mathrm{C}$ and $85^{\circ} \mathrm{C}$ heated samples, which showed some proteins may already change from $75{ }^{\circ} \mathrm{C}$. This result corresponded to an existing proteomic study, in which protein patterns in raw, skimmed and pasteurized milk differed from that in ultra-high heat treated, extended shelf life milk, and boiled milk (Brick et al., 2017).These change may be correlated with the decrease of bacteriostatic activity of milk as will be discussed further in section 4.3.4. 
A

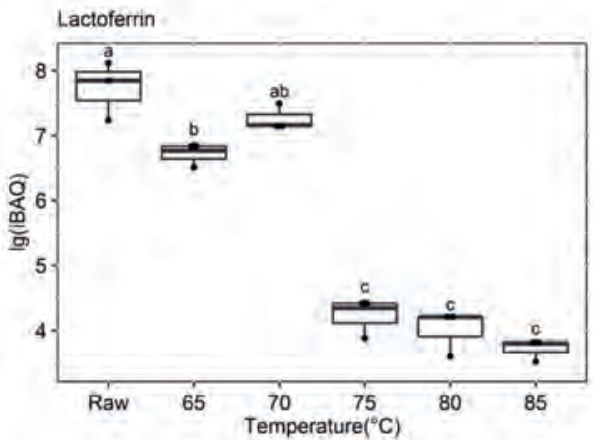

C

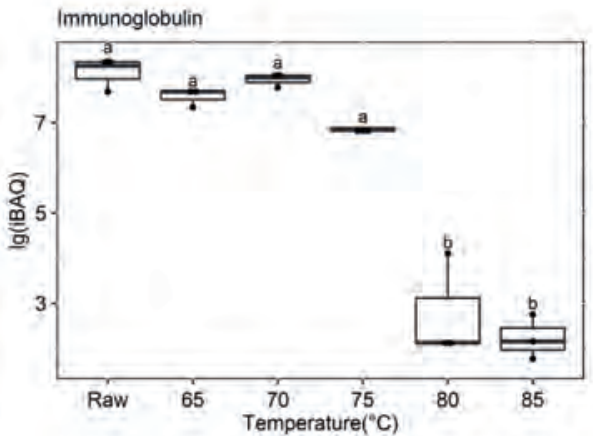

B.

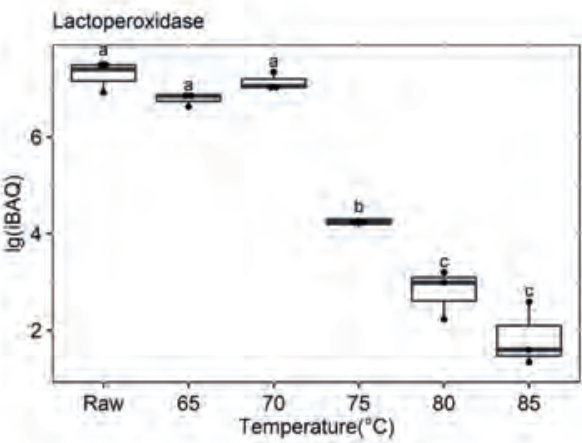

D

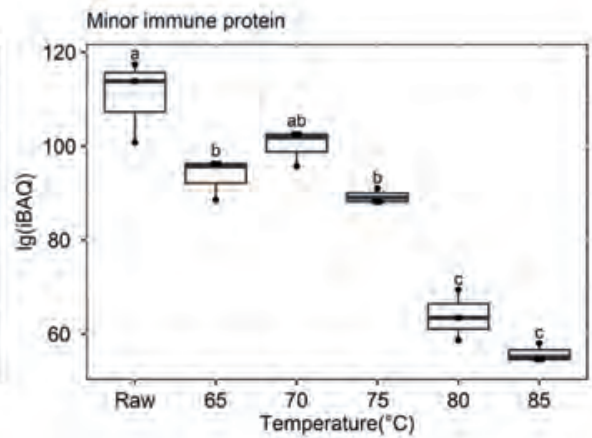

Figure 4-6 E ffect of different heat treatment on lactoferrin (A), lactoperoxidase (B), immunoglobulin (C) and minor immune proteins (D). Values are expressed as means \pm SD. Statistical significance was analyzed using ANOVA. M eans followed by the same letter are not significantly different $(p>0.05)$. Different letters indicate statistically significant difference among different heat treatments $(p<0.05)$ based on Tukey's HSD test. M inor immune protein (except lactoferrin, lactoperoxidase and immunoglobulin) reflect all detected protein related to immunity including immune response, complement, antibacterial, host defense, acute phase, and antigen binding. R aw, 65-85 reflect the data from raw skim milk or skim milk heated at the temperatures mentioned for $\mathbf{3 0 ~} \mathbf{m i n}$.

Gene ontology enrichment of genes of identified proteins was performed using The Database for Annotation, Visualization and Integrated Discovery (DAVID) v6.8 (https://david.ncifcrf.gov/home.jsp) (Huang, Sherman, \& Lempicki, 2009), with functional categories of identified proteins being shown in Supplementary table 4-1. Changes in proteins related to antimicrobial and immunity were shown in more detail in Figure 4-6 and Supplementary table 4-2. Considering that the bacteriostatic properties of whey have been attributed to the presence of specific antibacterial proteins, the level of these main antibacterial proteins, lactoferrin, lactoperoxidase, and immunoglobulin, were compared according to their iBAQ value (Fig. 4-6A-C). After heat treatment, significant decreases were found in all these major antibacterial proteins. Differences were especially found between milk samples heated 
E ect of heat treatment on bacteriostatic activity and protein pr le of bovine whey proteins

at $<75{ }^{\circ} \mathrm{C}$ and milk samples heated at $\geq 75{ }^{\circ} \mathrm{C}$. Unheated whey and whey heated at $65{ }^{\circ} \mathrm{C}$ and $70{ }^{\circ} \mathrm{C}$ showed no significant differences in lactoferrin, lactoperoxidase and immunoglobulin. Retention of lactoferrin in unheated whey, whey heated at $65^{\circ} \mathrm{C}$ and $70{ }^{\circ} \mathrm{C}$ showed a significant difference from that in whey heated at $75{ }^{\circ} \mathrm{C}, 80^{\circ} \mathrm{C}$ and $85^{\circ} \mathrm{C}(\mathrm{p}<0.05$; Fig. 4-6A), whereas no significant difference was observed among whey heated at $75^{\circ} \mathrm{C}, 80^{\circ} \mathrm{C}$ and $85^{\circ} \mathrm{C}$. This result is consistent with an earlier study that showed that $90 \%$ of lactoferrin was denatured after heating at $72{ }^{\circ} \mathrm{C}$ for $1300 \mathrm{~s}$ (apolactoferrin) and $4500 \mathrm{~s}$ (hololactoferrin) (Sánchez et al., 1992), and another study reported that more lactoferrin in milk denatured when it was heated above $65{ }^{\circ} \mathrm{C}$ for 30 min compared with milk heated below $65^{\circ} \mathrm{C}$ (Kulmyrzaev, Levieux, \& Dufour, 2005). In a radial immunodiffusion assay, lactoferrin remained active after a $65^{\circ} \mathrm{C} / 30 \mathrm{~min}$ treatment, but significantly lost its activity after a $75{ }^{\circ} \mathrm{C} / 30 \mathrm{~min}$ treatment (Elagamy, 2000). Combining our findings and previous data, $65-75{ }^{\circ} \mathrm{C}$ may be a key temperature range for denaturation of lactoferrin if heating for prolonged times (30 min). Similarly, there was a significant difference in retention of lactoperoxidase between milk samples heated at $<75{ }^{\circ} \mathrm{C}$ and milk samples heated at $\geq 75^{\circ} \mathrm{C}$, but lactoperoxidase more gradually decreased with increasing temperatures above $75^{\circ} \mathrm{C}$ (F ig. 4-6B). Our finding is similar to previous study which reported D-values for denaturation of lactoperoxidase decreased rapidly in the temperature range $70-76{ }^{\circ} \mathrm{C}$ (Marin, Sanchez, Perez, Puyol, \& Calvo, 2003). Like for lactoferrin and lactoperoxidase, retention of immunoglobulin in whey heated below $75{ }^{\circ} \mathrm{C}$ was significantly higher than that in whey heated at $>75^{\circ} \mathrm{C}$. The immunoglobulin concentration in whey heated at $75{ }^{\circ} \mathrm{C}$ was significantly higher than in samples heated at $80{ }^{\circ} \mathrm{C}$ and $85^{\circ} \mathrm{C}$, but still slightly lower than samples heated $<75{ }^{\circ} \mathrm{C}$. Our result showed that denaturation of immunoglobulin occurred mainly between $75{ }^{\circ} \mathrm{C}$ and $80{ }^{\circ} \mathrm{C}$. It was reported that $90 \%$ of immunoglobulin was denatured when it was heated at $72{ }^{\circ} \mathrm{C}$ for 3490 seconds (Mainer, Sanchez, Ena, \& Calvo, 1997), and a later study reported that IgG showed significant loss of activity after a $65{ }^{\circ} \mathrm{C} / 30$ min heat treatment, as determined by immunodiffusion assay (Elagamy, 2000). Lower D values for IgG were shown in Chen's study (Chen, Tu, \& Chang, 2000), with 200 seconds in PBS and 234 seconds when heated at $70{ }^{\circ} \mathrm{C}$, which is different from our study. This difference may be caused by different media in which $\operatorname{IgG}$ was treated. According to both the proteomics data and the SDS-PAGE result, the heat sensitivity of the main antibacterial proteins is in the order LPO, LF $>$ IG.

Besides these three main immunological proteins, the summed BAA values of all minor immune-related proteins (including immune response, complement, antibacterial, host defense, 
acute phase, and antigen binding) were compared among different heat treated milk samples (Fig. 4-6D). These proteins involved in immune response, complement, antibacterial, host defense, acute phase, and antigen binding biological process were selected according to the information provided by DAVID and Uniprot (https://www.uniprot.org/). Minor immuneactive proteins, e.g. complement components and cathelicidins, may also play an important role in the bacteriostatic effects of milk (Chen et al., 2005; Gordon et al., 2005). Fig. 4-6D shows a significant decrease in all minor immune-active proteins after heat treatment compared with unheated whey, with a significant difference between whey heated at $\leq 75^{\circ} \mathrm{C}$ and whey heated at $80^{\circ} \mathrm{C}, 85^{\circ} \mathrm{C}$. Detailed information about these minor protein are shown in Supplementary table 4-2. The level of low abundant immune-active proteins showed a slight decrease after heating at $65-75^{\circ} \mathrm{C}$ for $30 \mathrm{~min}$, which be contributed to monocyte differentiation antigen CD14, complement component $\mathrm{C} 7$, alpha-1-acid glycoprotein, and peptidoglycan recognition protein 1. This result coincides with other recent milk proteomic studies. For example, it was previously reported that proteins related to immunity showed only a slight decrease after pasteurization $\left(62-63{ }^{\circ} \mathrm{C} / 30 \mathrm{~min}\right.$ ) (Zhang, Boeren, et al., 2016), whereas another study showed that lactadherin, chitinase-3-like protein 1, and complement component C9 in colostrum decreased at least 2fold after heating at $60^{\circ} \mathrm{C}$ for 30,60 and $90 \mathrm{~min}$ (Tacoma et al., 2017) . Upon applying heating at a higher temperature $\left(80^{\circ} \mathrm{C} / 60 \mathrm{~min}\right)$, it was shown that peptidoglycan recognition protein in camel milk strongly decreased (Felfoul et al., 2017). Compared with these previous studies, we show a more detailed overview of the influence of small temperature changes within the pasteurisation temperature range on the native protein profile of bovine milk.

The low abundant immune-active proteins showed a gradual decrease during the whole heat treatment, with denaturation starting at $65^{\circ} \mathrm{C}$ and showing a more steep increase in denaturation above $75^{\circ} \mathrm{C}$, except cathelicidins that showed a high stability even after heat treatment at $80^{\circ} \mathrm{C}$.

Due to the fact that lactoperoxidase exerts its antibacterial activity by catalysing the peroxidation of thiocyanate and some halides, we determined the lactoperoxidase activity in whey after heat treatment (Fig. 4-7). No significant difference was observed for lactoperoxidase activity between unheated and $65{ }^{\circ} \mathrm{C}$ heated milk. Lactoperoxidase activity significantly decreased in milk heated at $70{ }^{\circ} \mathrm{C}$ compared with raw milk and milk heated at $65{ }^{\circ} \mathrm{C}$, and lost almost all its activity when heated at $75{ }^{\circ} \mathrm{C}$ and above. The proteomics data (Fig. 4-6B) shows no significant decrease for lactoperoxidase between raw milk and milk heated at $70{ }^{\circ} \mathrm{C}$, whereas lactoperoxidase activity showed a significant decrease (Fig. 4-7), indicating that 
lactoperoxidase already started to lose its catalytic activity when it was not completely denatured yet.

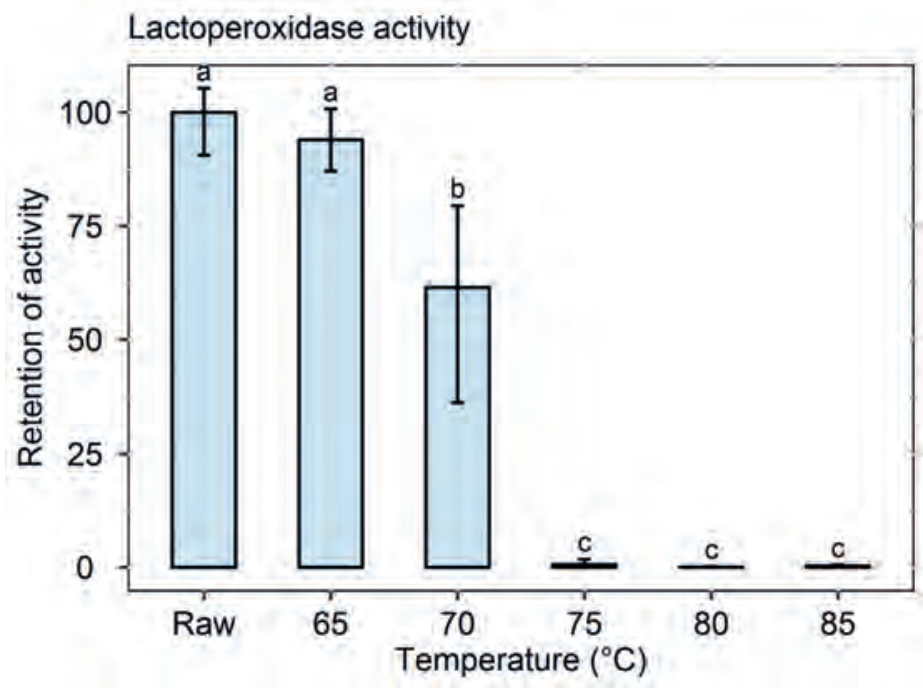

Figure 4-7 $\mathrm{L}$ actoperoxidase activity in native milk serum after different heat treatments. The activity of lactoper oxidase was shown relative to raw milk. The activity of lactoperoxidase was set as $100 \%$. Values are expressed as means \pm SD. Statistical significance was analyzed using ANOVA. M eans followed by the same letter are not significantly different $(p>0.05)$. Different letters indicate statistically significant difference among different heat treatments $(p<0.05)$ based on Tukey's HSD test. Raw, 65-85 reflect the data from raw skim milk or skim milk heated at the temperatures mentioned for $30 \mathrm{~min}$.

\subsubsection{Relationship between antibacterial protein retention and bacteriostatic capacity}

Considering that the growth rate of the four bacteria increased, and the three major antibacterial proteins decreased, with intensity of heat treatment, a negative correlation can be expected between bacterial growth rate and retention of native proteins. To confirm the existence of such a relationship, we determined the correlation coefficients between the $\mathrm{BBAQ}$ values of these three proteins, minor immune-active protein, total immune-active protein, and the bacterial growth rates (Fig. 4-8). This figure shows that levels of lactoferrin was strongly correlated with the growth rates of Streptococcus thermophilus $(r=-0.86, p<0.05)$, Lactococcus lactis $(r=-$ 0.92, $p<0.05)$ and Pseudomonas fluorescens $(r=-0.91, p<0.05)$, and the level of lactoperoxidase was strongly correlated with the growth rates of Lactococcus lactis $(r=-0.83$, $p<0.05$ ), while no significant relationship was found between either of the three proteins, or the two proteins groups, and Escherichia coli. 


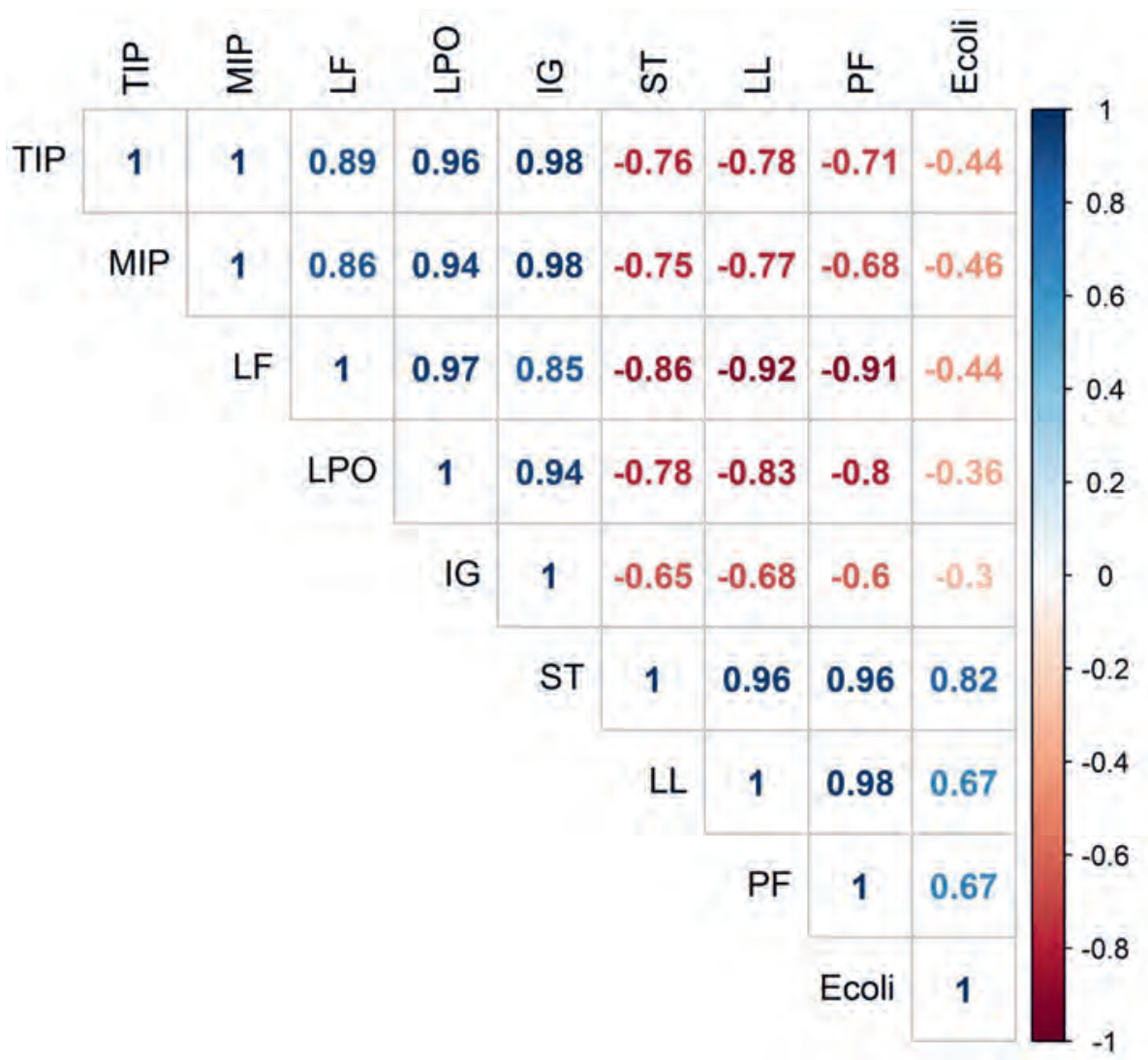

Figure 4-8 Correlation matrix of bacterial growth rates and iBAQ values of native antibacterial proteins. A bbreviation: TIP, total immune protein; MIP, minor immune protein; LF, lactoferrin; L PO,lactoperoxidase; IG, immunoglobulin; ST, Streptococaus themophilus, L L, Lactococaus lactis, PF, Pseudomonas fluorescens, E coli, Escherichia coli.

Lactoferrin was reported to significantly inhibit growth of Pseudomonas fluorescens in different media (Caputo et al., 2015; Del Olmo, Calzada, \& Nunez, 2010; del Olmo, Morales, \& Nunez, 2009; Harouna et al., 2015; Kim, Rahman, \& Shimazaki, 2008). We found that there is a significant difference in content of native lactoferrin between whey heated $<75^{\circ} \mathrm{C}$ and $\geqslant$ $75^{\circ} \mathrm{C}$ (Fig. 4-6A), which is consistent with the effect of these treatments on the growth rate of Pseudomonas fluorescens. The strong correlation between native lactoferrin and Pseudomonas fluorescens $(r=-0.91 ; \mathbf{F i g} \mathbf{4 - 8})$ indicates that lactoferrin may play an important role in retarding its growth, also supported by previous studies that reported bactericidal activity of lactoferrin against Pseudomonas (Olmo, Morales, \& Nunez, 2009; Singh, Parsek, Greenberg, \& Welsh, 2002). Activation of the lactoperoxidase system also showed bactericidal activity on Pseudomonas fluorescens in ewe and goat milk (Ay \& Bostan, 2017; Uceda, Guillen, Gaya, Medina, \& Nuñez, 1994; Zapico, Gaya, Nunez, \& Medina, 1995), which may explain the 
E ect of heat treatment on bacteriostatic activity and protein $\mathrm{pr}$ le of bovine whey proteins

correlation of the growth rate of this bacterium with lactoperoxidase $(r=-0.8, p=0.06$; Fig. 4-8).

Lactoferrin, and iron-binding proteins in general, were reported to exert an bactericidal activity on Escherichia coli (Berlov, Korableva, Andreeva, Ovchinnikova, \& Kokryakov, 2007; Bullen, Rogers, \& Leigh, 1972). It was reported that lactoferrin could clear Escherichia coli O157:H7 colonization in cattle and sheep (Rybarczyk et al., 2017; Yekta, Cox, Goddeeris, \& Vanrompay, 2011). We found only a weak correlation between the level of native lactoferrin and growth rate of Escherichia coli ( $r=-0.44$; Fig. 4-8). Lactoperoxidase was also previously shown to have bacteriostatic activity against Escherichia coli in milk (Kangumba, Venter, \& Coetzer, 1997; Seifu, Buys, Donkin, \& Petzer, 2004). Although whey containing more lactoperoxidase showed stronger activity against Escherichia coli (Fig. 4-2), only a weak correlation was found $(r=-0.36$; Fig. 4-8) between lactoperoxidase and the growth rate of Escherichia coli. Considering that growth rate of Escherichia coli is already increased in whey heated at temperatures of $65^{\circ} \mathrm{C}$ and above, the growth inhibition against Escherichia coli may be due to a very heat sensitive component besides the immune proteins taken into account for this analysis.

Due to their high abundance in bovine milk, immunoglobulin may be thought to contribute a lot to the antimicrobial activity of milk; however, our results do not support this hypothesis. No strong correlations were found between the retention of immunoglobulin with either of the four bacteria, which may be explained by the specificity of milk immunoglobulins in general. Besides, unlike lactoperoxidase and lactoferrin which exert direct antibacterial effect against pathogens, immunoglobulins neutralize pathogen not only by direct interaction with antigen, but also by activating the complement system. Both these aspects may make it difficult to find a correlation between level of total immunoglobulin with growth rate of bacteria in in vitro assays like applied in this study.

Interestingly, except the three main antibacterial proteins, several other minor immune proteins were found to have a close correlation with growth rate of bacteria (Supplementary Fig. 4-2). Lipopolysaccharide-binding protein was reported as an important component of the innate immune response and has a protective effect against bacterial infection (Knapp, de Vos, Florquin, Golenbock, \& van der Poll, 2003; Lamping et al., 1998). It was observed that lipopolysaccharide-binding protein has a close correlation with growth rate of Streptococcus thermophilus, Lactococcus lactis and Pseudomonas fluorescens $(r>0.8, p<0.05)$. Mannosebinding protein $\mathrm{C}$, with a carbohydrate-dependent bactericidal effects (Chen \& Wallis, 2004; 
Lee, Ichikawa, Kawasaki, Drickamer, \& Lee, 1992), was found to have a very strong correlation with growth rate of Streptococcus thermophilus, Lactococcus lactis and Pseudommas fluorescens with $r>0.98(p<0.05)$. Peptidoglycan recognition protein 1 , a ubiquitous protein in innate immunity, was observed to have a close correlation with four selected bacteria $(r>$ $0.87, p<0.05)$, especially Escherichia coli $(r=-0.94, p<0.05)$. Haptoglobin was reported to have the ability to selectively antagonize lipopolysaccharide (LPS) effects (Arredouani et al., 2005). It showed a good correlation with the growth rate of Streptococcus thermophilus, Lactococcus lactis and Pseudomonas fluorescens $(r>0.8, p<0.05)$. This data on the minor immune-active proteins indicates that these protein may also be relevant for the overall bacteriostatic activity of milk. Therefore, inhibition of bacteria may be an integral result of various antibacterial components, though abundant antibacterial proteins are thought to play an important role.

Milk is a complex system containing a wide variety of proteins, peptides, carbohydrates and other bioactive components. With so many factors that may influence the bacteriostatic capacity of bovine milk, it is hard to characterize the actual proportion of the bacteriostatic property provided by individual proteins, like the three antibacterial proteins targeted in this study, though we found several of them are well correlated to the growth rate of bacteria. Furthermore, the possible unrecognised synergistic effects between these components and the milk environment could further complicate matters (Spik et al., 1978; Stephens, Harkness, \& Cockle, 1979). Therefore, developing a model system of isolated single proteins may provide further evidence which protein(s) is/are most strongly associated with the bacteriostatic capacity, although this would lack the possible effects of the milk matrix. Furthermore, it is not clear how heating exactly causes a reduction of the antimicrobial function of immune-active proteins, though we found that the decrease of bacteriostatic capacity of whey correlates with a decrease in native immune-active proteins. Therefore, it would be interesting to explore in more detail the mechanism by which heating may cause this decrease of native protein's bacteriostatic capacity.

\subsection{Conclusion}

The present study described detailed changes of immune-active proteins after different heat treatments, and associated these changes in protein composition with bacteriostatic activity. This study found that unheated whey had the lowest bacterial growth rate, while whey heated at increasing temperatures resulted in increasing bacterial growth rates except for Escherichia 
coli, showing that the bacteriostatic capacity of milk is negatively correlated with heating intensity. Our study showed a strong correlation between decreases in the level of several native antibacterial proteins and bacterial growth rates, indicating that bacteriostatic activity can be a biomarker for loss of function of antibacterial proteins, and can be used as an indication for the extent of heat processing of dairy products including antibacterial proteins in a mild heat treatment. Besides the bacteriostatic properties of bovine milk, the large number of immuneactive proteins in bovine milk could also exert many other beneficial effect, such as immunomodulation, to facilitate the host's defense system. Therefore, heat treatment under $75^{\circ} \mathrm{C}$ will be suggested to be applied for inactivation of pathogens, while preserving native immune-related proteins, thereby improve function of milk for the consumer.

\section{Acknowledgements}

This research was funded by the Sino Dutch Dairy Development Centre (http://www.sdddc.org), and Sino-Dutch Doctoral Program on Sustainable Dairy from China Scholarship Council. The authors have no conflict of interest to declare. 


\section{Supplementary M aterials}

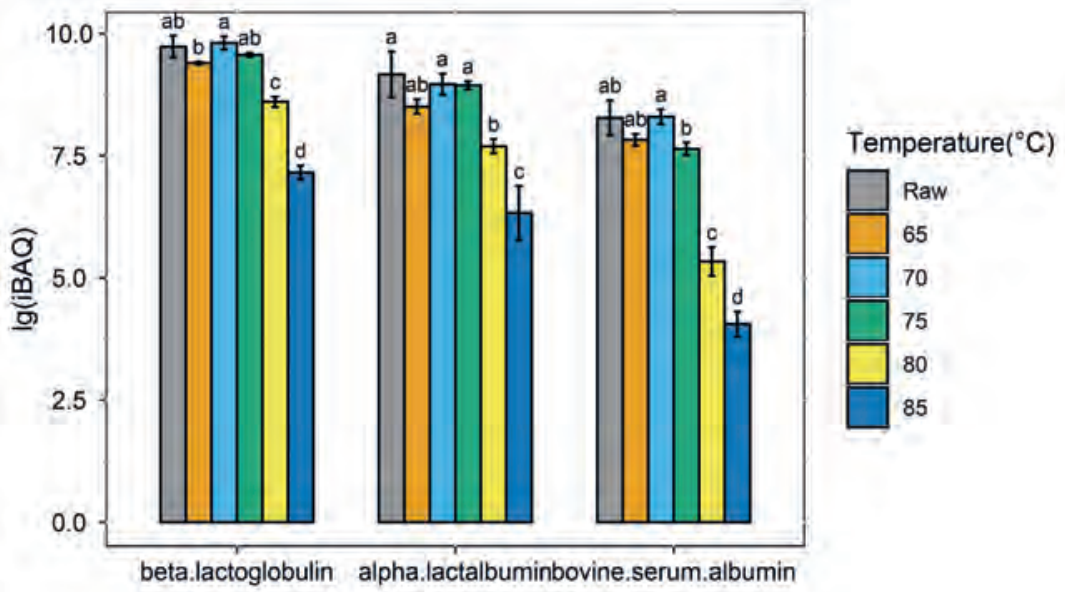

Supplementary figure 4-1 Proteomic analysis of $\beta$-lactoglobulin, $\alpha$-lactalbumin and bovine serum albumin in different heat treated milk serum samples. Different letters indicate statistically significant differences among different treatments $(p<0.05)$. 


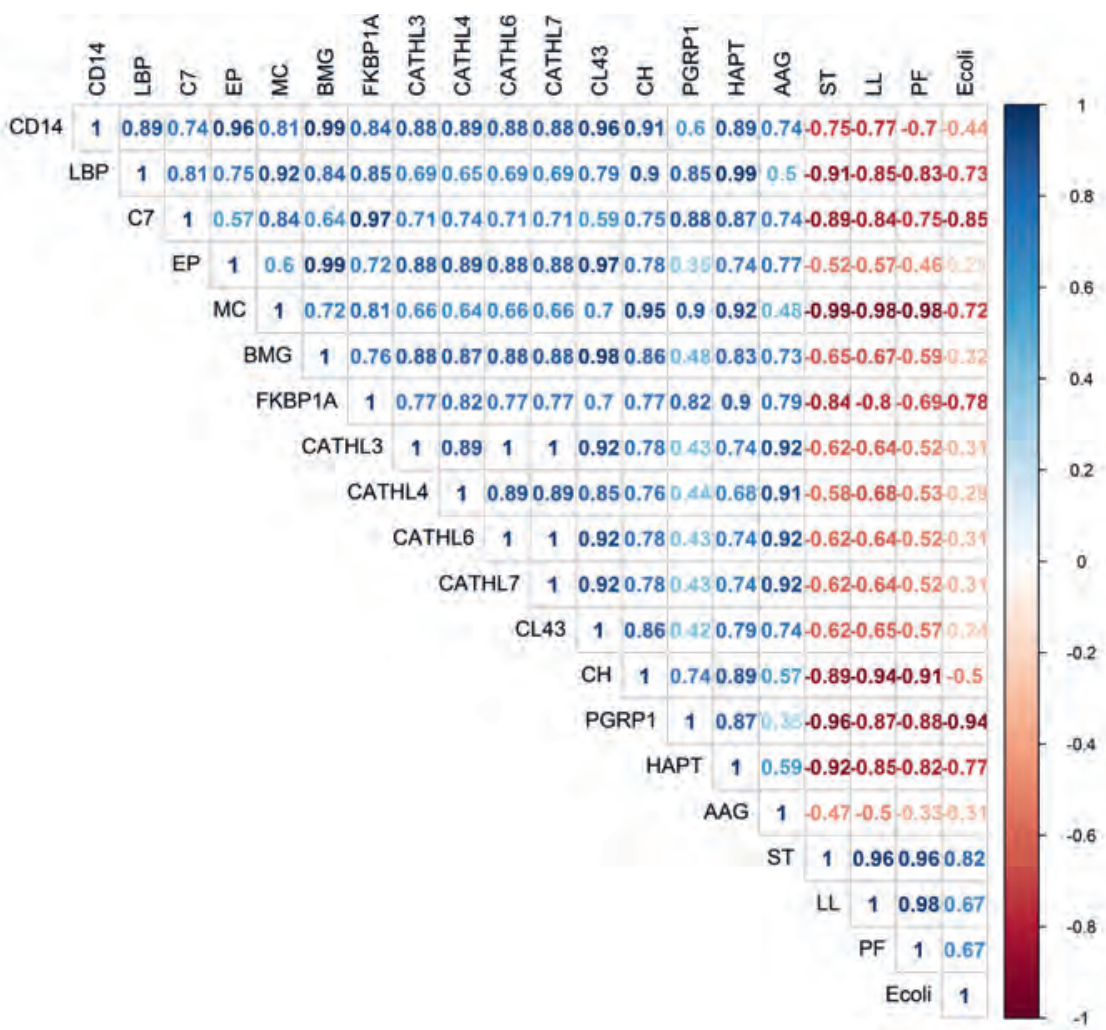

Supplementary figure 4-2 Correlation matrix of bacterial growth rates and iBAQ values of minor immune-active proteins. Abbreviations: ST, Streptococaus themophilus Ecoli, Escherichia coli; LL, Lactococaus lactis PF, Pseudomonas fluorescens CD14, Monocyte differentiation antigen CD14; LBP, Lipopolysaccharide-binding protein;C 7,Complement component C7; EP, Ectonucleotide pyrophosphatase/phosphodiesterase family member 3; M C, M annose-binding protein C; BM G, B eta-2-microglobulin; FK B P1A, Peptidyl-prolyl cis-trans isomerase FK B P1A; CATHL 3, Cathelicidin-3; CATHL 4, Cathelicidin-4; CATHL 6, Cathelicidin-6; CATHL7, Cathelicidin-7; CL 43, Collectin-43; CH, Complement factor H; PGRP1, Peptidoglycan recognition protein 1; HAPT, Haptoglobin; AAG, Alpha-1-acid glycoprotein. 
Supplementary table 4-1 Functional category of identified proteins by the DAVID gene ontology program.

\begin{tabular}{|c|c|c|c|}
\hline Terms & Count & Percentage $(\%)$ & $\mathrm{p}$-value \\
\hline Secreted & 102 & 34.7 & $5.6 \mathrm{E}-59$ \\
\hline Signal & 155 & 52.7 & 4.5E-49 \\
\hline Glycoprotein & 89 & 30.3 & $8.2 \mathrm{E}-36$ \\
\hline Disulfide bond & 104 & 35.4 & $4 \mathrm{E}-35$ \\
\hline Intermediate filament & 20 & 6. & $5.6 \mathrm{E}-19$ \\
\hline Serine protease inhibitor & 16 & 5.4 & $1.6 \mathrm{E}-18$ \\
\hline Protease inhibitor & 19 & 6.5 & $2.1 \mathrm{E}-18$ \\
\hline Keratin & 15 & 5.1 & 4.1E-14 \\
\hline Lipoprotein & 27 & 9.2 & $9.2 \mathrm{E}-12$ \\
\hline Antimicrobial & 13 & 4.4 & $5.6 \mathrm{E}-11$ \\
\hline Prenylation & 14 & 4.8 & $6.6 \mathrm{E}-11$ \\
\hline Antibiotic & 12 & 4.1 & $9.1 \mathrm{E}-11$ \\
\hline Milk protein & 7 & 2.4 & $1.3 \mathrm{E}-10$ \\
\hline Acute phase & 8 & 2.7 & 4.7E-10 \\
\hline Oxidation & 8 & 2.7 & 4.7E-10 \\
\hline Methylation & 25 & 8.5 & $1.3 \mathrm{E}-09$ \\
\hline Cytoplasmic vesicle & 19 & 6.5 & 0.000000007 \\
\hline Pyrrolidone carboxylic acid & 11 & 3.7 & 0.000000015 \\
\hline Cytoplasm & 58 & 19.7 & 0.00000022 \\
\hline Phosphoprotein & 76 & 25.9 & 0.00000043 \\
\hline Blood coagulation & 8 & 2.7 & 0.0000007 \\
\hline Hemostasis & 8 & 2.7 & 0.0000007 \\
\hline Polymorphism & 10 & 3.4 & 0.00000095 \\
\hline Allergen & 5 & 1.7 & 0.000001 \\
\hline HDL & 6 & 2 & 0.0000013 \\
\hline GTP-binding & 17 & 5.8 & 0.0000016 \\
\hline Immunity & 14 & 4.8 & 0.0000024 \\
\hline Innate immunity & 11 & 3.7 & 0.0000047 \\
\hline
\end{tabular}

Only p-value $<10^{-5}$ were listed. Terms means enriched terms associated with the gene list coding identified proteins; count means the number of gene related to specific function; percentage means involved genes/total genes; $p$-value means modified fisher exact $p$-value, the smaller, the better. 
E ect of heat treatment on bacteriostatic activity and protein $\mathrm{pr}$ le of bovine whey proteins

Supplementary table 4-2 E ffect of different heat treatment on minor immunological proteins.

\begin{tabular}{|c|c|c|c|c|c|c|}
\hline Protein name & Raw milk & $65^{\circ} \mathrm{C}$ & $70^{\circ} \mathrm{C}$ & $75^{\circ} \mathrm{C}$ & $80^{\circ} \mathrm{C}$ & $85^{\circ} \mathrm{C}$ \\
\hline $\begin{array}{l}\text { Monocyte } \\
\text { differentiation } \\
\text { antigen CD14 }\end{array}$ & $6.15 \pm 0.43^{\mathrm{a}}$ & $5.06 \pm 0.19^{b}$ & $5.52 \pm 0.08^{\mathrm{ab}}$ & $4.76 \pm 0.19^{b}$ & $2.71 \pm 0.40^{\mathrm{c}}$ & $2.34 \pm 0.25^{\mathrm{c}}$ \\
\hline $\begin{array}{l}\text { Lipopolysaccharide- } \\
\text { binding protein }\end{array}$ & $5.13 \pm 0.36^{\mathrm{a}}$ & $4.74 \pm 0.47^{\mathrm{a}}$ & $2.97 \pm 0.38^{\mathrm{b}}$ & $2.73 \pm 0.39^{b c}$ & $2.36 \pm 0.40^{\mathrm{bc}}$ & $1.81 \pm 0.29^{\mathrm{c}}$ \\
\hline $\begin{array}{l}\text { Complement } \\
\text { component } \mathrm{C} 7\end{array}$ & $4.95 \pm 0.53^{\mathrm{a}}$ & $2.81 \pm 0.42^{\mathrm{b}}$ & $3.42 \pm 0.35^{\mathrm{b}}$ & $3.26 \pm 0.30^{\mathrm{b}}$ & $3.02 \pm 0.42^{\mathrm{b}}$ & $2.37 \pm 0.54^{\mathrm{b}}$ \\
\hline $\begin{array}{l}\text { Phosphodiesterase } \\
\text { family member } 3\end{array}$ & $5.00 \pm 0.40^{\mathrm{a}}$ & $4.68 \pm 0.34^{\mathrm{a}}$ & $5.24 \pm 0.22^{\mathrm{b}}$ & $5.02 \pm 0.20^{\mathrm{b}}$ & $2.53 \pm 0.30^{\mathrm{b}}$ & $2.31 \pm 0.30^{\mathrm{b}}$ \\
\hline $\begin{array}{l}\text { Mannose-binding } \\
\text { protein C }\end{array}$ & $5.01 \pm 0.35^{\mathrm{a}}$ & $3.84 \pm 0.10^{\mathrm{bc}}$ & $3.89 \pm 0.15^{\mathrm{b}}$ & $2.73 \pm 0.28^{\mathrm{d}}$ & $3.07 \pm 0.48^{\mathrm{cd}}$ & $2.50 \pm 0.27^{\mathrm{d}}$ \\
\hline $\begin{array}{l}\text { Beta-2- } \\
\text { microglobulin }\end{array}$ & $6.60 \pm 0.48^{\mathrm{a}}$ & $6.04 \pm 0.25^{\mathrm{a}}$ & $6.37 \pm 0.39^{b}$ & $5.75 \pm 0.23^{b}$ & $2.73 \pm 0.38^{b}$ & $2.16 \pm 0.51^{\mathrm{b}}$ \\
\hline $\begin{array}{l}\text { Peptidyl-prolyl cis- } \\
\text { trans isomerase } \\
\text { FKBP1A }\end{array}$ & $4.85 \pm 0.11^{\mathrm{a}}$ & $3.00 \pm 1.07^{\mathrm{a}}$ & $3.48 \pm 1.23^{\mathrm{a}}$ & $3.58 \pm 0.94^{\mathrm{a}}$ & $2.76 \pm 1.14^{\mathrm{a}}$ & $2.40 \pm 0.67^{\mathrm{a}}$ \\
\hline Cathelicidin-3 & $5.41 \pm 0.51^{\mathrm{a}}$ & $4.98 \pm 0.15^{\mathrm{a}}$ & $5.50 \pm 0.17^{\mathrm{a}}$ & $5.25 \pm 0.14^{\mathrm{a}}$ & $4.83 \pm 0.19^{\mathrm{a}}$ & $4.07 \pm 0.19^{b}$ \\
\hline Cathelicidin-4 & $5.19 \pm 0.62^{\mathrm{ab}}$ & $3.58 \pm 1.22^{\mathrm{bcd}}$ & $5.43 \pm 0.17^{\mathrm{a}}$ & $4.63 \pm 0.38^{a b c}$ & $2.96 \pm 0.23^{\mathrm{cd}}$ & $2.80 \pm 0.38^{d}$ \\
\hline Cathelicidin-6 & $5.41 \pm 0.51^{\mathrm{a}}$ & $4.98 \pm 0.15^{\mathrm{a}}$ & $5.50 \pm 0.17^{\mathrm{a}}$ & $5.25 \pm 0.14^{\mathrm{a}}$ & $4.83 \pm 0.19^{\mathrm{a}}$ & $4.07 \pm 0.19^{b}$ \\
\hline Cathelicidin-7 & $5.41 \pm 0.51^{\mathrm{a}}$ & $4.98 \pm 0.15^{\mathrm{a}}$ & $5.50 \pm 0.17^{\mathrm{a}}$ & $5.25 \pm 0.14^{\mathrm{a}}$ & $4.83 \pm 0.19^{\mathrm{a}}$ & $4.07 \pm 0.19^{\mathrm{b}}$ \\
\hline $\begin{array}{l}\text { Complement factor } \\
\mathrm{H}\end{array}$ & $4.60 \pm 0.54^{\mathrm{a}}$ & $3.86 \pm 0.18^{\mathrm{a}}$ & $4.19 \pm 0.22^{\mathrm{a}}$ & $2.76 \pm 0.24^{b}$ & $2.63 \pm 0.47^{b}$ & $2.14 \pm 0.20^{\mathrm{b}}$ \\
\hline Collectin-43 & $4.02 \pm 0.58^{\mathrm{a}}$ & $3.97 \pm 0.29^{\mathrm{a}}$ & $4.21 \pm 0.38^{\mathrm{b}}$ & $3.77 \pm 0.14^{\mathrm{b}}$ & $2.82 \pm 0.08^{\mathrm{b}}$ & $2.22 \pm 0.10^{\mathrm{b}}$ \\
\hline $\begin{array}{l}\text { Alpha-1-acid } \\
\text { glycoprotein }\end{array}$ & $6.86 \pm 0.43^{\mathrm{a}}$ & $6.11 \pm 0.06^{\mathrm{b}}$ & $6.88 \pm 0.04^{\mathrm{a}}$ & $6.87 \pm 0.08^{\mathrm{a}}$ & $6.33 \pm 0.26^{\mathrm{ab}}$ & $5.83 \pm 0.18^{\mathrm{b}}$ \\
\hline $\begin{array}{l}\text { Peptidoglycan } \\
\text { recognition protein } \\
1\end{array}$ & $4.92 \pm 0.46^{\mathrm{a}}$ & $3.20 \pm 0.10^{\mathrm{b}}$ & $2.87 \pm 0.68^{\mathrm{b}}$ & $2.53 \pm 0.41^{\mathrm{b}}$ & $2.93 \pm 0.38^{b}$ & $2.57 \pm 0.29^{b}$ \\
\hline Haptoglobin & $4.02 \pm 0.59^{\mathrm{a}}$ & $3.32 \pm 0.46^{\mathrm{ab}}$ & $3.01 \pm 0.26^{\mathrm{ab}}$ & $2.94 \pm 0.48^{\mathrm{ab}}$ & $2.63 \pm 0.49^{b}$ & $2.20 \pm 0.33^{\mathrm{b}}$ \\
\hline Lactadherin & $6.82 \pm 0.64^{\mathrm{a}}$ & $5.96 \pm 0.13^{\mathrm{a}}$ & $6.07 \pm 0.22^{\mathrm{ab}}$ & $5.29 \pm 0.34^{\mathrm{b}}$ & $3.27 \pm 1.06^{\mathrm{c}}$ & $2.19 \pm 0.37^{\mathrm{c}}$ \\
\hline
\end{tabular}

Result was expressed as logarithm of iBAQ value. Different letters mean significant differences among different treatment group ( $\mathrm{p}<0.05$ ). Abbreviations: Raw, unheated milk; $65^{\circ} \mathrm{C} / 70^{\circ} \mathrm{C} / 75^{\circ} \mathrm{C} / 80^{\circ} \mathrm{C} / 85^{\circ} \mathrm{C}$, milk was heated at $65^{\circ} \mathrm{C} / 70^{\circ} \mathrm{C} / 75^{\circ} \mathrm{C} / 80^{\circ} \mathrm{C} / 85^{\circ} \mathrm{C}$ for $30 \mathrm{~min}$; Minor immune protein, all detected protein related to immunity including immune response, complement, antibacterial, host defense, acute phase, and antigen binding. 

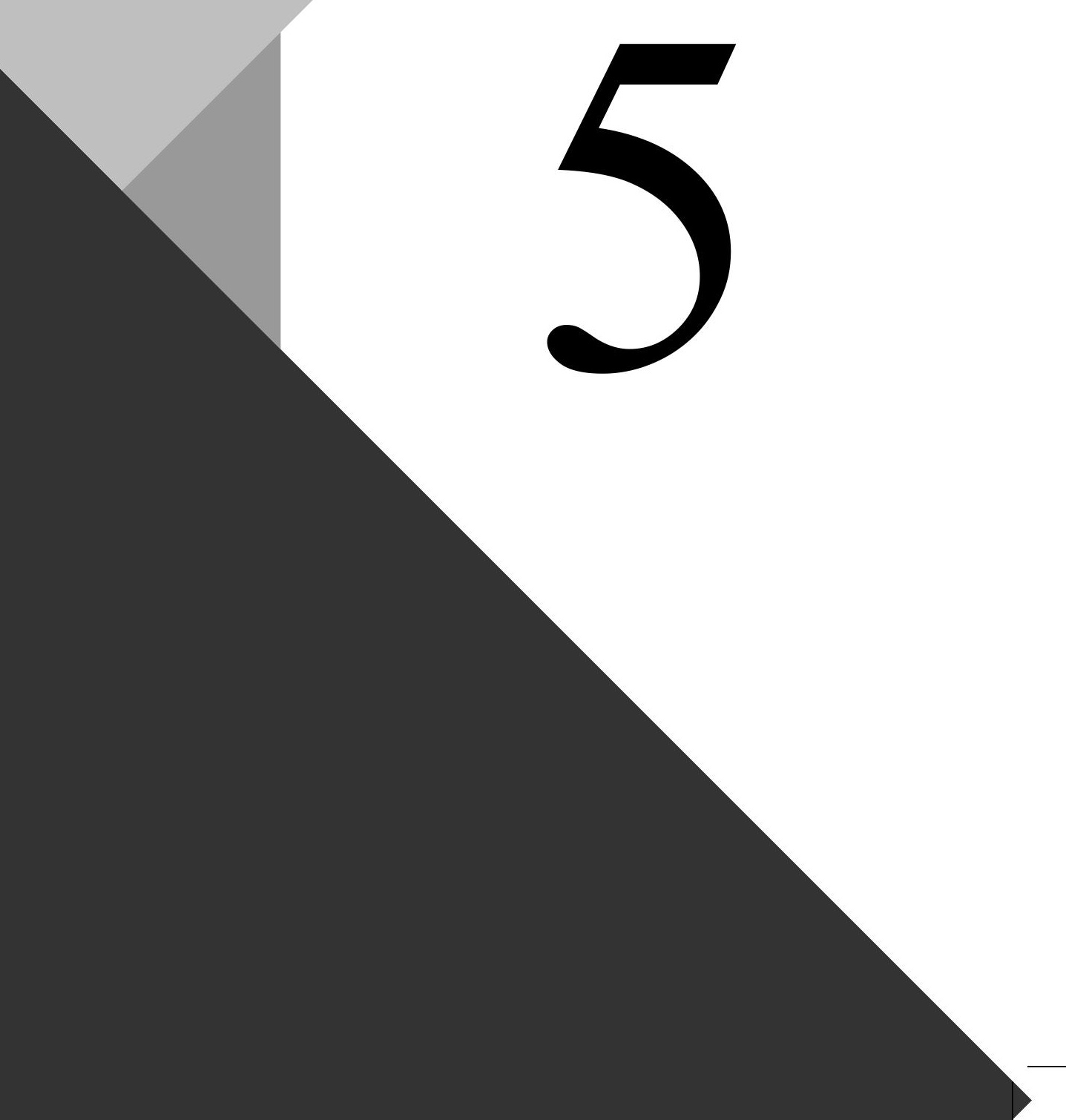


\section{CHAPTER 5.}

Loss of allergy-protective capacity of raw cow's milk after heat treatment coincides with loss of immunologically active whey proteins

This chapter has been published as:

Abbring, S. †, Xiong, L.†, Diks, M. A., Baars, T., Garssen, J., Hettinga, K. + , \& van Esch, B. C. $\ddagger$ (2020). Loss of allergy-protective capacity of raw cow's milk after heat treatment coincides with loss of immunologically active whey proteins. Food \& Function. $\dagger$ These authors have contributed equally to this work. $\$$ Shared last author. 


\section{Abstract}

The allergy-protective capacity of raw cow's milk was demonstrated to be abolished after heat treatment. The heat-sensitive whey protein fraction of raw milk is often implied to be the source of this allergy-protective effect, but a direct link between these proteins and the protection against allergic diseases is missing. This study therefore aimed at investigating the mechanistic relation between heat damage to whey proteins and allergy development. Raw cow's milk was heated for $30 \mathrm{~min}$ at $50,60,65,70,75$, or $80^{\circ} \mathrm{C}$ and the native whey protein profile of these differentially heated milk samples was determined using LC-MS/MS-based proteomics. Changes in the native protein profile were subsequently related to the capacity of these milk samples to prevent the development of ovalbumin-induced food allergy in a murine animal model. A substantial loss of native whey proteins, as well as extensive protein aggregation, was observed from $75{ }^{\circ} \mathrm{C}$. However, whey proteins with immune-related functionalities already started to denature from $65^{\circ} \mathrm{C}$, which coincided with the temperature at which a loss of allergy protection was observed in the murine model. Complement $\mathrm{C} 7$, monocyte differentiation antigen CD14, and polymeric immunoglobulin receptor concentrations decreased significantly at this temperature, although several other immunologically active whey proteins also showed a decrease around $65{ }^{\circ} \mathrm{C}$. The current study demonstrates that immunologically active whey proteins that denature around $65^{\circ} \mathrm{C}$ are important for the allergy-protective capacity of raw cow's milk and thereby provides key knowledge for the development of microbiologically safe alternatives to raw cow's milk.

Keywords: allergic diseases, immunologically active whey proteins, immunomodulation, milk processing, raw cow's milk 


\subsection{Introduction}

Allergic diseases are a serious health problem. They affect the lives of more than a billion people worldwide and their prevalence is expected to rise to four billion by 2050 . Because of the large number of people affected, society faces huge healthcare costs and major socioeconomic consequences.(European Academy of Allergy and Clinical Immunology, 2014).

The vast increase in the prevalence of allergic diseases is mainly evident in industrialized countries and is often linked to the Western lifestyle (Alfvén et al., 2006; Eder, Ege, \& von Mutius, 2006). This lifestyle is accompanied by the loss of rural living conditions resulting in a decreased microbial exposure in early life. In accordance with this so-called hygiene hypothesis, epidemiological studies have consistently shown that children growing up on a farm are at a significantly lower risk of developing allergic diseases than children living in the same rural area but not growing up on a farm (Alfvén et al., 2006; Braun-Fahrlander et al., 1999; Ernst \& Cormier, 2000; Kilpelainen, Terho, Helenius, \& Koskenvuo, 2000; Riedler, Eder, Oberfeld, \& Schreuer, 2000; von Ehrenstein et al., 2000; von Mutius \& Vercelli, 2010). Several farm exposures have been associated with this protective 'farm effect' (Ege et al., 2007; Ege, Mayer, et al., 2011; Remes, Iivanainen, Koskela, \& Pekkanen, 2003; Riedler et al., 2001), but particularly the consumption of raw, unprocessed, cow's milk is of interest, since this effect was found to be independent of living on a farm. This suggests that a general, non-farming, population might equally benefit from the consumption of raw cow's milk (Brick et al., 2016; Ege et al., 2007; Loss et al., 2011; Perkin \& Strachan, 2006). Raw cow's milk consumption can thus be considered a possible allergy-preventive measure. However, due to the potential presence of pathogens, its consumption is discouraged by regulatory agencies (Committee on Infectious Diseases \& Committee on Nutrition \& American Academy of Pediatrics, 2014).

A wide range of components have been hypothesized to contribute to the allergy-protective effects of raw cow's milk (Abbring, Hols, Garssen, \& van Esch, 2019; Braun-Fahrländer \& von Mutius, 2011; van Neerven, Knol, Heck, \& Savelkoul, 2012). Since recent research clearly demonstrates a loss of protection upon heat treatment, heat-sensitive raw milk components, like whey proteins, are the most likely candidates (Abbring, Ryan, et al., 2019; Abbring et al., 2017; Brick et al., 2016; Loss et al., 2011). In contrast to caseins, whey proteins are susceptible to heat treatment (Brick et al., 2017). Heating of these proteins induces processes like denaturation and aggregation which results in structural alterations that can lead to loss of functionality (Chen et al., 2005; Li-Chan, Kummer, Losso, Kitts, \& Nakai, 1995; McGuffey, Epting, Kelly, 
\& Foegeding, 2005). Particularly immunologically active whey proteins, like lactoferrin and immunoglobulins, are heat-sensitive (Zhang et al., 2016). Since these components have immune-related functionalities that can be linked to the allergy-protective effects of raw cow's milk, abolishing them by heat treatment could be underlying the loss of protection (Abbring, $\mathrm{G}$. Hols, et al., 2019). In addition to destroying immunologically active whey proteins, heat treatment can also induce the formation of new protein structures. Heating, for example, leads to aggregation of $\beta$-lactoglobulin and $\alpha$-lactalbumin, both with themselves as well as with casein micelles (Beaulieu, Pouliot, \& Pouliot, 1999; Chen et al., 2005; McGuffey et al., 2005). Aggregation of these whey proteins has been demonstrated to result in a shift in uptake from enterocytes to Peyer's patches thereby leading to increased immunogenicity (Roth-Walter et al., 2008). A better understanding of the heat sensitivity of whey proteins is key for the development of optimized processing parameters, that may lead to a safe and protective product in the future.

Although the effect of milk processing on whey proteins is widely studied, a direct link demonstrating the consequences on the allergy-protective effects associated with raw milk is lacking. Providing this link is crucial to gain more insight in the actual whey protein(s) involved in the allergy-protective effects of raw cow's milk. In the present study, native proteomics was therefore combined with a functional readout for allergic diseases. This study hereby aimed at achieving a better understanding of the underlying mechanism between heat damage to whey proteins and allergy development and is, to our knowledge, the first to compare different heating temperatures (instead of high heat vs no heat).

\subsection{M aterials and methods}

\subsubsection{Mice}

Specific pathogen-free, three-week-old, female $\mathrm{C} 3 \mathrm{H} / \mathrm{HeJ}$ mice were purchased from The Jackson Laboratory (Bar Harbor, ME, USA). Upon arrival, mice were randomly assigned to the control or experimental groups. They were housed at the animal facility of Utrecht University (Utrecht, The Netherlands) in filter-topped makrolon cages (one cage/group, $n=6-8 /$ cage) on a 12 h light/dark cycle with access to food ('Rat and Mouse Breeder and Grower Expanded'; Special Diet Services, Witham, UK) and water ad libitum Animal procedures were approved by the Ethical Committee for Animal Research of the Utrecht University and conducted in accordance with the European Directive 2010/63/EU on the protection of animals used for scientific purposes (AVD108002015346). 


\subsubsection{Milk collection and heat treatment}

Raw cow's milk was collected from a biodynamic dairy farm (Hof Dannwisch, Horst, Germany). Upon collection, part of the raw milk was heated to obtain the $50{ }^{\circ} \mathrm{C}, 60{ }^{\circ} \mathrm{C}, 65^{\circ} \mathrm{C}$, $70{ }^{\circ} \mathrm{C}, 75^{\circ} \mathrm{C}$, and $80^{\circ} \mathrm{C}$ milk samples. For each of these heat treatments, three $50 \mathrm{~mL}$ aliquots were placed in a water bath and as soon as the milk reached the target temperature, heating was continued for $30 \mathrm{~min}$. After these $30 \mathrm{~min}$, the milk was cooled on ice. The milk used for the animal experiment was then aliquoted and stored at $-20{ }^{\circ} \mathrm{C}$ until further use. The milk used for protein analysis was immediately used to obtain the whey fraction. An overview of all milk processing steps is shown in Figure 5-1A.

A

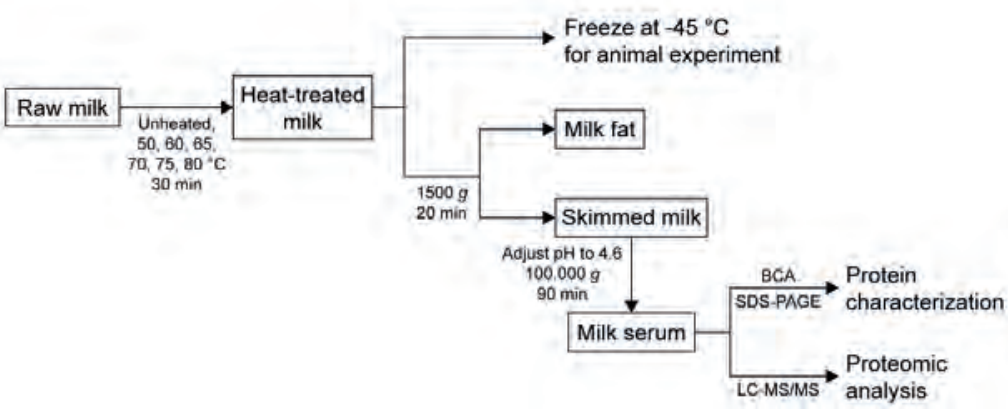

B

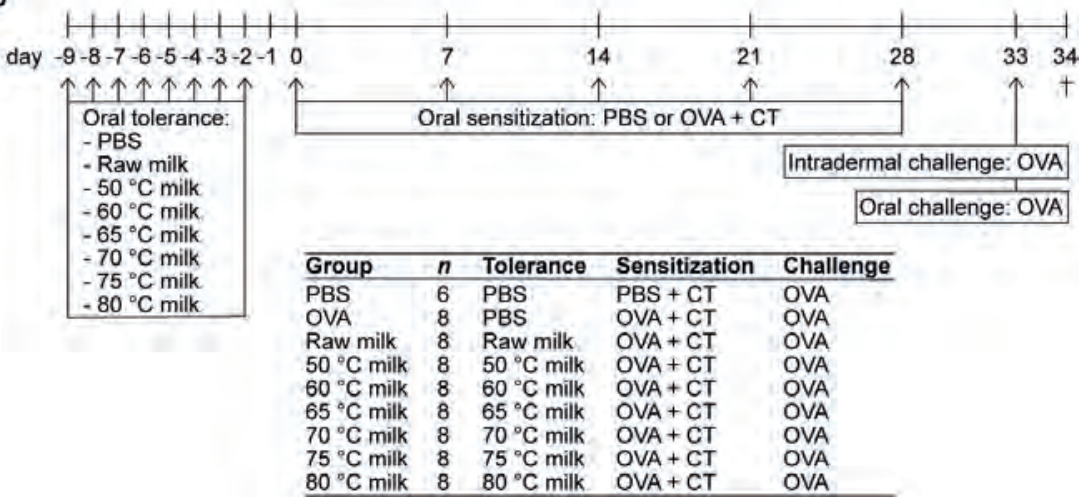

Figure 5-1 Schematic overview of the experimental setup (A) Flow chart of the various milk processing steps. (B) Experimental timeline of the animal study. OVA, ovalbumin; CT, cholera toxin.

\subsubsection{Whey fraction preparation}

After heat treatment, milk samples used for protein analysis were skimmed by centrifugation at $1500 \mathrm{~g}$ for $20 \mathrm{~min}$ at $10^{\circ} \mathrm{C}$ (Avanti J-26 XP, rotor 25.15; Beckman Coulter, Miami, FL, USA). Caseins and denatured proteins were subsequently removed as described previously (A. J. Law 
\& J. Leaver, 2000). After ultracentrifugation, samples were separated into three phases. The top layer was remaining milk fat, the middle layer was milk serum with the native whey proteins (the whey fraction), and the bottom layer (pellet) was micellar casein with denatured/aggregated proteins. The whey fraction was collected and used for further analysis as described below.

\subsubsection{Protein characterization by BCA assay and SDS-PAGE}

The soluble protein content remaining in the native whey fraction was determined by using the Pierce BCA Protein Assay Kit according to the manufacturer's instructions (Thermo Fisher Scientific, Paisley, Scotland). In addition, whey fraction samples were loaded onto an SDSPAGE and proteins were visualized using CBB R-250 Staining Solution (Bio-Rad, Veenendaal, The Netherlands), as described previously(Xiong, Li, Boeren, Vervoort, \& Hettinga, 2020b), to determine the abundance of milk proteins in the native whey fraction. Gels were scanned using the ChemiDoc XRS+ Imaging System (Bio-Rad) with Image Lab Software (Bio-Rad).

\subsubsection{Sample preparation for proteomics}

The Filter Aided Sample Preparation (FASP) method was carried out according to Wiśniewski et al. (Wiśniewski, Zougman, Nagaraj, \& Mann, 2009), with adaptations according to Hettinga et al. and Lu etal. (Hettinga et al., 2011; Lu et al., 2011). Briefly, protein samples (10 $\mu \mathrm{g}$ ), after reduction and alkylation, were transferred to a Pall 3K Omega filter (Pall Corporation, Port Washington, NY, USA), where they were washed with $8 \mathrm{M}$ urea and $\mathrm{ABC}$. The filter unit was then transferred to a new low-binding microcentrifuge tube and $100 \mu \mathrm{L} \mathrm{ABC}$ containing $0.5 \mu \mathrm{g}$ trypsin (Roche, Penzburg, Germany) was added to digest the protein. Finally, $6 \mu \mathrm{L}$ trifluoroacetic acid (TFA; Sigma-Aldrich) was added to the resulting peptide solutions to adjust the $\mathrm{pH}$ of the samples to around 2. These samples were then ready for LC-MS/MS.

\subsubsection{Proteomics by LC-MS/MS}

The LC-MS/MS parameters used were the same as described previously (Zhang et al., 2015a; Zhang et al., 2015b). Samples were analyzed by injecting $18 \mu \mathrm{L}$ of trypsin-digested whey protein fractions in a $0.10 \times 30 \mathrm{~mm}$ Magic C18AQ 200A $5 \mu \mathrm{m}$ beads (Michrom BioResources Inc., Auburn, CA, USA) pre-concentration column (prepared in house) at a maximum pressure of 800 bar. Peptides were eluted from the pre-concentration column onto a $0.10 \times 200 \mathrm{~mm}$ ReproSil-Pur 120 C18-AQ $1.9 \mu \mathrm{m}$ beads analytical column. Between the pre-concentration and analytical column, an electrospray potential of $3.5 \mathrm{kV}$ was applied directly to the eluent through a stainless steel needle fitted into the waste line of the micro cross. Full scan positive mode FTMS spectra were measured between m/z 380 and 1400 on an LTQ-Orbitrap XL (Thermo 
Electron, San Jose, CA, USA). CID-fragmented MS/MS scans of the four most abundant doubly- and triply-charged peaks in the FTMS scan were recorded in data-dependent mode in the linear trap.

\subsubsection{Data analysis proteomics}

Each run with all MS/MS spectra obtained was analyzed with MaxQuant 1.6.0.1 with the Andromeda search engine (Cox \& Mann, 2008). Trypsin was set as the digestion enzyme. Carbamidomethylation of cysteines was set as a fixed modification. Oxidation of methionine, $\mathrm{N}$-terminal acetylation and de-amidation of asparagine or glutamine were set as variable modifications for both identification and quantification. The bovine (taxonomy ID: 9913) reference database for peptide and protein searches was downloaded as fasta file from Uniprot with reverse sequences generated by MaxQuant (fasta file downloaded from Uniprot in 2013(UniProt, 2013)). A set of 31 protein sequences of common contaminants was used as well. A maximum of two missed cleavages were allowed and a mass deviation of $0.5 \mathrm{Da}$ for fragment MS/MS peaks, and $20 \mathrm{ppm}$ and $4.5 \mathrm{ppm}$ for the peptide MS peaks during the first and main search, respectively. The false discovery rate (FDR) was set to $1 \%$ on both peptide and protein level. The length of peptides was set to at least seven amino acids. Finally, proteins were identified based on minimally two distinct peptides of which at least one unique and at least one unmodified. The intensity based absolute quantification (iBAQ) algorithm, which has been reported to have a good correlation with known absolute protein concentrations, was used to reflect the quantitative effect of heating on the proteins (Schwanhausser et al., 2011). The proteomics data was further analyzed by Perseus 1.6.2.3 (Tyanova et al., 2016).

\subsubsection{Experimental design animal study}

A schematic representation of the experimental timeline is depicted in Fig. 1B. Mice were orally exposed, by using a blunt needle, to $0.5 \mathrm{~mL}$ raw milk, the milk samples heated at $50{ }^{\circ} \mathrm{C}, 60^{\circ} \mathrm{C}$, $65{ }^{\circ} \mathrm{C}, 70{ }^{\circ} \mathrm{C}, 75^{\circ} \mathrm{C}, 80^{\circ} \mathrm{C}$ or PBS (as a control) for eight consecutive days (days -9 to -2 ). Subsequently, mice ( $n=8 /$ group) were orally (by means of gavage) sensitized to $20 \mathrm{mg}$ ovalbumin (OVA; 20 mg/0.5 mL PBS; grade V; Sigma-Aldrich) using $15 \mu$ g cholera toxin (CT; List Biological Laboratories, Campbell, CA, USA) as an adjuvant (days 0, 7, 14, 21, and 28). Sham-sensitized control mice $(n=6)$ received CT alone $(15 \mu \mathrm{g} / 0.5 \mathrm{~mL}$ PBS $)$. OVA solutions were passed through Pierce High Capacity Endotoxin Removal Resin (Thermo Fisher Scientific) to remove lipopolysaccharide. Five days after the last sensitization (day 33), all mice were intradermally and orally (50 mg/0.5 mL PBS) challenged with OVA. Sixteen hours after the 
oral challenge (day 34), a blood sample was taken via cheek puncture and mice were killed by cervical dislocation.

\subsubsection{Assessment of the acute allergic skin response}

All mice were intradermally challenged in both ear pinnae with OVA (10 $\mu \mathrm{g}$ OVA/20 $\mu \mathrm{L}$ PBS $)$ to determine the magnitude of the acute allergic skin response. The acute allergic skin response is expressed as $\Delta$ ear swelling $(\mu \mathrm{m})$ and was calculated by subtracting mean basal ear thickness from mean ear thickness $1 \mathrm{~h}$ after intradermal challenge. Ear thickness at both timepoints was measured in duplicate for each ear using a digital micrometer (Mitutoyo, Veenendaal, The Netherlands). Measurements were carried out by a researcher blinded to treatment. To be able to perform the intradermal challenge and both ear measurements, mice were anesthetized using inhalation of isoflurane (Abbott, Breda, The Netherlands).

\subsubsection{Detection of OVA-specific IgE in serum}

Serum OVA-specific IgE levels were quantified by means of ELISA as described elsewhere (Abbring, Ryan, et al., 2019). Results are expressed in arbitrary units, calculated based on an internal standard curve of pooled sera.

\subsubsection{Flow cytometric analysis of immune cells}

Lymphocytes were isolated from spleen by crushing tissue through a $70 \mu \mathrm{m}$ nylon cell strainer and removing red blood cells using lysis buffer $\left(8.3 \mathrm{~g} \mathrm{NH}_{4} \mathrm{Cl}, 1 \mathrm{~g} \mathrm{KHC} 3 \mathrm{O}\right.$, and $37.2 \mathrm{mg}$ EDTA dissolved in $1 \mathrm{~L}$ demi water, filter sterilized). The obtained single cell suspensions were subsequently incubated for 15 min on ice with anti-mouse CD16/CD32 (Mouse BD Fc Block; BD Biosciences, Alphen aan de Rijn, The Netherlands) in PBS/1\% BSA (Sigma-Aldrich)/5\% fetal bovine serum (FBS; Bodinco, Alkmaar, The Netherlands) buffer to block non-specific binding sites. Cells were then extracellularly stained with the following antibodies (all purchased from eBioscience, Breda, The Netherlands, unless otherwise stated): CD4-PerCPCy5.5, CXCR3-PE, T1ST2-FITC (MD Bioproducts, St. Paul, MN, USA), CD25-Alexa Fluor ${ }^{\circledR}$ 488, latency-associated peptide (LAP)-PE-Cy7, F4/80-APC-eFluor ${ }^{\circledR}$ 780, CD11c-PerCPCy5.5, MHCII-FITC or CD45-PE-Cy7 for 30 min on ice. Fixable Viability Dye-eFluor ${ }^{\circledR} 780$ (eBioscience) was used to exclude dead cells from analysis. Cells only needed to be stained extracellularly were fixed using Intracellular Fixation Buffer (eBioscience). Cells also to be stained intracellularly were fixed and permeabilized using the FoxP3 Transcription Factor Staining Buffer Set (eBioscience) and then stained with FoxP3-APC or IL-10-PE (eBioscience). Fluorescently stained cells were measured with the FACS Canto II (BD Biosciences) and 
analyzed using FlowLogic Software (Inivai Technologies, Mentone, Australia). To detect LAP expression and IL-10 production, spleen-derived lymphocytes were polyclonally stimulated with anti-CD3 $(10 \mu \mathrm{g} / \mathrm{mL}) / \mathrm{CD} 28\left(1 \mu \mathrm{g} / \mathrm{mL}\right.$; eBioscience) for $24 \mathrm{~h}$ at $37{ }^{\circ} \mathrm{C}$ and $5 \% \mathrm{CO}_{2}$, of which the last $4 \mathrm{~h}$ in the presence of monensin (eBioscience), prior to staining.

\subsubsection{Statistical analysis}

Statistical analysis related to the protein analysis was performed using R 3.5 (The $\mathrm{R}$ Development Core Team, 2013). Packages 'ggplot2', 'gplots', and 'ggbiplot' were used for graphical representation of the data. Results on the total native whey protein content are presented as mean \pm SD of triplicates. Dunnett's multiple comparisons test was used to identify statistical differences between raw and heated milk samples. The hierarchical clustered heat maps, based on $\mathrm{Z}$ score normalized iBAQ values of the protein profiles, were created using the R package 'gplots'. Hierarchical clustering of both milk samples and proteins was performed using the complete agglomeration method and a Euclidean distance metric. Principal component analysis (PCA) was performed based on BBAQ values of the identified proteins using the R package 'prcomp' and plotted using the package 'ggbiplot'. For the statistical analyses related to the animal experiment, GraphPad Prism software (version 7.03; GraphPad Software, San Diego, CA, USA) was used. These data are presented as mean \pm SEM or as boxand-whisker Tukey plots when data were not normally distributed. Differences between preselected groups were statistically determined using one-way ANOVA, followed by Bonferroni's multiple comparisons test. For OVA-specific IgE levels, the Kruskal-Wallis test for non-parametric data followed by Dunn's multiple comparisons test for pre-selected groups was used. For all results, $\mathrm{P}<0.05$ was considered statistically significant.

\subsection{Results}

\subsubsection{Substantial loss of native whey proteins at heating temperatures of $70{ }^{\circ} \mathrm{C}$ and above}

To determine the remaining amount of native whey proteins present in milk after various heat treatments, the protein concentration of the native whey fraction was determined. The results of the BCA assay show that the total native protein content gradually decreased from raw, unheated, milk to milk heated at $80{ }^{\circ} \mathrm{C}$ (Fig. 5-2A). However, a significant decrease in native whey protein concentration was only observed from $70{ }^{\circ} \mathrm{C}$. To get a first indication about the effect of the different heat treatments on the most abundant whey proteins, the whey fraction was analyzed with a reducing SDS-PAGE. The two major whey proteins present in cow's milk, $\beta$-lactoglobulin and $\alpha$-lactalbumin, denatured at $80^{\circ} \mathrm{C}$, as demonstrated by reduced protein band 
intensities on the reducing SDS-PAGE. For BSA, denaturation occurred around $75{ }^{\circ} \mathrm{C}$. For whey proteins with immunomodulatory functionalities, such as immunoglobulins and lactoferrin, denaturation already happened at 70 and $65^{\circ} \mathrm{C}$, respectively (Fig. 5-2B). In addition, heat-induced aggregate formation through disulfide interchange, in both skim milk and whey fraction samples, was assessed using a non-reducing SDS-PAGE. This showed that proteins started to aggregate from $75^{\circ} \mathrm{C}$ and aggregates were more abundantly present in milk heated at $80{ }^{\circ} \mathrm{C}$ (Fig. 5-2C). As expected, aggregates were not visible on the non-reducing SDS-PAGE of whey fraction samples, since they were removed during acidified ultracentrifugation, after which only the native proteins remained (Fig. 5-2D).
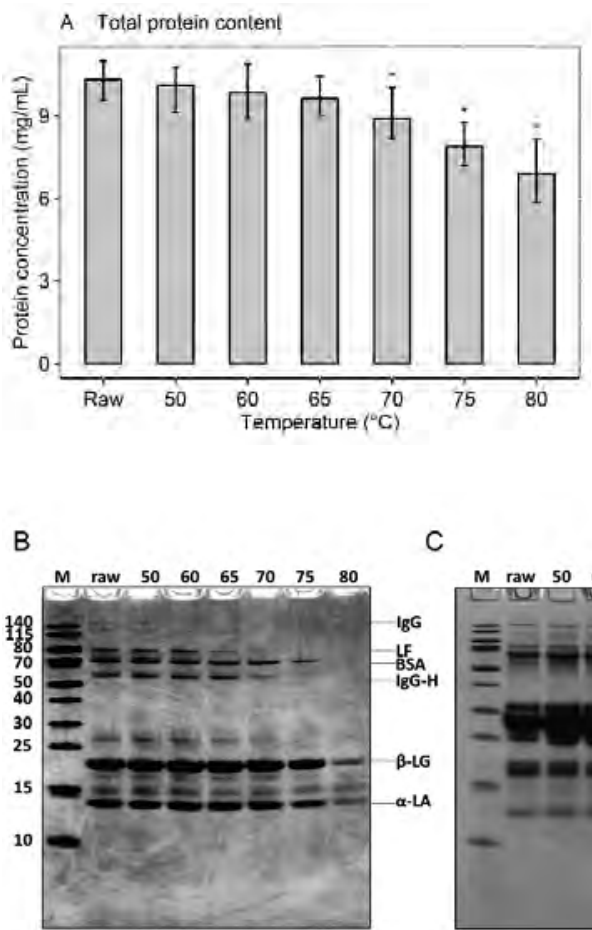

C

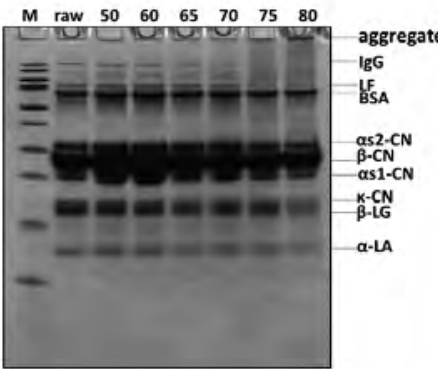

D

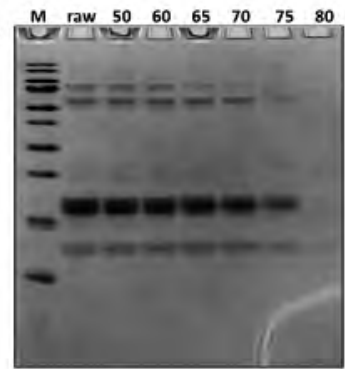

Figure 5-2 Reduced native whey protein concentration after heating at $70^{\circ} \mathrm{C}$ or higher. (A) T otal protein concentration in the native whey fraction after different heat treatments. (B) Reducing SDS-PAGE of the different native whey fraction samples after heat treatment and (C) non-reducing SDS-PAGE of the different skim milk samples and (D) whey fraction samples, with the main proteins that can be identified on the gel indicated. Protein concentrations are presented as mean $\pm \mathbf{S D}$ of triplicates. $* \mathbf{P}<0.05$ compared to raw milk as analyzed with Dunnett's multiple comparisons test. M, marker; raw, raw cow's milk; 50-80 ${ }^{\circ} \mathrm{C}$, raw cow's milk heated at the indicated temperature for $30 \mathrm{~min}$; I GG, immunoglobulin G; LF, lactoferrin; BSA, bovine serum albumin; IgG-H, heavy chain of immunoglobulin G; $\alpha$ s2-CN, as2-casein; $\beta$-CN, $\beta$-casein; $\alpha$ 1-CN, $\alpha$ s-casein; $\kappa$-CN, $\kappa$-casein; $\beta$-LG, $\beta$-lactoglobulin; $\alpha$-LA, $\alpha$-lactalbumin. 


\subsubsection{Cluster analysis of the native protein profile separated 75 and $80^{\circ} \mathrm{C}$ from lower}

\section{heating temperatures}

To further analyze the impact of heating on the native whey protein composition, proteomics was performed by means of LC-MS/MS. As expected, results showed that the protein profile has a reduced number of native proteins remaining after increasing heating intensity. A heat map was subsequently created which visualized the native protein profile of the different heattreated milk samples. According to the clusters presented in the heat map, the native protein profile of samples heated at 75 and $80{ }^{\circ} \mathrm{C}$ differed from samples heated at lower temperatures (Fig. 5-3). No clear distinction could be made among samples heated below $75^{\circ} \mathrm{C}$ (Fig. 5-3). To determine more in detail whether the differentially heat-treated milk groups could be distinguished, a PCA plot was created. Based on principal component 1, which accounted for $57.5 \%$ of the total variation, milk samples heated at 75 and $80{ }^{\circ} \mathrm{C}$ differed from samples heated at lower temperatures (Fig. 5-4). Unheated and $\leq 70{ }^{\circ} \mathrm{C}$ heat-treated milk groups differed from each other mainly on principal component 2 , which accounted for $9.9 \%$ of the total.
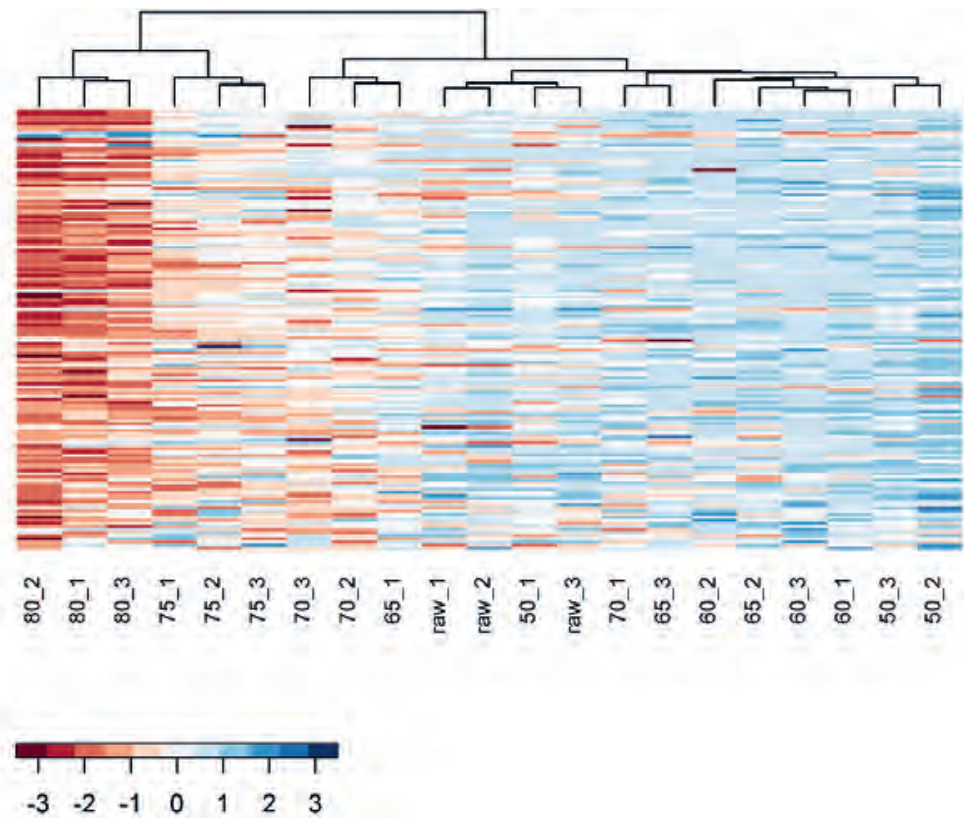

Figure 5-3 Hierarchical cluster analysis separated 75 and $80^{\circ} \mathrm{C}$ from lower heating temperatures based on native proteomics pattern. Protein profile of whey fraction samples based on Z score normalized iBAQ values. C olumns reflect individual samples. The number indicates the heating temperature, while the number after the underscore indicates the replicate. Rows reflect individual proteins. Hierarchical clustering was performed using complete agglomeration method and a E uclidean distance metric. The color scale reflects the iBAQ value-based Z score. 
To further analyze the impact of heating on the native whey protein composition, proteomics was performed by means of LC-MS/MS. As expected, results showed that the protein profile has a reduced number of native proteins remaining after increasing heating intensity. A heat map was subsequently created which visualized the native protein profile of the different heattreated milk samples. According to the clusters presented in the heat map, the native protein profile of samples heated at 75 and $80{ }^{\circ} \mathrm{C}$ differed from samples heated at lower temperatures (Fig. 5-3). No clear distinction could be made among samples heated below $75^{\circ} \mathrm{C}$ (Fig. 5-3). To determine more in detail whether the differentially heat-treated milk groups could be distinguished, a PCA plot was created. Based on principal component 1, which accounted for $57.5 \%$ of the total variation, milk samples heated at 75 and $80{ }^{\circ} \mathrm{C}$ differed from samples heated at lower temperatures (Fig. 5-4). Unheated and $\leq 70{ }^{\circ} \mathrm{C}$ heat-treated milk groups differed from each other mainly on principal component 2 , which accounted for $9.9 \%$ of the total variation, whereas milk heated at 50 and $60{ }^{\circ} \mathrm{C}$ could not be distinguished from each other (Fig. 5-4).
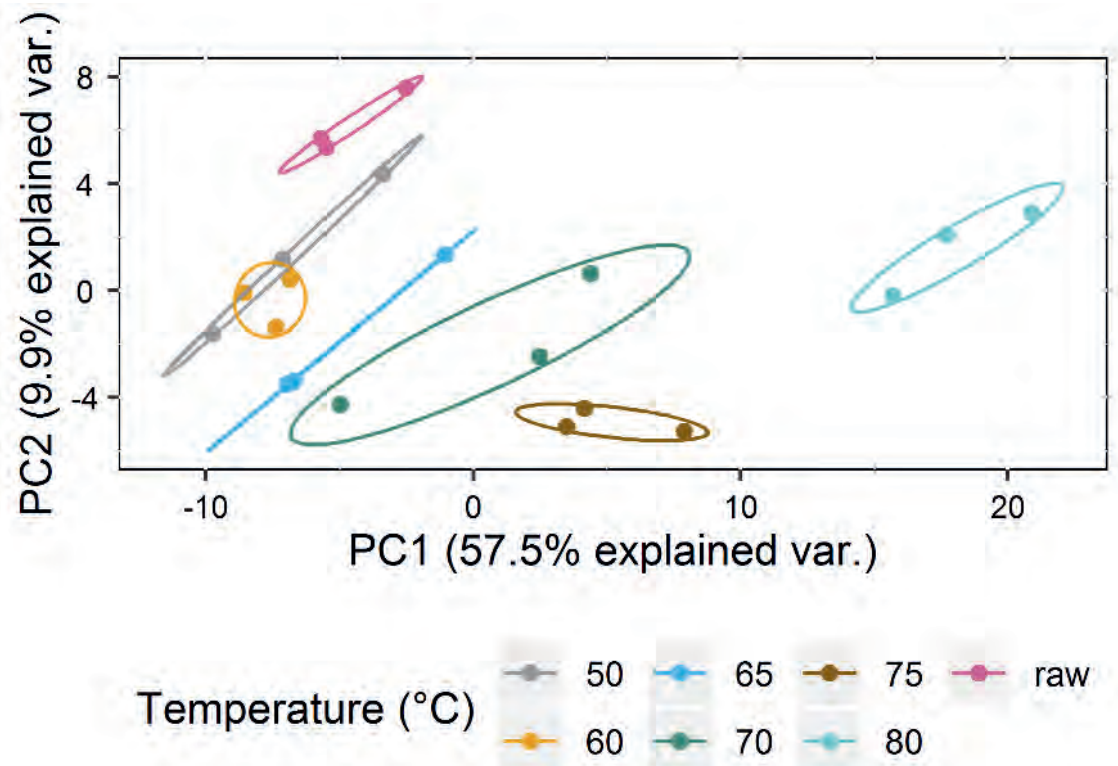

Figure 5-4 Principal Component Analysis (PCA) distinguished different heat-treated milk groups based on native protein profile. M ilk heated at 50 and $60{ }^{\circ} \mathrm{C}$ could not be distinguished from each other. Colored symbols refer to the seven milk groups tested. The first two principal axes explained $67.4 \%$ of the variance. The variation (\%) explained by each PCA axis is in parentheses. PC 1, principal component 1; PC 2, principal component 2. 


\subsubsection{Loss of allergy protection in murine OVA-induced food allergy model already evident}

from $65{ }^{\circ} \mathrm{C}$

To assess whether a reduction in the amount of native whey proteins results in a loss of the allergy-protective capacity, the same milk samples were tested in a murine OVA-induced food allergy model. As expected, intradermal challenge with OVA increased the acute allergic skin response in OVA-sensitized allergic control mice compared to PBS-sensitized control mice (Fig. 5-5A). Treating mice with raw milk prior to OVA-sensitization significantly reduced the acute allergic skin response compared to PBS-treated allergic control mice. A shift in allergy protection appeared to occur from 60 to $65{ }^{\circ} \mathrm{C}$; mice treated with milk heated at $60{ }^{\circ} \mathrm{C}$ still showed a significant reduction in the acute allergic skin response compared to PBS-treated allergic control mice, whereas milk heated at $65^{\circ} \mathrm{C}$ was no longer protective. A loss of allergyprotection was also observed in mice treated with milk heated at 70,75 , and $80^{\circ} \mathrm{C}(\mathbf{F i g} \cdot \mathbf{5 - 5 A})$. Although not significant, OVA-specific IgE levels were higher in OVA-sensitized allergic control mice compared to PBS-sensitized control mice. No differences in OVA-IgE levels were observed between milk-treated mice (Fig. 5-5B).

A
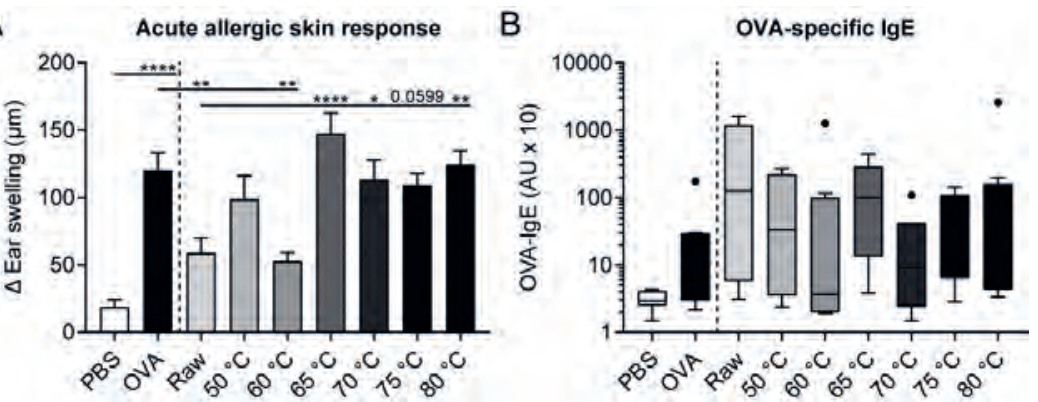

Figure 5-5 Heat treatment at $65^{\circ} \mathrm{C}$ or higher destroyed allergy-protective capacity of raw milk in murine OV A-induced food allergy model. (A) The acute allergic skin response (expressed as $\Delta$ ear swelling) measured $1 \mathrm{~h}$ after intradermal challenge in both ear pinnae with OVA. (B) OVA-specific IgE levels measured in serum $16 \mathrm{~h}$ after oral challenge with OVA. Data are presented as mean \pm SEM for the acute allergic skin response and as box-and-whisker Tukey plot (in which outliers are shown as separately plotted points) for OVA-specific IgE levels, $n=6$ in PBS group and $n=6-8$ in all other groups. $* \mathbf{P}<0.05, * * \mathbf{P}<0.01, * * * * \mathbf{P}<0.0001$ as analyzed with one-way ANOV A followed by Bonferroni's multiple comparisons test for pre-selected groups (A) or K ruskal-Wallis test for non-parametric data followed by Dunn's multiple comparisons test for pre-selected groups (B). OV A, ovalbumin; raw, raw cow's milk; $50-80{ }^{\circ} \mathrm{C}$, raw cow's milk heated at the indicated temperature for $30 \mathrm{~min}$; AU, arbitrary units. 


\subsubsection{Induction of regulatory Tr1 cells correspond to acute allergic skin response}

Since regulatory $\mathrm{T}$ cells (Tregs) are key for the induction of oral tolerance to food proteins (Pabst \& Mowat, 2012), the effect of the different milk types on Treg subsets in the spleen was assessed. The percentage of $\mathrm{CD} 25^{+} \mathrm{FoxP} 3^{+}$Treg cells was significantly decreased in OVAsensitized allergic control mice compared to PBS-sensitized control mice. $\mathrm{CD} 25^{+} \mathrm{FoxP} 3^{+}$Treg cell frequency did, however, not differ between milk-treated mice (Fig. 5-6A). Interestingly, the percentage of IL-10-producing $\operatorname{Tr} 1$ cells increased significantly in raw milk- and $50{ }^{\circ} \mathrm{C}$ milk-treated mice compared to PBS-treated allergic control mice (Fig. 5-6B). This increase coincided with the reduced acute allergic skin response observed in these groups (Fig. 5-5A). Although protection against allergic symptoms was also observed for milk heated at $60{ }^{\circ} \mathrm{C}$, the percentage of $\operatorname{Tr} 1$ cells was not increased simultaneously (Fig. 5-6B). Compared to raw milk, milk heated at 65,75 and $80{ }^{\circ} \mathrm{C}$ showed a reduction in $\operatorname{Tr} 1$ cell frequency (Fig. 5-6B), which is in line with the observed loss of protection against the OVA-induced acute allergic skin response (Fig. 5-5A). For the percentage of TGF- $\beta$-producing Th3 cells, the highest heating temperatures showed the lowest cell frequency, but differences were not significant (Fig. 5-6C).
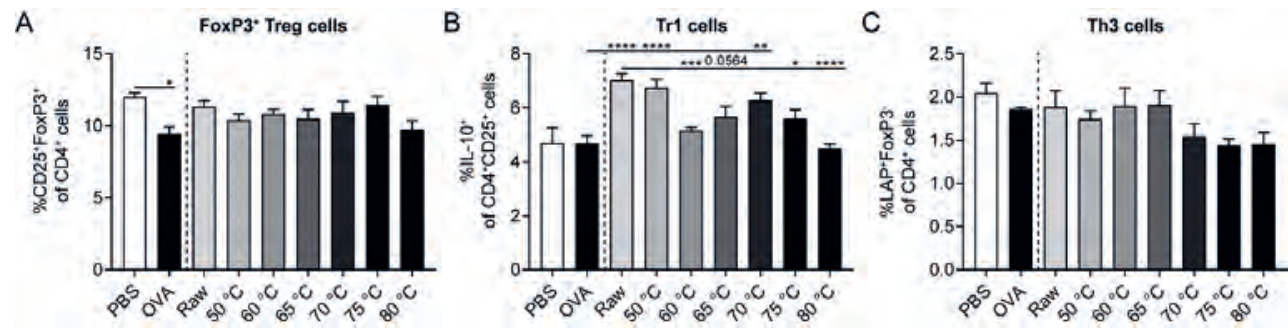

Figure 5-6 Percentage of regulatory Tr1 cells coincided with acute allergic skin response. Percentage of (A) F oxP3 ${ }^{+} \mathrm{Tr}_{\mathrm{reg}}$ cells (CD25+F oxP3 $3^{+}$of CD4+ cells), (B) Tr1 cells (IL $-10^{+}$of CD4+CD25+ cells), and (C) Th3 cells (L AP+F oxP3- of CD4 ${ }^{+}$ cells) in the spleen. Data are presented as mean \pm SE $M, n=6$ in PBS group and $n=6-8$ in all other groups. $* P<0.05$, $* * \mathbf{P}<0.01, * * * \mathbf{P}<0.001, * * * * \mathbf{P}<0.0001$ as analyzed with one-way ANOVA followed by Bonferroni's multiple comparisons test for pre-selected groups. OVA, ovalbumin; raw, raw cow's milk; 50-80 ${ }^{\circ} \mathrm{C}$, raw cow's milk heated at the indicated temperature for $\mathbf{3 0} \mathrm{min}$. 

dendritic cells (DCs)

A

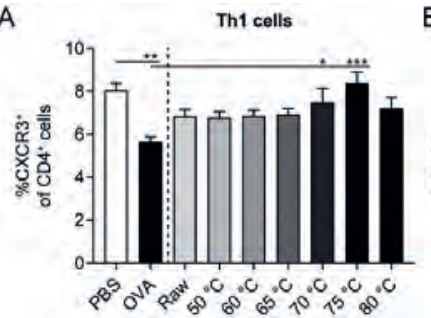

B

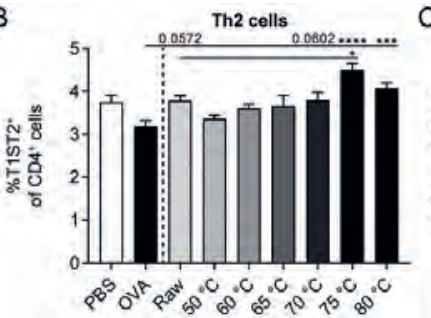

C CD11'MHCII' DCs

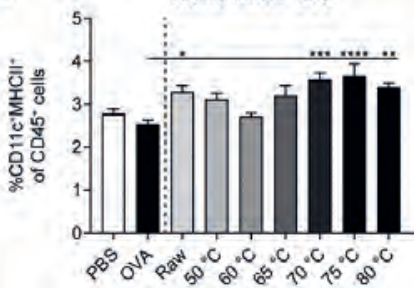

Figure 5-7 Increased Th1, Th2 and DC percentages at heating temperatures of $70^{\circ} \mathrm{C}$ and above. Percentage of (A) Th1 cells (CXCR3 $3^{+}$of CD4 $4^{+}$cells), (B) Th2 cells (T 1ST 2 $2^{+}$of CD4 cells), and (C) CD11c $\mathrm{M} \mathrm{HCII}^{+}$DCs (CD11c $\mathrm{M} \mathrm{HCII}^{+}$of CD45 cells) in the spleen. Data are presented as mean \pm SE M, $n=6$ in PBS group and $n=6-8$ in all other groups. ${ }^{*} \mathbf{P}<$ $0.05, * * \mathrm{P}<0.01, * * * \mathrm{P}<0.001, * * * \mathrm{P}<0.0001$ as analyzed with one-way ANOVA followed by Bonferroni's multiple comparisons test for pre-selected groups. OVA, ovalbumin; raw, raw cow's milk; $50-80^{\circ} \mathrm{C}$, raw cow's milk heated at the indicated temperature for $30 \mathrm{~min}$.

Besides Tregs, also other immune cells influence the strength of the allergic response. In order to investigate the effect of the different heating temperatures on Th1 cells, Th2 cells, and DCs, splenocytes were isolated and analyzed by flow cytometry. A decrease in Th1 cells was observed in OVA-sensitized allergic control mice compared to PBS-sensitized control mice (Fig. 5-7A). Th2 and DC frequency did not differ between these control groups (Fig. 5-7B \& C). Although raw milk treatment protected against allergic symptoms, which was associated with an increased percentage of regulatory $\operatorname{Tr} 1$ cells, it also tended to increase the percentage of Th2 cells (Fig. 5-7B). In addition, $\mathrm{CD} 11 \mathrm{c}^{+} \mathrm{MHCII}^{+} \mathrm{DCs}$ were elevated in raw milk-treated mice compared to PBS-treated allergic control mice (Fig. 5-7C). Milk heated at $70{ }^{\circ} \mathrm{C}$ or higher increased the percentages of Th1, Th2, and DCs compared to PBS-treated allergic control mice (Fig. 5-7A-C). These increased immune responses coincided with a loss of allergy protection (Fig. 5-5A) and low numbers of regulatory Tr1 cells (Fig. 5-6B).

\subsubsection{Denaturation of several immunologically active whey proteins already started at} $60 / 65^{\circ} \mathrm{C}$

Even though the overall protein profile (BCA assay, clustered heat map, and PCA) showed major differences in the native protein profile from $70 / 75{ }^{\circ} \mathrm{C}$ onwards, a loss of allergy protection was already demonstrated at $65^{\circ} \mathrm{C}$. To get a more detailed perspective on changes in immunologically active whey proteins, a heat map solely focusing on these specific whey proteins was created. In this heat map, a relatively clear difference is observed between milk 
samples heated at temperatures below $65^{\circ} \mathrm{C}$ and milk samples heated at temperatures of $65^{\circ} \mathrm{C}$ and above (Fig. 5-8), which corresponds to the loss of allergy protection observed in the murine OVA-induced food allergy model (Fig. 5-5A).
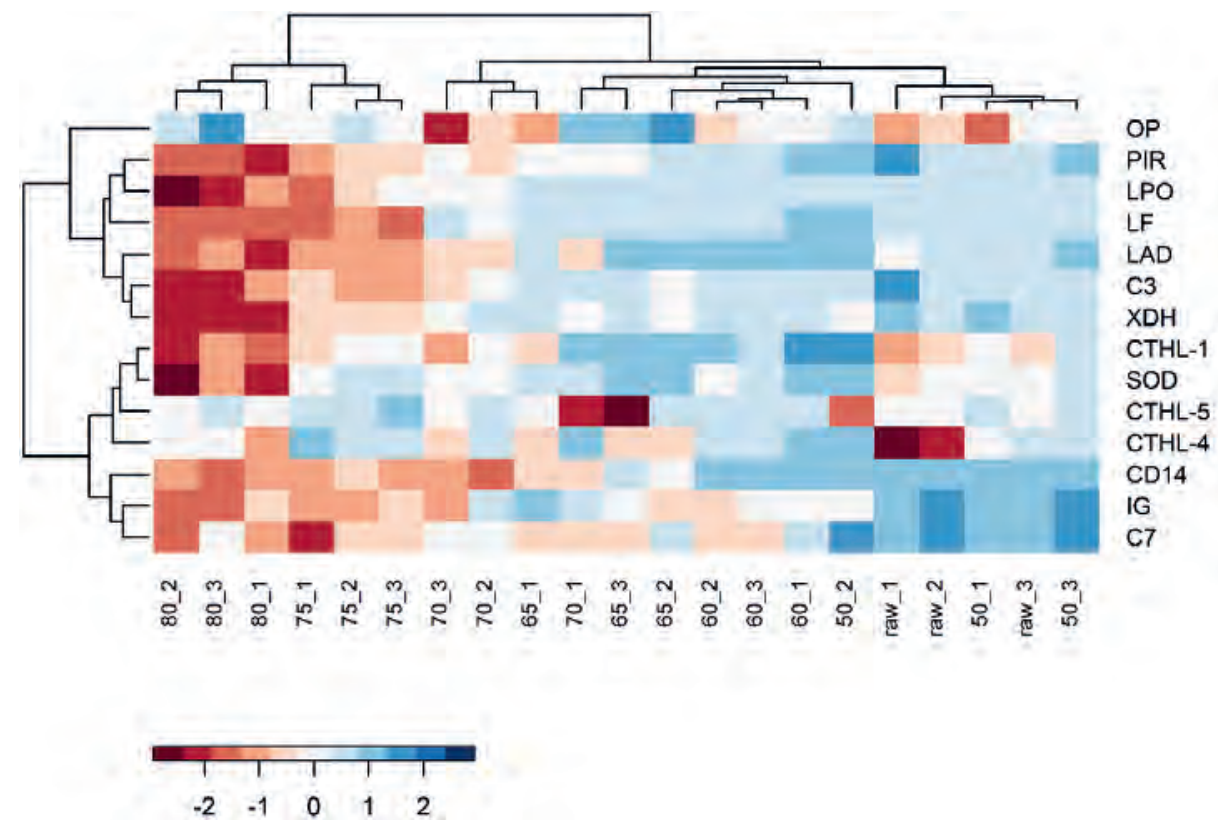

Figure 5-8 Hierarchical cluster analysis of immunologically active whey proteins demonstrated that the denaturation of these proteins already starts at $65{ }^{\circ} \mathrm{C}$. Protein profile of whey fraction samples based on Z score normalized iBAQ values. Columns reflect individual samples. The number indicates the heating temperature, while the number after the underscore indicates the replicate. Rows reflect immunologically active whey proteins. Hierarchical clustering was performed using complete agglomeration method and a E uclidean distance metric. The color scale reflects the iBAQ value-based Z score. OP, osteopontin; PIR, polymeric immunoglobulin receptor; L PO, lactoperoxidase; L F, lactoferrin; LAD, lactadherin; C 3, complement component 3; XDH, xanthine dehydrogenase/oxidase; CTHL -1, cathelicidin-1; SOD super oxide dismutase; CTHL -5, cathelicidin-5; CTHL -4, cathelicidin-4; CD14, monocyte differentiation antigen CD 14; IG, immunoglobulin; C 7, complement component 7.

To zoom in on the effects of the various heat treatments on the immunologically active whey proteins, and to get an idea about their concentration, Table 5-1 was compiled to show the differences in iBAQ intensities for these proteins. Interestingly, complement component 7 (C7) decreased significantly at $60{ }^{\circ} \mathrm{C}$ and polymeric immunoglobulin receptor and monocyte differentiation antigen $\mathrm{CD} 14$ at $65^{\circ} \mathrm{C}$. For immunoglobulins, denaturation also started already around $60 / 65{ }^{\circ} \mathrm{C}$, but due to a larger variation between replicates, the reduction only reached significance at $75^{\circ} \mathrm{C}$. Most of the other immunologically active whey proteins only decreased significantly from $75{ }^{\circ} \mathrm{C}$, although they already started to decrease, to varying extents, from 
lower temperatures. For superoxide dismutase, cathelicidins, and osteopontin, no clear decrease with increasing temperature was observed (T able 5-1).

Table 5-1 iB AQ values of immunologically active whey proteins after different heat treatments.

\begin{tabular}{|c|c|c|c|c|c|c|c|}
\hline$\underbrace{\log 10(\mathrm{IBAQ})}_{\text {Protein name }}$ & Raw & $50^{\circ} \mathrm{C}$ & $60^{\circ} \mathrm{C}$ & $65^{\circ} \mathrm{C}$ & $70^{\circ} \mathrm{C}$ & $75^{\circ} \mathrm{C}$ & $80^{\circ} \mathrm{C}$ \\
\hline Complement C 7 & $3.86 \pm 0.22$ & $4.06 \pm 0.14$ & $2.96 \pm 0.30^{*}$ & $2.95 \pm 0.34^{*}$ & $2.99 \pm 0.09 *$ & $2.38 \pm 0.58 *$ & $2.38 \pm 0.54^{*}$ \\
\hline $\begin{array}{l}\text { Monocyte differentiation } \\
\text { antigen CD14 }\end{array}$ & $5.02 \pm 0.08$ & $5.07 \pm 0.20$ & $4.98 \pm 0.14$ & $3.82 \pm 0.69^{*}$ & $2.50 \pm 0.44^{*}$ & $2.70 \pm 0.18^{*}$ & $2.36 \pm 0.28^{*}$ \\
\hline $\begin{array}{l}\text { Polymeric immunoglobulin } \\
\text { receptor }\end{array}$ & $7.14 \pm 0.61$ & $6.92 \pm 0.20$ & $6.79 \pm 0.11$ & $6.03 \pm 0.28^{*}$ & $5.64 \pm 0.52 *$ & $4.99 \pm 0.25^{*}$ & $3.96 \pm 0.20^{*}$ \\
\hline L actadherin & $5.49 \pm 0.10$ & $5.85 \pm 0.15$ & $5.97 \pm 0.07^{*}$ & $5.83 \pm 0.19$ & $4.93 \pm 0.15^{*}$ & $4.62 \pm 0.07 *$ & $4.30 \pm 0.38^{*}$ \\
\hline Immunoglobulin & $4.70 \pm 0.15$ & $4.29 \pm 0.63$ & $3.35 \pm 0.35$ & $3.71 \pm 0.68$ & $3.32 \pm 0.99$ & $2.54 \pm 0.31^{*}$ & $2.12 \pm 0.58^{*}$ \\
\hline Complement C 3 & $5.90 \pm 0.70$ & $5.68 \pm 0.09$ & $5.71 \pm 0.05$ & $5.29 \pm 0.36$ & $5.03 \pm 0.32$ & $4.23 \pm 0.38^{*}$ & $3.36 \pm 0.74^{*}$ \\
\hline L actoperoxidase & $6.49 \pm 0.15$ & $6.54 \pm 0.19$ & $6.70 \pm 0.08$ & $6.61 \pm 0.21$ & $6.19 \pm 0.25$ & $4.74 \pm 1.08^{*}$ & $3.49 \pm 1.10^{*}$ \\
\hline $\begin{array}{l}\text { Xanthine } \\
\text { dehydrogenase/oxidase }\end{array}$ & $5.40 \pm 0.18$ & $5.32 \pm 0.33$ & $5.37 \pm 0.05$ & $5.22 \pm 0.26$ & $4.98 \pm 0.18$ & $4.30 \pm 0.22 *$ & $2.77 \pm 0.19^{*}$ \\
\hline L actoferrin & $6.58 \pm 0.02$ & $6.61 \pm 0.28$ & $6.75 \pm 0.11$ & $6.44 \pm 0.31$ & $6.03 \pm 0.23$ & $2.85 \pm 0.24 *$ & $2.16 \pm 0.33^{*}$ \\
\hline Superoxide dismutase & $4.28 \pm 0.15$ & $4.66 \pm 0.19$ & $4.68 \pm 0.20$ & $4.87 \pm 0.16^{*}$ & $4.52 \pm 0.21$ & $4.59 \pm 0.18$ & $3.47 \pm 0.40^{*}$ \\
\hline C athelicidin-1 & $4.44 \pm 0.13$ & $4.90 \pm 0.29$ & $5.05 \pm 0.15^{*}$ & $4.87 \pm 0.30$ & $4.70 \pm 0.39$ & $4.66 \pm 0.09^{*}$ & $4.10 \pm 0.26^{*}$ \\
\hline C athelicidin-4 & $3.10 \pm 0.77$ & $4.04 \pm 0.30^{*}$ & $4.09 \pm 0.09^{*}$ & $3.55 \pm 0.09$ & $3.96 \pm 0.46$ & $4.12 \pm 0.06^{*}$ & $3.65 \pm 0.24$ \\
\hline C athelicidin-5 & $4.49 \pm 0.14$ & $4.29 \pm 0.72$ & $4.88 \pm 0.07$ & $4.08 \pm 1.22$ & $4.18 \pm 0.92$ & $4.89 \pm 0.13$ & $4.60 \pm 0.07^{*}$ \\
\hline Osteopontin & $6.54 \pm 0.11$ & $6.54 \pm 0.25$ & $6.61 \pm 0.08$ & $6.69 \pm 0.30$ & $6.49 \pm 0.34$ & $6.65 \pm 0.04$ & $6.79 \pm 0.20^{*}$ \\
\hline
\end{tabular}

${ }^{*} \mathbf{p}<0.05$ compared to raw milk as analyzed with Dunnett's multiple comparisons test. Raw, raw cow's milk; $50-80{ }^{\circ} \mathrm{C}$, raw cow's milk heated at the indicated temperature for $30 \mathrm{~min}$.

\subsection{Discussion}

The present study demonstrates that heat treatment of milk results in a substantial loss of native whey proteins due to denaturation and aggregation processes. A considerable decrease in the amount of native whey proteins was observed from $75{ }^{\circ} \mathrm{C}$ and above, but immunologically active whey proteins already started to decrease from $65{ }^{\circ} \mathrm{C}$. Interestingly, the loss of immunologically active whey proteins coincided with the loss of allergy protection observed in a murine OVA-induced food allergy model. In this model, we observed a clear shift in allergy protection from 60 to $65{ }^{\circ} \mathrm{C}$, where milk heated at $65^{\circ} \mathrm{C}$ or higher was no longer protective.

Raw cow's milk consumption has repeatedly been reported to protect against childhood asthma and allergies (Abbring, Ryan, et al., 2019; Abbring et al., 2017; Brick et al., 2016; Ege et al., 2007; Loss et al., 2011; Perkin \& Strachan, 2006), which has often been related to the bioactive whey protein fraction of the milk (Abbring, Hols, et al., 2019; van Neerven et al., 2012), 
although a direct link between individual proteins and this protection has never been demonstrated. The whey protein fraction of raw cow's milk consists of hundreds of proteins and each of these proteins has its own denaturation kinetics (Brick et al., 2017). Heating milk at different temperatures may therefore result in different native protein profiles. Relating the changes in these native protein profiles to the capacity of the milk to prevent the development of allergic diseases may give an indication of the proteins responsible for the protective effect. The current study therefore used small differences in heating temperature $(50,60,65,70,75$, and $80{ }^{\circ} \mathrm{C}$, chosen to be ranging from almost no to almost full whey protein denaturation) and tested the various heat-treated milk samples for their native protein profile and their allergyprotective capacity.

As expected, the number of denatured proteins increased with increased heating intensity. Consequently, the native protein profile differed considerably between the different heat-treated milk samples. The different data analyses of the overall native protein profile (BCA assay, clustered heat map, and PCA) showed a significant difference between milk heated $\geq 75^{\circ} \mathrm{C}$ and milk heated $<75^{\circ} \mathrm{C}$, which is in line with our previous results (Xiong et al., 2020b). Similar effects were also reported by Brick et al. who demonstrated a decrease in detectable native whey proteins after heating with an intensity higher than pasteurization $\left(72{ }^{\circ} \mathrm{C}\right.$ for $20 \mathrm{~s}$ ) (Brick et al., 2017). According to the BCA assay, a significant decrease in the native whey protein concentration was also observed in milk heated at $70{ }^{\circ} \mathrm{C}$. However, due to a larger variation between replicates, this group was not clustered with milk heated at 75 and $80{ }^{\circ} \mathrm{C}$ in the subsequent analyses. When specifically focusing on immunologically active whey proteins, their denaturation already started at a lower temperature. This is in accordance with previous studies, which demonstrated that particularly the immune active proteins present in the whey fraction have a high heat sensitivity (Zhang et al., 2016). Although also for these proteins a sharp decrease was observed from $75^{\circ} \mathrm{C}$, a gradual decrease was already visible from $65^{\circ} \mathrm{C}$.

To determine the consequences of the heat-induced reduction in native whey proteins on the allergy-protective effects associated with raw milk, milk samples were tested in a murine OVAinduced food allergy model. As demonstrated before, treating mice with raw milk prior to sensitization and challenge with OVA significantly reduced the acute allergic skin response (Abbring, Ryan, et al., 2019; Abbring, Wolf, et al., 2019). The current study shows that this protective effect lasted up to $60{ }^{\circ} \mathrm{C}$. Interestingly, a loss of allergy protection was observed at heating temperatures of $65{ }^{\circ} \mathrm{C}$ and above, thereby coinciding with the denaturation of immunologically active whey proteins. The effects on the acute allergic skin response were not 
reflected in OVA-IgE levels but did correspond with regulatory $\operatorname{Tr} 1$ cell numbers, involved in the induction of oral tolerance to food proteins (Pabst \& Mowat, 2012).

As mentioned earlier, particularly immunologically active whey proteins were shown to denature from $65^{\circ} \mathrm{C}$ onwards. A closer look at these proteins revealed that the concentration of complement $\mathrm{C} 7$, monocyte differentiation antigen CD14, and polymeric immunoglobulin receptor decreased significantly from this temperature. Complement $\mathrm{C} 7$ is a protein involved in the complement system of the innate immune system and is part of the membrane attack complex. How complement C7 may be involved in the allergy-protective effect of raw cow's milk remains unclear, although a role of the complement pathway in the development of asthma and allergy has been described (Gerard \& Gerard, 2002). Monocyte differentiation antigen CD14 is also a molecule of the innate immune system and acts as a receptor and carrier for bacterial endotoxin. Interestingly, CD14 expression was markedly higher in farmers' children than in non-farmers' children (Lauener et al., 2002). In addition, polymorphisms in the CD14 gene have been demonstrated to modify the effect of raw cow's milk consumption on allergic diseases (Bieli et al., 2007; Ege, Strachan, et al., 2011). Polymeric immunoglobulin receptor is an $\mathrm{Fc}$ receptor which facilitates the transcytosis of soluble IgA and immune complexes. Breast milk immune complexes are shown to be potent inducers of oral tolerance and prevented asthma development in mice (Mosconi et al., 2010). Whether the formation of immune complexes also contributes to the allergy-protective effect of raw cow's milk remains to be elucidated.

The significant decrease in complement $\mathrm{C} 7, \mathrm{CD} 14$, and polymeric immunoglobulin receptor concentrations after heat treatment at $65{ }^{\circ} \mathrm{C}$ may partly explain the loss of allergy protection at the same temperature. However, many other immunologically active whey proteins also showed a, non-significant, decrease around $65^{\circ} \mathrm{C}$. Because of the many immunologically active whey proteins present in raw cow's milk, even small changes in each of them could affect the final allergic response. In addition, we have to acknowledge that some proteins like enzymes with a relatively low abundance but a high activity, such as alkaline phosphatase, were not detected with the method used. The wide variety of proteins and the subtle changes in each of them after the different heat treatments makes it hard to pinpoint one unique protein responsible for the allergy-protective effect. Eventually, the synergistic effect of changes in several proteins simultaneously probably underlies the loss of protection.

In addition to the observed loss of protection from $65^{\circ} \mathrm{C}$, this study also demonstrates that raw milk can be heated up to $60{ }^{\circ} \mathrm{C}$ (for $30 \mathrm{~min}$ ) without negative consequences for its allergy- 
protective capacity. Immunologically active whey proteins were hardly affected by these temperatures and although milk heated at $50{ }^{\circ} \mathrm{C}$ did not significantly reduce the acute allergic skin response, the PCA could not distinguish between 50 - and $60{ }^{\circ} \mathrm{C}$-treated milk samples. This knowledge can be very relevant for the development of mildly processed milk in which bioactive raw milk components are retained and future studies should investigate whether the observed effects also hold for other allergens. However, heat treatment at these low temperatures is not considered safe and has only been used to gain a better understanding of the immunologically active whey proteins involved in the allergy-protective effects of raw cow's milk.

Besides the loss of immunologically active whey proteins, the formation of protein aggregates can also underlie the loss of allergy protection upon heat treatment. These protein aggregates were reported to have an increased immunogenicity compared to their native counterparts because of a shifted uptake from enterocytes to Peyer's patches (Roth-Walter et al., 2008). Heat-induced protein aggregate formation, through disulphide interchange, was therefore assessed in the differentially heated milk samples. Protein aggregates started to form from $75{ }^{\circ} \mathrm{C}$ onwards and might therefore be responsible for the enhanced immune response, demonstrated by increased percentages of Th1 cells, Th2 cells, and DCs, observed in mice treated with milk samples heated at the same temperature. However, since the loss of allergy protection was already demonstrated from $65{ }^{\circ} \mathrm{C}$, the formation of immunogenic protein aggregates is most likely not responsible for this effect.

In conclusion, we demonstrated that the allergy-protective effect of raw cow's milk is lost after heating milk for $30 \mathrm{~min}$ at $65{ }^{\circ} \mathrm{C}$ or higher. This loss of protection coincided with a reduction in native immunologically active whey proteins. A significant reduction was demonstrated for complement $\mathrm{C} 7$, monocyte differentiation antigen $\mathrm{CD} 14$, and polymeric immunoglobulin receptor, but many other immunologically active whey proteins also showed a decrease around $65{ }^{\circ} \mathrm{C}$. As, possible immunogenic, aggregates were not yet formed at this temperature, they probably do not play a role in the allergy-protective effect of raw cow's milk. The current study provides a better understanding of the mechanistic relation between heat damage to whey proteins and allergy development, which is essential for the development of microbiologically safe alternatives to raw cow's milk that still retain its protective capacity. 


\section{Conflicts of interest}

J.G. and B.C.A.M.v.E. are partly employed at Danone Nutricia Research. All other authors report no conflicts of interest.

\section{Acknowledgements}

This research was financially supported by Danone Nutricia Research, the Sino Dutch Dairy Development Centre (http://www.sdddc.org) and Sino-Dutch Doctoral Program on Sustainable Dairy from China Scholarship Council and the Software AG Foundation Germany. 

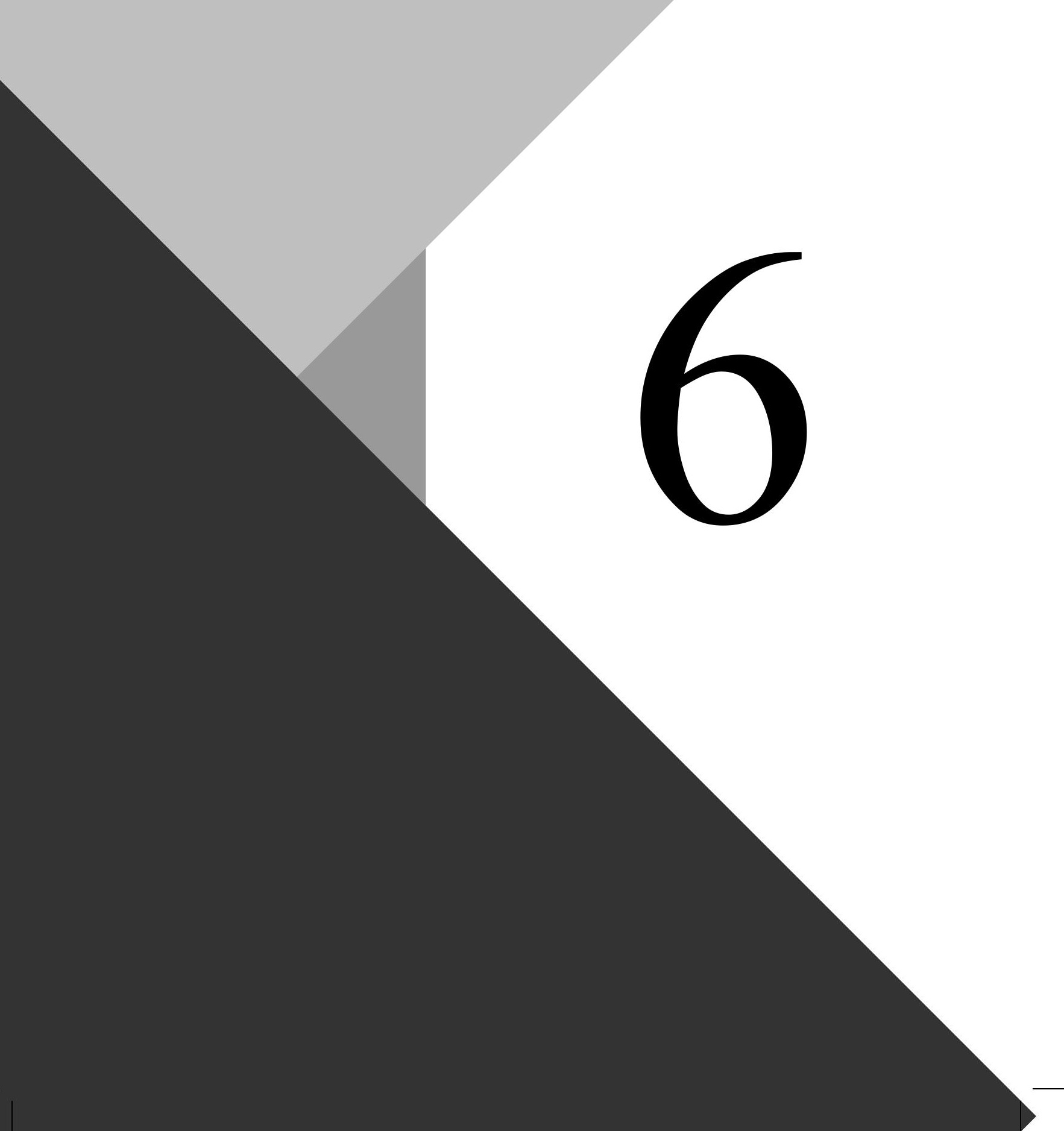


\section{CHAPTER 6. \\ General Discussion}




\subsection{Introduction}

Milk contains a wide variety of nutritional and bioactive components. Heat treatment, as applied in pasteurization and sterilization, is generally used to inactivate pathogens and spoilage microorganisms, to ensure safety upon human consumption as well as to prolong the shelf life of dairy products. However, heat treatment can also induce denaturation, aggregation, and glycation of whey proteins, which may affect their nutritional properties and biological activity. This thesis investigated the effect of heat treatment within the pasteurization temperature range on denaturation and aggregation of immune-active proteins in bovine milk, and the consequences of denaturation and aggregation on their digestion and biological activity. This was done in order to provide a better understanding about the mechanisms by which heat treatment decreased the immune activity of native immune-active proteins in the bovine milk matrix. In addition, the knowledge obtained can help to optimize dairy processing, for example, by adjusting the heating intensity or when possible combining with non-thermal technologies, to maximally preserve biological activity of immune-active proteins on the condition that milk safety can still be ensured. SDS-PAGE, FASP, and in-gel digestion combined with LC-MS/MS were the main techniques applied to characterize the changes of physicochemical properties of whey proteins (C hapter 2-5), whereas microbiological assays and an animal experiment were applied to evaluate the change of biological activities of the proteins (Chapter 3-5).

To achieve this objective, the disulphide linked aggregation of lactoferrin with major whey protein ( $\beta$-lactoglobulin, $\alpha$-lactalbumin, bovine serum albumin) was studied, including a detailed analysis of disulphide bond interchange, both among lactoferrin molecules and between lactoferrin and $\beta$-lactoglobulin, using LC-MS/MS (Chapter 2). Among these three major whey proteins, $\beta$-lactoglobulin is the most active protein involved in the disulphide linked aggregation with lactoferrin. Among lactoferrin's cysteine residues, Cys36, Cys45, Cys115, Cys198, Cys405, Cys457, Cys515, Cys573 were the most reactive for disulphide bond interchange, both among lactoferrin molecules and between lactoferrin and $\beta$-lactoglobulin, when heated at $85^{\circ} \mathrm{C}$. Besides the major whey proteins, other low abundant whey proteins may also be involved in the aggregation of lactoferrin, but to a much lesser extent. The aggregation of lactoferrin with the other whey proteins (including non-micellar casein), and the effect on the bacteriostatic activity and digestion of lactoferrin were studied in C hapter 3. Aggregation of lactoferrin was enhanced in the presence of whey proteins, which accelerated the loss of bacteriostatic activity. Mild heating conditions $\left(<70{ }^{\circ} \mathrm{C} / 30 \mathrm{~min}\right)$ induced denaturation and aggregation of lactoferrin with a concomitant enhancement of its gastric digestion, while more 
intensive aggregation at higher temperatures decreased its gastric digestion in an invitro infant digestion model. In addition to lactoferrin, hundreds of potentially bioactive proteins are present in bovine milk. The denaturation of whey proteins in milk, especially immune-active proteins with its corresponding modification of bacteriostatic activity of whey after different heat treatments was investigated in Chapter 4. The data showed that the bacteriostatic activity of milk serum was rapidly decreased after heating at $75{ }^{\circ} \mathrm{C}$ for $30 \mathrm{~min}$. This decrease of bacteriostatic activity correlated with a loss of native immune-active proteins, especially lactoferrin, lactoperoxidase and several low-abundant antibacterial proteins (lipopolysaccharide-binding protein, mannose-binding protein $\mathrm{C}$, peptidoglycan recognition protein 1, haptoglobin). Different proteins may contribute differently to specific bioactivities of whey. The denaturation of whey proteins in milk, especially immune-active proteins after different heat treatments and the corresponding change of the allergy-protective activity of milk, were evaluated in Chapter 5. Heating at $65^{\circ} \mathrm{C}$ for 30 min reduced the allergy-protective activity of milk in a murine model, which was correlated with the decrease of complement $\mathrm{C} 7$, monocyte differentiation antigen $\mathrm{CD} 14$, and polymeric immunoglobulin receptor, and a globally subtle decrease of other immune-active proteins.

Combining all these results, aggregation of lactoferrin in a whey protein model system, milk serum, and skim milk and the effect of this aggregation on its digestion and biological activity are discussed first in this chapter. Second, the changes of the proteome of native whey after different heat treatments in the pasteurisation range and aggregation of whey proteins in the presence/absence of lactoferrin are discussed. Third, the contribution of different whey proteins in the bacteriostatic and allergy-protective activity of raw milk, according to their changes after different heat treatment, are discussed. Last, the potential to preserve native immune-active proteins, combining low temperature heat treatment with non-thermal methods is discussed. Finally, the main conclusion from this thesis are given.

\subsection{E ffect of heat treatment on physicochemical properties and biological activity of lactoferrin}

\subsubsection{Aggregation of lactoferrin in a whey protein model system, milk serum and skim milk}

Thermal stability of whey proteins are highly dependent on the matrix. Functional properties of whey proteins are modified after unfolding and aggregation among proteins (Liu et al., 2016; Mulcahy, Fargier-Lagrange, Mulvihill, \& O'Mahony, 2017). Understanding of the underlying mechanisms can help to manipulate the functional and nutritional properties of whey protein in 
different food matrices (Wagner et al., 2020). The breakage of native disulphide bonds and reformation into different intermolecular disulphide bonds, combined with hydrophobic and electrostatic interactions, were suggested to contribute to an irreversible aggregation of whey proteins (Anema, 2000; Wijayanti et al., 2014).

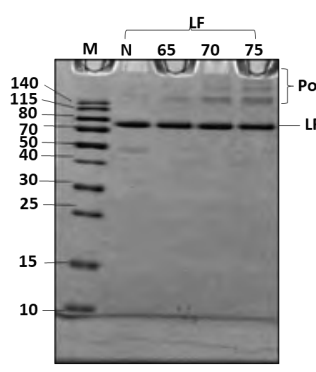

A

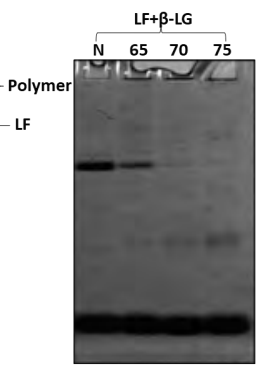

B

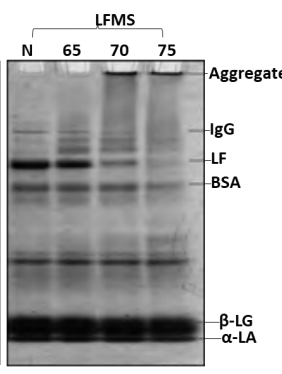

C

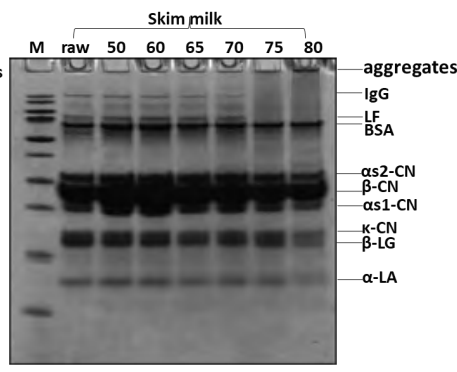

D

Figure 6-1 Disulphide linked aggregation of lactoferrin when heated alone (A, C hapter 3), with $\beta$-lactoglobulin (B, Chapter 3), in milk serum (c, Chapter 3) and in skim milk (D, chapter 5). LFM S, milk serum with addition of $1 \mathrm{mg} / \mathrm{ml}$ lactoferrin. $\mathrm{N}$, sample without heat treatment; $65 / 70 / 75 / 80$ refer to samples being heated at $65 / 70 / 75 / 80{ }^{\circ} \mathrm{C}$ for $30 \mathrm{~min}$. Abbreviations: IgG, immunoglobulin G; LF, lactoferrin; BSA, bovine serum albumin; $\beta$-LG, $\beta$-lactoglobulin; $\alpha$-LA, $\alpha$ lactalbumin.

Our study showed that disulphide linked aggregation of lactoferrin was largely affected by the presence of other whey proteins during heating, as indicated by the difference in the level of disulphide linked aggregation of lactoferrin when it was heated alone in milk ultrafiltrate (C hapter 2), in protein model systems (Chapter 2), in milk serum (Chapter 3), and in skim milk (Chapter $4 \&$ 5) in the temperature range of $50-85^{\circ} \mathrm{C}$, as measured by non-reducing SDSPAGE and LC-MS/MS.

Aggregation of lactoferrin occurred at $65{ }^{\circ} \mathrm{C}$ or above when lactoferrin was heated alone, as indicated by the increase of turbidity of lactoferrin solutions (C hapter $\mathbf{3}$ ), which is consistent with published results (Brisson et al., 2007b). Disulphide linked aggregation of lactoferrin also occurred from $65^{\circ} \mathrm{C}$, but to a less extent, as indicated by a small quantity of dimers and trimers in the $65{ }^{\circ} \mathrm{C} / 30 \mathrm{~min}$ heated samples when it was heated in milk ultrafiltrate in the absence of other milk proteins, which indicates that the breakage of existing disulphide bonds already occurred from $65{ }^{\circ} \mathrm{C}$ (Chapter $\mathbf{2} \& \mathbf{3}$ ). However, a more clear decrease of monomeric lactoferrin was observed only after heating at $75{ }^{\circ} \mathrm{C}$, indicating that intermolecular disulphide bond interchanges were not happening to a large extent for isolated lactoferrin at temperatures $<75{ }^{\circ} \mathrm{C}$. Intramolecular disulphide bonds are important for stabilizing the secondary and tertiary structure of proteins. The secondary structure of lactoferrin, making up the backbone of 
the protein, changed after heating at $70{ }^{\circ} \mathrm{C}$, while the tertiary structure was affected at lower temperatures indicating changes in overall structure, probably flexible loops at lower temperatures (Schwarcz, Carnelocce, Silva, Oliveira, \& Goncalves, 2008). However, more disulphide-linked aggregates were observed only after heating at $75^{\circ} \mathrm{C} / 30 \mathrm{~min}$, which means that the reduction of disulphide bonds or intramolecular disulphide bond interchange was predominant at temperatures lower than $75{ }^{\circ} \mathrm{C}$, which is in agreement with the changes of free thiol group content of the protein model system in Chapter 2. Taking all results together, only minor disulphide breakage seems to occur below $75^{\circ} \mathrm{C}$ whereas more extensive intermolecular disulphide rearrangements occur at higher temperatures.

When lactoferrin was heated in a protein model system consisting of $\alpha$-LA, $\beta$-LG and/or BSA, $\beta$-LG was observed to enhance the disulphide-linked aggregation of lactoferrin the most, while $\alpha$-LA and BSA did hardly affect it. $\beta$-LG contains a free thiol group, which is hidden in the native state, that becomes accessible upon unfolding, making it reactive for disulphide bond interchanges with other protein, such as $\alpha$-LA (Schokker et al., 2000). $\alpha$-LA was involved in disulphide aggregation with itself or lactoferrin only at temperatures above $85{ }^{\circ} \mathrm{C}$ because it contains no free thiol group. Cys36, Cys45, Cys115, Cys198, Cys405, Cys457, Cys515 and Cys573 of lactoferrin were observed to be involved in intermolecular disulphide bond rearrangements between lactoferrin and $\beta$-lactoglobulin when heated at $85{ }^{\circ} \mathrm{C}$. Those cysteines are located both in the N-lobe and C-lobe of lactoferrin. Probably due to the high temperature used in our experiments, it induced the unfolding of the two lobes simultaneously, although the C-lobe is known to be more compact than the N-lobe (Anderson, Baker, Norris, Rice, \& Baker, 1989). The high temperature used may thus explain why cysteine residues in both lobes participated in the intermolecular disulphide bond interchange.

When lactoferrin was heated in milk serum containing whey proteins and non-micellar caseins, more lactoferrin aggregated via disulphide crosslinking, as indicated by the big decrease of monomeric lactoferrin from $65{ }^{\circ} \mathrm{C}$ to $70{ }^{\circ} \mathrm{C}$, as measured by non-reducing SDS-PAGE (Chapter 3), and an increase of the level of aggregated lactoferrin from $65{ }^{\circ} \mathrm{C}$ to $70{ }^{\circ} \mathrm{C}$, as determined by LC-MS/MS (Chapter 3). Lactoferrin was shown to be more heat-labile when heated in milk than in a phosphate buffer (Sánchez et al., 1992), which can be partly ascribed to aggregation via intermolecular disulphide bond interchange between lactoferrin and whey proteins, according to our study. Intermolecular disulphide bond formation may also impact the physical properties of proteins, such as increasing the gel strength (Visschers \& de Jongh, 2005). Therefore, the increase of the elastic modulus of WPI gels after adding $30 \%$ lactoferrin 
(Li \& Zhao, 2018) can be partly explained by the formation of intermolecular disulphide bonds between lactoferrin and whey proteins, especially with $\beta$-lactoglobulin according to our results.

When lactoferrin was heated in skim milk, the largest decrease of the monomeric form of lactoferrin occurred from $70{ }^{\circ} \mathrm{C}$ to $75^{\circ} \mathrm{C}$, indicating that most of the lactoferrin was involved in disulphide linked aggregation at $75^{\circ} \mathrm{C}$. This coincides with a previous study which showed that lactoferrin was not detected in the whey fraction from rennet skim milk that was heated at $75{ }^{\circ} \mathrm{C}$ (Brisson et al., 2007a). Comparing the thermal aggregation of lactoferrin in milk serum and skim milk, the presence of casein may prevent disulphide bond interchange between lactoferrin and whey proteins. When casein micelles are present, $\beta$-LG may preferentially aggregate with the $\kappa$-casein on the surface of the casein micelle (Vasbinder, Alting, \& de Kruif, 2003), making it less reactive towards lactoferrin. Casein micelles were reported to promote denaturation, but limit aggregation of whey protein (O'Kennedy \& Mounsey, 2006). Based on these previous findings, lactoferrin would be expected to be less involved in $\beta$-LG-induced aggregation in skim milk, compared to the whey protein systems used in this thesis.

From our results, heating lactoferrin in the presence of whey proteins can increase the irreversible aggregation by sulphydryl-disulphide interchange. Comparing the different whey proteins, $\beta$-LG affected the covalent aggregation of lactoferrin the most. Therefore, decreasing the level of $\beta-\mathrm{LG}$ or blocking its free thiol group may also contribute to reducing aggregation of lactoferrin. A variety of approaches to reduce the aggregation of whey proteins were previously studied. SH-blocking reagents, such as dithio(bis)-p-nitrobenzoate, Nethylmaleimide and DL-thioctic acid can effectively prevent disulphide linked aggregation, but they can also induce other undesirable modification by reacting with other side-groups of protein (Wijayanti et al., 2014). The addition of free cysteine for preventing thiol-disulphide exchange was also explored. Aggregation of $\alpha$-LA and whey protein isolate was reduced at a low dose of cysteine (Nielsen, Lund, Davies, Nielsen, \& Nielsen, 2018; Zhu \& Labuza, 2010). Besides SH-blocking reagents, $\mathrm{H}_{2} \mathrm{O}_{2}$, a oxidizing agent, was reported to decrease the aggregation of WPI by interfering with the intermolecular sulfhydryl-disulphide interchange (Sutariya \& Patel, 2017). To prevent lactoferrin from irreversible denaturation and aggregation, other protective components were also explored. Heat stability of lactoferrin can be improved in the presence of sodium alginate and okra polysaccharide (Li et al., 2019; Xu, Zhao, Guo, \& $\mathrm{Du}, 2019)$. Although many studies have tried to prevent aggregation of whey proteins by incorporating other components, most of them are using components that are not food grade and require precise control of their concentration. From a practical point of view, it would thus 
be more feasible and easier to heat lactoferrin and other protein ingredients in dairy products separately, which may decrease the disulphide linked aggregation of lactoferrin with other proteins, ultimately helping to decrease its irreversible denaturation, as indicated from our study

\subsubsection{The effect of aggregation on digestion of lactoferrin}

Unfolding, aggregation and chemical modification may occur upon heating, resulting in different digestion kinetics of the protein (van Lieshout et al., 2019). Heat-induced denaturation was reported to enhance the digestion of globular proteins, such as $\beta$-LG (Peram et al., 2013). Glycation, on the other hand, was reported to hinder the hydrolysis of protein (Deng, Wierenga, Schols, Sforza, \& Gruppen, 2017; Zenker, van Lieshout, van Gool, Bragt, \& Hettinga, 2020). Therefore, the impact of heating of milk proteins on their digestion kinetics is highly dependent on the balance of the different reactions that are induced, which in turn depend on the precise heat load and food matrix composition.

Our study showed that heating lactoferrin at $65-75{ }^{\circ} \mathrm{C}$ for $30 \mathrm{~min}$ can generally enhance the gastric digestion of lactoferrin compared to the unheated one, but without obvious effects on overall gastrointestinal digestion (Chapter 3). Noticeably, the digestion of lactoferrin heated at $65-75^{\circ} \mathrm{C}$ in milk serum showed an increase at $65-70{ }^{\circ} \mathrm{C}$, but then decreased when heated at 70 $75^{\circ} \mathrm{C}$. Our preliminary study showed that the Maillard reaction between lactoferrin and lactose hardly happened when heated at $65-85{ }^{\circ} \mathrm{C}$ for $30 \mathrm{~min}$ in an aqueous system, indicating that glycation is not involved in the alteration of lactoferrin digestion. Therefore, unfolding and aggregation may play more critical roles for the digestion of lactoferrin. For the point of molecular structure, the proteolysis rate of a protein was highly dependent on the accessibility of a cleavage site in a protein to protease. Pepsin and trypsin are the main enzyme for protein digestion in the gastrointestinal tract (Singh, Ye, \& Ferrua, 2015). Pepsin prefers to cleave around bulky hydrophobic residues of protein (Tang, 1963), which are exposed upon unfolding, which is thereby increasing the accessibility to pepsin. Trypsin cleaves peptide chains mainly at the carboxyl side of the amino acids lysine or arginine (Olsen, Ong, \& Mann, 2004), which is largely affected by the glycation level of the protein, because this reaction can modify lysine and arginine (Deng et al., 2017). The digestion by trypsin was hardly diminished due to limited glycation in our protein samples at lysine or arginine residues, as mentioned above. Aggregation was also reported to affect the digestion rate of a protein. Large aggregates may have a smaller total surface area than smaller aggregates, which may therefore cause more resistance to digestion (Zhang \& Vardhanabhuti, 2014). The size of the aggregates was dependent on both hydrophobic interaction and disulphide bonds. Intermolecular disulphide bonds were suggested 
to result in larger insoluble protein aggregates of lactoferrin (Brisson et al., 2007b), and disulphide bonded aggregates were harder to digest than non-covalent linked aggregates (Zhang \& Vardhanabhuti, 2014). Therefore, blocking disulphide bond interchange between proteins, as discussed in section 6.2.1, could be a way to prevent the formation of large insoluble aggregates and produce smaller aggregates, leading to higher digestibility. The results obtained in this thesis about digestion of lactoferrin heated in the presence/absence of whey proteins may benefit designing milk products enriched in lactoferrin from the aspect of controlling the heating intensity and the matrix in which it is heated, aimed at retaining intact lactoferrin as much as possible during gastric digestion, as the protein is most active in its native from.

\subsubsection{The effect of heat treatment on bacteriostatic activity of lactoferrin}

Biological activities of lactoferrin are highly dependent on its native structure. Heat induced structural changes may lead to changes of its biological activity. Heating lactoferrin at $100{ }^{\circ} \mathrm{C}$ for 3 min decreased its antitumor activity, whereas no obvious decrease was observed when it was heated at $50{ }^{\circ} \mathrm{C}$ and $70{ }^{\circ} \mathrm{C}$ for $3 \mathrm{~min}$ (Li et al., 2019). Similarly, heat treatment at $95{ }^{\circ} \mathrm{C}$ for $10 \mathrm{~min}$ led to the loss of the osteogenic activity of lactoferrin, while heating at $65{ }^{\circ} \mathrm{C} / 30 \mathrm{~min}$, $72{ }^{\circ} \mathrm{C} / 10 \mathrm{~s}$ and $85^{\circ} \mathrm{C} / 10 \mathrm{~min}$ did not affect this activity, although changes of secondary structure were observed in all heated forms of lactoferrin (Fan et al., 2019). When lactoferrin was heated in a phosphate buffer, the bacteriostatic activity of bovine lactoferrin decreased after heating at $72{ }^{\circ} \mathrm{C} / 15 \mathrm{~min}$ and $85^{\circ} \mathrm{C} / 10 \mathrm{~min}$, due to aggregation of lactoferrin, while no decrease was found after heating at $62.5^{\circ} \mathrm{C}$ for $30 \mathrm{~min}$ and $72{ }^{\circ} \mathrm{C}$ for $15 \mathrm{~s}$ (Conesa et al., 2010; Harouna et al., 2015). Combining all the results, aggregation affected the biological activity of lactoferrin more than just by its unfolding, which was supported by our data in Chapter $\mathbf{2} \& \mathbf{3}$. We observed that the loss of LF activity after heating depended on the matrix, with a rapid loss in activity when heated in the presence of whey protein (C hapter 3), because of extensive aggregation between LF and whey protein. LF has a strong bacteriostatic activity, and to keep it active it can be heated separately to prevent aggregation with other proteins when it would be added to dairy products. When lactoferrin was heated in the presence of casein micelles (C hapter $\mathbf{5}$ ), as discussed in 6.2.1, heat-induced sulfhydryl/disulphide interchange of lactoferrin may actually be reduced due to the reaction between $\beta$-LG and $\kappa$-casein on the surface of casein micelles (Chapter 5). However, the effect of the presence of casein on the bacteriostatic activity of lactoferrin when heating in the presence of whey protein needs to be studied further.

When protein is ingested, it needs to go through the gastrointestinal digestion before it can exert its biological activity, often in the intestinal tract. Aggregation affected the bacteriostatic 
activity not only by directly modifying the structure of protein, but also by altering the digestion kinetics of protein. As discussed in 6.2.2, aggregation can affect the gastric digestion of proteins. From the perspective of in vivo digestion, which was part of the animal experiment (Chapter 5), retaining proteins in a form that resists gastric digestion is indeed important for retention of its biological activity. Due to the different mechanisms by which lactoferrin exerts its biological activities, conformational changes may affect the biological activity of lactoferrin to a different degree. The different studies in this thesis show that heating lactoferrin in the presence of whey proteins resulted in more aggregation of lactoferrin, and a faster reduction of its bacteriostatic activity. It can be assumed that other biological activities, such as immunomodulatory activity, would also be reduced by aggregation. Therefore, heating lactoferrin and other protein ingredients in dairy products separately can prevent aggregation of lactoferrin, ultimately retaining more biological activity.

\subsection{E ffect of heat treatment on proteome and biological activity of whey protein}

\subsubsection{Proteome of native whey protein after different heat treatment}

Heat treatment combined with acid precipitation to remove casein and denatured whey proteins, followed by FASP and LC-MS/MS were applied to get a comprehensive understanding how different heat treatments affected the whey proteome, especially focusing on the low abundant proteins. In Chapter $\mathbf{4}$, skim milk was heated at $65,70,75,80$, and $85^{\circ} \mathrm{C}$. Whey protein profiles showed the largest differences between milk heated at $<75^{\circ} \mathrm{C}$ and $\geq 75^{\circ} \mathrm{C}$. In $\mathbf{C h a p t e r} \mathbf{5}$, skim milk was heated at $50,60,65,70,75$, and $80^{\circ} \mathrm{C}$. Whey protein profiles showed the largest difference between milk heated at $\leq 75^{\circ} \mathrm{C}$ and $>75^{\circ} \mathrm{C}$. This clustering was consistent with Brick's study (Brick et al., 2017), which showed a difference in protein profiles between high temperature heat treatments (boiling, UHT, ESL) with heating temperatures above $95{ }^{\circ} \mathrm{C}$ and no/low temperature heat treatments (raw, skimmed, pasteurized) that involved heating temperatures below $72{ }^{\circ} \mathrm{C}$. Our study provided evidence that heating at $75{ }^{\circ} \mathrm{C} / 30 \mathrm{~min}$ is a turning point for the change of native whey proteins, which fills the gap between the heat treatments of $72{ }^{\circ} \mathrm{C}$ and $95^{\circ} \mathrm{C}$ as studied previously. A change of the biological activity of whey protein was thus expected after heating at $75{ }^{\circ} \mathrm{C} / 30 \mathrm{~min}$, as the loss of biological activity was expected to coincide with the loss of the proteins' native form. 


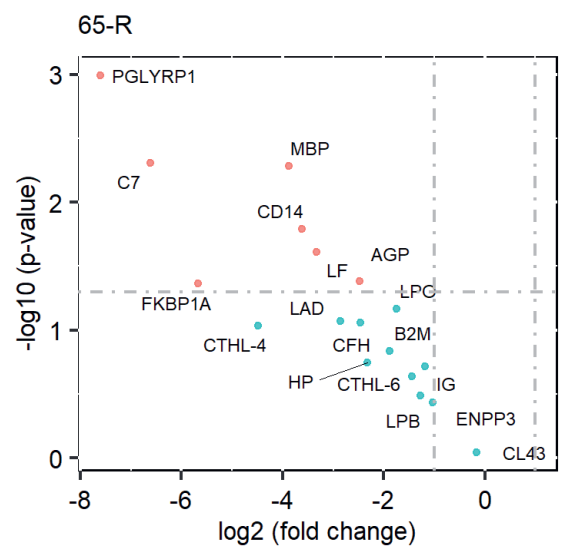

- Decreased - Not significant

$75-R$

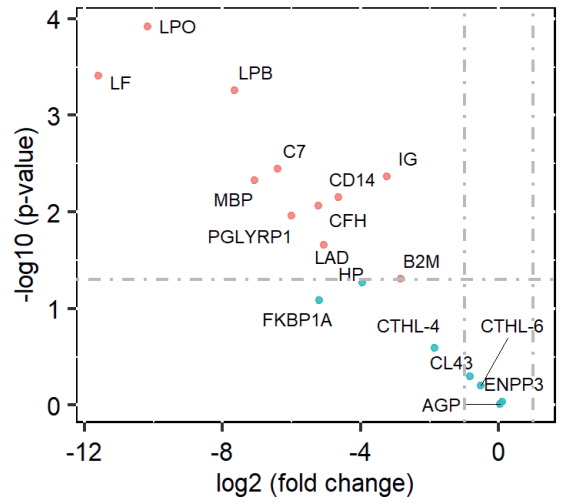

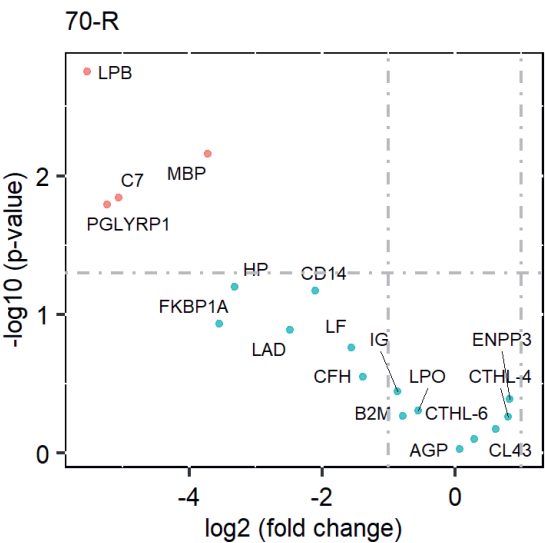

Decreased Not significant

$80-\mathrm{R}$

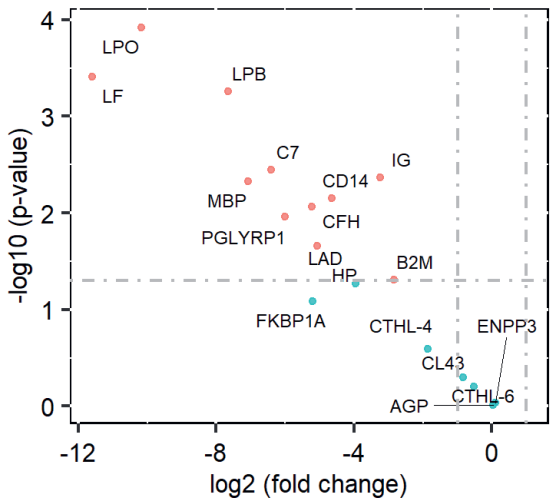

Decreased - Not significant

Figure 6-2 Volcano plots of milk serum proteins after different heat treatments compared with raw milk. 65-R, 70-R, 75-R, 80-R represent the significantly changed immune-active proteins in milk heated at $65,70,75,80^{\circ} \mathrm{C}$ compared with raw milk. LF, lactoferrin; L PO, lactoperoxidase; IG, immunoglobulins; C D14, monocyte differentiation antigen CD14; LBP, lipopolysaccharide-binding protein; C7, complement component C 7; ENPP3, ectonucleotide pyrophosphatase/phosphodiesterase family member 3; M BP, mannose-binding protein C; B 2M, beta-2-microglobulin; FKBP1A, peptidyl-prolyl cis-trans isomerase FKBP1A; CATHL 4, cathelicidin-4; CATHL6, cathelicidin-6; CL 43, collectin-43; CFH, complement factor H; PGLYRP1, peptidoglycan recognition protein 1; HP, haptoglobin; AGP, alpha-1-acid glycoprotein; LAD, lactadherin.

Brick et al. (Brick et al., 2017) showed that 23 proteins differed between high heat treatments (boiling, UHT, ESL) and no/low heat treatment, among which most of them were immuneactive proteins. However, it is not clear from that study from which temperature the changes started, due to the large temperature gaps between the commercially processed samples. A more 
detailed perspective on the changes of immune-active proteins in this temperature range can be found in this thesis (Fig. 6-2). When heated at $50{ }^{\circ} \mathrm{C}$ for $30 \mathrm{~min}$, no obvious effects on the immune-active proteins was observed (Chapter 5), coinciding with Brick's study, in which no change of whey proteins was observed in milk treated at $50{ }^{\circ} \mathrm{C}$ (Brick et al., 2017). When heated at $60{ }^{\circ} \mathrm{C}$ for $30 \mathrm{~min}$, complement component $\mathrm{C} 7$ started to decrease (C hapter 5). This heat load is a bit lower than LTLT $\left(62.5^{\circ} \mathrm{C} / 30 \mathrm{~min}\right)$. Therefore, our result fill the gap of a recent study showing that complement component $\mathrm{C} 7$ was not detectable after being heated at $95{ }^{\circ} \mathrm{C}$ for $15 \mathrm{~s}$, of which the heat load is higher than LTLT (Liu, Zhang, Han, Zhang, \& Zhou, 2020). When heated at $65^{\circ} \mathrm{C}$ for $30 \mathrm{~min}$, complement component $\mathrm{C} 7$, monocyte differentiation antigen $\mathrm{CD} 14$, and polymeric immunoglobulin receptor showed a significant decrease (Chapter 5). The change of CD14 in bovine milk coincides with that in human milk, where it was shown that holder pasteurization $\left(62.5^{\circ} \mathrm{C} / 30 \mathrm{~min}\right.$ ) decreased the concentration of CD14 (Cossey et al., 2009). A decrease of polymeric immunoglobulin receptor in bovine milk after commercial pasteurization was also previously observed (Zhang, Boeren, et al., 2016). However, another study reported that it decreased after HTST $\left(72{ }^{\circ} \mathrm{C} / 15 \mathrm{~s}\right)$ but not after LTLT $\left(63{ }^{\circ} \mathrm{C} / 30 \mathrm{~min}\right)$ heating of colostrum (Chatterton et al., 2020), which indicates that $63{ }^{\circ} \mathrm{C}-65^{\circ} \mathrm{C}$ for 30 minutes is the critical heat load for the denaturation of polymeric immunoglobulin receptor, although this temperature needs to be confirmed in future studies. Besides that, mannose-binding protein C, alpha-1-acid glycoprotein, peptidoglycan recognition protein 1, haptoglobin also showed a decrease after $65^{\circ} \mathrm{C} / 30 \mathrm{~min}$ treatment (C hapter 4). In human milk, pasteurization $\left(62.5^{\circ} \mathrm{C} / 30\right.$ min) did not affect the level of mannose-binding protein C (Cossey et al., 2009). The temperature range $62.5^{\circ} \mathrm{C}-65^{\circ} \mathrm{C}$ may thus also for this protein be critical, but it is important that the data was collected from bovine milk and human milk, respectively, which extensively differ in composition, which may have impacted the effect of heating on protein denaturation. As shown in Chapter $\mathbf{2} \& \mathbf{3}$, and discussed in 6.2, the denaturation and concomitant change of biological activity of proteins were affected by the presence of other proteins during heating. Therefore, the heat stability of mannose-binding protein $\mathrm{C}$ within the pasteurization range needs to be determined in a bovine milk matrix. Alpha-1-acid glycoprotein was reported to be decreased by $10 \%$ after heating at $62-63{ }^{\circ} \mathrm{C}$ for $30 \mathrm{~min}$ (Zhang, Boeren, et al., 2016), which is in agreement with our data. A recent study reported that peptidoglycan recognition protein decreased after a $95{ }^{\circ} \mathrm{C} / 15 \mathrm{~s}$ heat treatment (Liu, Zhang, et al., 2020). In camel milk, peptidoglycan recognition protein was not detectable after heating at $80{ }^{\circ} \mathrm{C}$ for $60 \mathrm{~min}$ (Felfoul, Jardin, Gaucheron, Attia, \& Ayadi, 2017). Peptidoglycan recognition protein decreased after $65^{\circ} \mathrm{C} / 30 \mathrm{~min}$ in our study, which filled the temperature gap in the above mentioned studies in 
which the heat treatments used were more intense than LTLT $\left(62.5^{\circ} \mathrm{C} / 30 \mathrm{~min}\right)$. When heated at $70{ }^{\circ} \mathrm{C}$ for $30 \mathrm{~min}$, lactadherin decreased in addition to above mentioned proteins (C hapter 4

\& 5), which extends a recent which that showed that lactaherin quantities were not significantly affected by LTLT and HTST, which are both less intense than $70{ }^{\circ} \mathrm{C} / 30 \mathrm{~min}$ (Chatterton et al., 2020). When heated at $75^{\circ} \mathrm{C}$, most immune-active proteins denatured, as shown in $\mathbf{C}$ hapter $\mathbf{5}$, including lactoferrin, immunoglobulin, complement $\mathrm{C} 3$, lactoperoxidase and xanthine dehydrogenase/oxidase. The native form of those proteins could almost not be detected at all when heated at $80{ }^{\circ} \mathrm{C}$ and $85{ }^{\circ} \mathrm{C}$, where the iBAQ value presented in Chapter $\mathbf{4} \& \mathbf{5}$ were imputed from a normal distribution for the statistical analysis.

Generally, immune-active proteins were largely affected by heat treatments $\geq 75^{\circ} \mathrm{C} / 30 \mathrm{~min}$. However, some immune-active proteins already decreased to a certain extent from $60{ }^{\circ} \mathrm{C} / 30$ min. Because each protein has a specific denaturation temperature as well as biological activity, it is possible that the biological activity already changes after a heat treatment below $75^{\circ} \mathrm{C} / 30$ min. The impact of these proteome changes on proteins' functionality will be discussed in 6.3.4.

\subsubsection{Disulphide linked aggregation of whey protein with/without addition of lactoferrin after heating}

When milk serum was heated at 65,70 , and $75{ }^{\circ} \mathrm{C}$ for $30 \mathrm{~min}$, disulphide linked aggregates were visualized by non-reducing SDS-PAGE (Chapter 3). Those proteins involved in aggregates that are too large to enter the SDS-PAGE remained in the stacking gel and were identified and quantified by LC-MS/MS. In total, 36 proteins were identified and quantified, including the major whey proteins, non-micellar casein and several low abundant proteins. The cysteines and disulphide bond distribution of these proteins was displayed in the Table 6-1. Nine of these low-abundant proteins were immune related proteins, including lactoferrin, lactoperoxidase, xanthine dehydrogenase, polymeric immunoglobulin receptor, lactadherin, complement $\mathrm{C} 3$, complement factor B, sulfhydryl oxidase, and complement C7. After heating at $75{ }^{\circ} \mathrm{C}$ for $30 \mathrm{~min}$, the level of most identified proteins in the aggregates significantly increased, including the above mentioned immune-active proteins, as shown in Chapter $\mathbf{3}$, which suggests that those proteins have undergone disulphide linked aggregation. This result can partly explain the loss of native whey proteins in bovine milk heated at $75^{\circ} \mathrm{C}$ for $30 \mathrm{~min}$ as found in Chapter 4, as such covalently bound whey protein aggregates would have been removed by the acidified ultracentrifugation step as used for the sample preparation. 
Table 6-1 Cysteines and disulphide bond distribution of 36 proteins identified in protein aggregates.

\begin{tabular}{|c|c|c|c|}
\hline Protein name & $\begin{array}{l}\text { Number of cysteine } \\
\text { residues }\end{array}$ & $\begin{array}{l}\text { Number of disulphide } \\
\text { bonds }\end{array}$ & $\begin{array}{l}\text { Free thiol } \\
\text { groups }\end{array}$ \\
\hline Lactoferrin & 34 & 17 & 0 \\
\hline Beta-lactoglobulin & 5 & 2 & 1 \\
\hline Alpha-lactalbumin & 8 & 4 & 0 \\
\hline Bovine serum albumin & 35 & 17 & 1 \\
\hline Lactoperoxidase & 15 & 7 & 1 \\
\hline Kappa-casein & 2 & 1 & 0 \\
\hline Alpha-S1-casein & 0 & 0 & 0 \\
\hline Xanthine dehydrogenase/oxidase & 38 & - & - \\
\hline Polymeric immunoglobulin receptor & 20 & - & - \\
\hline Butyrophilin subfamily 1 member & 10 & - & - \\
\hline Ig-like domain-containing protein & - & - & - \\
\hline Fibroblast growth factor-binding protein 1 & 4 & - & - \\
\hline Uncharacterized protein & - & - & - \\
\hline $\begin{array}{l}\text { Sodium-dependent phosphate transport } \\
\text { protein } 2 \mathrm{~B}\end{array}$ & 26 & - & - \\
\hline Lactadherin & 12 & - & - \\
\hline Complement $\mathrm{C} 3$ & 27 & - & - \\
\hline Serotransferrin & 18 & 36 & 0 \\
\hline $\begin{array}{l}\text { ATP-binding cassette sub-family G } \\
\text { member } 2\end{array}$ & 11 & - & - \\
\hline Platelet glycoprotein 4 & 10 & - & - \\
\hline Uncharacterized protein & - & - & - \\
\hline Beta-1,4-galactosyltransferase 1 & 7 & - & - \\
\hline Uncharacterized protein & - & - & - \\
\hline Fatty acid-binding protein & 5 & - & - \\
\hline Complement factor B & 23 & - & - \\
\hline Actin, cytoplasmic 2 & 6 & - & - \\
\hline Lipocalin 2 & 2 & - & - \\
\hline Junction plakoglobin & 13 & - & - \\
\hline Sulfhydryl oxidase & 38 & - & - \\
\hline Fibrinogen gamma-B chain & 11 & - & - \\
\hline Perilipin-2 & 5 & - & - \\
\hline Uncharacterized protein & - & - & - \\
\hline Fibronectin & 62 & - & - \\
\hline Fatty acid synthase & 50 & - & - \\
\hline Complement $\mathrm{C} 7$ & 56 & - & - \\
\hline Desmoplakin & 13 & - & - \\
\hline
\end{tabular}


Lactoferrin was added into milk serum prior to heat treatment to get more insights into the interaction between lactoferrin and whey proteins. When milk serum to which lactoferrin was added was heated at 65,70 , and $75^{\circ} \mathrm{C}$ for $30 \mathrm{~min}$, the level of proteins involved in disulphide linked aggregation increased, especially after heating at $70{ }^{\circ} \mathrm{C}$ for $30 \mathrm{~min}$ (Chapter $\mathbf{3}$ ). The nine immune-active proteins mentioned earlier showed a significant increase in the aggregates formed upon heating at $65^{\circ} \mathrm{C}$ to $70{ }^{\circ} \mathrm{C}$, indicating the interaction between lactoferrin and those proteins, directly or indirectly. Noticeably, $\beta$-LG showed a significantly increase in the amount of aggregates after adding lactoferrin also from $65{ }^{\circ} \mathrm{C}$ to $70{ }^{\circ} \mathrm{C}$, and the direct disulphide interchange of $\beta$-LG with lactoferrin and the main contribution for aggregation of lactoferrin with the three major whey proteins, as described in Chapter $\mathbf{2} \& \mathbf{3}$, were confirmed. However, for other low-abundant proteins, it is not clear whether they interact with lactoferrin directly or that the aggregation is mediated by $\beta-\mathrm{LG}$, because most of them increased in the aggregates concomitantly with $\beta$-LG when heated at $70{ }^{\circ} \mathrm{C}$ after adding $\mathrm{LF}$, which thus needs to be investigated further. Direct aggregation between lactoferrin and $\kappa$-casein was also previously reported (Brisson et al., 2007a). The increase of $\kappa$-casein in the aggregates after heating at $75^{\circ} \mathrm{C}$ in the presence of lactoferrin is thus probably due to direct interaction between these proteins. Although most proteins are associated by disulphide linked aggregation, it cannot excluded that there is involvement of other covalent interaction, e.g. because $\alpha_{\mathrm{s} 1}$-casein that contains no cysteine was also present in the aggregates, which might have been due to its association with $\kappa$-casein.

Our study showed that the loss of native immune-active proteins was partly associated with disulphide interchange among whey proteins. The addition of lactoferrin enhanced the disulphide linked aggregation of whey protein, suggesting that aggregation of whey protein was affected by protein composition. Therefore, when enriching bioactive proteins in products, the concentration of these proteins and heat induced interaction among different proteins and the potential consequences of these interactions for their activity need to be considered.

\subsubsection{Implication of whey protein in biological activity of raw milk}

Because proteins contribute differently to the specific biological activities of whey and milk, the gradual denaturation of whey proteins between $50-85{ }^{\circ} \mathrm{C}$ may result in different turning points for different biological activities, which was confirmed in this thesis. The rapid decrease of bacteriostatic activity occurred after heating at $75^{\circ} \mathrm{C} / 30 \mathrm{~min}$ (C hapter 4), while the loss of allergy protective activity already occurred at a temperature of $65^{\circ} \mathrm{C}$ (Chapter 5), indicating 
that different proteins predominated in exerting these two activities, or that the requirement of the protein to be correctly folded differs for different functionalities.

The bacteriostatic proteins in whey are mainly lactoferrin, lactoperoxidase and immunoglobulin, with some other low-abundant proteins. The decrease of the bacteriostatic activity of milk serum was associated with the reduction of the native form of these bacteriostatic proteins. When milk was heated at $65{ }^{\circ} \mathrm{C}$ and $70{ }^{\circ} \mathrm{C}$ for 30 mins, the bacteriostatic activity decreased slightly, which was associated with a slight decrease of lactoferrin, monocyte differentiation antigen $\mathrm{CD} 14$, complement $\mathrm{C} 7$, mannose-binding protein $\mathrm{C}$, and peptidoglycan recognition protein 1 . The bacteriostatic activity showed a larger decrease after heating at $75^{\circ} \mathrm{C}$, which was associated with a significant decrease of lactoferrin, lactoperoxidase and most other immuneactive proteins (C hapter $\mathbf{4})$.

Different from the bacteriostatic activity, that decreased rapidly after $75^{\circ} \mathrm{C} / 30 \mathrm{~min}$, the loss of allergy protective activity already occurred from $65^{\circ} \mathrm{C} / 30 \mathrm{~min}$, which was associated with a decrease of polymeric immunoglobulin receptor, complement component $\mathrm{C} 7$ and monocyte differentiation antigen CD14 (C hapter 5). However, their specific role in the loss of the allergyprotective effect still needs to be confirmed by studying the effect of purified proteins or fractions enriched in one or more of these proteins. For example, adding alkaline phosphatase in pasteurized milk was suggested to restore the allergy-protective effect of milk that was destroyed by heat processing for $15 \mathrm{~s}$ at $78{ }^{\circ} \mathrm{C}$ (Abbring et al., 2019). In addition to the above mentioned proteins, immunoglobulin, lactoferrin, xanthine dehydrogenase, complement component $\mathrm{C} 3$ also showed a slight decrease, which is similar to the results of $\mathbf{C}$ hapter $\mathbf{4}$.

Whey protein, as a whole, would possess a stronger biological activity due to synergy between the immune-active proteins. Although part of the immune-active proteins are heat stable, their global biological activity may decrease due to denaturation of other heat-labile proteins, which result in the loss of a synergic effect. For example, lactoferrin can form a complex with osteopontin (Liu et al., 2019). The denaturation of lactoferrin may affect the formation of this complex, thus decreasing the biological activity of the complex, even if osteopontin itself would not be affected by the heat treatment.

Our results suggest that different whey proteins contribute to specific bioactivities, which was reflected by the change of two studied bioactivities, bacteriostatic activity and allergy protective activity, after different heat treatments. Heat processing of whey-protein containing products, in which these biological activities need to be retained, thus needs to be customized to achieve 
the maximal preservation of the specific required activity. For retaining the bacteriostatic activity, a heat intensity below $75^{\circ} \mathrm{C} / 30 \mathrm{~min}$ would meet the requirement. For preservation of the allergy protective activity, on the other hand, a heat intensity below $65{ }^{\circ} \mathrm{C} / 30 \mathrm{~min}$ would need to be applied, which means that microbiological safety can't be guaranteed. This may however be solved by applying non-thermal processing methods, as these may be able to inactivate pathogen, while retaining the proteins' bioactivities.

\subsection{Non-thermal dairy processing to preserve more immune-active whey proteins}

Our study showed that heat processing resulted in a decrease of native immune-active proteins to a different degree, depending on the precise heat load. As heat treatments below the regular pasteurisation heat load may lead to issues with microbial safety, non-thermal processing or decreased heat treatment combined non-thermal processing may be good alternatives to prevent denaturation of immune-active proteins and simultaneously ensuring microbiological safety. Non-thermal technology, including pulsed electric fields processing (PEF), high pressure processing (HPP), ultrasound, ultraviolet treatment (UV-C) and microfiltration were explored for their application in dairy. Some information is available about their effect on bioactive proteins and the biological activity of milk, although more evidence is needed.

PEF in combination with low temperature heating has the potential to achieve microbiological safety in milk equivalent to conventional thermal pasteurisation, while inducing relative minor chemical and physical changes (Buckow, Chandry, Ng, McAuley, \& Swanson, 2014). It can also provide greater effective retention of lactoferrin than pasteurisation (Sui, Roginski, Williams, Versteeg, \& Wan, 2010). However, the effect of PEF on the whey proteome as a whole has not been studied yet.

HPP has been well studied as an alternative to conventional thermal pasteurization based on its efficient inactivation of microorganisms. The effect of HPP on proteins varied depending on both HPP intensity and types of milk. HPP increasing from 400 to $600 \mathrm{MPa}$ resulted in more denaturation of native milk proteins, leading to altered immunogenicity, compared with HTST (Bogahawaththa, Buckow, Chandrapala, \& Vasiljevic, 2018; Liu et al., 2020). For human milk, HHP at $500 \mathrm{MPa}$ for 8 min better preserved lactoferrin, lysozyme and lipase than LTLT (Pitino et al., 2019). These conflicting results may be caused by different intensity and the particular type of milk (bovine vs human). Therefore, a precise intensity of HPP that can inactivate pathogens and simultaneously preserve bioactive compounds needs to be further investigated 
in different types of milk. Although ultrasound was found to eliminate spoilage and potential pathogens to a required level without a negative effect on the total protein or casein content (Cameron, McMaster, \& Britz, 2009), the ultrasonic application on milk needs additional study because it was shown to lead to more loss of native proteins in bovine milk compared to LTLT, HTST and HPP.

The potential of UV-C treatment to preserve the bioactive proteins was explored in both human milk and bovine milk. It was reported that UV-C irradiated human milk showed a similar bacteriostatic activity to unheated milk, and significantly higher levels of immunological proteins than LTLT $\left(62.5^{\circ} \mathrm{C} / 30 \mathrm{~min}\right)$ on the condition of a $5-\log _{10}$ bacterial reduction (Christen et al., 2013). Also in bovine milk, UV-C treatment can retain more native whey proteins than LTLT and HTST, again based on a $10^{5}$ reduction of native bacteria in milk (Liu, Xiong, et al., 2020).

Microfiltration can remove pathogens and ensure microbiological safety of milk very well (Saboyainsta \& Maubois, 2000), which was, for example, applied for making cheese from raw milk. However, a direct comparison of the retention of bioactive proteins, and their activity, between microfiltered and pasteurized milk is lacking.

From the perspective of feasibility of industrial processing, microfiltration is a promising technique that can be easily applied since it can be applied on a large scale and also already has been used to produce many different dairy ingredients. Although a microfiltration membrane is easily blocked by milk fat, if microfiltration is proven to be a promising way to preserve the immune-active proteins, skim milk with most native protein retained can be produced. Also, mixing pasteurized cream and microfiltrated skim milk to produce whole milk is possible. In addition, the microfiltrated skim milk could also be added into normally pasteurized milk, to produce semi-skim milk enriched in native immune-active proteins. Generally, although there is a potential of non-thermal processing technologies for achieving a better retention of the biological activity of milk, the effect of those technologies on the immune-active proteins and their activity still needs to be investigated in more detail, especially from the perspective of actual biological functionality. 


\subsection{Conclusion}

The main conclusions of the work described in this thesis are:

1. $\beta$-lactoglobulin increases the disulphide linked aggregation of lactoferrin the most among the major whey proteins, $\beta$-lactoglobulin, $\alpha$-lactalbumin and bovine serum albumin.

2. Whey proteins accelerate the irreversible denaturation of lactoferrin, resulting in more loss of bacteriostatic activity than when lactoferrin is heated alone.

3. Heat-induced denaturation of lactoferrin increases its gastric digestibility in an in vitro infant digestion model, while lactoferrin incorporated into large aggregates with other whey proteins reduced this digestibility.

4. Heat treatments below $75{ }^{\circ} \mathrm{C} / 30$ min retained most of the bacteriostatic activity of bovine milk, whereas a heat intensity below $65{ }^{\circ} \mathrm{C} / 30 \mathrm{~min}$ was required for preservation of the allergy protective effect of raw bovine milk. 


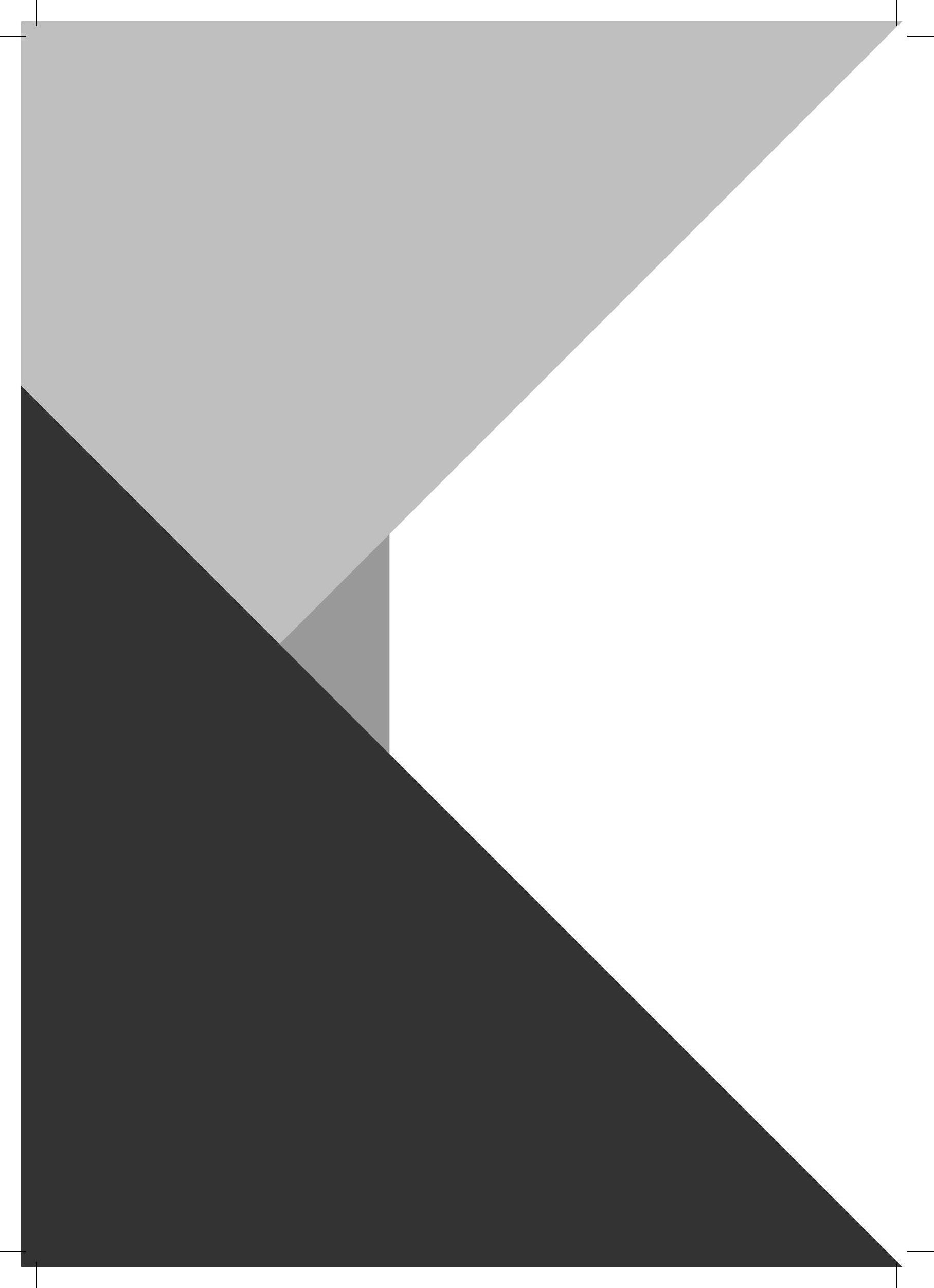


References 
Abbring, S., Hols, G., Garssen, J., \& van Esch, B. C. A. M. (2019). Raw cow's milk consumption and allergic diseases - The potential role of bioactive whey proteins. Eur. J. Pharmacol., 843, 55-65. doi:10.1016/j.ejphar.2018.11.013

Abbring, S., Ryan, J. T., Diks, M. A. P., Hols, G., Garssen, J., \& van Esch, B. C. A. M. (2019). Suppression of food allergic symptoms by raw cow's milk in mice is retained after skimming but abolished after heating the milk - A promising contribution of alkaline phosphatase. Nutrients, 11(7), 1499. doi:10.3390/nu11071499

Abbring, S., Verheijden, K. A., Diks, M. A., Leusink-Muis, A., Hols, G., Baars, T., \& van Esch, B. C. (2017). Raw cow's milk prevents the development of airway inflammation in a murine house dust mite-induced asthma model. Frontiers in immunology, 8, 1045.

Abbring, S., Wolf, J., Ayechu-Muruzabal, V., Diks, M. A. P., Alashkar Alhamwe, B., Alhamdan, F., \& van Esch, B. C. A. M. (2019). Raw cow's milk reduces allergic symptoms in a murine model for food allergy - A potential role for epigenetic modifications. Nutrients, 11(8), 1721. doi:10.3390/nu11081721

Abe, H., Saito, H., Miyakawa, H., Tamura, Y., Shimamura, S., Nagao, E., \& Tomita, M. (1991). Heat stability of bovine lactoferrin at acidic $\mathrm{pH}$.J Dairy Sci, 74(1), 65-71.

Al-Shehri, S. S., Duley, J. A., \& Bansal, N. (2020). Xanthine oxidase-lactoperoxidase system and innate immunity: Biochemical actions and physiological roles. Redox Biology, 101524.

Alfvén, T., Braun-Fahrlander, C., Brunekreef, B., von Mutius, E., Riedler, J., Scheynius, A., Pershagen, G. (2006). Allergic diseases and atopic sensitization in children related to farming and anthroposophic lifestyle - The PARSIFAL study. Allergy, 61(4), 414-421. doi:10.1111/j.13989995.2005.00939.x

Alimentarius, C. (2004). Code of hygienic practice for milk and milk products. CAC/RCP, 57.

Almaas, H., Cases, A.-L., Devold, T. G., Holm, H., Langsrud, T., Aabakken, L., Vegarud, G. E. (2006). In vitro digestion of bovine and caprine milk by human gastric and duodenal enzymes. International DairyJ ournal, 16(9), 961-968.

Andersen, B. F., Baker, H. M., Morris, G. E., Rumball, S. V., \& Baker, E. N. (1990). Apolactoferrin structure demonstrates ligand-induced conformational change in transferrins. Nature, 344(6268), 784

Anderson, B. F., Baker, H. M., Dodson, E. J., Norris, G. E., Rumball, S. V., Waters, J. M., \& Baker, E. N. (1987). Structure of human lactoferrin at 3.2-A resolution. Proceedings of the National Academy of Sciences, 84(7), 1769-1773.

Anderson, B. F., Baker, H. M., Norris, G. E., Rice, D. W., \& Baker, E. N. (1989). Structure of human lactoferrin crystallographic structure analysis and refinement at 2.8-A resolution. Journal of Molecular Biology, 209(4), 711-734. doi:10.1016/0022-2836(89)90602-5

Anema, S. G. (2000). Effect of milk concentration on the irreversible thermal denaturation and disulfide aggregation of $\beta$-lactoglobulin. J ournal of Agricultural and Food Chemistry, 48(9), 4168-4175.

Anema, S. G. (2008a). Heat and/or high-pressure treatment of skim milk: changes to the casein micelle size, whey proteins and the acid gelation properties of the milk. International J ournal of Dairy Technology, 61(3), 245-252. doi:10.1111/j.1471-0307.2008.00418.x

Anema, S. G. (2008b). On heating milk, the dissociation of kappa-casein from the casein micelles can precede interactions with the denatured whey proteins. J ournal of Dairy Research, 75(4), 415-421. doi:10.1017/s0022029908003555

Aprodu, I., Stănciuc, N., Dumitraşcu, L., Râpeanu, G., \& Stanciu, S. (2014). Investigations towards understanding the thermal denaturation of lactoperoxidase. International Dairy J ournal, 38(1), 4754.

Arnold, R. R., \& Cole, M. F. (1977). A bactericidal effect for human lactoferrin. Science, 197(4300), 263-265.

Arredouani, M. S., Kasran, A., Vanoirbeek, J. A., Berger, F. G., Baumann, H., \& Ceuppens, J. L. (2005). Haptoglobin dampens endotoxin-induced inflammatory effects both in vitro and in vivo. Immunology, $114(2), 263-271$.

Ay, M., \& Bostan, K. (2017). Effects of activated lactoperoxidase system on microbiological quality of raw milk. Kafkas Univ Vet Fak Derg, 23, 131-136.

Baker, H. M., \& Baker, E. N. (2004). Lactoferrin and iron: structural and dynamic aspects of binding and release. Biometals, 17(3), 209-216. 
Bals, R., \& Wilson, J. (2003). Cathelicidins-a family of multifunctional antimicrobial peptides. Cellular and Molecular LifeSciences CMLS, 60(4), 711-720.

Beaulieu, M., Pouliot, Y., \& Pouliot, M. (1999). Thermal aggregation of whey proteins in model solutions as affected by casein/whey protein ratios. J . Food Sci., 64(5), 776-780. doi:10.1111/j.13652621.1999.tb15910.x

Berlov, M. N., Korableva, E. S., Andreeva, Y. V., Ovchinnikova, T. V., \& Kokryakov, V. N. (2007). Lactoferrin from canine neutrophils: Isolation and physicochemical and antimicrobial properties. Biochemistry-Moscow, 72(4), 445-451. doi:10.1134/s0006297907040128

Bieli, C., Eder, W., Frei, R., Braun-Fahrlander, C., Klimecki, W., Waser, M., Martinez, F. D. (2007). A polymorphism in CD14 modifies the effect of farm milk consumption on allergic diseases and CD14 gene expression. J . Allergy Clin. Immunol., 120(6), 1308-1315. doi:10.1016/j.jaci.2007.07.034

Bielow, C., Mastrobuoni, G., \& Kempa, S. (2016). Proteomics quality control: quality control software for MaxQuant results. J Proteome Res, 15(3), 777-787.

Björck, L. (1978). Antibacterial effect of the lactoperoxidase system on psychrotrophic bacteria in milk. J ournal of Dairy Research, 45(1), 109-118.

Bjorck, L., Rosen, C. G., Marshall, V., \& Reiter, B. (1975). Antibacterial activity of lactoperoxidase system in milk against Pseudomonads and other Gram-negative bacteria. Applied Microbiology, 30(2), 199-204.

Bogahawaththa, D., Buckow, R., Chandrapala, J., \& Vasiljevic, T. (2018). Comparison between thermal pasteurization and high pressure processing of bovine skim milk in relation to denaturation and immunogenicity of native milk proteins. Innovative Food Science \& Emerging Technologies, 47, 301-308.

Bogahawaththa, D., Chandrapala, J., \& Vasiljevic, T. (2017). Thermal denaturation of bovine immunoglobulin $\mathrm{G}$ and its association with other whey proteins. Food Hydrocolloids, 72, 350-357.

Boggs, I., Hine, B., Smolenski, G., Hettinga, K., Zhang, L., \& Wheeler, T. T. (2016). Proteomics data in support of the quantification of the changes of bovine milk proteins during mammary gland involution. Data in brief, 8, 52-55.

Bokkhim, H., Bansal, N., GrØndahl, L., \& Bhandari, B. (2013). Physico-chemical properties of different forms of bovine lactoferrin. Food Chem 141(3), 3007-3013.

Bokkhim, H., Bansal, N., Grøndahl, L., \& Bhandari, B. (2016). In-vitro digestion of different forms of bovine lactoferrin encapsulated in alginate micro-gel particles. Food Hydrocolloids, 52, 231-242.

Boor, K. J., Wiedmann, M., Murphy, S., \& Alcaine, S. (2017). A 100-year review: microbiology and safety of milk handling. J Dairy Sci, 100(12), 9933-9951.

Branen, J., \& Davidson, P. (2000). Activity of hydrolysed lactoferrin against foodborne pathogenic bacteria in growth media: the effect of EDTA. Letters in Applied Microbiology, 30(3), 233-237.

Braun-Fahrlander, C., Gassner, M., Grize, L., Neu, U., Sennhauser, F. H., Varonier, H. S., \& Wuthrich, B. (1999). Prevalence of hay fever and allergic sensitization in farmer's children and their peers living in the same rural community. SCARPOL team. Swiss Study on Childhood Allergy and Respiratory Symptoms with Respect to Air Pollution. Clin. Exp. Allergy, 29(1), 28-34.

Braun-Fahrländer, C., \& von Mutius, E. (2011). Can farm milk consumption prevent allergic diseases? Clin. Exp. Allergy, 41(1), 29-35. doi:10.1111/j.1365-2222.2010.03665.x

Brick, T., Ege, M., Boeren, S., Bock, A., von Mutius, E., Vervoort, J., \& Hettinga, K. (2017). Effect of processing intensity on immunologically active bovine milk serum proteins. Nutrients, 9(9), 963. doi:10.3390/nu9090963

Brick, T., Schober, Y., Böcking, C., Pekkanen, J., Genuneit, J., Loss, G., \& Nockher, W. A. (2016). $\omega$ 3 fatty acids contribute to the asthma-protective effect of unprocessed cow's milk. J ournal of allergy and clinical immunology, 137(6), 1699-1706. e1613.

Brisson, G., Britten, M., \& Pouliot, Y. (2007a). Effect of iron saturation on the recovery of lactoferrin in rennet whey coming from heat-treated skim milk. J ournal of dairy science, 90(6), 2655-2664. doi:10.3168/jds.2006-725

Brisson, G., Britten, M., \& Pouliot, Y. (2007b). Heat-induced aggregation of bovine lactoferrin at neutral pH: Effect of iron saturation. International Dairy J ournal, 17(6), 617-624. doi:10.1016/j.idairyj.2006.09.002

Brodkorb, A., Croguennec, T., Bouhallab, S., \& Kehoe, J. J. (2016). Heat-induced denaturation, aggregation and gelation of whey proteins. In Advanced dairy chemistry (pp. 155-178): Springer. 
Bruni, N., Capucchio, M. T., Biasibetti, E., Pessione, E., Cirrincione, S., Giraudo, L., \& Dosio, F. (2016). Antimicrobial Activity of Lactoferrin-Related Peptides and Applications in Human and Veterinary Medicine. Molecules, 21(6). doi:10.3390/molecules21060752

Brüssow, H., Hilpert, H., Walther, I., Sidoti, J., Mietens, C., \& Bachmann, P. (1987). Bovine milk immunoglobulins for passive immunity to infantile rotavirus gastroenteritis. Journal of clinical microbiology, 25(6), 982-986.

Buckow, R., Chandry, P. S., Ng, S. Y., McAuley, C. M., \& Swanson, B. G. (2014). Opportunities and challenges in pulsed electric field processing of dairy products. International Dairy J ournal, 34(2), 199-212.

Bullen, J., Rogers, H. J., \& Leigh, L. (1972). Iron-binding proteins in milk and resistance to Escherichia coli infection in infants. Br Med J, 1(5792), 69-75.

Butler, J. E. (1969). Bovine immunoglobulins: A review. J Dairy Sci, 52(12), 1895-1909.

Calvo, M. M., Leaver, J., \& Banks, J. M. (1993). Influence of other whey proteins on the heat-induced aggregation of $\alpha$-lactalbumin. International Dairy J ournal, 3(8), 719-727.

Cameron, M., McMaster, L. D., \& Britz, T. J. (2009). Impact of ultrasound on dairy spoilage microbes and milk components. Dairy Science \& Technology, 89(1), 83-98.

Caputo, L., Quintieri, L., Bianchi, D. M., Decastelli, L., Monaci, L., Visconti, A., \& Baruzzi, F. (2015). Pepsin-digested bovine lactoferrin prevents Mozzarella cheese blue discoloration caused by Pseudomonas fluorescens. Food Microbiology, 46, 15-24. doi:10.1016/j.fm.2014.06.021

Chance, B., \& Maehly, A. (1955). Preparation and assays of enzymes. Methods Enzymol, 2, 773-775.

Chatterton, D. E., Aagaard, S., Hansen, T. H., Nguyen, D. N., De Gobba, C., Lametsch, R., \& Sangild, P. T. (2020). Bioactive proteins in bovine colostrum and effects of heating, drying and irradiation. Food Funct, 11(3), 2309-2327.

Chatterton, D. E., Nguyen, D. N., Bering, S. B., \& Sangild, P. T. (2013). Anti-inflammatory mechanisms of bioactive milk proteins in the intestine of newborns. Theinternational journal of biochemistry \& cell biology, 45(8), 1730-1747.

Chen, C.-B., \& Wallis, R. (2004). Two mechanisms for mannose-binding protein modulation of the activity of its associated serine proteases. J ournal of Biological Chemistry, 279(25), 26058-26065. Retrieved from http://www.jbc.org/content/279/25/26058.full.pdf

Chen, C. C., Tu, Y. Y., \& Chang, H. M. (2000). Thermal stability of bovine milk immunoglobulin G (IgG) and the effect of added thermal protectants on the stability. J Food Sci, 65(2), 188-193. Retrieved from https://onlinelibrary.wiley.com/doi/pdf/10.1111/j.1365-2621.2000.tb15977.x

Chen, W. L., Hwang, M. T., Liau, C. Y., Ho, J. C., Hong, K. C., \& Mao, S. J. T. (2005). BetaLactoglobulin is a thermal marker in processed milk as studied by electrophoresis and circular dichroic spectra. J . Dairy Sci., 88(5), 1618-1630. doi:10.3168/jds.S0022-0302(05)72833-2

Chen, X., Niyonsaba, F., Ushio, H., Okuda, D., Nagaoka, I., Ikeda, S., \& Ogawa, H. (2005). Synergistic effect of antibacterial agents human $\beta$-defensins, cathelicidin LL-37 and lysozyme against Staphylococcus aureus and Escherichia coli. J ournal of dermatological science, 40(2), 123-132.

Chen, Z.-L., Meng, J.-M., Cao, Y., Yin, J.-L., Fang, R.-Q., Fan, S.-B., \& Tan, D. (2019). A high-speed search engine pLink 2 with systematic evaluation for proteome-scale identification of cross-linked peptides. Nature communications, 10(1), 1-12.

Chevalier, F., Hirtz, C., Sommerer, N., \& Kelly, A. L. (2009). Use of reducing/nonreducing twodimensional electrophoresis for the study of disulfide-mediated interactions between proteins in raw and heated bovine milk. J Agric Food Chem 57(13), 5948-5955. doi:10.1021/jf900518n

Chevalier, F., \& Kelly, A. L. (2010). Proteomic quantification of disulfide-linked polymers in raw and heated bovine milk. J Agric Food Chem 58(12), 7437-7444.

Cho, Y. H., Singh, H., \& Creamer, L. K. (2003). Heat-induced interactions of beta-lactoglobulin A and kappa-casein B in a model system. J ournal of Dairy Research, 70(1), 61-71. doi:10.1017/s0022029902005642

Christen, L., Lai, C. T., Hartmann, B., Hartmann, P. E., \& Geddes, D. T. (2013). The effect of UV-C pasteurization on bacteriostatic properties and immunological proteins of donor human milk. PLoS One, 8(12), e85867. doi:10.1371/journal.pone.0085867

Claeys, W. L., Van Loey, A. M., \& Hendrickx, M. E. (2002). Kinetics of alkaline phosphatase and lactoperoxidase inactivation, and of beta-lactoglobulin denaturation in milk with different fat content J ournal of Dairy Research, 69(4), 541-553. doi:10.1017/s0022029902005721 
Committee on Infectious Diseases \& Committee on Nutrition \& American Academy of Pediatrics. (2014). Consumption of raw or unpasteurized milk and milk products by pregnant women and children. Pediatrics, 133(1), 175-179. doi:10.1542/peds.2013-3502

Comstock, S. S., Reznikov, E. A., Contractor, N., \& Donovan, S. M. (2014). Dietary bovine lactoferrin alters mucosal and systemic immune cell responses in neonatal piglets. The Journal of nutrition, 144(4), 525-532.

Conesa, C., Rota, C., Castillo, E., Perez, M. D., Calvo, M., \& Sanchez, L. (2010). Effect of heat treatment on the antibacterial activity of bovine lactoferrin against three foodborne pathogens. International J ournal of Dairy Technology, 63(2), 209-215. doi:10.1111/j.1471-0307.2010.00567.x

Cornacchia, L., Forquenot de la Fortelle, C. c., \& Venema, P. (2014). Heat-induced aggregation of whey proteins in aqueous solutions below their isoelectric point. J Agric Food Chem 62(3), 733-741.

Corredig, M., \& Dalgleish, D. G. (1999). The mechanisms of the heat-induced interaction of whey proteins with casein micelles in milk. International DairyJ ournal, 9(3-6), 233-236.

Corrochano, A. R., Arranz, E., De Noni, I., Stuknyte, M., Ferraretto, A., Kelly, P. M., \& Giblin, L. (2018). Intestinal health benefits of bovine whey proteins after simulated gastrointestinal digestion. J ournal of Functional Foods, 49, 526-535. doi:10.1016/j.jff.2018.08.043

Cossey, V., Jeurissen, A., Bossuyt, X., \& Schuermans, A. (2009). Effect of pasteurisation on the mannose-binding lectin activity and the concentration of soluble CD14 in human milk. Journal of Hospital Infection, 73(1), 96-97.

Cox, J., \& Mann, M. (2008). MaxQuant enables high peptide identification rates, individualized ppbrange mass accuracies and proteome-wide protein quantification. Nature biotechnology, 26(12), $1367-1372$.

Cox, J., Neuhauser, N., Michalski, A., Scheltema, R., Olsen, J., \& Mann, M. (2011). Andromeda: a peptide search engine integrated into the MaxQuant environment. J ournal of Proteome research, 10(4), 1794-1805.

Creamer, L. K., Bienvenue, A., Nilsson, H., Paulsson, M., van Wanroij, M., Lowe, E. K., \& JiménezFlores, R. (2004). Heat-induced redistribution of disulfide bonds in milk proteins. 1. Bovine $\beta$ lactoglobulin. J Agric Food Chem 52(25), 7660-7668.

Cross, M. L., \& Gill, H. (2000). Immunomodulatory properties of milk. British J ournal of Nutrition, 84(S1), 81-89.

Dalgleish, D. G., Senaratne, V., \& Francois, S. (1997). Interactions between $\alpha$-lactalbumin and $\beta$ lactoglobulin in the early stages of heat denaturation. J Agric Food Chem 45(9), 3459-3464.

Dalsgaard, T. K., Nielsen, J. H., \& Larsen, L. B. (2007). Proteolysis of milk proteins lactosylated in model systems. Molecular Nutrition \& Food Research, 51(4), 404-414. doi:10.1002/mnfr.200600112

de la Fuente, M. A., Singh, H., \& Hemar, Y. (2002). Recent advances in the characterisation of heatinduced aggregates and intermediates of whey proteins. Trends inFood Science \& Technol ogy, 13(8), 262-274.

De Vos, M., Huygelen, V., Van Raemdonck, G., Willemen, S., Fransen, E., Van Ostade, X., \& Van Ginneken, C. (2014). Supplementing formula-fed piglets with a low molecular weight fraction of bovine colostrum whey results in an improved intestinal barrier. J AnimSci, 92(8), 3491-3501.

De Wit, J., \& Swinkels, G. (1980). A differential scanning calorimetric study of the thermal denaturation of bovine $\beta$-lactoglobulin Thermal behaviour at temperatures up to $100 \mathrm{C}$. Biochimica et Biophysica Acta (BBA)-Protein Structure, 624(1), 40-50.

Deglaire, A., De Oliveira, S. C., Jardin, J., Briard-Bion, V., Emily, M., Menard, O., \& Dupont, D. (2016) Impact of human milk pasteurization on the kinetics of peptide release during in vitro dynamic term newborn digestion. Electrophoresis, 37(13), 1839-1850. doi:10.1002/elps.201500573

del Angel, C. R., \& Dalgleish, D. G. (2006). Structures and some properties of soluble protein complexes formed by the heating of reconstituted skim milk powder. Food Research International, 39(4), 472479. doi:10.1016/j.foodres.2005.09.010

Del Olmo, A., Calzada, J., \& Nunez, M. (2010). Short communication: Antimicrobial effect of lactoferrin and its amidated and pepsin-digested derivatives against Salmonella Enteritidis and Pseudomonas fluorescens. J Dairy Sci, 93(9), 3965-3969. doi:10.3168/jds.2010-3152 
del Olmo, A., Morales, P., \& Nunez, M. (2009). Bactericidal Activity of Lactoferrin and Its Amidated and Pepsin-Digested Derivatives against Pseudomonas fluorescens in Ground Beef and Meat Fractions. J ournal of Food Protection, 72(4), 760-765.

Deng, Y., Wierenga, P. A., Schols, H. A., Sforza, S., \& Gruppen, H. (2017). Effect of Maillard induced glycation on protein hydrolysis by lysine/arginine and non-lysine/arginine specific proteases. Food Hydrocolloids, 69, 210-219. doi:10.1016/j.foodhyd.2017.02.007

Dingess, K. A., De Waard, M., Boeren, S., Vervoort, J., Lambers, T. T., Van Goudoever, J. B., \& Hettinga, K. (2017). Human milk peptides differentiate between the preterm and term infant and across varying lactational stages. Food Funct, 8(10), 3769-3782.

Dissanayake, M., Ramchandran, L., Piyadasa, C., \& Vasiljevic, T. (2013). Influence of heat and pH on structure and conformation of whey proteins. International DairyJ ournal, 28(2), 56-61.

Donato, L., Guyomarc'h, F., Amiot, S., \& Dalgleish, D. G. (2007). Formation of whey protein/kappacasein complexes in heated milk: Preferential reaction of whey protein with kappa-casein in the casein micelles. International DairyJ ournal, 17(10), 1161-1167. doi:10.1016/j.idairyj.2007.03.011

Donovan, S. M. (2016). The role of lactoferrin in gastrointestinal and immune development and function: a preclinical perspective. The J ournal of pediatrics, 173, S16-S28.

Dritsakou, K., Liosis, G., Valsami, G., Polychronopoulos, E., \& Skouroliakou, M. (2016). Improved outcomes of feeding low birth weight infants with predominantly raw human milk versus donor banked milk and formula. J ournal of Maternal-Fetal \& Neonatal Medicine, 29(7), 1131-1138. doi: $10.3109 / 14767058.2015 .1038232$

Dumitrascu, L., Stanciuc, N., Stanciu, S., \& Rapeanu, G. (2012). Thermal inactivation of lactoperoxidase in goat, sheep and bovine milk - A comparative kinetic and thermodynamic study. J ournal of Food Engineering, 113(1), 47-52. doi:10.1016/j.jfoodeng.2012.05.028

Eder, W., Ege, M. J., \& von Mutius, E. (2006). The asthma epidemic. N. Engl. J . Med., 355(21), 22262235. doi:10.1056/NEJMra054308

Ege, M. J., Frei, R., Bieli, C., Schram-Bijkerk, D., Waser, M., Benz, M. R., \& von Mutius, E. (2007). Not all farming environments protect against the development of asthma and wheeze in children. J. Allergy Clin. Immunol., 119(5), 1140-1147. doi:10.1016/j.jaci.2007.01.037

Ege, M. J., Mayer, M., Normand, A. C., Genuneit, J., Cookson, W. O., Braun-Fahrlander, C., \& von Mutius, E. (2011). Exposure to environmental microorganisms and childhood asthma. N. Engl. J. Med., 364(8), 701-709. doi:10.1056/NEJMoa1007302

Ege, M. J., Strachan, D. P., Cookson, W. O., Moffatt, M. F., Gut, I., Lathrop, M., \& von Mutius, E. (2011). Gene-environment interaction for childhood asthma and exposure to farming in Central Europe. J . Allergy Clin. Immunol., 127(1), 138-144. doi:10.1016/j.jaci.2010.09.041

Elagamy, E. I. (2000). Effect of heat treatment on camel milk proteins with respect to antimicrobial factors: a comparison with cows' and buffalo milk proteins. Food Chem 68(2), 227-232. doi:10.1016/s0308-8146(99)00199-5

Elliot, R., McLay, J., Kennedy, M., \& Simmonds, R. (2004). Inhibition of foodborne bacteria by the lactoperoxidase system in a beef cube system. International journal of food microbiology, 91(1), 7381.

Ernst, P., \& Cormier, Y. (2000). Relative scarcity of asthma and atopy among rural adolescents raised on a farm. Am J. Respir. Crit. Care Med., 161(5), 1563-1566. doi:10.1164/ajrccm.161.5.9908119

European Academy of Allergy and Clinical Immunology. (2014). Global atlas of allergy.

European Commission. (2012). Commission Decision of 22 November 2012 authorising the placing on the market of bovine lactoferrin as a novel food ingredient under Regulation (EC) No 258/97 of the European Parliament and of the Council (FrieslandCampina). Official J ournal of the European Union, L327, 52-54.

Ewbank, J. J., \& Creighton, T. E. (1993). Structural characterization of the disulfide folding intermediates of bovine. alpha.-lactalbumin. Biochemistry, 32(14), 3694-3707.

Fan, F., Liu, M., Shi, P., Xu, S., Lu, W., \& Du, M. (2019). Effects of thermal treatment on the physicochemical properties and osteogenic activity of lactoferrin. J ournal of Food Processing and Preservation, e14068.

Fang He, E. T., Heikki Arvilommi, Seppo Salminen. (2001). Modulation of human humoral immune response through orally administered bovine colostrum. FEMS Immunology and Medical Microbiology, 31, 93-96. 
Farnaud, S., \& Evans, R. W. (2003). Lactoferrin - a multifunctional protein with antimicrobial properties. Molecular Immunology, 40(7), 395-405. doi:10.1016/s0161-5890(03)00152-4

Felfoul, I., Jardin, J., Gaucheron, F., Attia, H., \& Ayadi, M. (2017). Proteomic profiling of camel and cow milk proteins under heat treatment. Food chemistry, 216, 161-169.

Gathercole, J., Reis, M. G., Agnew, M., Reis, M. M., Humphrey, R., Harris, P., \& Dyer, J. M. (2017). Molecular modification associated with the heat treatment of bovine milk. International Dairy J ournal, 73, 74-83. doi:10.1016/j.idairyj.2017.05.008

Gerard, N. P., \& Gerard, C. (2002). Complement in allergy and asthma. Curr. Opin. Immunol., 14(6), 705-708.

Gezimati, J., Singh, H., \& Creamer, L. K. (1995). Aggregation and gelation of bovine $\beta$-lactoglobulin, $\alpha$-lactalbumin, and serum albumin. In: ACS Publications.

Gordon, Y. J., Huang, L. C., Romanowski, E. G., Yates, K. A., Proske, R. J., \& McDermott, A. M. (2005). Human cathelicidin (LL-37), a multifunctional peptide, is expressed by ocular surface epithelia and has potent antibacterial and antiviral activity. Current eyeresearch, 30(5), 385-394.

Greenwood, S. L., \& Honan, M. C. (2019). Symposium review: Characterization of the bovine milk protein profile using proteomic techniques. J Dairy Sci, 102(3), 2796-2806.

Grosvenor, A. J., Haigh, B. J., \& Dyer, J. M. (2014). Digestion proteomics: tracking lactoferrin truncation and peptide release during simulated gastric digestion. Food Funct, 5(11), 2699-2705. doi:10.1039/c4fo00165f

Halabi, A., Deglaire, A., Hamon, P., Bouhallab, S., Dupont, D., \& Croguennec, T. (2020). Kinetics of heat-induced denaturation of proteins in model infant milk formulas as a function of whey protein composition. Food Chem 302, 125296.

Halpern, M. D., \& Denning, P. W. (2015). The role of intestinal epithelial barrier function in the development of NEC. Tissuebarriers, 3(1-2), e1000707.

Harouna, S., Carraminana, J. J., Navarro, F., Perez, M. D., Calvo, M., \& Sanchez, L. (2015). Antibacterial activity of bovine milk lactoferrin on the emerging foodborne pathogen Cronobacter sakazakii: Effect of media and heat treatment. Food Control, 47, 520-525. doi:10.1016/j.foodcont.2014.07.061

Havea, P., Carr, A. J., \& Creamer, L. K. (2004). The roles of disulphide and non-covalent bonding in the functional properties of heat-induced whey protein gels. J ournal of Dairy Research, 71(3), 330339.

Havea, P., Singh, H., \& Creamer, L. K. (2000). Formation of new protein structures in heated mixtures of BSA and $\alpha$-lactalbumin. J Agric Food Chem 48(5), 1548-1556.

Havea, P., Singh, H., \& Creamer, L. K. (2001). Characterization of heat-induced aggregates of $\beta$ lactoglobulin, $\alpha$-lactalbumin and bovine serum albumin in a whey protein concentrate environment. J ournal of Dairy Research, 68(3), 483-497.

He, S., McEuen, A. R., Blewett, S. A., Li, P., Buckley, M. G., Leufkens, P., \& Walls, A. F. (2003). The inhibition of mast cell activation by neutrophil lactoferrin: uptake by mast cells and interaction with tryptase, chymase and cathepsin G. Biochemical pharmacology, 65(6), 1007-1015.

Hettinga, K., Van Valenberg, H., De Vries, S., Boeren, S., Van Hooijdonk, T., van Arendonk, J., \& Vervoort, J. (2011). The host defense proteome of human and bovine milk. Plos One, 6(4), e19433. doi:10.1371/journal.pone.0019433

Hoffmann, M. A., \& van Mil, P. J. (1997). Heat-induced aggregation of $\beta$-lactoglobulin: role of the free thiol group and disulfide bonds. J Agric Food Chem 45(8), 2942-2948.

Huang, D. W., Sherman, B. T., \& Lempicki, R. A. (2009). Systematic and integrative analysis of large gene lists using DAVID bioinformatics resources. Nat Protoc, 4(1), 44.

Hurley, W. L., \& Theil, P. K. (2011). Perspectives on immunoglobulins in colostrum and milk. Nutrients, 3(4), 442-474. doi:10.3390/nu3040442

Iametti, S., Cairoli, S., De Gregori, B., \& Bonomi, F. (1995). Modifications of High-Order Structures upon Heating of. beta.-Lactoglobulin: Dependence on the Protein Concentration.J Agric Food Chem 43(1), 53-58.

James C. King, J., Ginny E. Cummings, Nan Guo, yLeena Trivedi, Bernard X. Readmond, Virginia Keane, Susan Feigelman, and zRick de Waard. (2007). A Double-Blind, Placebo-Controlled, Pilot Study of Bovine Lactoferrin Supplementation in Bottle-fed Infants. Journal of Pediatric Gastroenterology and Nutrition, 44, 245-251. 
Jêvinen, K.-M., Laine, S. T., Jêvenpêê, A.-L., \& Suomalainen, H. K. (2000). Does low IgA in human milk predispose the infant to development of cow's milk allergy? Pediatric research, 48(4), 457-462.

Jiang, R., \& Lönnerdal, B. (2016). Biological roles of milk osteopontin. Current Opinion in Clinical Nutrition and Metabolic Care, 19(3), 214-219.

Jooyandeh, H., Aberoumand, A., \& Nasehi, B. (2011). Application of lactoperoxidase system in fish and food products: a review. Am Eurasian J. Agric. Environ. Sci., 10, 89-96.

Kaetzel, C. S. (2005). The polymeric immunoglobulin receptor: bridging innate and adaptive immune responses at mucosal surfaces. Immunological reviews, 206(1), 83-99.

Kangumba, J.-G. K., Venter, E., \& Coetzer, J. (1997). The effect of activation of the lactoperoxidase system and souring on certain potential human pathogens in cows' milk. J ournal of theSouth African Veterinary Association, 68(4), 130-136.

Kawakami, H., Tanaka, M., Tatsumi, K., \& Dosako, S. i. (1992). Effects of ionic strength and pH on the thermostability of lactoferrin. International DairyJ ournal, 2(5), 287-298.

Kilpelainen, M., Terho, E. O., Helenius, H., \& Koskenvuo, M. (2000). Farm environment in childhood prevents the development of allergies. Clin. Exp. Allergy, 30(2), 201-208.

Kim, W. S., Rahman, M. M., \& Shimazaki, K. I. (2008). Antibacterial activity and binding ability of bovine lactoferrin against Pseudomonas spp. Journal of Food Safety, 28(1), 23-33. doi:10.1111/j.1745-4565.2007.00092.x

Kirchner, B., Pfaffl, M. W., Dumpler, J., von Mutius, E., \& Ege, M. J. (2016). microRNA in native and processed cow's milk and its implication for the farm milk effect on asthma. J ournal of allergy and clinical immunology, 137(6), 1893-1895. e1813.

Knapp, S., de Vos, A. F., Florquin, S., Golenbock, D. T., \& van der Poll, T. (2003). Lipopolysaccharide binding protein is an essential component of the innate immune response to Escherichia coli peritonitis in mice. Infection and I mmunity, 71(12), 6747-6753.

Korhonen, H., Marnila, P., \& Gill, H. (2000). Milk immunoglobulins and complement factors. British J ournal of Nutrition, 84(S1), 75-80.

Korhonen, H., Marnila, P., \& Gill, H. S. (2007). Milk immunoglobulins and complement factors. British J ournal of Nutrition, 84(S1). doi:10.1017/s0007114500002282

Krämer, A. C., Torreggiani, A., \& Davies, M. J. (2017). Effect of oxidation and protein unfolding on cross-linking of $\beta$-lactoglobulin and $\alpha$-lactalbumin. J Agric Food Chem 65(47), 10258-10269.

Kruzel, M. L., Bacsi, A., Choudhury, B., Sur, S., \& Boldogh, I. (2006). Lactoferrin decreases pollen antigen-induced allergic airway inflammation in a murine model of asthma. Immunology, 119(2), 159-166.

Kulmyrzaev, A. A., Levieux, D., \& Dufour, É. (2005). Front-face fluorescence spectroscopy allows the characterization of mild heat treatments applied to milk. Relations with the denaturation of milk proteins. J Agric Food Chem 53(3), 502-507.

Kummer, A., Kitts, D. D., Li-Chan, E., Losso, J. N., Skura, B. J., \& Nakai, S. (2008). Quantification of bovine IgG in milk using enzyme-linked immunosorbent assay. Food and Agricultural Immunology, 4(2), 93-102. doi:10.1080/09540109209354757

Kussendrager, K. D., \& van Hooijdonk, A. C. M. (2000). Lactoperoxidase: physico-chemical properties, occurrence, mechanism of action and applications. British J ournal of Nutrition, 84, S19-S25.

Labéta, M. O., Vidal, K., Nores, J. E. R., Arias, M., Vita, N., Morgan, B. P., \& Schmid, D. (2000). Innate recognition of bacteria in human milk is mediated by a milk-derived highly expressed pattern recognition receptor, soluble CD14. The J ournal of experimental medicine, 191(10), 1807-1812.

Lakbub, J. C., Shipman, J. T., \& Desaire, H. (2018). Recent mass spectrometry-based techniques and considerations for disulfide bond characterization in proteins. Anal Bioanal Chem 410(10), 24672484.

Lamping, N., Dettmer, R., Schröder, N., Pfeil, D., Hallatschek, W., Burger, R., \& Schumann, R. R. (1998). LPS-binding protein protects mice from septic shock caused by LPS or gram-negative bacteria. The J ournal of clinical investigation, 101(10), 2065-2071.

Larson, B., \& Rolleri, G. (1955). Heat denaturation of the specific serum proteins in milk. J Dairy Sci, 38(4), 351-360.

Lauener, R. P., Birchler, T., Adamski, J., Braun-Fahrlander, C., Bufe, A., Herz, U., \& Sennhauser, F. H. (2002). Expression of CD14 and Toll-like receptor 2 in farmers' and non-farmers' children. Lancet, 360(9331), 465-466. doi:10.1016/S0140-6736(02)09641-1 
Law, A. J., \& Leaver, J. (2000). Effect of $\mathrm{pH}$ on the thermal denaturation of whey proteins in milk. J Agric Food Chem 48(3), 672-679.

Le, T. T., Deeth, H. C., Bhandari, B., Alewood, P. F., \& Holland, J. W. (2012). A proteomic approach to detect lactosylation and other chemical changes in stored milk protein concentrate. Food Chem 132(1), 655-662. doi:10.1016/j.foodchem.2011.11.012

Le, T. T., Deeth, H. C., Bhandari, B., Alewood, P. F., \& Holland, J. W. (2013). Quantification of lactosylation of whey proteins in stored milk powder using multiple reaction monitoring. Food Chem 141(2), 1203-1210. doi:10.1016/j.foodchem.2013.03.073

Lee, R. T., Ichikawa, Y., Kawasaki, T., Drickamer, K., \& Lee, Y. C. (1992). Multivalent ligand binding by serum mannose-binding protein. Archives of biochemistry and biophysics, 299(1), 129-136.

Leeb, E., Gotz, A., Letzel, T., Cheison, S. C., \& Kulozik, U. (2015). Influence of denaturation and aggregation of beta-lactoglobulin on its tryptic hydrolysis and the release of functional peptides. Food Chemistry, 187, 545-554. doi:10.1016/j.foodchem.2015.04.034

Li-Chan, E., Kummer, A., Losso, J. N., Kitts, D. D., \& Nakai, S. (1995). Stability of bovine immunoglobulins to thermal-treatment and processing. Food Res. Int, 28(1), 9-16. doi:10.1016/0963-9969(95)93325-O

Li, H. Y., Yang, H. G., Li, P., Wang, Y. Z., Huang, G. X., Xing, L., \& Zheng, N. (2019). Effect of Heat Treatment on the Antitumor Activity of Lactoferrin in Human Colon Tumor (HT29) Model. J ournal of Agricultural and Food Chemistry, 67(1), 140-147. doi:10.1021/acs.jafc.8b05131

Li, Q., Lan, H., \& Zhao, Z. (2019). Protection effect of sodium alginate against heat-induced structural changes of lactoferrin molecules at neutral pH. LWT-Food Science and Technology, 99, 513-518. doi:10.1016/j.lwt.2018.10.019

Li, Q., \& Zhao, Z. (2018). Interaction between lactoferrin and whey proteins and its influence on the heat-induced gelation of whey proteins. Food Chem 252, 92-98.

Li, S., Bomser, J., \& Zhang, Q. (2005). Effects of pulsed electric fields and heat treatment on stability and secondary structure of bovine immunoglobulin G. J ournal of agricultural and food chemistry, 53(3), 663-670.

Li, Y., Jensen, M. L., Chatterton, D. E., Jensen, B. B., Thymann, T., Kvistgaard, A. S., \& Sangild, P. T. (2014). Raw bovine milk improves gut responses to feeding relative to infant formula in preterm piglets. American J ournal of Physiology-Gastrointestinal and Liver Physiology, 306(1), G81-G90.

Li, Y., Østergaard, M. V., Jiang, P., Chatterton, D. E., Thymann, T., Kvistgaard, A. S., \& Sangild, P. T. (2013). Whey protein processing influences formula-induced gut maturation in preterm pigs. The J ournal of nutrition, 143(12), 1934-1942.

Liu, G., Carøe, C., Qin, Z., Munk, D. M., Crafack, M., Petersen, M. A., \& Ahrné, L. (2020). Comparative study on quality of whole milk processed by high hydrostatic pressure or thermal pasteurization treatment. LWt, 109370.

Liu, G., Jæger, T. C., Lund, M. N., Nielsen, S. B., Ray, C. A., \& Ipsen, R. (2016). Effects of disulphide bonds between added whey protein aggregates and other milk components on the rheological properties of acidified milk model systems. International dairy journal, 59, 1-9.

Liu, L., Jiang, R., \& Lönnerdal, B. (2019). Assessment of bioactivities of the human milk lactoferrinosteopontin complex in vitro. The J ournal of nutritional biochemistry, 69, 10-18.

Liu, Y., Xiong, L., Kontopodi, E., Zhang, L., Boeren, S., Zhou, P., \& Hettinga, K. (2020). Comparative proteomics of milk serum proteins in thermal and non-thermal treatments. Innovative Food Science $\&$ Emerging Technologies.

Liu, Y., Zhang, W., Han, B., Zhang, L., \& Zhou, P. (2020). Changes in bioactive milk serum proteins during milk powder processing. Food chemistry, 314, 126177.

Loss, G., Apprich, S., Waser, M., Kneifel, W., Genuneit, J., Büchele, G., \& Horak, E. (2011). The protective effect of farm milk consumption on childhood asthma and atopy: the GABRIELA study. J ournal of Allergy and Clinical Immunology, 128(4), 766-773. e764.

Loss, G., Apprich, S., Waser, M., Kneifel, W., Genuneit, J., Buchele, G., \& Braun-Fahrlander, C. (2011). The protective effect of farm milk consumption on childhood asthma and atopy: the GABRIELA study. J . Allergy Clin. Immunol., 128(4), 766-773 e764. doi:10.1016/j.jaci.2011.07.048

Loss, G., Depner, M., Ulfman, L. H., Van Neerven, R. J., Hose, A. J., Genuneit, J., \& Roduit, C. (2015). Consumption of unprocessed cow's milk protects infants from common respiratory infections. J ournal of Allergy and Clinical Immunology, 135(1), 56-62. e52. 
Loss, G., Depner, M., Ulfman, L. H., van Neerven, R. J., Hose, A. J., Genuneit, J., \& group, P. s. (2015). Consumption of unprocessed cow's milk protects infants from common respiratory infections. J Allergy Clin Immunol, 135(1), 56-62. doi:10.1016/j.jaci.2014.08.044

Lowe, E. K., Anema, S. G., Bienvenue, A., Boland, M. J., Creamer, L. K., \& Jiménez-Flores, R. (2004). Heat-induced redistribution of disulfide bonds in milk proteins. 2. Disulfide bonding patterns between bovine $\beta$-lactoglobulin and $\kappa$-casein. J Agric Food Chem 52(25), 7669-7680.

Lu, J., Boeren, S., De Vries, S., Van Valenberg, H., Vervoort, J., \& Hettinga, K. (2011a). Filter-aided sample preparation with dimethyl labeling to identify and quantify milk fat globule membrane proteins. J Proteomics, 75(1), 34-43.

Madureira, A., Tavares, T., Gomes, A. M., Pintado, M., \& Malcata, F. X. (2010). Invited review: physiological properties of bioactive peptides obtained from whey proteins. J ournal of dairy science, 93(2), 437-455.

Madureira, A. R., Pereira, C. I., Gomes, A. M. P., Pintado, M. E., \& Xavier Malcata, F. (2007). Bovine whey proteins - Overview on their main biological properties. Food Research International, 40(10), 1197-1211. doi:10.1016/j.foodres.2007.07.005

Mainer, G., Sanchez, L., Ena, J., \& Calvo, M. (1997). Kinetic and thermodynamic parameters for heat denaturation of bovine milk IgG, IgA and IgM. J Food Sci, 62(5), 1034-1038.

Marin, E., Sanchez, L., Perez, M., Puyol, P., \& Calvo, M. (2003). Effect of heat treatment on bovine lactoperoxidase activity in skim milk: kinetic and thermodynamic analysis. J Food Sci, 68(1), 89-93.

Marks, N., Grandison, A., \& Lewis, M. (2001). Challenge testing of the lactoperoxidase system in pasteurized milk. J ournal of Applied Microbiology, 91(4), 735-741.

Martin, H. M., Hancock, J. T., Salisbury, V., \& Harrison, R. (2004). Role of xanthine oxidoreductase as an antimicrobial agent. Infection and Immunity, 72(9), 4933-4939.

Mata, L., Sánchez, L., Headon, D. R., \& Calvo, M. (1998). Thermal denaturation of human lactoferrin and its effect on the ability to bind iron. J Agric Food Chem 46(10), 3964-3970.

Matsushita, A., Son, D. O., Satsu, H., Takano, Y., Kawakami, H., Totsuka, M., \& Shimizu, M. (2008). Inhibitory effect of lactoperoxidase on the secretion of proinflammatory cytokine interleukin-8 in human intestinal epithelial Caco-2 cells. International DairyJ ournal, 18(9), 932-938.

Maturin, L., \& Peeler, J. (2001). Bacteriological analytical manual. Chapter 3. Aerobic plate count. Food and Drug Administration.

McGuffey, M. K., Epting, K. L., Kelly, R. M., \& Foegeding, E. A. (2005). Denaturation and aggregation of three $\alpha$-lactalbumin preparations at neutral pH. J Agric Food Chem 53(8), 3182-3190.

Ménard, O., Bourlieu, C., De Oliveira, S., Dellarosa, N., Laghi, L., Carrière, F., \& Deglaire, A. (2018). A first step towards a consensus static in vitro model for simulating full-term infant digestion. Food Chem, 240, 338-345.

Mietens, C., Keinhorst, H., Hilpert, H., Gerber, H., Amster, H., \& Pahud, J. (1979). Treatment of infantile E. coli gastroenteritis with specific bovine anti-E. coli milk immunoglobulins. European journal of pediatrics, 132(4), 239-252.

Milkovska-Stamenova, S., \& Hoffmann, R. (2016). Identification and quantification of bovine protein lactosylation sites in different milk products. J Proteomics, 134, 112-126. doi:10.1016/j.jprot.2015.07.021

Miyamoto, Y., Matsumiya, K., Kubouchi, H., Noda, M., Nishimura, K., \& Matsumura, Y. (2009). Effects of Heating Conditions on Physicochemical Properties of Skim Milk Powder during Production Process. Food Science and Technology Research, 15(6), 631-638. doi:10.3136/fstr.15.631

Montagne, P., Cuilliere, M., Mole, C., Bene, M., \& Faure, G. (2001). Changes in lactoferrin and lysozyme levels in human milk during the first twelve weeks of lactation. In Bioactive components of human milk (pp. 241-247): Springer.

Montjaux-Regis, N., Cristini, C., Arnaud, C., Glorieux, I., Vanpee, M., \& Casper, C. (2011). Improved growth of preterm infants receiving mother's own raw milk compared with pasteurized donor milk. Acta Paediatrica, 100(12), 1548-1554. doi:10.1111/j.1651-2227.2011.02389.x

Moore, S. A., Anderson, B. F., Groom, C. R., Haridas, M., \& Baker, E. N. (1997). Three-dimensional structure of diferric bovine lactoferrin at $2.8 \AA$ resolution. J ournal of Molecular Biology, 274(2), 222-236. 
Mosconi, E., Rekima, A., Seitz-Polski, B., Kanda, A., Fleury, S., Tissandie, E., \& Glaichenhaus, N. (2010). Breast milk immune complexes are potent inducers of oral tolerance in neonates and prevent asthma development. Mucosal immunology, 3(5), 461-474.

Moscovici, A. M., Joubran, Y., Briard-Bion, V., Mackie, A., Dupont, D., \& Lesmes, U. (2014). The impact of the Maillard reaction on the in vitro proteolytic breakdown of bovine lactoferrin in adults and infants. Food \& Function, 5(8), 1898-1908. doi:10.1039/c4fo00248b

Mounsey, J. S., \& O'Kennedy, B. T. (2007). Conditions limiting the influence of thiol-disulphide interchange reactions on the heat-induced aggregation kinetics of $\beta$-lactoglobulin. International Dairy J ournal, 17(9), 1034-1042.

Mulcahy, E. M., Fargier-Lagrange, M., Mulvihill, D. M., \& O'Mahony, J. A. (2017). Characterisation of heat-induced protein aggregation in whey protein isolate and the influence of aggregation on the availability of amino groups as measured by the ortho-phthaldialdehyde (OPA) and trinitrobenzenesulfonic acid (TNBS) methods. Food Chem 229, 66-74.

Mulet-Cabero, A. I., Mackie, A. R., Wilde, P. J., Fenelon, M. A., \& Brodkorb, A. (2019). Structural mechanism and kinetics of in vitro gastric digestion are affected by process-induced changes in bovine milk. Food Hydrocolloids, 86, 172-183. doi:10.1016/j.foodhyd.2018.03.035

Nakano, M., Suzuki, M., Wakabayashi, H., Hayama, K., Yamauchi, K., Abe, F., \& Abe, S. (2019). Synergistic anti-candida activities of lactoferrin and the lactoperoxidase system. Drug discoveries \& therapeutics, 13(1), 28-33.

Navis, M., Muncan, V., Sangild, P. T., Møller Willumsen, L., Koelink, P. J., Wildenberg, M. E., \& Renes, I. B. (2020). Beneficial effect of mildly pasteurized whey protein on intestinal integrity and innate defense in preterm and near-term piglets. Nutrients, 12(4), 1125.

Nguyen, D. N., Sangild, P. T., Li, Y. Q., Bering, S. B., \& Chatterton, D. E. W. (2016). Processing of whey modulates proliferative and immune functions in intestinal epithelial cells. J Dairy Sci, 99(2), 959-969. doi:10.3168/jds.2015-9965

Nguyen, H. N., Wong, M., Fanny, G. H., Havea, P., \& Anema, S. G. (2012). Effects of modifying thioldisulphide interactions in skim milk on the rheological properties of acid gels.

Nielsen, L. R., Lund, M. N., Davies, M. J., Nielsen, J. H., \& Nielsen, S. B. (2018). Effect of free cysteine on the denaturation and aggregation of holo $\alpha$-lactalbumin. International DairyJ ournal, 79, 52-61.

Nissen, A., Bendixen, E., Ingvartsen, K. L., \& Rontvedt, C. M. (2013). Expanding the bovine milk proteome through extensive fractionation. Journal of dairy science, 96(12), 7854-7866. doi:10.3168/jds.2013-7106

O'Kennedy, B. T., \& Mounsey, J. S. (2006). Control of heat-induced aggregation of whey proteins using casein. J ournal of Agricultural and Food Chemistry, 54(15), 5637-5642.

Oldfield, D. J., Singh, H., \& Taylor, M. W. (2005). Kinetics of heat-induced whey protein denaturation and aggregation in skim milks with adjusted whey protein concentration. J ournal of Dairy Research, 72(3), 369-378.

Oldfield, D. J., Singh, H., Taylor, M. W., \& Pearce, K. N. (1998). Kinetics of denaturation and aggregation of whey proteins in skim milk heated in an ultra-high temperature (UHT) pilot plant. International DairyJ ournal, 8(4), 311-318.

Oliver, S. P., Jayarao, B. M., \& Almeida, R. A. (2005). Foodborne pathogens in milk and the dairy farm environment: food safety and public health implications. Foodbourne Pathogens \& Disease, 2(2), 115-129.

Olmo, A. d., Morales, P., \& Nunez, M. (2009). Bactericidal activity of lactoferrin and its amidated and pepsin-digested derivatives against Pseudomonas fluorescens in ground beef and meat fractions. J ournal of Food Protection, 72(4), 760-765.

Olsen, J. V., Ong, S.-E., \& Mann, M. (2004). Trypsin cleaves exclusively C-terminal to arginine and lysine residues. Molecular \& Cellular Proteomics, 3(6), 608-614.

Pabst, O., \& Mowat, A. M. (2012). Oral tolerance to food protein. Mucosal Immunol., 5(3), 232-239. doi: $10.1038 / \mathrm{mi} .2012 .4$

Papiz, M., Sawyer, L., Eliopoulos, E., North, A., Findlay, J., Sivaprasadarao, R., . . Kraulis, P. (1986). The structure of $\beta$-lactoglobulin and its similarity to plasma retinol-binding protein. Nature, 324(6095), 383-385. 
Parrón, J. A., Ripollés, D., Pérez, M. D., Calvo, M., Rasmussen, J. T., \& Sanchez, L. (2016). Effect of heat treatment on antirotaviral activity of bovine and ovine whey. International Dairy J ournal, 60, 78-85.

Paulsson, M. A., Svensson, U., Kishore, A. R., \& Naidu, A. S. (1993). Thermal behaviorof bovine lactoferrin in water and its relation to bacterial interaction and antibacterial activity. J Dairy Sci, 76(12), 3711-3720. doi:10.3168/jds.S0022-0302(93)77713-9

Peram, M. R., Loveday, S. M., Ye, A., \& Singh, H. (2013). In vitro gastric digestion of heat-induced aggregates of $\beta$-lactoglobulin. J Dairy Sci, 96(1), 63-74.

Perkin, M. R., \& Strachan, D. P. (2006). Which aspects of the farming lifestyle explain the inverse association with childhood allergy? J ournal of allergy and clinical immunology, 117(6), 1374-1381.

Pierce, A., COLAVIZZA, D., BENAISSA, M., MAES, P., TARTAR, A., MONTREUIL, J., \& SPIK, G. (1991). Molecular cloning and sequence analysis of bovine lactotransferrin. European J ournal of Biochemistry, 196(1), 177-184.

Pitino, M. A., Unger, S., Doyen, A., Pouliot, Y., Aufreiter, S., Stone, D., \& O'Connor, D. L. (2019). High hydrostatic pressure processing better preserves the nutrient and bioactive compound composition of human donor milk. The J ournal of Nutrition, 149(3), 497-504.

Puddu, P., Latorre, D., Carollo, M., Catizone, A., Ricci, G., Valenti, P., \& Gessani, S. (2011). Bovine lactoferrin counteracts Toll-like receptor mediated activation signals in antigen presenting cells. PLoS One, 6(7).

Raikos, V. (2010). Effect of heat treatment on milk protein functionality at emulsion interfaces. A review. Food Hydrocolloids, 24(4), 259-265.

Rainard, P. (2002). Complement factor B and the alternative pathway of complement activation in bovine milk. TheJ ournal of dairy research, 69(1), 1.

Rauh, V. M., Johansen, L. B., Bakman, M., Ipsen, R., Paulsson, M., Larsen, L. B., \& Hammershoj, M. (2015). Protein lactosylation in UHT milk during storage measured by Liquid Chromatography-Mass Spectrometry and quantification of furosine. International J ournal of Dairy Technology, 68(4), 486494. doi:10.1111/1471-0307.12265

Reiter, B., Marshall, V., \& Philips, S. (1980). The antibiotic activity of the lactoperoxidase-thiocyanatehydrogen peroxide system in the calf abomasum. Research in Veterinary Science, 28(1), 116-122.

Reiter, B., Marshall, V. M. E., Bjorck, L., \& Rosen, C. G. (1976). Nonspecific bactericidal activity of lactoperoxidase thiocyanate-hydrogen peroxide system of milk against Escherichia-coli and some Gram-negative pathogens. Infection and Immunity, 13(3), 800-807.

Remes, S. T., Iivanainen, K., Koskela, H., \& Pekkanen, J. (2003). Which factors explain the lower prevalence of atopy amongst farmers' children? Clin. Exp. Allergy, 33(4), 427-434.

Rérat, A., Calmes, R., Vaissade, P., \& Finot, P.-A. (2002). Nutritional and metabolic consequences of the early Maillard reaction of heat treated milk in the pig. European journal of nutrition, 41(1), 1-11.

Riddles, P. W., Blakeley, R. L., \& Zerner, B. (1979). Ellman's reagent: 5, 5'-dithiobis (2-nitrobenzoic acid) - a reexamination. Analytical Biochemistry, 94(1), 75-81.

Riedler, J., Braun-Fahrlander, C., Eder, W., Schreuer, M., Waser, M., Maisch, S., \& von Mutius, E. (2001). Exposure to farming in early life and development of asthma and allergy: a cross-sectional survey. Lancet, 358(9288), 1129-1133. doi:10.1016/S0140-6736(01)06252-3

Riedler, J., Eder, W., Oberfeld, G., \& Schreuer, M. (2000). Austrian children living on a farm have less hay fever, asthma and allergic sensitization. Clin. Exp. Allergy, 30(2), 194-200.

Rombouts, I., Lagrain, B., Scherf, K. A., Lambrecht, M. A., Koehler, P., \& Delcour, J. A. (2015). Formation and reshuffling of disulfide bonds in bovine serum albumin demonstrated using tandem mass spectrometry with collision-induced and electron-transfer dissociation. Sci Rep, 5, 12210.

Roth-Walter, F., Berin, M. C., Arnaboldi, P., Escalante, C. R., Dahan, S., Rauch, J., \& Mayer, L. (2008). Pasteurization of milk proteins promotes allergic sensitization by enhancing uptake through Peyer's patches. Allergy, 63(7), 882-890. doi:10.1111/j.1398-9995.2008.01673.x

Rybarczyk, J., Kieckens, E., De Zutter, L., Remon, J. P., Vanrompay, D., \& Cox, E. (2017). Effects of lactoferrin treatment on Escherichia coli O157:H7 rectal colonization in cattle. Vet Microbiol, 202, 38-46. doi:10.1016/j.vetmic.2015.12.013

Saboyainsta, L. V., \& Maubois, J.-L. (2000). Current developments of microfiltration technology in the dairy industry. Le Lait, 80(6), 541-553. 
Sánchez, L., Peiro, J., Castillo, H., Perez, M., Ena, J., \& Calvo, M. (1992). Kinetic parameters for denaturation of bovine milk lactoferrin. J Food Sci, 57(4), 873-879.

Sava, N., Van der Plancken, I., Claeys, W., \& Hendrickx, M. (2005). The kinetics of heat-induced structural changes of $\beta$-lactoglobulin. J Dairy Sci, 88(5), 1646-1653.

Schokker, E., Singh, H., \& Creamer, L. (2000). Heat-induced aggregation of $\beta$-lactoglobulin A and B with $\alpha$-lactalbumin. International DairyJ ournal, 10(12), 843-853.

Schwanhausser, B., Busse, D., Li, N., Dittmar, G., Schuchhardt, J., Wolf, J., \& Selbach, M. (2011). Global quantification of mammalian gene expression control. Nature, 473(7347), 337-342. doi:10.1038/nature10098

Schwarcz, W. D., Carnelocce, L., Silva, J. L., Oliveira, A. C., \& Goncalves, R. B. (2008). Conformational changes in bovine lactoferrin induced by slow or fast temperature increases. Biological chemistry, 389(8), 1137-1142.

Seifu, E., Buys, E., Donkin, E., \& Petzer, I.-M. (2004). Antibacterial activity of the lactoperoxidase system against food-borne pathogens in Saanen and South African Indigenous goat milk. Food Control, 15(6), 447-452.

Sharma, R., \& Rajput, Y. (2014). Rapid methods for assessing efficiency of heat treatment of milk. J ournal of food science and technology, 51(7), 1416-1420.

Shimo, P., Wu, X., Ding, X., Xiong, L., \& Yan, P. (2015). The Influence of Heat Treatment in Liquid Whey at Various $\mathrm{pH}$ on Immunoglobulin $\mathrm{G}$ and Lactoferrin from Yak and Cows' Colostrum/Milk. J ournal of Food Processing \& Technology, 6(10), 1.

Sicherer, S. H., \& Sampson, H. A. (2010). Food allergy. J ournal of Allergy and Clinical Immunology, 125(2), S116-S125.

Silvestre, D., Ruiz, P., Martinez-Costa, C., Plaza, A., \& Lopez, M. C. (2008). Effect of Pasteurization on the Bactericidal Capacity of Human Milk. J ournal of Human Lactation, 24(4), 371-376. doi: $10.1177 / 0890334408319158$

Singh, H. (2004). Heat stability of milk. International J ournal of Dairy Technology, 57(2-3), 111-119. doi:10.1111/j.1471-0307.2004.00143.x

Singh, H., Ye, A., \& Ferrua, M. J. (2015). Aspects of food structures in the digestive tract. Current opinion in food science, 3, 85-93.

Singh, P. K., Parsek, M. R., Greenberg, E. P., \& Welsh, M. J. (2002). A component of innate immunity prevents bacterial biofilm development. Nature, 417(6888), 552.

Somers, J. M., Guinee, T. P., \& Kelly, A. L. (2002). The effect of plasmin activity and cold storage of cheese milk on the composition, ripening and functionality of mozzarella-type cheese. International J ournal of Dairy Technology, 55(1), 5-11.

Sozańska, B., Pearce, N., Dudek, K., \& Cullinan, P. (2013). Consumption of unpasteurized milk and its effects on atopy and asthma in children and adult inhabitants in rural Poland. Allergy, 68(5), 644650.

Spadaro, M., Caorsi, C., Ceruti, P., Varadhachary, A., Forni, G., Pericle, F., \& Giovarelli, M. (2008). Lactoferrin, a major defense protein of innate immunity, is a novel maturation factor for human dendritic cells. TheFASEB J ournal, 22(8), 2747-2757.

Spik, G., Brunet, B., Mazurier-Dehaine, C., Fontaine, G., \& Montreuil, J. (1982). Characterization and properties of the human and bovine lactotransferrins extracted from the faeces of newborn infants. Acta Paediatrica, 71(6), 979-985.

Spik, G., Cheron, A., Montreuil, J., \& Dolby, J. (1978). Bacteriostasis of a milk-sensitive strain of Escherichia coli by immunoglobulins and iron-binding proteins in association. Immunology, 35(4), 663.

Spik, G., Coddeville, B., Mazurier, J., Bourne, Y., Cambillaut, C., \& Montreuil, J. (1994). Primary and three-dimensional structure of lactotransferrin (lactoferrin) glycans. In Lactoferrin (pp. 21-32): Springer.

Sreedhara, A., Flengsrud, R., Prakash, V., Krowarsch, D., Langsrud, T., Kaul, P., \& Vegarud, G. E. (2010). A comparison of effects of $\mathrm{pH}$ on the thermal stability and conformation of caprine and bovine lactoferrin. International DairyJ ournal, 20(7), 487-494. doi:10.1016/j.idairyj.2010.02.003

Steijns, J. M., \& van Hooijdonk, A. C. M. (2000). Occurrence, structure, biochemical properties and technological characteristics of lactoferrin. BritishJ ournal of Nutrition, 84, S11-S17.

Stelwagen, K., Carpenter, E., Haigh, B., Hodgkinson, A., \& Wheeler, T. T. (2009). Immune components of bovine colostrum and milk. J AnimSci, 87(13 Suppl), 3-9. doi:10.2527/jas.2008-1377 
Stephens, S., Dolby, J., Montreuil, J., \& Spik, G. (1980). Differences in inhibition of the growth of commensal and enteropathogenic strains of Escherichia coli by lactotransferrin and secretory immunoglobulin A isolated from human milk. Immunology, 41(3), 597.

Stephens, S., Harkness, R., \& Cockle, S. M. (1979). Lactoperoxidase activity in guinea-pig milk and saliva: correlation in milk of lactoperoxidase with bactericidal activity against Escherichia coli. British journal of experimental pathology, 60(3), 252.

Still, J., Delahaut, P., Coppe, P., Kaeckenbeeck, A., \& Perraudin, J. (1990). Treatment of induced enterotoxigenic col ibacillosis (scours) in cal ves by the lactoperoxidasesystemand lactoferrin. Paper presented at the Annales de Recherches Veterinaires.

Sui, Q., Roginski, H., Williams, R. P., Versteeg, C., \& Wan, J. (2010). Effect of pulsed electric field and thermal treatment on the physicochemical properties of lactoferrin with different iron saturation levels. International dairy journal, 20(10), 707-714.

Surroca, Y., Haverkamp, J., \& Heck, A. (2002). Towards the understanding of molecular mechanisms in the early stages of heat-induced aggregation of $\beta$-lactoglobulin AB. J ournal of Chromatography A, 970(1-2), 275-285.

Sutariya, S., \& Patel, H. (2017). Effect of hydrogen peroxide on improving the heat stability of whey protein isolate solutions. Food Chem 223, 114-120.

Szwajkowska, M., Wolanciuk, A., Barlowska, J., Krol, J., \& Litwinczuk, Z. (2011). Bovine milk proteins as the source of bioactive peptides influencing the consumers' immune system - a review. Animal Science Papers and Reports, 29(4), 269-280.

Tacoma, R., Gelsinger, S., Lam, Y., Scuderi, R., Ebenstein, D., Heinrichs, A. J., \& Greenwood, S. (2017) Exploration of the bovine colostrum proteome and effects of heat treatment time on colostrum protein profile. J Dairy Sci, 100(11), 9392-9401.

Tang, J. (1963). Specificity of pepsin and its dependence on a possible 'hydrophobic binding site'. Nature, 199(4898), 1094-1095.

Telang, S. (2018). Lactoferrin: A Critical Player in Neonatal Host Defense. Nutrients, 10(9). doi:10.3390/nu10091228

Tenovuo, J., Moldoveanu, Z., Mestecky, J., Pruitt, K., \& Rahemtulla, B. (1982). Interaction of specific and innate factors of immunity: IgA enhances the antimicrobial effect of the lactoperoxidase system against Streptococcus mutans. The J ournal of Immunology, 128(2), 726-731.

The R Development Core Team. (2013). R: a language and environment for statistical computing.

Tomita, M., Bellamy, W., Takase, M., Yamauchi, K., Wakabayashi, H., \& Kawase, K. (1991). Potent antibacterial peptides generated by pepsin digestion of bovine lactoferrin.J Dairy Sci, 74(12), 41374142.

Tyanova, S., Temu, T., Sinitcyn, P., Carlson, A., Hein, M. Y., Geiger, T., \& Cox, J. (2016). The Perseus computational platform for comprehensive analysis of (prote)omics data. Nat. Methods, 13(9), 731740. doi:10.1038/Nmeth.3901

Uceda, R., Guillen, A., Gaya, P., Medina, M., \& Nuñez, M. (1994). The effect of ewe milk lactoperoxidase system on Pseudomonas fluorescens growth, casein breakdown, peptide formation and milk coagulation characteristics. Milchwissenschaft (Germany).

Ulfman, L. H., Leusen, J. H. W., Savelkoul, H. F. J., Warner, J. O., \& van Neerven, R. J. J. (2018). Effects of Bovine Immunoglobulins on Immune Function, Allergy, and Infection. Frontiers in nutrition, 5. doi:10.3389/fnut.2018.00052

UniProt, C. (2013). Universal protein resource (Uniprot).

Van Gysel, M., Cossey, V., Fieuws, S., \& Schuermans, A. (2012). Impact of pasteurization on the antibacterial properties of human milk. European journal of pediatrics, 171(8), 1231-1237.

Van Hooijdonk, A. C., Kussendrager, K., \& Steijns, J. (2000). In vivo antimicrobial and antiviral activity of components in bovine milk and colostrum involved in non-specific defence. British J ournal of Nutrition, 84(S1), 127-134.

van Lieshout, G. A., Lambers, T. T., Bragt, M. C., \& Hettinga, K. A. (2019). How processing may affect milk protein digestion and overall physiological outcomes: A systematic review. Crit Rev Food Sci Nutr, 1-24.

van Neerven, R. J., Knol, E. F., Heck, J. M., \& Savelkoul, H. F. (2012). Which factors in raw cow's milk contribute to protection against allergies? J ournal of Allergy and Clinical Immunology, 130(4), 853858. 
Vasbinder, A. J., Alting, A. C., \& de Kruif, K. G. (2003). Quantification of heat-induced casein-whey protein interactions in milk and its relation to gelation kinetics. Colloids and surfaces B: Biointerfaces, 31(1-4), 115-123.

Visschers, R. W., \& de Jongh, H. H. (2005). Disulphide bond formation in food protein aggregation and gelation. Biotechnology advances, 23(1), 75-80.

von Ehrenstein, O. S., von Mutius, E., Illi, S., Baumann, L., Bohm, O., \& von Kries, R. (2000). Reduced risk of hay fever and asthma among children of farmers. Clin. Exp. Allergy, 30(2), 187-193. Retrieved from https://www.ncbi.nlm.nih.gov/pubmed/10651770

von Mutius, E., \& Vercelli, D. (2010). Farm living: effects on childhood asthma and allergy. Nat Rev. Immunol., 10(12), 861-868. doi:10.1038/nri2871

Wada, Y., \& Loennerdal, B. (2014). Effects of Different Industrial Heating Processes of Milk on SiteSpecific Protein Modifications and Their Relationship to in Vitro and in Vivo Digestibility. J Agric Food Chem 62(18), 4175-4185. doi:10.1021/jf501617s

Wada, Y., \& Lonnerdal, B. (2015). Effects of Industrial Heating Processes of Milk-Based Enteral Formulas on Site-Specific Protein Modifications and Their Relationship to in Vitro and in Vivo Protein Digestibility. J Agric Food Chem 63(30), 6787-6798. doi:10.1021/acs.jafc.5b02189

Wagner, J., Biliaderis, C. G., \& Moschakis, T. (2020). Whey proteins: Musings on denaturation, aggregate formation and gelation. Crit Rev Food Sci Nutr, 1-14.

Wang, B., Timilsena, Y., Blanch, E., \& Adhikari, B. (2019). Lactoferrin: Structure, function, denaturation and digestion. Critical Reviews in Food Science and Nutrition, 59(4), 580-596. doi:10.1080/10408398.2017.1381583

Wang, B., Timilsena, Y. P., Blanch, E., \& Adhikari, B. (2017). Mild thermal treatment and in-vitro digestion of three forms of bovine lactoferrin: Effects on functional properties. International Dairy J ournal, 64, 22-30.

Wang, W., Nema, S., \& Teagarden, D. (2010). Protein aggregation — pathways and influencing factors. International journal of pharmaceutics, 390(2), 89-99.

Waser, M., Michels, K., Bieli, C., Flöistrup, H., Pershagen, G., Von Mutius, E., \& Brunekreef, B. (2007). Inverse association of farm milk consumption with asthma and allergy in rural and suburban populations across Europe. Clinical \& Experimental Allergy, 37(5), 661-670.

Wei, Z., Nishimura, T., \& Yoshida, S. (2000). Presence of a glycan at a potential N-glycosylation site, Asn-281, of bovine lactoferrin. J ournal of dairy science, 83(4), 683-689.

Westerik, N., Scholten, E., \& Corredig, M. (2015). The effect of calcium on the composition and physical properties of whey protein particles prepared using emulsification. Food chemistry, 177, 72-80.

Wijayanti, H. B., Bansal, N., \& Deeth, H. C. (2014). Stability of Whey Proteins during Thermal Processing: A Review. Comprehensive Reviews in Food Science and Food Safety, 13(6), 1235-1251. doi:10.1111/1541-4337.12105

Wirunsawanya, K., Upala, S., Jaruvongvanich, V., \& Sanguankeo, A. (2018). Whey protein supplementation improves body composition and cardiovascular risk factors in overweight and obese patients: a systematic review and meta-analysis. J ournal of theAmerican Collegeof Nutrition, 37(1), 60-70.

Wiśniewski, J. R., Zougman, A., Nagaraj, N., \& Mann, M. (2009). Universal sample preparation method for proteome analysis. Nat Methods, 6(5), 359.

Wong, C., Seow, H., Husband, A., Regester, G., \& Watson, D. (1997). Effects of purified bovine whey factors on cellular immune functions in ruminants. Veterinary I mmunology and I mmunopathology, 56(1-2), 85-96.

Xiong, L., Li, C., Boeren, S., Vervoort, J., \& Hettinga, K. (2020a). Effect of heat treatment on bacteriostatic activity and protein profile of bovine whey proteins. Food Research International, 127, 108688.

Xu, K., Zhao, Z., Guo, M., \& Du, J. (2019). Conjugation between okra polysaccharide and lactoferrin and its inhibition effect on thermal aggregation of lactoferrin at neutral $\mathrm{pH}$. Lwt-Food Science and Technology, 107, 125-131. doi:10.1016/j.1wt.2019.02.082

Xu, K., Zhao, Z. T., Guo, M. M., \& Du, J. H. (2019). Conjugation between okra polysaccharide and lactoferrin and its inhibition effect on thermal aggregation of lactoferrin at neutral pH. LWT-Food Science and Technology, 107, 125-131. doi:10.1016/j.lwt.2019.02.082 
Ye, A. Q., Anema, S. G., \& Singh, H. (2008). Changes in the surface protein of the fat globules during homogenization and heat treatment of concentrated milk. J ournal of Dairy Research, 75(3), 347-353. doi:10.1017/s0022029908003464

Yekta, M. A., Cox, E., Goddeeris, B. M., \& Vanrompay, D. (2011). Reduction of Escherichia coli O157:H7 excretion in sheep by oral lactoferrin administration. Vet Microbiol, 150(3-4), 373-378. doi:10.1016/j.vetmic.2011.02.052

Yoshida, S., Wei, Z., Shinmura, Y., \& Fukunaga, N. (2000). Separation of lactoferrin-a and-b from bovine colostrum. J ournal of dairy science, 83(10), 2211-2215.

Zapico, P., Gaya, P., Nunez, M., \& Medina, M. (1995). Activity of goats' milk lactoperoxidase system on Pseudomonas fluorescens and Escherichia coli at refrigeration temperatures. Journal of Food Protection, 58(10), 1136-1138.

Zenker, H. E., van Lieshout, G. A., van Gool, M. P., Bragt, M. C., \& Hettinga, K. A. (2020). Lysine blockage of milk proteins in infant formula impairs overall protein digestibility and peptide release. Food Funct.

Zhan, L., Liu, Y., Xie, X., Xiong, C., \& Nie, Z. (2018). Heat-Induced Rearrangement of the Disulfide Bond of Lactoglobulin Characterized by Multiply Charged MALDI-TOF/TOF Mass Spectrometry. Anal Chem 90(18), 10670-10675.

Zhang, L., Boeren, S., Hageman, J. A., van Hooijdonk, T., Vervoort, J., \& Hettinga, K. (2015a). Bovine milk proteome in the first 9 days: protein interactions in maturation of the immune and digestive system of the newborn. PLoS One, 10(2), e0116710.

Zhang, L., Boeren, S., Hageman, J. A., van Hooijdonk, T., Vervoort, J., \& Hettinga, K. (2015b). Perspective on calf and mammary gland development through changes in the bovine milk proteome over a complete lactation. J . Dairy Sci., 98(8), 5362-5373. doi:10.3168/jds.2015-9342

Zhang, L., Boeren, S., Smits, M., van Hooijdonk, T., Vervoort, J., \& Hettinga, K. (2016). Proteomic study on the stability of proteins in bovine, camel, and caprine milk sera after processing. Food Research International, 82, 104-111. doi:10.1016/j.foodres.2016.01.023

Zhang, L., de Waard, M., Verheijen, H., Boeren, S., Hageman, J. A., van Hooijdonk, T., \& Hettinga, K. (2016). Changes over lactation in breast milk serum proteins involved in the maturation of immune and digestive system of the infant. J Proteomics, 147, 40-47. doi:10.1016/j.jprot.2016.02.005

Zhang, S., \& Vardhanabhuti, B. (2014). Effect of initial protein concentration and pH on in vitro gastric digestion of heated whey proteins. Food Chem 145, 473-480.

Zhou, Y.-J., Gao, J., Yang, H.-M., Yuan, X.-L., Chen, T.-X., \& He, Z.-J. (2010). The role of the lactadherin in promoting intestinal DCs development in vivo and vitro. Clinical and Developmental Immunology, 2010.

Zhu, D., \& Labuza, T. P. (2010). Effect of cysteine on lowering protein aggregation and subsequent hardening of whey protein isolate (WPI) protein bars in WPI/buffer model systems. J Agric Food Chem, 58(13), 7970-7979. 


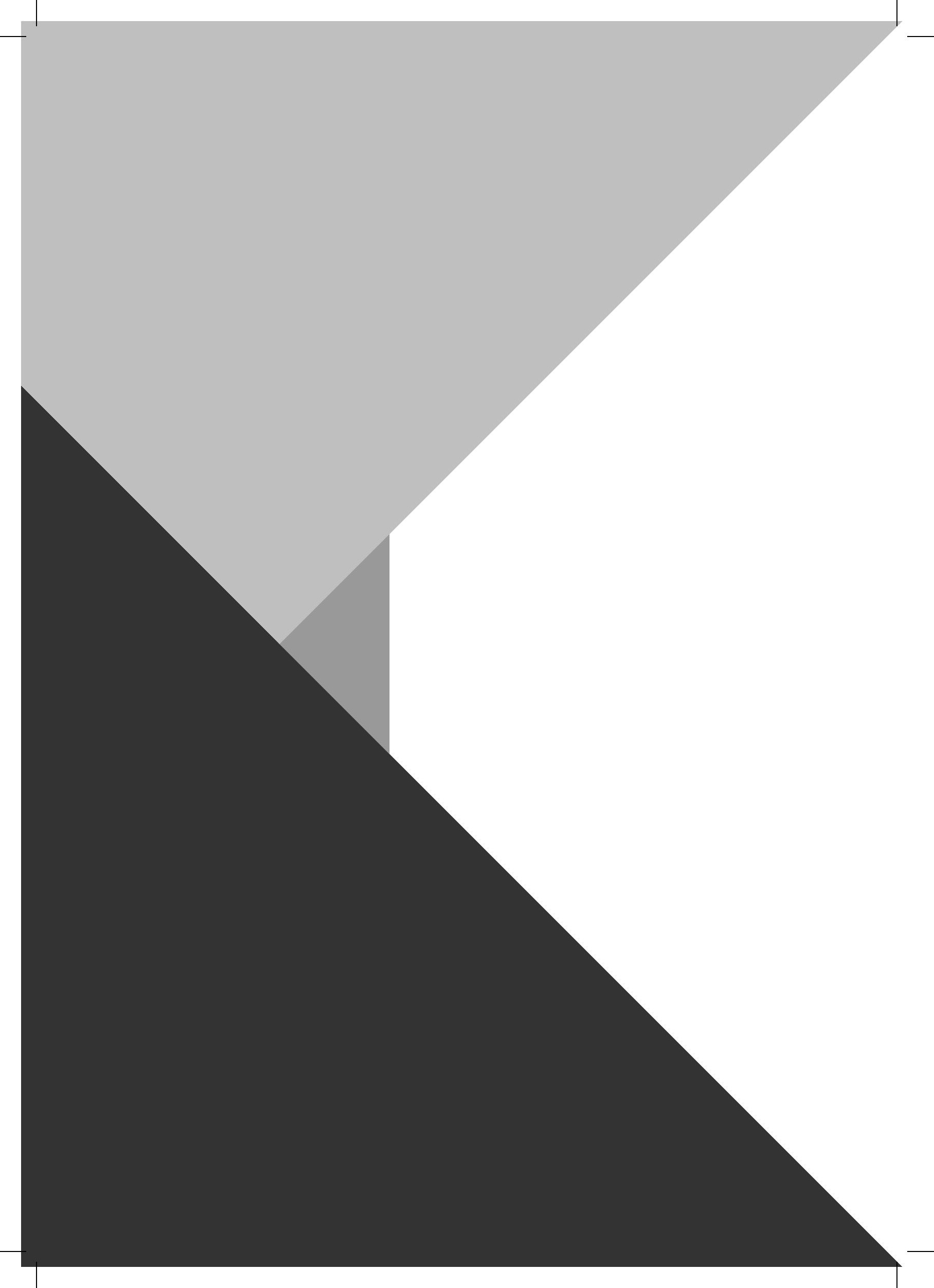


Milk proteins are one of the important nutritional components in bovine milk, besides carbohydrates, lipids and vitamins. Bovine milk proteins can be classified into two groups, casein and whey proteins. Whey proteins, accounting for $20 \%$ of the amount of bovine milk proteins, include $\beta$-lactoglobulin, $\alpha$-lactalbumin, bovine serum albumin, and hundreds of other less abundant proteins. The milk proteins not only provide amino acids as nutrients for the body, but also exhibit several biological functions like bacteriostatic activity and immunomodulation. Immune-active proteins in whey, like lactoferrin, immunoglobulin, and lactoperoxidase, are mainly responsible for these immune-modulating functionalities. A variety of pathogens can multiply in milk due to due to its richness in nutrients, which could pose serious health risks to consumers. Heat treatments, such as pasteurization and sterilization, are extensively used in dairy industry to ensure the safety of dairy products and to extend shelf life. However, heat treatment induced denaturation, aggregation and glycation of whey proteins result in the changes of physicochemical properties and biological activity. This thesis sought to investigate how different heat treatments within the pasteurization range induce structure changes of immune-active proteins, and subsequently change their physicochemical properties and immune functionality.

As one of the important immune-active proteins in milk, lactoferrin is often enriched in infant formula or functional food products, to provide immune benefits for consumer. The aggregation of lactoferrin with other whey proteins may occur during heating, which could reduce the immunological activity of lactoferrin. Therefore, the role of major whey proteins ( $\beta$ lactoglobulin, $\alpha$-lactalbumin and bovine serum albumin) in the disulphide linked aggregation of lactoferrin after heating at $55-90{ }^{\circ} \mathrm{C}$ for $30 \mathrm{~min}$ were investigated in Chapter 2 . The disulphide bond interchange within lactoferrin as well as between $\beta$-lactoglobulin and lactoferrin were measured to explore the underlying mechanism for disulphide-linked aggregation of lactoferrin. Our results showed that $\beta$-lactoglobulin enhanced the disulphide linked-aggregation of lactoferrin the most among these three proteins $\beta$-lactoglobulin, $\alpha$ lactalbumin and bovine serum albumin, which was attributed to the presence of the free thiol group within $\beta$-lactoglobulin. After heating at $85^{\circ} \mathrm{C}$ for $30 \mathrm{~min}, 8$ cysteines formed 36 different disulphide bonds in 47 different crosslinked peptides among lactoferrin molecules (inter- and intramolecular disulphide bonds) were found. Among these cysteines, 8 cysteines from lactoferrin formed 9 different disulphide bonds in 21 heterologous crosslinked peptides with 2 cysteines from $\beta$-lactoglobulin (intermolecular disulphide bonds). 
Besides the major whey proteins studied in Chapter 2, whey proteins encompass many more hundreds of proteins that could possibly interact with lactoferrin during heating, with subsequent changes in physicochemical properties and biological activity. The aggregation of lactoferrin in milk serum after heating 65,70 , and $75^{\circ} \mathrm{C}$ for $30 \mathrm{~min}$ was characterized, and the effect of such aggregation on bacteriostatic activity and in vitro digestion were further investigated in Chapter 3. The aggregation of lactoferrin was enhanced when LF was heated in milk serum, compared to it being heated alone. Lactoferrin heated alone at $70{ }^{\circ} \mathrm{C}$ or above led to self-aggregation via disulphide interchange, whereas heating lactoferrin in milk serum already led to the disulphide linked aggregation of lactoferrin at $65^{\circ} \mathrm{C}$ and above. Lactoferrin formed disulphide-linked aggregates with whey protein and non-micellar casein, which involved $\beta$-lactoglobulin, $\alpha$-lactalbumin, bovine serum albumin, immunoglobulin, $\kappa$-casein and many low abundant proteins. Lactoferrin also formed disulphide-linked aggregates when it was heated with $\beta$-lactoglobulin, indicating that the formation of lactoferrin-whey protein complexes was, at least partly, mediated by $\beta$-lactoglobulin. The more loss of bacteriostatic activity was observed when heating lactoferrin with whey protein, which was associated with their aggregation. Lactoferrin that was involved in whey protein aggregates formed at $65{ }^{\circ} \mathrm{C}$ and $70{ }^{\circ} \mathrm{C}$ were more susceptible to infant in vitro digestion, while those formed at $75{ }^{\circ} \mathrm{C}$ were much more resistant to digestion. In conclusion, whey protein affected the aggregation of lactoferrin, which subsequently changed both its bacteriostatic activity and digestion behaviour.

Not only lactoferrin is antibacterial, but a wider range of whey proteins its bacteriostatic activity, such as lactoperoxidase and immunoglobulins, as well as low abundant immune-active proteins. Different heat treatments can induce the denaturation of these proteins to a different degree, which could result in a gradual change of their bacteriostatic activity. The effect of different heat treatments on the proteome of whey proteins and their bacteriostatic activity were investigated in Chapter 4. Skim milk samples were heated at $65^{\circ} \mathrm{C}, 70{ }^{\circ} \mathrm{C}, 75^{\circ} \mathrm{C}, 80^{\circ} \mathrm{C}$, and $85{ }^{\circ} \mathrm{C}$, for 30 minutes. Milk serum was isolated from the heat-treated skim milk and the bacteriostatic capacity of this milk serum was tested against Streptococcus thermophilus, Escherichia coli, Lactococcus lactis and Pseudomonas fluorescens. The bacteriostatic activity of milk serum negatively correlated with the intensity of heat treatment, which was also reflected in the reduced level of native antibacterial proteins. There is a slight decrease of bacteriostatic activity, which was associated with denaturation of low abundant immune-active proteins, such as complement $\mathrm{C} 7$, monocyte differentiation antigen CD14 and polymeric immunoglobulin receptor. There is a significant difference between milk samples treated for 30 
minutes at $<75^{\circ} \mathrm{C}$ and milk samples treated at $\geq 75^{\circ} \mathrm{C}$ in both bacteriostatic capacity and native antibacterial proteins. Growth rates of Streptococcus thermophilus, Lactococcus lactis, and Pseudomonas fluorescens were negatively correlated with the retention of lactoferrin and lactoperoxidase. In conclusion, the bacteriostatic capacity of milk serum decreases with increasing heating intensity, which is strongly correlated with the denaturation of antibacterial proteins that extensively occurred after heating at $75^{\circ} \mathrm{C}$ for $30 \mathrm{~min}$.

In addition to bacteriostatic activity, immune-active proteins were indicated to be involved in the protection from the development of allergic diseases, but a direct link between these proteins and the protection against allergic diseases was missing, which therefore has been investigated in Chapter 5. Raw cow's milk was heated at 50, 60, 65, 70, 75 and $80{ }^{\circ} \mathrm{C}$ for $30 \mathrm{~min}$ and the native whey protein profile of these differentially heated milk samples was determined using LC-MS/MS-based proteomics. The capacity of different heat treated milk samples to prevent the development of ovalbumin-induced food allergy was evaluated in a murine animal model. The allergy-protective effect of raw cow's milk was lost after heating milk for 30 min at $65{ }^{\circ} \mathrm{C}$ or higher temperatures. Although a substantial loss of native whey proteins, as well as extensive protein aggregation, was observed from $75{ }^{\circ} \mathrm{C}$, whey proteins with immune-related functionalities already started to denature from $65^{\circ} \mathrm{C}$, which coincided with the temperature at which a loss of allergy protection was observed in the murine model. Of the immune-active whey proteins, complement $\mathrm{C} 7$, monocyte differentiation antigen $\mathrm{CD} 14$, and polymeric immunoglobulin receptor concentrations decreased significantly at this temperature. In addition, several other immune-active whey proteins also showed a decrease around $65^{\circ} \mathrm{C}$. This chapter thus suggests that immune-active whey proteins that denature around $65^{\circ} \mathrm{C}$ are probably mainly responsible for the allergy-protective capacity of raw cow's milk, although their specific role in the loss of the allergy-protective effect still needs to be confirmed.

Chapter 6 discussed how the obtained results in this thesis contribute to our understanding about how different heat treatments within the pasteurization temperature range affected the structure, digestion, and biological function of immune-active whey proteins. Comparison of the aggregation of lactoferrin in a whey protein model system, milk serum and skim milk suggested that heating lactoferrin in the presence of other proteins can increase the irreversible aggregation by sulfhydryl-disulphide interchange. It thereby provides evidence that heating lactoferrin and other protein ingredients in dairy products separately may decrease the disulphide-linked aggregation of lactoferrin with other proteins, which may ultimately help to retain protein bioactivity. The extensive aggregation of lactoferrin with whey proteins, partly 
via disulphide bond interchange, retards the in vitro gastric digestion of lactoferrin. Therefore, preventing disulphide bond interchange between proteins could be a way to prevent formation of large insoluble aggregates or produce smaller aggregates, leading to higher digestibility. The contribution of different whey proteins in the bacteriostatic and allergy protective activity of raw milk, and the appropriate heat treatment for preserving them, were discussed. A heat intensity below $75^{\circ} \mathrm{C} / 30 \mathrm{~min}$ would meet the requirement to maintain the bacteriostatic activity, whereas a heat intensity below $65{ }^{\circ} \mathrm{C} / 30$ min would be required to preserve the allergy protective activity. However, with heating below $65^{\circ} \mathrm{C} / 30 \mathrm{~min}$, the microbiological safety can't be guaranteed, therefore, non-thermal methods may be used to inactivate pathogen or other time/temp combinations, other raw milk criteria, etc. could also be used to inactivate pathogen. 


\section{Acknowledgement}

When I was 12 years old, I wrote in my wish card that I want to do study abroad. I never thought that I will start the wonderful journey in Netherlands after 13 years and obtained so much during my $\mathrm{PhD}$, not only about knowledge in science, but also communication with so many adorable and respectful people. I am so thankful to all the people who involved in my project in the past four years.

I sincerely thank my two supervisors, Kasper Hettinga and Jacques Vervoort. I feel so honored and lucky to have you as my supervisors. I am very grateful to my daily supervisor Kasper. Kasper, I know you for the first time when you worked in China Agricultural University as a visiting scholar in 2015. I never imagine that I will be your student after one year then. In the past four years, you instruct me with lots of patience and tenderness. When I have difficulty, you always discuss with me and help me quickly and carefully. That give me a sense of safety. I really enjoy to work with you. Every time I proposed new idea for my topic, you always support me and encourage me to try, which make me derive great delight from research. Your detailed, wise and valuable comments on my every paper help me to improve my writing and logic thinking a lot. My PhD study is very happy because of your superb supervision. Aside from research, your cheerful personality is also adorable and influenced me a lot. You are always positive and enjoy everything in life. Talking with you is always a nice experience. If I become a teacher in the future, you will be my best role model.

I also want to express my gratitude to my co-supervisor Jacques. Every time I come to you, you always try your best to help me. You taught me to be critical and don't blindly believe publication. Your good sense of humor make me feel very relaxed.

I want to thank Sjef Boeren. Thank you for teaching me basic knowledge about proteomics and your valuable suggestion about my topic. Thank you for your Chinese tea.

My gratitude also goes to Sino-Dutch Dairy Development Center (SDDDC), Pro.Shengli Li (李胜利), Mr Kai Liu(刘凯), Prof. Kees de Koning, Prof. Tiny Boekel, and Mr Hao Su(苏吴) and organizer of Sino-Dutch Doctoral Program on Sustainable Dairy, Renjie Dong(董仁杰), Wanli Zheng(郑万里) and Wanqin Zhang(张万钦). I won't have the opportunity to do a PhD in Netherlands without your efforts. Thank you for organizing so many interesting activities to help me to improve myself and broaden my knowledge. 
I would like to thank my master supervisor Huiyuan Guo(郭慧媛), and co-supervisor Prof Fazheng Ren(任发政), thank you for your help and encouragement during my master and the application of $\mathrm{PhD}$ position. I am so gratitude for your valuable suggestion for my personal life and future career during my master and $\mathrm{PhD}$.

I want to thank Vincenzo. Thank you for your countless effort to make FQD better and give us a good working environment. Reading your email and announcement in LinkedIn is always a fun for me.

I would like to thank our secretaries Kimberley, Lysanne and Corine. Thank you for your help with all the administrative issues and organizing so many enjoyable activities.

I would like to thank the technicians of FQD, Charlotte, Erik, Frans, Mike, Geert and Xandra for all your help for my lab work during my $\mathrm{PhD}$ study, especially for Erik and Frans. Erik, you are so supportive and brought me a lot of fun during lab work.

I would like to thank all colleagues in FQD for the company in the past four years. Thank Jonna for helping me to find my Phone in Australia. Thank Hannah, Lucia, Mostafa, Sara, Alim, and Moheb for organizing the wonderful $\mathrm{PhD}$ trip in Australia for us.

I would like to thanks all the members in Dairy group, Tiny, Hein, Thom, Etske, Sine, Sara, Hannah, Eva, Pieter, Naomi, Julie, Yaowei, Jiaying, Qing. I really enjoy work with you and have the DST meeting with you. Pieter, thank you for your useful tip for learning $\mathrm{R}$ and nice talk . Eva, thank you for your help for my microbiological experiments. Hannah, thank you for your help for my experiment related to Maillard reaction.

I also want to thank all the master and bachelor students who joined my project. Chengkang Li(李呈康), Weizhen Jiao (焦维桢), Hang Xu (许航), Joost Dechering, Jiuyou Liu (刘久悠) and Laura Veltkamp, thank you for your contribution for this project.

Thank you for my dear paranymphs, Lijiao and Sara. I am very happy to have you stay with me during my defense.

Sara, I know each other when I just started my $\mathrm{PhD}$, you are always friendly and easy-going. We shared the apartment during the trip in Australia, it is always a nice experience to live with you. I often feel relaxed and happy when staying with you. 
丽娇, 我们一起经历了澳大利亚旅行和意大利之行。你在我心里总是像亲人一般的存在, 你稳重 靠谱的性格总是能给我安全感。无论什么时候我找你, 你总是不遗余力的帮助我。谢谢你三年 来的陪伴与帮助。

兵兵, 之珺, 宏威, 跟你们在一块总是让我觉得很安心, 谢谢你们一直以来的陪伴与帮助。刘要卫, 沈易, 解雅晶, 呼延宗尧, 胡珂青, 孙越, 感谢你们疫情期间的陪伴, 跟你们聚餐, 散步, 看电影和打 篮球的时光总是温馨又快乐。陈瑶, 方亮, 谢谢你们的忽油面, 一起唱 $\mathrm{K}$, 打羽毛球的日子总是开 心又放松。张浩, 陈琳天翔, 陈翰宇, 赵若阳, 谢谢你们四年来对我的美食投喂。谢谢季一鸣, 张 宁一, 王一丹的陪伴, 跟你们拍汉服照的日子总是很放松和开心, 希望有一天我们还能一起旅行, 一起拍汉服照。春月师姐, 谢谢你在我初到瓦村的时候以及博士期间给予我的帮助。孟天瑶, 韦 还和, 王鹏, 文彩芳, 袁桃林, 邓亚乐, 刘晓姣, 谢谢你们在我初到瓦村的时候的帮助和陪伴。感谢 瓦村的中国小伙伴, 刘宁京, 杨与争, 颜静, 王荔, 冯纪璐, 黄展, 薛墨庸, 刘嘉宁, 韩晴, 张露, 刑沈 荟, 彭郁, 刘钥, 安然, 王桃军, 欧扬雯珊, 在我博士期间的陪伴, 鼓励与帮助。谢谢 SDDDC 的小 伙伴, 张春月, 何源, 路海博, 杨与争, 岳笑梅, 周梦婷, 韩若竹, 王越, 我们一起参加过的活动也会是 我博士期间的美好回忆。

感谢我的家人, 爸爸, 妈妈, 姐姐, 谢谢你们一直以来给我的无私的爱, 支持与信任, 希望我们的家 庭越来越好, 我爱你们!

-Ling Xiong 熊玲 


\section{A bout the author}

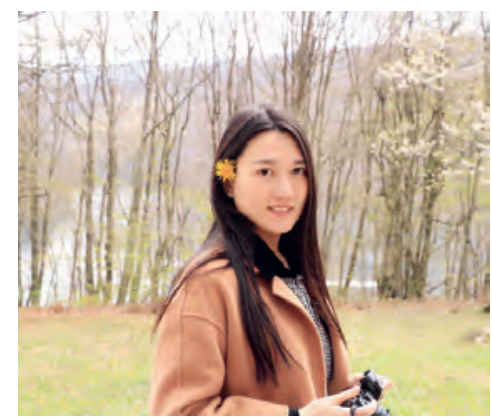

Ling Xiong was born on the $8^{\text {th }}$ of November 1991 in Anhui, China. She finished her Bachelor in 2014 and Master in 2016 at China Agricultural University. During her master, she studied the modulatory effect of lactoferrin on high-fat diet induced obesity. In 2016, She started her $\mathrm{PhD}$ program in Wageningen University and Research sponsor by Sino Dutch Dairy Development Centre and China Scholarship Council (Sino-Dutch Doctoral Program on Sustainable Dairy). During her $\mathrm{PhD}$, she worked on effect of heat treatment on immune-active proteins in bovine milk, with the focus on lactoferrin. The results of her research are presented in this thesis. 


\section{List of publications}

\section{This thesis:}

X iong, L., Liu, J., Boeren, S., Vervoort, J., \& Hettinga, K. (2020). Aggregation and disulphide bond interchange of lactoferrin with major whey proteins during heat treatment. (In preparation)

X iong, L., Boeren, S., Vervoort, J., \& Hettinga, K. (2020). Effect of milk serum proteins on aggregation, bacteriostatic activity and digestion of lactoferrin after heat treatment. Food Chemistry, 337, 127973.

Abbring, S.\#, Xiong, L.\#, Diks, M. A., Baars, T., Garssen, J., Hettinga, K., \& van Esch, B. C. (2020). Loss of allergy-protective capacity of raw cow's milk after heat treatment coincides with loss of immunologically active whey proteins. Food \& Function, 11, 4982-4993. (Co-first author)

Xiong, L., Boeren, S., Vervoort, J., \& Hettinga, K. (2020). Dataset on proteomic changes of whey protein after different heat treatment. Data in brief, 29, 105227.

Xiong, L., Li, C., Boeren, S., Vervoort, J., \& Hettinga, K. (2020). Effect of heat treatment on bacteriostatic activity and protein profile of bovine whey proteins. Food Research International, 127, 108688.

\section{Others:}

Liu, Y., Xiong, L., Kontopodi, E., Zhang, L., Boeren, S., Zhou, P., \& Hettinga, K. (2020). Comparative proteomics of milk serum proteins in thermal and non-thermal treatments. Innovative Food Science \& Emerging Technologies. (In press)

Xiong, L., Ren, F., Lv, J., Zhang, H., \& Guo, H. (2018). Lactoferrin attenuates high-fat diet-induced hepatic steatosis and lipid metabolic dysfunctions by suppressing hepatic lipogenesis and downregulating inflammation in C57BL/6J mice. Food \& Function, 9(8), 4328-4339.

Sun, J., Ren, F., Xiong, L., Zhao, L., \& Guo, H. (2016). Bovine lactoferrin suppresses high-fat diet induced obesity and modulates gut microbiota in C57BL/6J mice. Journal of Functional Foods, 22, 189200.

Zhao, L., Wang, S., Liu, F., Dong, P., Huang, W., Xiong, L ., \& Liao, X. (2013). Comparing the effects of high hydrostatic pressure and thermal pasteurization combined with nisin on the quality of cucumber juice drinks. Innovative Food Science \& Emerging Technologies, 17, 27-36. 


\section{Overview of complete training activities}

\section{Discipline specific activities}

\section{Courses}

Advanced Food Analysis (VLAG, Wageningen, The Netherlands, 2017)

Advanced Proteomics (VLAG, Wageningen, The Netherlands, 2017)

Healthy and sustainable diets: synergies and trade-offs (VLAG, Wageningen, The Netherlands, 2017)

Summer Course Glycosciences (VLAG, Wageningen, The Netherlands, 2017)

Masterclass “Dairy Protein Biochemistry” (VLAG, Wageningen, The Netherlands, 2018)

Food proteins: functionality, modifications and analysis (VLAG, Wageningen, The Netherlands \& Department of Food Science, University of Copenhagen, 2018)

\section{Conferences and meetings}

11th NIZO Dairy Conference-Milk Protein Functionality, Arnhem, The Netherlands, 2019

14th International Conference on Lactoferrin Structure, Function and Applications, Lima, Peru, 2019

17th Annual International Symposium on Milk Science and Health, California, USA, 2020 (Student Travel Award, oral presentation)

\section{G eneral Courses}

Information Literacy for $\mathrm{PhD}$ including EndNote Introduction (WGS, Wageningen, The Netherlands, 2016)

PhD week (VLAG, Wageningen, The Netherlands, 2017)

VLAG Statistics courses (VLAG, Wageningen, The Netherlands, 2017)

Scientific Writing-9 (WGS, Wageningen, The Netherlands, 2019)

Career assessment (WGS, Wageningen, The Netherlands, 2020) 
Brain friendly working and writing (WGS, Wageningen, The Netherlands, 2020)

Career Perspectives (WGS, Wageningen, The Netherlands, 2020)

R Markdown (VLAG, Wageningen, The Netherlands, 2020)

\section{O ptional activities}

Preparation of research proposal (Wageningen, The Netherlands, 2016)

Scientific meetings, seminars and colloquia (Wageningen, The Netherlands, 2016-2020)

International excursions- $\mathrm{PhD}$ trip to Australia (Australia, 2018) 
The research described in this thesis was financially supported by Sino Dutch Dairy Development Centre and Sino-Dutch Doctoral Program on Sustainable Dairy from China Scholarship Council

The Financial support from Wageningen University and Research for printing this thesis is gratefully acknowledged.

Cover design by Digiforce/ ProefschriftMaken

Printed by Digiforce/ ProefschriftMaken 